Prepared for the U.S. Department of Energy

Under Contract DE-AC05-76RL01830

\title{
EFRT M-12 Issue Resolution: Solids Washing
}
DL Baldwin
PW Eslinger
PP Schonewill
BD Hanson
JJ Toth
DE Kurath
JL Huckaby
MJ Minette

January 2010

Pacific Northwest

NATIONAL LABORATORY

Proudly Operated by Battelle Since 1965 
WTP-RPT-187, Rev 1

PNNL-18499, Rev 1

\title{
EFRT M12 Issue Resolution: Solids Washing
}

\author{
DL Baldwin \\ PW Eslinger \\ PP Schonewill \\ BD Hanson \\ JJ Toth \\ DE Kurath \\ JL Huckaby \\ MJ Minette
}

January 2010

Test Specification: 24590-PTF-TSP-RT-07-001 Rev 2

Work Authorization: WA\# 2007-024

Test Plan: TP-RPP-WTP-506, Rev. 0.4, TP-WTP-PEP-044, Rev. 0.2

Test Exceptions: $\quad$ 24590-PTF-TEF-RT-08-00002

24590-WTP-TEF-RT-09-00003

24590-PTF-TEF-RT-09-00001

24590-WTP-TEF-RT-09-00002 Rev 0

24590-WTP-TEF-RT-09-00001 Rev 1

R\&T focus area: Pretreatment

Test Scoping Statement(s): NA

Prepared for

the U.S. Department of Energy

Under Contract DE-AC05-76RL01830

Pacific Northwest National Laboratory

Richland, Washington 99352 


\section{COMPLETENESS OF TESTING}

This report describes the results of work and testing specified by Test Specification 24590-PTF-TSP-RT-07-001 Rev 2 "Pretreatment Engineering Platform (PEP) Testing (Phase 1)" and Test Plans TP-RPP-WTP-506 Rev 0.4 "Pretreatment Engineering Platform (PEP) Testing (Phase 1)" and TP-WTP-PEP-044 Rev 0.2 "Test Plan for the PEP Parallel Laboratory Testing." The work and any associated testing followed the quality assurance requirements outlined in the Test Specification/Plan. The descriptions provided in this test report are an accurate account of both the conduct of the work and the data collected. Test Plan results are reported. Also reported are any unusual or anomalous occurrences that are different from expected results. The test results and this report have been reviewed and verified.

\section{Approved:}

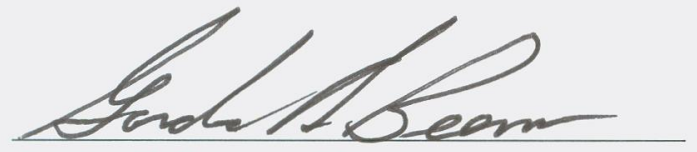

Gordon H. Beeman, Manager WTP R\&T Support Project

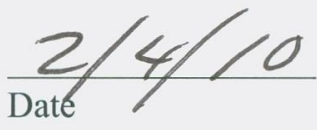




\section{REVISION HISTORY}

\begin{tabular}{|c|c|c|c|}
\hline $\begin{array}{l}\text { Revision } \\
\text { Number }\end{array}$ & $\begin{array}{c}\text { Interim } \\
\text { Change No. }\end{array}$ & Effective Date & Description of Change \\
\hline 0 & 0 & $8 / 14 / 09$ & Initial issue. \\
\hline 1 & 0 & When issued. & $\begin{array}{l}\text { Acronyms: Removed SBMS and replaced with HDI; changed SWRI } \\
\text { to SwRI for consistency with other documents. } \\
\text { Executive Summary/Section 2: Updated to reference HDI instead of } \\
\text { SBMS. } \\
\text { Table } 3.1 \text { and 3.2: The units were incorrectly shown as mg/g. They } \\
\text { were changed to } \mu \mathrm{g} / \mathrm{g} \text {. } \\
\text { Table 3.1: The liquid and slurry densities for Integrated Test B were } \\
\text { switched in Rev } 0 \text {. They were corrected in this revision. } \\
\text { Table } 3.1 \text { and 3.2: The uncertainty calculation for free hydroxide } \\
\text { was revised. The updated numbers are added in this revision. } \\
\text { Section 4.0: The equation section was revised to be consistent with } \\
\text { Section } 10.5 \text { in WTP-RPT-197 and clarify the distinction } \\
\text { between } \mathrm{C}_{\mathrm{n}} \text { and } \mathrm{C}_{\mathrm{n}}{ }^{*} \text {. Equation } 4.1 \text { was added and the old } \\
\text { equations were all incremented up by one. } \\
\text { Section 5.3: Several instances where "Tracer test" appears were } \\
\text { changed to "Tracer Test" to be consistent in the notation. A } \\
\text { comma was replaced with a period at the bottom of page } 5.25 \text {. } \\
\text { Section } 8.0: \text { The term "run sheets" was replaced with "Test } \\
\text { Instructions" in item 1; in item 7, the projected number of } \\
\text { batches was added to the conclusion for consistency with } \\
\text { WTP-RPT-197. } \\
\text { Table A.1, pg. A.2: A footnote was added to clarity the total } \\
\text { permeate mass for Integrated Test A, post-caustic-leach wash. } \\
\text { The footnoted value is provided for agreement with } \\
\text { WTP-RPT-197. }\end{array}$ \\
\hline
\end{tabular}





\section{Contents}

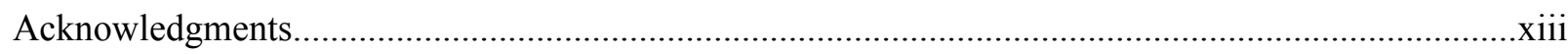

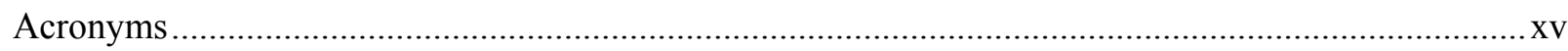

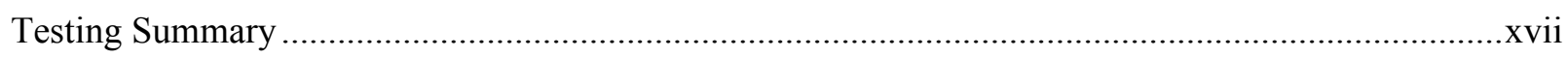

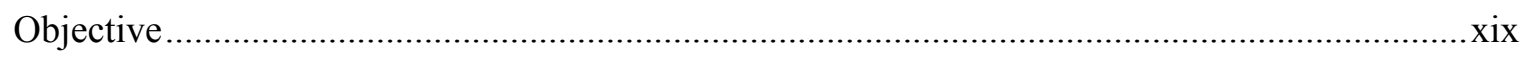

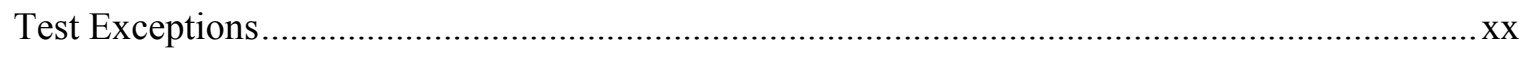

Results and Performance Against Success Criteria ............................................................xiv

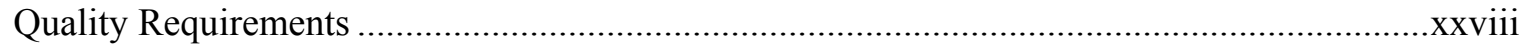

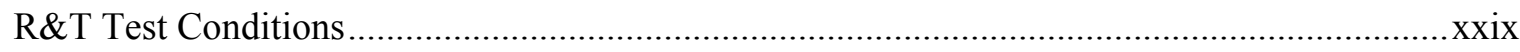

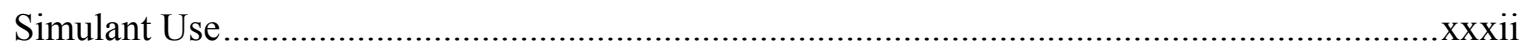

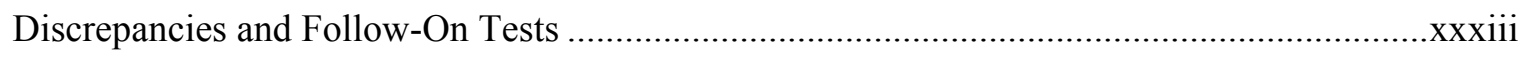

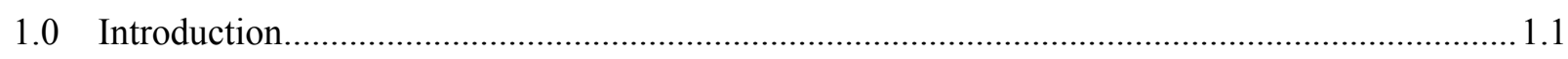

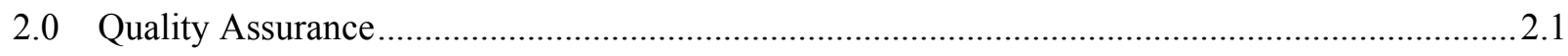

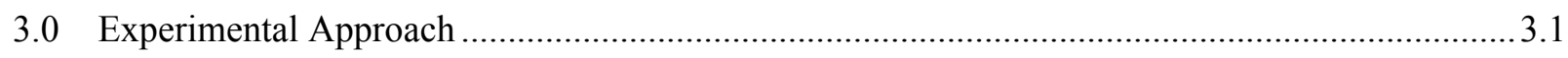

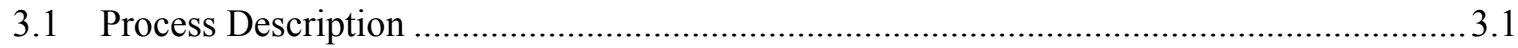

3.1.1 Integrated Test A: Vessel T01A/B Caustic-Leach Test Process Description ............3.3

3.1.2 Integrated Test B: Vessel T02A Caustic-Leach Test Process Description .................. 3.6

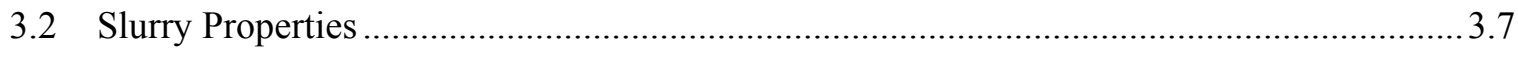

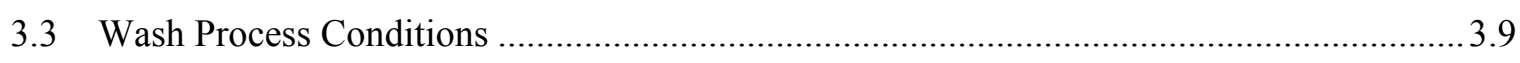

3.3.1 Post-Caustic-Leach Wash Process Conditions ............................................................ 3.9

3.3.2 Post-Oxidative-Leach Wash Process Conditions ....................................................... 3.18

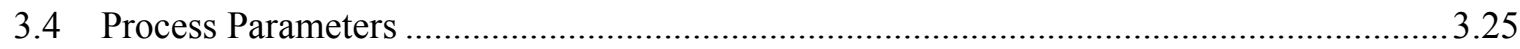

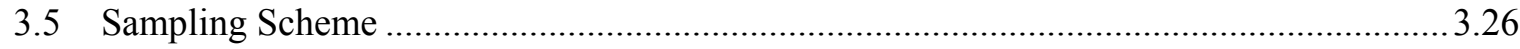

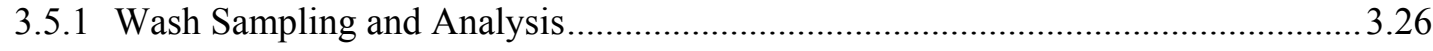

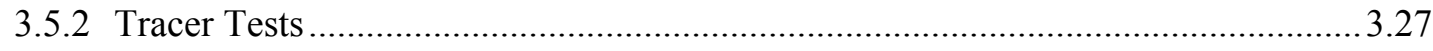

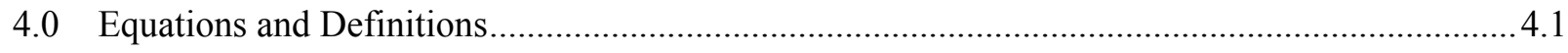

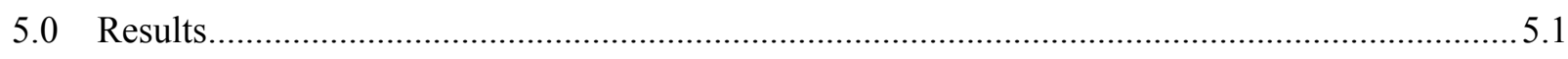

5.1 Post-Caustic-Leach Wash Tests ................................................................................. 5.1

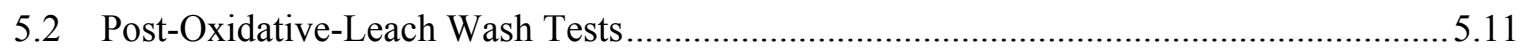

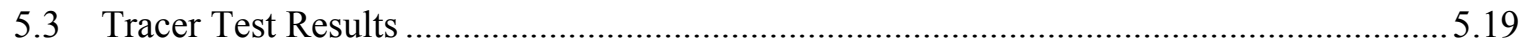

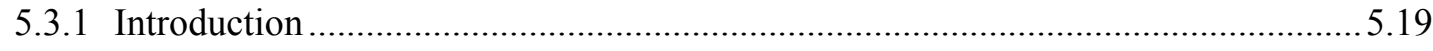

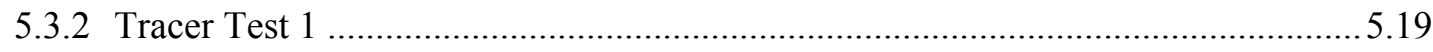

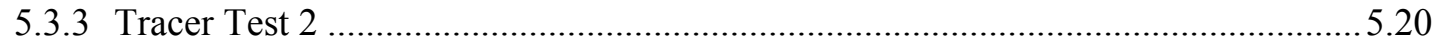

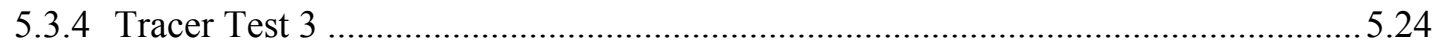




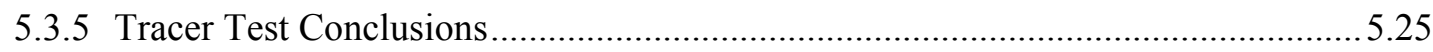

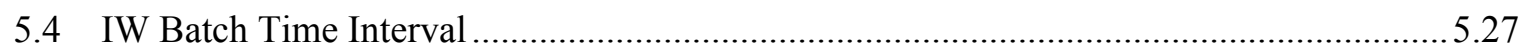

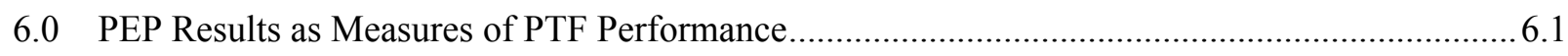

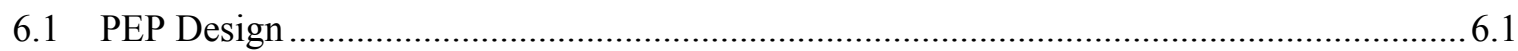

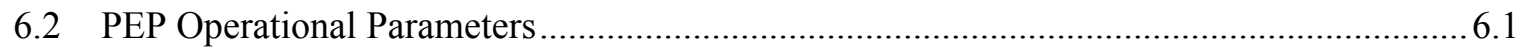

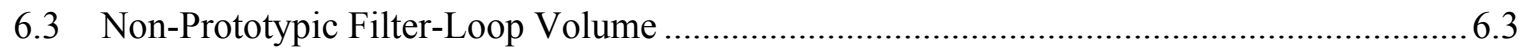

6.4 Deviations of Operational Parameters from Targeted Values ............................................ 6.5

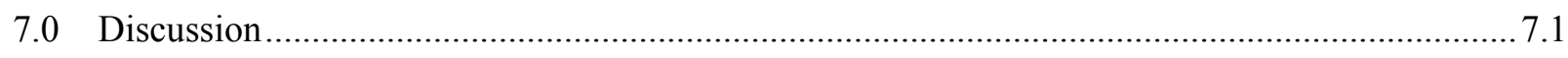

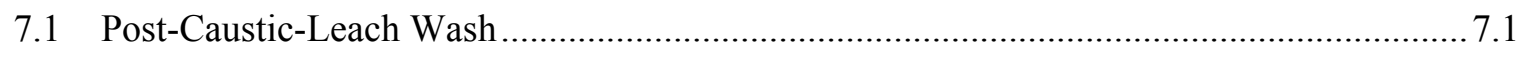

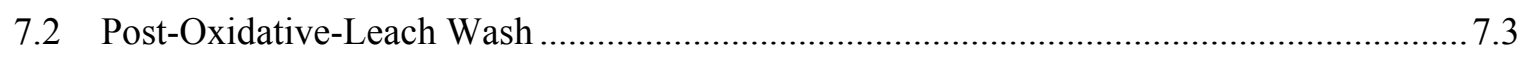

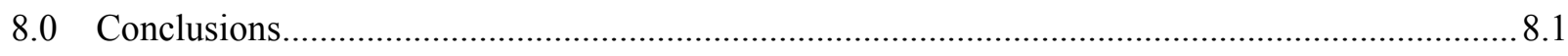

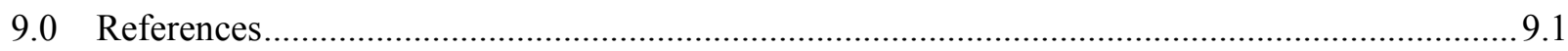

Appendix A: Target Parameters for Each Wash Step Compared to Actual Parameters...................... A.1

Appendix B: Filter-Loop Volume vs. Filter-Loop Flow Rate Model ............................................ B.1 


\section{Figures}

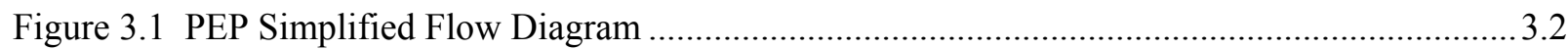

Figure 3.2 Caustic- and Oxidative-Leach and Ultrafilter Operations ................................................ 3.3

Figure 3.3 Schematic of Vessel T02A Loop and Filtration. .............................................................. 3.4

Figure 3.4 Measured Density for Post-Caustic-Leach Wash for Integrated Tests A and B................3.11

Figure 3.5 UDS for Post-Caustic-Leach Wash for Integrated Tests A and B................................3.12

Figure 3.6 Temperature in Vessel T02A During Post-Caustic-Leach Washing as a Function of IW Batch Number.

Figure 3.7 Total Permeate Flow Rate (sum of five filters) During Post-Caustic-Leach Washing as a Function of the IW Batch Number for Integrated Test A (black, closed symbols) and Integrated Test B (red, open symbols).

Figure 3.8 Average Normalized Flux (of the five filters) During Post-Caustic-Leach Washing as a Function of the IW Batch Number for Integrated Test A (black, closed symbols) and Integrated Test B (red, open symbols).

Figure 3.9 The Laser Level in Vessel T02A During Post-Caustic-Leach Washing as a Function of the IW Batch Number for Integrated Test A (black, closed symbols) and Integrated

Test B (red, open symbols).

Figure 3.10 Flow Rate in the Filtration Loop During Post-Caustic-Leach Washing as a Function of the IW Batch Number for Integrated Test A (black, closed symbols) and Integrated Test B (red, open symbols).

Figure 3.11 Bulk Slurry Density and Supernate Density for Both Integrated Tests A and B Post-Oxidative-Leach Wash as a Function of IW Batch Number.

Figure 3.12 The UDS in the Slurry for Both Integrated Tests A and B for Post-Oxidative-Leach Wash as a Function of the IW Batch Number.

Figure 3.13 Temperature in Vessel T02A During Post-Oxidative-Leach Washing as a Function of IW Batch Number.

Figure 3.14 Total Permeate Flow Rate (sum of five filters) During Post-Oxidative-Leach Washing as a Function of the IW Batch Number for Integrated Test A (black, closed symbols) and Integrated Test B (red, open symbols).

Figure 3.15 Average Normalized Flux (of the five filters) During Post-Oxidative-Leach Washing as a Function of the IW Batch Number for Integrated Test A (black, closed symbols) and Integrated Test B (red, open symbols).

Figure 3.16 The Laser Level in Vessel T02A During Post-Oxidative-Leach Washing as a Function of the IW Batch Number for Integrated Test A (black, closed symbols) and Integrated Test B (red, open symbols).

Figure 3.17 Flow Rate in the Filtration Loop During Post-Oxidative-Leach Washing as a Function of the IW Batch Number for Integrated Test A (black, closed symbols) and Integrated Test B (red, open symbols). 


\section{Figures}

Figure 3.18 In-Tank Sampling, Showing the Three Radial Positions at Three Heights and Sampling Flow Loop...

Figure 5.1 Incremental Wash Efficiency (left y-axis) and Concentration Ratio (right y-axis) for Aluminum During Post-Caustic-Leach Washing, Comparing Integrated Test A and Integrated Test B.

Figure 5.2 Incremental Wash Efficiency (left y-axis) and Concentration Ratio (right y-axis) for Sulfate During Post-Caustic-Leach Washing, Comparing Integrated

Test A and Integrated Test B.

Figure 5.3 Incremental Wash Efficiency (left y-axis) and Concentration Ratio (right y-axis) for Nitrate During Post-Caustic-Leach Washing, Comparing Integrated Test A and Integrated Test B.

Figure 5.4 Incremental Wash Efficiency (left y-axis) and Concentration Ratio (right y-axis) for Nitrite During Post-Caustic-Leach Washing, Comparing Integrated Test A and Integrated Test $\mathrm{B}$

Figure 5.5 Incremental Wash Efficiency (left y-axis) and Concentration Ratio (right y-axis) for Free Hydroxide During Post-Caustic-Leach Washing, Comparing Integrated Test A and Integrated Test B.

Figure 5.6 Incremental Wash Efficiency (left y-axis) and Concentration Ratio (right y-axis) for Chromium During Post-Oxidative-Leach Washing, Comparing Integrated Test $\mathrm{A}$ and Integrated Test $\mathrm{B}$.

Figure 5.7 Incremental Wash Efficiency (left y-axis) and Concentration Ratio (right y-axis) for Sodium During Post-Oxidative-Leach Washing, Comparing Integrated Test A and Integrated Test B.

Figure 5.8 Incremental Wash Efficiency (left y-axis) and Concentration Ratio (right y-axis) for Oxalate During Post-Oxidative-Leach Washing, Comparing Integrated Test A and Integrated Test B

Figure 5.9 Incremental Wash Efficiency (left y-axis) and Concentration Ratio (right y-axis) for Nitrate During Post-Oxidative-Leach Washing, Comparing Integrated Test A and Integrated Test B.

Figure 5.10 Incremental Wash Efficiency (left y-axis) and Concentration Ratio (right y-axis) for TDS During Post-Oxidative-Leach Washing.

Figure 5.11 Loop Flow Rate During Tracer Test 1.

Figure 5.12 Cesium Tracer Concentration During Tracer Test 1 Sampled from Two Locations: The Filtration Loop (black) and Vessel T02A at the Outer-Low Location (red)

Figure 5.13 Loop Flow Rate During Tracer Test 2.

Figure 5.14 Cesium Tracer Concentration During Tracer Test 2 Sampled from Two Locations: The Filtration Loop (black) and Vessel T02A at the Outer-Low Location (red)

Figure 5.15 Loop Flow Rate During Tracer Test 3 


\section{Figures}

Figure 5.16 Cesium Tracer Concentration During Tracer Test 3 Sampled from Two Locations: The Filtration Loop (black) and Vessel T02A at the Outer-Low Location (red)............ 5.27

Figure 5.17 IW Batch Time Interval, in Minutes, for Integrated Test A Post-Caustic-Leach Wash...5.28

Figure 5.18 IW Batch Time Interval, in Minutes, for Integrated Test A Post-Oxidative-Leach Wash

Figure 5.19 IW Batch Time Interval, in Minutes, for Integrated Test B Post-Caustic-Leach Wash. .. 5.30

Figure 5.20 IW Batch Time Interval, in Minutes, for Integrated Test B Post-Oxidative-Leach Wash

Figure 5.21 Tank Liquid Level and IW Additions to Vessel T02A During Post-Oxidative-Leach Wash for Batches 76 to 80

Figure 6.1 Plot of Normalized Solute Concentrations and Wash Efficiencies as Functions of Wash Batch Number for Two Filter-Loop Volumes Under Integrated Test A Conditions as Predicted by Appendix B Model

Figure 6.2 Plot of Normalized Solute Concentrations and Wash Efficiencies as Functions of Wash Batch Number for Two Filter-Loop Volumes Under Integrated Test B Conditions as Predicted by Appendix B Model

Figure 6.3 Plot of Normalized Solute Concentrations and Wash Efficiencies as Functions of Wash Batch Number for Two Filter-Loop Flow Rates Under Integrated Test A Conditions as Predicted by the Appendix B Model. 


\section{Tables}

Table S.1 Summary of Test Objectives and Results ......................................................................

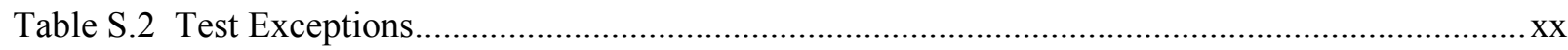

Table S.3 Deviations from Test Specification …............................................................................

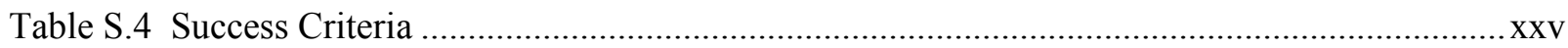

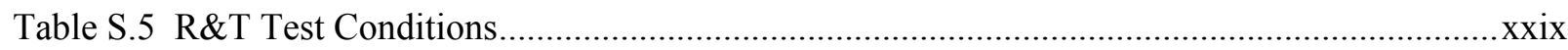

Table 3.1 Initial Slurry Composition for Post-Caustic-Leach Wash ................................................... 3.7

Table 3.2 Initial Slurry Composition for Post-Oxidative-Leach Wash................................................ 3.8

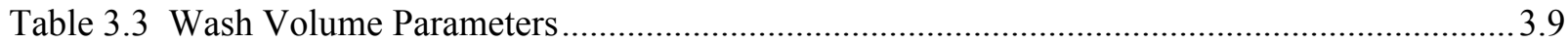

Table 5.1 Wash Efficiency for Completely Soluble Analytes During Post-Caustic-Leach Washing as Calculated Using the Weighted Least Squares Method of Equation 4.7 ..........................5.2

Table 5.2 Concentration and Incremental Wash Efficiency for Soluble Analytes Measured During the Integrated Test A Post-Caustic-Leach Wash .................................................. 5.7

Table 5.3 Concentration and Incremental Wash Efficiency for Partially Soluble Analytes Measured During the Integrated Test A Post-Caustic-Leach Wash .....................................5.8

Table 5.4 Concentration Data and Incremental Wash Efficiency for Fully Soluble Analytes Measured During the Integrated Test B Post-Caustic-Leach Wash

Table 5.5 Concentration Data and Incremental Wash Efficiency for Partially Soluble Analytes Measured During the Integrated Test B Post-Caustic-Leach Wash.

Table 5.6 Wash Efficiency for Completely Soluble Analytes During Post-Oxidative-Leach Washing as Calculated Using the Weighted Least Squares Method of Equation 4.7 ......... 5.12

Table 5.7 Concentration Data and Incremental Wash Efficiency for Selected Analytes Measured During the Integrated Test A Post-Oxidative-Leach Wash

Table 5.8 Concentration Data and Incremental Wash Efficiency for Selected Analytes Measured During the Integrated Test B Post-Oxidative-Leach Wash................................................ 5.18

Table 6.1 Appendix B Model Input Parameters for Figure 6.1 ..................................................... 6.4

Table 6.2 Appendix B Model Input Parameters for Figure 6.2 …....................................................... 6.5

Table 6.3 Appendix B Model Input Parameters for Figure 6.3 ......................................................... 6.7 


\section{Acknowledgments}

The authors would like to thank Wayne Cosby for valuable editorial support, Dave MacPherson and Kirsten Meier for Quality Assurance support throughout the project, and Rick Shimskey and Gary Josephson for their careful and thorough technical reviews and discussions.

In addition to the authors, this report was supported by many dedicated staff involved in laboratory experiments, sampling, data acquisition, data processing, data-quality confirmation, technical reviews, and data analysis.

$\begin{array}{lll}\text { JM Alzheimer } & \text { CA Burns } & \text { RD Scheele } \\ \text { C Arimescu } & \text { JM Cuta } & \text { GJ Sevigny } \\ \text { DD Bachand } & \text { MS Fountain } & \text { SV Shoemaker } \\ \text { EBK Baer } & \text { CE Guzman-Leong } & \text { DM Smith } \\ \text { S Barnes } & \text { RE Hohimer } & \text { PS Sundar } \\ \text { AW Baumann } & \text { ML Kimura } & \text { JJ Toth } \\ \text { GH Beeman } & \text { WL Kuhn } & \text { JC Tucker } \\ \text { DL Blanchard Jr } & \text { WE Lawrence } & \text { MW Urie } \\ \text { JC Bower } & \text { S Lehrman } & \text { BE Wells } \\ \text { OP Bredt } & \text { RP Pires } & \text { JK Young } \\ \text { GN Brown } & \text { DE Rinehart } & \\ \text { SA Bryan } & \text { RL Russell } & \end{array}$

These individuals and the rest of the operations and sampling crew are especially recognized for supporting the Pretreatment Engineering Platform Project by working unpredictable, long, and off-hour shifts for the better part of a year. The tests and reports could not have gotten this far without their extraordinary effort. 



\section{Acronyms}

$\begin{array}{ll}\text { AFA } & \text { antifoam agent } \\ \text { ASME } & \text { American Society of Mechanical Engineers } \\ \text { ASO } & \text { Analytical Support Operations } \\ \text { BNI } & \text { Bechtel National Inc. } \\ \text { CFR } & \text { Code of Federal Regulations } \\ \text { CUF } & \text { Cells Unit Filter } \\ \text { DAS } & \text { data acquisition system } \\ \text { DOE } & \text { U.S. Department of Energy } \\ \text { EFRT } & \text { External Flowsheet Review Team } \\ \text { FE } & \text { flow element } \\ \text { FEP } & \text { Feed Evaporation Process } \\ \text { HDI } & \text { "How Do I ...?" } \\ \text { HLW } & \text { high-level waste } \\ \text { IC } & \text { ion chromatography } \\ \text { ICP } & \text { inductively coupled plasma } \\ \text { IW } & \text { inhibited water } \\ \text { JTG } & \text { Joint Task Group } \\ \text { LAW } & \text { low-activity waste } \\ \text { LCS } & \text { laboratory control sample } \\ \text { MDL } & \text { minimum detection limit } \\ \text { MS } & \text { mass spectrometry } \\ \text { NCR } & \text { non-conformance report } \\ \text { OES } & \text { optical emission spectrometry } \\ \text { PEP } & \text { Pretreatment Engineering Platform } \\ \text { PJM } & \text { pulse jet mixer } \\ \text { PLM } & \text { polarized light microscopy } \\ \text { PNNL } & \text { Pacific Northwest National Laboratory } \\ \text { PTF } & \text { Pretreatment Facility } \\ \text { QA } & \text { quality assurance } \\ \text { QAM } & \text { Quality Assurance Manual } \\ \text { QAP } & \text { Quality Assurance Plan } \\ \text { QARD } & \text { Quality Assurance Requirements and Descriptions } \\ \text { RL } & \text { River Protection Project } \\ \text { RPology }\end{array}$




$\begin{array}{ll}\text { SwRI } & \text { Southwest Research Institute } \\ \text { TDS } & \text { total dissolved solids } \\ \text { TMP } & \text { transmembrane pressure } \\ \text { TOC } & \text { total organic carbon } \\ \text { UDS } & \text { undissolved solids } \\ \text { UFP } & \text { ultrafiltration process } \\ \text { WTP } & \text { Hanford Tank Waste Treatment and Immobilization Plant }\end{array}$




\section{Testing Summary}

Pacific Northwest National Laboratory (PNNL) was tasked by Bechtel National Inc. (BNI) on the River Protection Project-Hanford Tank Waste Treatment and Immobilization Plant (RPP-WTP) project to perform research and development activities to resolve technical issues identified for the Pretreatment Facility (PTF). The Pretreatment Engineering Platform (PEP) was designed, constructed, and operated as part of a plan to respond to issue M12, "Undemonstrated Leaching Processes" of the External Flowsheet Review Team (EFRT) issue response plan. ${ }^{\text {(a) }}$ The PEP is a $1 / 4.5$-scale test platform designed to simulate the WTP pretreatment caustic leaching, oxidative leaching, ultrafiltration solids concentration, and slurry washing processes. The PEP replicates the WTP leaching processes using prototypic equipment and control strategies. The PEP also includes non-prototypic ancillary equipment to support the core processing.

Two operating scenarios are currently being evaluated for the ultrafiltration process (UFP) and leaching operations. The first scenario has caustic leaching performed in the UFP-2 ultrafiltration feed vessels (i.e., vessel UFP-VSL-T02A in the PEP and vessels UFP-VSL-00002A and B in the WTP PTF). The second scenario has caustic leaching conducted in the UFP-1 ultrafiltration feed preparation vessels (i.e., vessels UFP-VSL-T01A and B in the PEP; vessels UFP-VSL-00001A and B in the WTP PTF).

In both scenarios, $19 \mathrm{M}$ sodium hydroxide solution ( $\mathrm{NaOH}$, caustic) is added to the waste slurry in the vessels to leach solid aluminum compounds (e.g., gibbsite, boehmite). Caustic addition is followed by a heating step that uses direct injection of steam to accelerate the leach process. Following the caustic-leach, the vessel contents are cooled using vessel cooling jackets and/or external heat exchangers. The main difference between the two scenarios is that for leaching in UFP-1, the $19 \mathrm{M} \mathrm{NaOH}$ is added to unconcentrated waste slurry (3- to 8-wt\% solids), while for leaching in UFP-2, the slurry is concentrated to nominally 20 -wt $\%$ solids using cross-flow ultrafiltration before adding caustic.

The PEP testing program was conducted under Test Plan TP-RPP-WTP-506 $6^{(\text {b) }}$ using a waste simulant that was developed in response to Task 5 from the M-12 External Flowsheet Review Team (EFRT) issue response plan. ${ }^{(a)}$ The testing included the following tests with simulated Hanford tank waste:

- Shakedown/Functional testing: Tested process operations (e.g., slurry transfers, steam heating of the vessels and the accumulation of condensate, filter backpulsing and flushing), process controls (e.g., transmembrane pressure [TMP] and axial flow velocity in the filter-loop), and certain test functions (e.g., in-line slurry sampling accuracy and precision).

- Integrated Test A: Demonstrated integrated processing when caustic leaching $\left(98^{\circ} \mathrm{C}\right)$ is performed in UFP-VSL-00001A/B with the $\mathrm{Cr}$ simulant component added after the post-caustic-leach washing step.

(a) SM Barnes and R Voke. 2006. "Issue Response Plan for Implementation of External Flowsheet Review Team (EFRT) Recommendations - M12: Undemonstrated Leaching Process." 24590-WTP-PL-ENG-06-0024 Rev. 0 Bechtel National Inc., Richland, Washington.

(b) GB Josephson, OP Bredt, JK Young, and DE Kurath. 2009. Pretreatment Engineering Platform (PEP) Testing (Phase I). TP-RPP-WTP-506, Rev. 0.4, Pacific Northwest National Laboratory, Richland Washington. 
- Integrated Test B: Demonstrated integrated processing when the caustic leaching $\left(98^{\circ} \mathrm{C}\right)$ is performed in UFP-VSL-00002A with the Cr simulant component added after the post-caustic-leach washing step.

- Integrated Test D: Demonstrated integrated processing when the caustic leaching is performed at a lower temperature $\left(85^{\circ} \mathrm{C}\right)$ in UFP-VSL-00002A and with the $\mathrm{Cr}$ simulant component added to the initial batch of simulant.

Integrated Test $\mathrm{C}$ was deleted from the scope of the testing (ICN-TP-RPP-WTP-506_R0.2).

This report discusses two different solids washing steps that are carried out during slurry processing, the first taking place after caustic leaching and the second after oxidative leaching. Results for the solids washing steps from Integrated Tests A and B are included in this report, with highlights summarized below.

Washing operations in PEP Integrated Tests A and B were conducted successfully as per the approved run sheets. However, minor instrument problems occurred, and some of the process conditions specified in the run sheet during the wash operations, such as filter-loop flow rate targets, were not met.

The following five analytes were selected based on full solubility and monitored in the post-caustic-leach wash as successful indicators of washing efficiency: aluminum, sulfate, nitrate, nitrite, and free hydroxide. Other analytes, including sodium, oxalate, phosphate, and total dissolved solids (TDS), showed indications of solids dissolution; therefore, they were unsuitable for monitoring washing efficiency.

In the post-oxidative-leach wash, two analytes with full solubility and good concentration behavior were selected as suitable indicators of washing efficiency. These were chromium and oxalate. The concentration curves for other analytes, including sodium, manganese, nitrate, and TDS, exhibited an abnormal curvature and were therefore unsuitable for monitoring washing efficiency.

An overall wash efficiency of $1.00 \pm 0.01$ was calculated for the post-caustic-leach wash. The overall wash efficiency for the post-oxidative-leach wash was determined to be $0.99 \pm 0.01$. These wash efficiencies were based on a weighted least squares fit of the full data set for each applicable analyte and are an average of several analytes traced during the washing steps in Integrated Tests A and B. Incremental wash efficiencies as a function of wash step were also calculated to provide an indication of the variability during the washing process.

Chemical tracer tests resulted in the conclusion that nearly complete mixing was achieved between 2 and 4 minutes after tracer injection. With inconsistent filter-loop flow rates and other mixing parameters, future process conditions should be taken into account during further interpretation of these data. A slight decrease of 8 to $10 \%$ in the tracer concentration between 4 and 60 minutes suggests that there was a relatively small unmixed region that mixed over the course of the 1-hour test. Some of this may be attributed to a dead-leg volume of approximately 9 gallons in the filter-loop.

The inhibited water (IW) batch time interval, defined as the duration between the start of the IW wash injection for a batch to the start time for the subsequent batch, was often comparable to the 2- to 4-minute mixing time indicated by the tracer tests. Such short batch durations do not appear to have significantly impacted the washing efficiencies. 


\section{Objective}

Table S.1 summarizes the objectives and results of this testing along with a discussion of how the objectives were met, as described in the approved Test Plan, TP-RPP-WTP-506, Rev. 0.4. ${ }^{\text {(a) }}$ The objectives for the entire PEP testing program are provided with discussion limited to those objectives met by the scope of this report. Objectives not met by the scope of this report are shaded in gray.

Table S.1. Summary of Test Objectives and Results

\begin{tabular}{|c|c|c|}
\hline Test Objective & $\begin{array}{l}\text { Objective } \\
\text { Met? }\end{array}$ & Discussion \\
\hline $\begin{array}{l}\text { Caustic-leach process: Compare } \\
\text { engineering- and laboratory-scale } \\
\text { results to determine impact of } \\
\text { scale-up. }\end{array}$ & NA & $\begin{array}{l}\text { Results to meet this objective are discussed in report WTP-RPT-186 } \\
\text { and WTP-RPT-197. }\end{array}$ \\
\hline $\begin{array}{l}\text { Oxidative-leach process: } \\
\text { Compare engineering- and } \\
\text { laboratory-scale results to } \\
\text { determine impact of scale-up. }\end{array}$ & NA & $\begin{array}{l}\text { Results to meet this objective are discussed in report WTP-RPT-188 } \\
\text { and WTP-RPT-197. }\end{array}$ \\
\hline $\begin{array}{l}\text { Cross-flow ultrafiltration: } \\
\text { Monitor cross-flow filter } \\
\text { performance at engineering- and } \\
\text { laboratory-scale to determine } \\
\text { scale-up. }\end{array}$ & NA & $\begin{array}{l}\text { Results to meet this objective are discussed in report WTP-RPT-185 } \\
\text { and WTP-RPT-197. }\end{array}$ \\
\hline $\begin{array}{l}\text { Slurry wash process: Determine } \\
\text { the post-caustic and oxidative } \\
\text { leaching slurry wash efficiencies. }\end{array}$ & $\bar{Y}$ & $\begin{array}{l}\text { An overall wash efficiency of } 1.00 \pm 0.01 \text { (Section 5.1) was } \\
\text { determined for the post-caustic-leach wash, and the overall wash } \\
\text { efficiency for the post-oxidative-leach wash was also determined to be } \\
0.99 \pm 0.01 \text { (Section 5.2). These wash efficiencies were based on the } \\
\text { weighted least squares fit of the full data set for each applicable } \\
\text { analyte and are an average of several analytes traced during the } \\
\text { washing steps in Integrated Tests A and B. Incremental wash } \\
\text { efficiencies as a function of wash step were also provided in } \\
\text { Sections } 5.1 \text { and } 5.2 \text { to indicate the variability during the washing } \\
\text { process. } \\
\text { The wash efficiency is explicitly defined in Section 4.0; for fully } \\
\text { soluble components, it is the ratio of the material removed to the } \\
\text { amount of material expected to be removed in an ideal washing } \\
\text { system. } \\
\text { Results to meet this objective are discussed in WTP-RPT-197. }\end{array}$ \\
\hline
\end{tabular}

(a) GB Josephson, OP Bredt, JK Young, and DE Kurath. 2009. Pretreatment Engineering Platform (PEP) Testing (Phase I). TP-RPP-WTP-506, Rev. 0.4, Pacific Northwest National Laboratory, Richland Washington. 
Table S.1. Summary of Test Objectives and Results

\begin{tabular}{||l|c|l||}
\hline \multicolumn{1}{|c|}{ Test Objective } & $\begin{array}{c}\text { Objective } \\
\text { Met? }\end{array}$ & \multicolumn{1}{|c|}{ Discussion } \\
\hline $\begin{array}{l}\text { Process Integration: Evaluate the } \\
\text { chemical addition, filter operation } \\
\text { cycle performance, and pressure } \\
\text { pot operations. Also perform } \\
\text { mass balances for aluminum, } \\
\text { chromium, manganese, sodium, } \\
\text { hydroxide, oxalate, phosphate, } \\
\text { sulfate, and water and monitor } \\
\text { permeates for post-filtration } \\
\text { precipitation. }\end{array}$ & NA & Results to meet this objective are discussed in WTP-RPT-197. \\
\hline $\begin{array}{l}\text { Monitor the performance of the } \\
\text { recirculation system pumps, } \\
\text { filters, and heat exchanger to } \\
\text { support engineering fabrication } \\
\text { decisions for these components. }\end{array}$ & NA & $\begin{array}{l}\text { The data required to meet this objective were provided on compact } \\
\text { disks transmitted in the following reference: Letter from GH Beeman } \\
\text { to H Hazen, "Subcontract No. 24590-QL-HC9-WA49-00001, Project } \\
\text { No. 53569 (WA-024) Engineering Ties Data Transmittal: The } \\
\text { Electronic File Enclosed with this letter Has Been Reviewed for } \\
\text { Technical Accuracy Per the Quality Assurance (QA) Program,” } \\
\text { WTP/RPP-MOA-PNNL-00392, dated 4/10/09. }\end{array}$ \\
\hline
\end{tabular}

\section{Test Exceptions}

A summary description of the Test Exceptions applied to these tests is shown in Table S.2.

Table S.2. Test Exceptions

\begin{tabular}{|c|c|}
\hline Test Exceptions & Description of Test Exceptions \\
\hline $\begin{array}{l}\text { 1) } 24590 \text {-PTF-TEF-RT-08- } \\
\text { 00002, incorporated into ICN-1 } \\
\text { to Test Plan TP-RPP-WTP-506. }\end{array}$ & $\begin{array}{l}\text { This Test Exception: } \\
\text { 1. Added a stage during the filter conditioning section of the Functional Test } \\
\text { where the simulant slurry is concentrated from approximately } 5 \text {-wt } \% \text { solids to } \\
20 \text {-wt\% solids in one operation. This is in addition to the previously } \\
\text { specified low-solids filter and high-solids filter testing. } \\
\text { 2. Documented the Joint Test Group (JTG) decision regarding the number of } \\
\text { replicate samples to be collected at various processing times. } \\
\text { 3. Revised the terminology specifying the Coriolis densitometer (CD) sample } \\
\text { locations changed to be consistent with PEP operating procedures. Renamed } \\
\text { the "center" array to "inner." } \\
\text { The sampling specified in the low-solids filtration test over-specifies the } \\
\text { sample collection timing required. The technical requirement is to get } \\
30 \text { unique samples. The sampling schedule specified is not required to } \\
\text { achieve this test objective. }\end{array}$ \\
\hline \begin{tabular}{|l|} 
2) 24590-PTF-TEF-RT-09- \\
00001, incorporated into ICN-2 \\
and ICN-3 to Test Plan \\
TP-RPP-WTP-506.
\end{tabular} & $\begin{array}{l}\text { 1. In several steps, the sampling location was changed from the filer-loop in-line } \\
\text { location to a middle-low CD sample loop location in the UFP-VSL-T02A } \\
\text { vessel. This change impacted sampling in the Functional and all Integrated } \\
\text { tests (ref CCN 187749). } \\
\text { 2. Added a step to the Shakedown/Functional Test (step A.1.31) to add sodium }\end{array}$ \\
\hline
\end{tabular}


Table S.2. Test Exceptions

\begin{tabular}{|c|c|}
\hline Test Exceptions & Description of Test Exceptions \\
\hline & 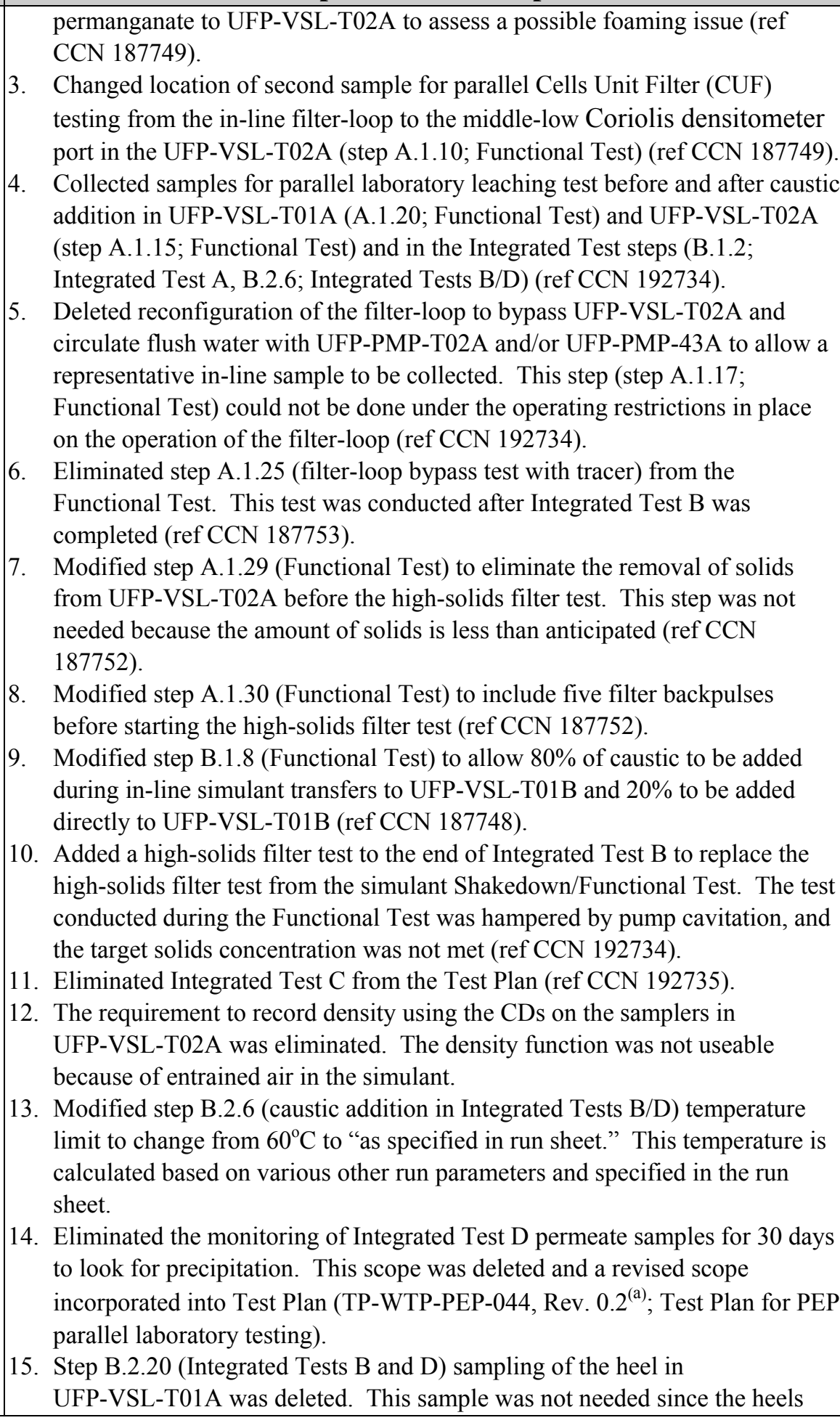 \\
\hline
\end{tabular}

(a) RL Russell. 2008. "Test Plan for the PEP Parallel Laboratory Testing." TP-WTP-PEP-044, Rev. 0.2, Pacific Northwest National Laboratory, Richland, Washington. 
Table S.2. Test Exceptions

\begin{tabular}{|c|c|}
\hline Test Exceptions & Description of Test Exceptions \\
\hline & $\begin{array}{l}\text { were removed before follow-on testing. } \\
\text { 16. Step B.1.26 (Integrated Test A) sampling of heel in UFP-VSL-T01B was } \\
\text { deleted. This sample was not needed since the heels were removed before } \\
\text { follow-on testing. } \\
\text { 17. Steps B.1.25 (Integrated Test A) and B.2.19 (Integrated Tests B/D) were } \\
\text { modified from "transfer slurry from UFP-VSL-T02A to HLP-VSL-T27" to } \\
\text { "Transfer slurry from UFP-VSL-T02A to UFP-VSL-62A/B or to totes for } \\
\text { storage as directed by the WTP test director." The HLP-VSL-T27 vessel was } \\
\text { no longer available for use since it served as the receipt vessel for the } \\
\text { filter-loop pressure safety valves. } \\
\text { 18. Added a second batch of leaching to Integrated Tests B/D in } \\
\text { UFP-VSL-T02A. This additional leaching batch was needed to provide a } \\
\text { sufficient quantity of solids to operate the UFP-VSL-T02A at prototypic } \\
\text { levels for the steps following caustic leaching. } \\
\text { 19. Added a filter bypass tracer test following the post-caustic-leach dewatering } \\
\text { step in Integrated Test B. This test replaced the filter bypass tracer test that } \\
\text { could not be conducted during the simulant Shakedown/Functional testing. } \\
\text { 20. Deleted instructions to route permeate to a specific tank (i.e., } \\
\text { UFP-VSL-T62A/B). There was no need to segregate various permeate } \\
\text { streams. } \\
\text { 21. Minor changes were made to make the Test Plan consistent with the approved } \\
\text { run sheets. }\end{array}$ \\
\hline $\begin{array}{l}\text { 3) } 24590 \text {-WTP-TEF-RT-09- } \\
\text { 00003 incorporated into ICN-1 } \\
\text { to Test Plan TP-WTP-PEP-044. }\end{array}$ & $\begin{array}{l}\text { This Test Exception specified activities to be performed with permeate samples } \\
\text { obtained from Integrated Test D. The Integrated Test D permeate samples were } \\
\text { originally stored in a temperature-controlled environment and then moved to a } \\
\text { location with a reduced temperature where precipitation was likely to occur. The } \\
\text { Test Exception requested that the approximate size-distribution of the solids be } \\
\text { measured in several ( } 3 \text { or 4) selected PEP samples from Integrated Test D using } \\
\text { polarized light microscopy (PLM). Size-calibrated photographs should be } \\
\text { provided along with the analysis. If possible, record the mineral identification of } \\
\text { the solids phase(s) along with the particle-size-distribution. The samples will be } \\
\text { selected by WTP personnel in consultation with the subcontractor and will be } \\
\text { based in part on observation of which samples contain the most solids or appear to } \\
\text { contain different types of solids. Repeat the size-distribution analysis } \\
\text { approximately } 1 \text { week after the initial measurements to determine whether there } \\
\text { was a significant change in crystal size, habit, or composition. } \\
\text { Perform each size-distribution analysis by measuring the diameter (or length and } \\
\text { width for elongated crystals) of approximately } 100 \text { individual particles in each } \\
\text { sample. The size may be measured either on the microscope slide, using a } \\
\text { calibrated ocular scale, or on the size-calibrated photographs. The program } \\
\text { recognizes the limitations of the statistical significance of a size-distribution } \\
\text { measurement based on such a small population. This Test Exception did not } \\
\text { affect any of the existing Test Plan objectives. }\end{array}$ \\
\hline
\end{tabular}


Table S.2. Test Exceptions

\begin{tabular}{|c|c|}
\hline Test Exceptions & Description of Test Exceptions \\
\hline $\begin{array}{l}\text { 4) } 24590-W T P-T E F-R T-09- \\
00002 \text { Rev 0, incorporated into } \\
\text { ICN-4 to Test Plan } \\
\text { TP-RPP-WTP-506. }\end{array}$ & $\begin{array}{l}\text { This Test Exception: } \\
\text { 1. Requests a report summarizing the lessons learned during scale-up. } \\
\text { manufacture and transport of the PEP simulant. } \\
\text { 2. Specifies the sampling and analysis scope to be performed to complete the } \\
\text { prototypic nitric acid PEP filter cleaning process. } \\
\text { 3. Deletes the Engineering Ties report scope. } \\
\text { 4. Specifies additional experimental and analytical work required to estimate the } \\
\text { amount of excess caustic in caustic leachate samples and post-caustic-leach } \\
\text { wash solutions containing } \approx 3.5 \mathrm{M} \mathrm{Na} \text {. }\end{array}$ \\
\hline $\begin{array}{l}\text { 5) } 24590-W T P-T E F-R T-09- \\
\text { 00001 Rev } 1 \text { incorporated into } \\
\text { ICN-2 to Test Plan } \\
\text { TP-WTP-PEP-044. }\end{array}$ & $\begin{array}{l}\text { This Test Exception specifies additional work to be conducted with caustic-leach } \\
\text { solutions and post-caustic-leach washing permeate samples obtained from PEP } \\
\text { Integrated Tests A, B and D. It contains the following tasks: } \\
\text { 1) Determination of precipitate mineralogy, precipitate phase compositions and } \\
\text { solution saturation composition. } \\
\text { 2) Determination of rate of approach to saturation concentrations. } \\
\text { 3) Identification and characterization of precipitates formed in } \\
\text { post-caustic-leach filtrate. } \\
\text { 4) Determination of the dilution required to redissolve the precipitate. } \\
\text { 5) Determination of super-saturation in post-caustic-leach filtrates from } \\
\text { Integrated Test B in the PEP. } \\
\text { 6) Determine the effects of blending during the post-caustic-leach dewatering } \\
\text { and wash cycle. }\end{array}$ \\
\hline
\end{tabular}

As documented in the PEP Test Plan, the deviations from the Test Specification are provided in Table S.3. 
Table S.3. Deviations from Test Specification

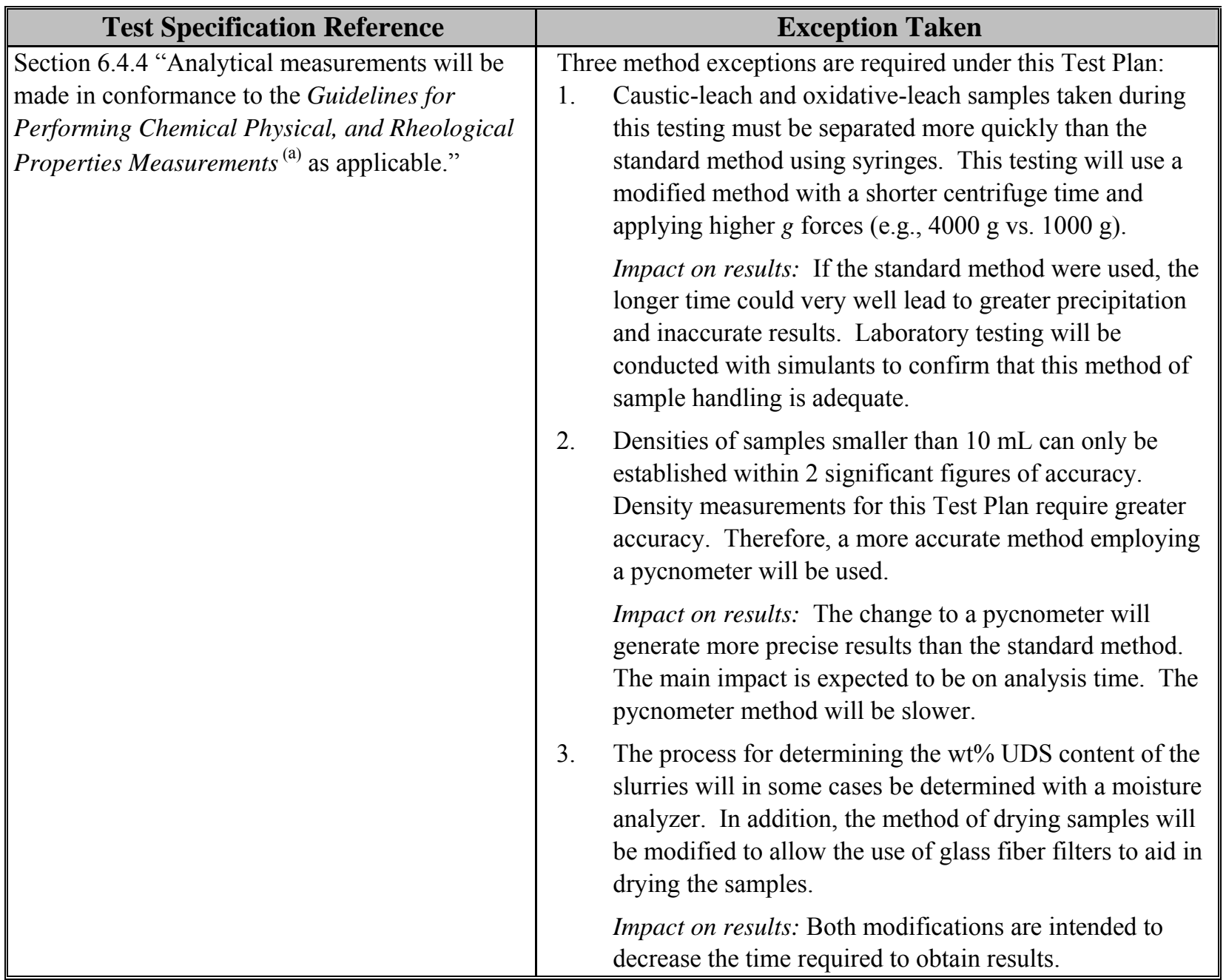

\section{Results and Performance Against Success Criteria}

The PEP system tests were designed to generate the data necessary to:

- Provide engineering-scale system performance data. This information is used to support the WTP computer process models' projections of the waste processing campaign.

- Confirm the operability and functionality of UFP system components.

The research and technology (R\&T) success criteria for achieving these objectives are discussed in Table S.4. The success criteria for the entire PEP testing program are provided with discussion limited to the success criteria covered by the scope of this report. The success criteria not addressed in this report are shaded in gray.

(a) GL Smith and K Prindiville. May 20, 2002. Guidelines for Performing Chemical, Physical, and Rheological Properties Measurements. 24590-WTP-GPG-RTD-001, Rev 0, Bechtel National, Inc., Richland, Washington. 
Table S.4. Success Criteria

\begin{tabular}{|c|c|c|c|}
\hline Success Criteria & \multicolumn{3}{|c|}{ How Testing Did or Did Not Meet Success Criteria } \\
\hline \multicolumn{4}{|l|}{ UFP System Process Performance } \\
\hline $\begin{array}{l}\text { Measure the aluminum leaching } \\
\text { performance of the PEP and } \\
\text { laboratory systems as a function of } \\
\text { time under WTP UFP-1 and UFP- } 2 \\
\text { projected leaching conditions at } \\
\text { bounding high and low process } \\
\text { temperatures (nominally } 100^{\circ} \mathrm{C} \text { and } \\
80^{\circ} \mathrm{C} \text { ). }\end{array}$ & \multicolumn{3}{|c|}{$\begin{array}{l}\text { Results to meet this success criterion are discussed in reports WTP-RPT-186 } \\
\text { and WTP-RPT-197. }\end{array}$} \\
\hline $\begin{array}{l}\text { Compare aluminum leach } \\
\text { performance in UFP-1 where all of } \\
\text { the } \mathrm{NaOH} \text { is added in-line to the } \\
\text { case where a fraction of the total } \\
\mathrm{NaOH} \text { is added directly to the tank. }\end{array}$ & \multicolumn{3}{|c|}{ Results to meet this success criterion are discussed in report WTP-RPT-197. } \\
\hline $\begin{array}{l}\text { Measure chromium leaching } \\
\text { performance in the PEP and } \\
\text { laboratory systems as a function of } \\
\text { time at the WTP projected } \\
\text { conditions in UFP-2 for both the } \\
\text { UFP-1 and UFP-2 aluminum } \\
\text { leaching flowsheets. }\end{array}$ & \multicolumn{3}{|c|}{$\begin{array}{l}\text { Results to meet this success criterion are discussed in reports WTP-RPT-188 } \\
\text { and WTP-RPT-197. }\end{array}$} \\
\hline $\begin{array}{l}\text { Evaluate the process control } \\
\text { strategy for specification of } \\
\text { required reagent additions, } \\
\text { including } \mathrm{NaOH}, \mathrm{NaMnO}_{4} \text {, and } \\
\text { wash solutions provided in the PEP } \\
\text { Phase } 1 \text { Testing Process } \\
\text { Description. }\end{array}$ & \multicolumn{3}{|c|}{$\begin{array}{l}\text { Results to meet this success criterion are discussed in report WTP-RPT-198 } \\
\text { for Integrated Tests A and B. Additional discussion and results for } \\
\text { Integrated Test D are discussed in WTP-RPT-197. }\end{array}$} \\
\hline $\begin{array}{l}\text { Measure the filter system } \\
\text { performance at the nominal flow } \\
\text { velocity and TMPs for the solids } \\
\text { concentration and washing stages } \\
\text { for the UFP-1 and UFP-2 aluminum } \\
\text { leaching flowsheets. }\end{array}$ & \multicolumn{3}{|c|}{ Results to meet this success criterion are discussed in report WTP-RPT-197. } \\
\hline $\begin{array}{l}\text { Evaluate the control strategy for } \\
\text { make-up additions from } \\
\text { UFP-VSL-00001A/B to } \\
\text { UFP-VSL-00002A/B during initial } \\
\text { dewatering process. }\end{array}$ & \multicolumn{3}{|c|}{ Results to meet this success criterion are discussed in report WTP-RPT-197. } \\
\hline \multirow{2}{*}{$\begin{array}{l}\text { Measure the wash-water volumes } \\
\text { required to remove or reduce the } \\
\text { free hydroxide following the } \\
\text { aluminum leaching stage and } \\
\text { dissolved chromium after the } \\
\text { oxidative leaching process to the } \\
\text { specified concentrations. }\end{array}$} & Test & $\begin{array}{l}\text { Number of IW } \\
\text { Batches Required to } \\
\text { Reach } 0.25 \mathrm{M} \\
\text { Hydroxide }\end{array}$ & $\begin{array}{l}\text { IW Volume Required } \\
\text { to Reach } 0.25 \mathrm{M} \\
\text { Hydroxide }\end{array}$ \\
\hline & $\begin{array}{l}\text { Integrated Test A: } \\
\text { Caustic leaching in } \\
\text { Vessel T01A/B }\end{array}$ & 64 & $\begin{array}{l}718 \text { gal } \\
\text { (slurry vol. } 269 \text { gal) }\end{array}$ \\
\hline
\end{tabular}


Table S.4. Success Criteria

\begin{tabular}{|c|c|c|c|}
\hline \multirow[t]{3}{*}{ Success Criteria } & \multicolumn{3}{|c|}{ How Testing Did or Did Not Meet Success Criteria } \\
\hline & $\begin{array}{l}\text { Integrated Test B: } \\
\text { Caustic leaching in } \\
\text { Vessel T02A }\end{array}$ & 39 & $\begin{array}{l}436 \text { gal } \\
\text { (slurry vol. } 154 \text { gal) }\end{array}$ \\
\hline & \multicolumn{3}{|c|}{$\begin{array}{l}\text { Results to meet this success criterion for Integrated Test D are discussed } \\
\text { in WTP-RPT-197. } \\
\text { Wash-water volumes for the post-oxidative leaching process are not } \\
\text { provided since there is no washing specification for Cr. }\end{array}$} \\
\hline $\begin{array}{l}\text { Perform mass balances for selected } \\
\text { constituents, including aluminum, } \\
\text { chromium, manganese, sodium, } \\
\text { hydroxide, oxalate, phosphate, } \\
\text { sulfate, and water to evaluate } \\
\text { leaching and washing process } \\
\text { performance. }\end{array}$ & \multicolumn{3}{|c|}{$\begin{array}{l}\text { Results to meet this success criterion are discussed for Cr in the oxidative } \\
\text { leaching process for Integrated Tests A and B in report WTP-RPT-188 and } \\
\text { will be fully discussed for all constituents in report WTP-RPT-197. }\end{array}$} \\
\hline $\begin{array}{l}\text { Measure solids distribution under } \\
\text { scaled mixing conditions before and } \\
\text { after caustic leaching evolutions. }\end{array}$ & \multicolumn{3}{|c|}{ Results to meet this success criterion are discussed in report WTP-RPT-197. } \\
\hline $\begin{array}{l}\text { Measure the rheology of the slurry } \\
\text { simulant and shear strength of the } \\
\text { settled solids before and after each } \\
\text { leaching and washing unit operation } \\
\text { and following final concentration. }\end{array}$ & \multicolumn{3}{|c|}{ Results to meet this success criterion are discussed in report WTP-RPT-197 } \\
\hline $\begin{array}{l}\text { Estimate the quantity of excess } \\
\text { hydroxide added in the process that } \\
\text { may not be needed to keep } \\
\text { aluminate in solution following } \\
\text { filtration. }\end{array}$ & \multicolumn{3}{|c|}{ Results to meet this success criterion are discussed in report WTP-RPT-197. } \\
\hline $\begin{array}{l}\text { Collect and retain permeate samples } \\
\text { for extended precipitation studies } \\
\text { (including permeate/simulated } \\
\text { supernatant blended cases) from } \\
\text { each concentration cycle. }\end{array}$ & \multicolumn{3}{|c|}{$\begin{array}{l}\text { Samples were collected and retained for extended precipitation studies. The } \\
\text { results of the precipitation studies are discussed in WTP-RPT-197, } \\
\text { WTP-RPT-200, and WTP-RPT-205. }\end{array}$} \\
\hline \multicolumn{4}{|c|}{ UFP System Operability and Functionality } \\
\hline $\begin{array}{l}\text { Verify that the dual, in-series pump } \\
\text { configuration is controllable and } \\
\text { maintains the required slurry } \\
\text { velocity and pressures for ultrafilter } \\
\text { operation. }\end{array}$ & \multicolumn{3}{|c|}{$\begin{array}{l}\text { The data required to meet this success criterion were provided on compact } \\
\text { disks transmitted in the following reference: Letter from GH Beeman to } \\
\text { H Hazen, "Subcontract No. 24590-QL-HC9-WA49-00001, Project } \\
\text { No. 53569 (WA-024) Engineering Ties Data Transmittal: The Electronic } \\
\text { File Enclosed with this letter Has Been Reviewed for Technical Accuracy } \\
\text { Per the QA Program," WTP/RPP-MOA-PNNL-00392, dated 4/10/09. }\end{array}$} \\
\hline
\end{tabular}


Table S.4. Success Criteria

\begin{tabular}{|c|c|}
\hline Success Criteria & How Testing Did or Did Not Meet Success Criteria \\
\hline $\begin{array}{l}\text { Measure the operating } \\
\text { characteristics for the cooling heat } \\
\text { exchanger for the UFP-VSL-00002 } \\
\text { filter recirculation loop } \\
\text { (temperature changes as a function } \\
\text { of flow to determine how to achieve } \\
\text { the desired performance in the PTF } \\
\text { analog). }\end{array}$ & $\begin{array}{l}\text { The data required to meet this success criterion were provided on compact } \\
\text { disks transmitted in the following reference: Letter from GH Beeman to } \\
\text { H Hazen, "Subcontract No. 24590-QL-HC9-WA49-00001, Project } \\
\text { No. } 53569 \text { (WA-024) Engineering Ties Data Transmittal: The Electronic } \\
\text { File Enclosed with this letter Has Been Reviewed for Technical Accuracy } \\
\text { Per the QA Program," WTP/RPP-MOA-PNNL-00392, dated 4/10/09. }\end{array}$ \\
\hline $\begin{array}{l}\text { Confirm whether the WTP process } \\
\text { control strategies for ultrafilter } \\
\text { system filling, operating, } \\
\text { backpulsing, draining, flushing, and } \\
\text { cleaning are adequate for stable } \\
\text { operation. Provide to WTP data to } \\
\text { determine whether backpulsing is a } \\
\text { required and effective means of } \\
\text { restoring the filter permeate rates to } \\
\text { verify that production throughput is } \\
\text { maintained and whether operation } \\
\text { of the backpulse system induces } \\
\text { any process or equipment } \\
\text { operations issues. } \\
\end{array}$ & Results to meet this success criterion are discussed in report WTP-RPT-197. \\
\hline $\begin{array}{l}\text { Use only the process information } \\
\text { and data available to the WTP PTF } \\
\text { operating staff during WTP } \\
\text { operations (e.g., caustic and } \\
\text { permanganate addition volumes, } \\
\text { permeate mass balances for solids } \\
\text { concentration) to operate the PEP. }\end{array}$ & Results to meet this success criterion are discussed in report WTP-RPT-197. \\
\hline $\begin{array}{l}\text { Confirm whether the elevated } \\
\text { temperature pulse jet mixer (PJM) } \\
\text { operating strategy is adequate for } \\
\text { stable PEP and WTP operation. }\end{array}$ & Results to meet this success criterion are discussed in report WTP-RPT-197. \\
\hline $\begin{array}{l}\text { Measure the heat-up rate and } \\
\text { controllability of the PEP } \\
\text { UFP-VSL-00001 and } \\
\text { UFP-VSL-00002 vessels and the } \\
\text { cooling performance for UFP } \\
\text { vessels. }\end{array}$ & Results to meet this success criterion are discussed in report WTP-RPT-197. \\
\hline $\begin{array}{l}\text { Measure the performance of the } \\
\text { in-line addition of process } \\
\text { chemicals into the simulated wastes } \\
\text { and determine the extent of } \\
\text { blending in the process vessels. }\end{array}$ & Results to meet this success criterion are discussed in report WTP-RPT-197. \\
\hline
\end{tabular}


Table S.4. Success Criteria

\begin{tabular}{|l|l|}
\hline \multicolumn{1}{|c|}{ Success Criteria } & \multicolumn{1}{|c|}{ How Testing Did or Did Not Meet Success Criteria } \\
\hline $\begin{array}{l}\text { Monitor ultrafilter performance (to } \\
\text { include visual inspection of the } \\
\text { filter tubes, tube sheets, and heads } \\
\text { from an ultrafilter for any evidence } \\
\text { of flow mal-distribution and/or } \\
\text { solids buildup at least once during } \\
\text { Phase 1). }\end{array}$ & Results to meet this success criterion are discussed in report WTP-RPT-197. \\
\hline $\begin{array}{l}\text { Measure, record, and control } \\
\text { ultrafiltration temperature, TMP, } \\
\text { and slurry flow during filter-loop } \\
\text { operations. }\end{array}$ & $\begin{array}{l}\text { Data to meet this success criterion are discussed in WTP-RPT-185 for the } \\
\text { low- and high-solids tests and will be discussed for the remaining tests in the } \\
\text { run reports for each of the Integrated tests. }\end{array}$ \\
\hline $\begin{array}{l}\text { Record any solids accumulations } \\
\text { observed during any operating stage } \\
\text { or maintenance evolution. }\end{array}$ & Results to meet this success criterion are discussed in report WTP-RPT-197. \\
\hline $\begin{array}{l}\text { Monitor the permeate production } \\
\text { rate of each ultrafilter assembly in } \\
\text { operation. }\end{array}$ & $\begin{array}{l}\text { Results to meet this success criterion are discussed in WTP-RPT-185 for the } \\
\text { low- and high-solids tests and will be discussed for the remaining tests in } \\
\text { report WTP-RPT-197. }\end{array}$ \\
\hline $\begin{array}{l}\text { Record the operating time of each } \\
\text { ultrafilter assembly. }\end{array}$ & Results to meet this success criterion are discussed in report WTP-RPT-197. \\
\hline $\begin{array}{l}\text { Record each ultrafilter assembly } \\
\text { cleaning event (backpulse, flush, } \\
\text { chemical cleaning, etc.). }\end{array}$ & Results to meet this success criterion are discussed in report WTP-RPT-197. \\
\hline $\begin{array}{l}\text { Evaluate the pulse-pot operation } \\
\text { and backpulse operation strategies } \\
\text { contained in PEP Phase 1 Testing } \\
\text { Process Description. }\end{array}$ & Results to meet this success criterion are discussed in report WTP-RPT-197. \\
\hline $\begin{array}{l}\text { Evaluate permeate and permeate } \\
\text { blends for precipitation of solids, } \\
\text { particularly aluminum and oxalate } \\
\text { solids. }\end{array}$ & $\begin{array}{l}\text { Results to meet this success criterion are discussed in reports WTP-RPT-197, } \\
\text { WTP-RPT-200, and WTP-RPT-205. }\end{array}$ \\
\hline
\end{tabular}

\section{Quality Requirements}

The PNNL Quality Assurance Program is based upon the requirements as defined in the U.S. Department of Energy (DOE) Order 414.1C, Quality Assurance and 10 CFR 830, Energy/Nuclear Safety Management, Subpart A-Quality Assurance Requirements (a.k.a. the Quality Rule). PNNL has chosen to implement the following consensus standards in a graded approach:

- ASME NQA-1-2000, Quality Assurance Requirements for Nuclear Facility Applications, Part 1, Requirements for Quality Assurance Programs for Nuclear Facilities.

- ASME NQA-1-2000, Part II, Subpart 2.7, Quality Assurance Requirements for Computer Software for Nuclear Facility Applications.

- ASME NQA-1-2000, Part IV, Subpart 4.2, Graded Approach Application of Quality Assurance Requirements for Research and Development. 
The procedures necessary to implement the requirements are documented in PNNL's "How Do I ...?" (HDI) system. ${ }^{(a)}$

PNNL implements the RPP-WTP quality requirements by performing work in accordance with the River Protection Project - Waste Treatment Plant Support Program (RPP-WTP) Quality Assurance Plan (RPP-WTP-QA-001, QAP). Work was performed to the quality requirements of NQA-1-1989 Part I, Basic and Supplementary Requirements, NQA-2a-1990, Part 2.7 and DOE/RW-0333P, Rev 13, Quality Assurance Requirements and Descriptions (QARD) as applicable. These quality requirements are implemented through the River Protection Project - Waste Treatment Plant Support Program (RPP-WTP) Quality Assurance Manual (RPP-WTP-QA-003, QAM). The requirements of DOE/RW-0333P Rev 13, Quality Assurance Requirements and Descriptions (QARD) and 10 CFR 830 Subpart A were not required for this work.

RPP-WTP addresses internal verification and validation activities by conducting an independent technical review of the final data report in accordance with RPP-WTP's procedure QA-RPP-WTP-604. This review procedure is part of PNNL's RPP-WTP Quality Assurance Manual (RPP-WTP-QA-003). Following this procedure, a technical review would verify that the reported results are traceable, that inferences and conclusions are soundly based, and the reported work satisfies the objectives.

Key analytes in the laboratory control sample (LCS) and PEP control sample were plotted over time to look for anomalies. The PEP control sample is a project-provided material generated from material very similar to the initial simulant feed. In general, the plots constructed to date associated with the inductively coupled plasma (ICP) and ion chromatography (IC) analyses of solutions show recoveries within limits of $80 \%$ to $120 \%$.

\section{R\&T Test Conditions}

The R\&T test conditions as defined in the Test Specification are summarized in Table S.5. The R\&T test conditions for the entire PEP testing program are provided with discussion limited to the R\&T test conditions covered by the scope of this report. R\&T test conditions not addressed in this report are shaded in gray.

Table S.5. R\&T Test Conditions

\begin{tabular}{||l|l||}
\hline List R\&T Test Conditions & Were Test Conditions Followed? \\
\hline General Requirements & \multicolumn{2}{|l||}{$\begin{array}{l}\text { Perform mass balances for selected constituents, } \\
\text { including aluminum, chromium, manganese, sodium, } \\
\text { hydroxide, oxalate, phosphate, sulfate, and water, to } \\
\text { evaluate leaching and washing process performance. }\end{array}$} & $\begin{array}{l}\text { This R\&dition is discussed for Cr in the } \\
\text { oxidative-leach process in Integrated Tests A and B } \\
\text { in WTP-RPT-188 and will be fully discussed in } \\
\text { report WTP-RPT-197. }\end{array}$ \\
\hline $\begin{array}{l}\text { Evaluate ultrafilter performance (to include visual } \\
\text { inspection of the filter tubes, tube sheets, and heads } \\
\text { from an ultrafilter for any evidence of flow } \\
\text { mal-distribution and/or solids buildup or evidence of } \\
\text { potential failure). }\end{array}$ & $\begin{array}{l}\text { This R\&T test condition is discussed in report } \\
\text { WTP-RPT-197. }\end{array}$ \\
\hline
\end{tabular}

(a) HDI is PNNL's system for managing the delivery of laboratory-level policies, requirements, and procedures. xxix 
Table S.5. R\&T Test Conditions

\begin{tabular}{|c|c|}
\hline List R\&T Test Conditions & Were Test Conditions Followed? \\
\hline $\begin{array}{l}\text { Assess the blending achieved during in-line additions } \\
\text { of leaching and washing solutions. }\end{array}$ & $\begin{array}{l}\text { In-line addition of wash-water during Integrated } \\
\text { Tests A and B are assessed in this report and will } \\
\text { be fully discussed in report WTP-RPT-197. }\end{array}$ \\
\hline $\begin{array}{l}\text { Record any solids accumulations observed during } \\
\text { any operating stage or maintenance evolution (e.g., } \\
\text { photography, particle-size-distribution). }\end{array}$ & $\begin{array}{l}\text { This R\&T test condition is discussed in report } \\
\text { WTP-RPT-197. }\end{array}$ \\
\hline \multicolumn{2}{|l|}{ Leaching Operations } \\
\hline $\begin{array}{l}\text { Maintain caustic leaching temperature at the required } \\
\text { setpoint and record steam usage to remain in the } \\
\text { temperature range. }\end{array}$ & $\begin{array}{l}\text { This R\&T test condition is discussed in reports } \\
\text { WTP-RPT-186 and WTP-RPT-197. }\end{array}$ \\
\hline $\begin{array}{l}\text { Maintain oxidative leaching temperature at the } \\
\text { required setpoint. }\end{array}$ & $\begin{array}{l}\text { This R\&T test condition is discussed in reports } \\
\text { WTP-RPT-188 and WTP-RPT- } 197 .\end{array}$ \\
\hline $\begin{array}{l}\text { Obtain periodic samples during the leaching } \\
\text { operations to monitor the amount of aluminum or } \\
\text { chromium that has dissolved and concentrations of } \\
\text { the reactants and products in the liquid fraction in the } \\
\text { vessel. }\end{array}$ & $\begin{array}{l}\text { This R\&T test condition is discussed in reports } \\
\text { WTP-RPT-186, WTP-RPT-188, and } \\
\text { WTP-RPT-197. }\end{array}$ \\
\hline $\begin{array}{l}\text { Provide data to demonstrate the WTP process control } \\
\text { strategy for the caustic and permanganate addition. }\end{array}$ & $\begin{array}{l}\text { This R\&T test condition is discussed in report } \\
\text { WTP-RPT- } 197 \text {. }\end{array}$ \\
\hline $\begin{array}{l}\text { Measure the rheology of the slurry simulant and } \\
\text { shear strength of the settled solids before and } \\
\text { following each leaching unit operation. }\end{array}$ & $\begin{array}{l}\text { This R\&T test condition is discussed in report } \\
\text { WTP-RPT-197. }\end{array}$ \\
\hline \multicolumn{2}{|l|}{ Concentration Operations } \\
\hline $\begin{array}{l}\text { Monitor the permeate production rate of each } \\
\text { ultrafilter assembly in operation. }\end{array}$ & $\begin{array}{l}\text { This R\&T test condition is discussed in report } \\
\text { WTP-RPT-185, the run reports for the individual } \\
\text { tests, and WTP-RPT- } 197 \text {. }\end{array}$ \\
\hline Record operating time of each ultrafilter assembly. & $\begin{array}{l}\text { This R\&T test condition is discussed in report } \\
\text { WTP-RPT-197. }\end{array}$ \\
\hline $\begin{array}{l}\text { Record each ultrafilter assembly "cleaning" event } \\
\text { (backpulse, flush, chemical cleaning, etc.). }\end{array}$ & $\begin{array}{l}\text { This R\&T test condition is discussed in report } \\
\text { WTP-RPT- } 197 .\end{array}$ \\
\hline $\begin{array}{l}\text { Confirm pulse-pot operation and backpulse operation } \\
\text { strategies. }\end{array}$ & $\begin{array}{l}\text { This R\&T test condition is discussed in report } \\
\text { WTP-RPT-197. }\end{array}$ \\
\hline $\begin{array}{l}\text { Control ultrafiltration temperature, TMP, and slurry } \\
\text { flow as specified in test-specific run sheets. }\end{array}$ & $\begin{array}{l}\text { This R\&T test condition is discussed in report } \\
\text { WTP-RPT-185, the run reports for the individual } \\
\text { tests, and WTP-RPT- } 197 \text {. }\end{array}$ \\
\hline $\begin{array}{l}\text { Collect and retain permeate samples for extended } \\
\text { precipitation studies (including permeate/simulated } \\
\text { supernatant blended cases) from each concentration } \\
\text { cycle. }\end{array}$ & $\begin{array}{l}\text { Samples were collected and retained for extended } \\
\text { precipitation studies. The results of the } \\
\text { precipitation studies are discussed in } \\
\text { WTP-RPT-197, WTP-RPT-200, and } \\
\text { WTP-RPT-205. }\end{array}$ \\
\hline $\begin{array}{l}\text { Demonstrate WTP ultrafiltration system control } \\
\text { scheme in normal operating modes (e.g., fill and } \\
\text { startup, operation, backpulsing, flush and drain, } \\
\text { cleaning and return to service). }\end{array}$ & $\begin{array}{l}\text { This R\&T test condition is discussed in report } \\
\text { WTP-RPT-197. }\end{array}$ \\
\hline
\end{tabular}


Table S.5. R\&T Test Conditions

\begin{tabular}{|c|c|}
\hline List R\&T Test Conditions & Were Test Conditions Followed? \\
\hline \multicolumn{2}{|l|}{ Washing Operations } \\
\hline $\begin{array}{l}\text { Wash slurries using a washing protocol to be } \\
\text { specified in test-specific run sheets. }\end{array}$ & $\begin{array}{l}\text { Yes. The slurries were washed per the protocols } \\
\text { specified in the approved run sheets. } \\
\text { Some of the process conditions specified in the run } \\
\text { sheet were not met during the washing. } \\
\text { Integrated Test A: The filter-loop flow rate target } \\
\text { of } 109 \pm 10 \text { gpm was not achieved for the } \\
\text { post-caustic-leach and post-oxidative-leach } \\
\text { washing. The actual flow rate is not known } \\
\text { because of a failure of the filter-loop flowmeter } \\
\text { and air entrainment. The target temperature of } \\
25 \pm 2{ }^{\circ} \mathrm{C} \text { was not achieved for the first seven } \\
\text { washes of the post-caustic-leach wash because of } \\
\text { extreme pump behavior that added excess heat to } \\
\text { the system. The air flow to the spargers and the } \\
\text { steam-ring were much lower than the target values. } \\
\text { The air flow was reduced in an effort to manage air } \\
\text { entrainment in the system. } \\
\text { Integrated Test B: The filter-loop flow rate target } \\
\text { of } 109 \pm 10 \text { gpm was not achieved for the } \\
\text { post-caustic and post-oxidative-leach washing. } \\
\text { The pumps were operated at the maximum } \\
\text { achievable flow rate, which was lower than the } \\
\text { minimum target of } 99 \text { gpm. The air flow to the } \\
\text { spargers and the steam-ring was off during the } \\
\text { washing steps in an effort to minimize air } \\
\text { entrainment in the system. } \\
\text { This R\&T test condition for Integrated Test D is } \\
\text { discussed in WTP-RPT-197. }\end{array}$ \\
\hline $\begin{array}{l}\text { Sample permeate immediately before each wash } \\
\text { solution addition to monitor washing } \\
\text { performance/efficiency. }\end{array}$ & $\begin{array}{l}\text { Yes. The samples were obtained before each wash } \\
\text { solution addition. } \\
\text { This R\&T test condition for Integrated Test D is } \\
\text { discussed in WTP-RPT-197. }\end{array}$ \\
\hline Measure rheology of the washed solids. & $\begin{array}{l}\text { Yes. The rheology of the washed solids was } \\
\text { measured. } \\
\text { This R\&T test condition for Integrated Test D is } \\
\text { discussed in WTP-RPT-197. }\end{array}$ \\
\hline
\end{tabular}




\section{Simulant Use}

PEP process testing was performed with a nonradioactive aqueous slurry of simulant waste chemicals and solids. The simulant composition and make-up recipe were provided by WTP as documented in Simulant Recommendation for Phase 1 Testing in the Pretreatment Engineering Platform. ${ }^{\text {(a) }}$ Aqueous chemical concentrations were within ranges expected for waste feeds to the PTF except for the hydroxide, oxalate, and phosphate anions. The hydroxide concentration was approximately one standard deviation from the average concentration expected in the feeds to the plant. The oxalate and phosphate components were at their respective solubility limits. The solids components and blend were selected to obtain targeted solids mass loss (aluminum and chromium leaching and oxalate washing) and treatment time. The simulant was not selected to represent any particular Hanford tank waste type.

The simulant was blended from the components listed below. The basis for selecting the individual components and comparison to actual waste behavior is provided where applicable in the indicated references:

- Boehmite (for Al) (Russell et al. 2009a)

- Gibbsite (for Al) (Russell et al. 2009b)

- Chrome oxyhydroxide (CrOOH) slurry (Rapko et al. 2007)

- Sodium oxalate

- Filtration simulant (Russell et al. 2009c)

- Supernate.

Because the high-temperature caustic leaching process was found to dissolve significant amounts of the $\mathrm{CrOOH}$ solids, a separate chromium solids simulant was prepared and added to the PEP process after post-caustic-leach washing (a non-prototypic addition) in Integrated Tests A and B. In Integrated Test D, the chromium solids component of the simulant was added to the feed to demonstrate the PTF permanganate addition strategy.

Simulant was procured from NOAH Technologies Corporation (San Antonio, TX). Samples of each simulant batch were characterized to verify that chemical and physical properties requirements were met. Batches of the simulant were procured as follows:

- A 15-gallon trial batch of the blended simulant for laboratory testing to demonstrate the efficacy of the simulant fabrication procedure.

- A 250-gallon scale-up batch of the blended simulant to demonstrate scale-up of the simulant fabrication procedure to an intermediate scale.

- Batches 0, 1, and 2, each nominally 3500 gallons, of blended simulant for the Shakedown/Functional Tests and Integrated Tests A and B. These batches did not contain the $\mathrm{CrOOH}$ component.

- Batch 3, nominally 1200 gal, for Integrated Test D. This batch contained the CrOOH solids component.

(a) P Sundar. 2008. Simulant Recommendation for Phase 1 Testing in the Pretreatment Engineering Platform. 24590-PTF-RT-08-006, Rev 0, Bechtel National, Inc., Richland, Washington. 
- The CrOOH solids slurry for the Shakedown/Functional Test and Integrated Tests A and B was obtained in two separate batches containing nominally 18 and $36 \mathrm{~kg}$ of $\mathrm{Cr}$ as $\mathrm{CrOOH}$.

\section{Discrepancies and Follow-On Tests}

No discrepancies or follow-on tests were identified. 



\subsection{Introduction}

Selected data and analyses from Integrated Tests A and B are necessary for the Hanford Tank Waste Treatment and Immobilization Plant (WTP) to answer and close out issues raised by the External Flowsheet Review Team (EFRT). A separate report is available for each of the four main unit operations: 1) caustic leaching, 2) oxidative leaching, 3) ultrafiltration performance (e.g., filter flux), and 4) solids washing. Each report includes, as needed, results from laboratory tests with the Phase I Pretreatment Engineering Platform (PEP) simulant (including parallel Cells Unit Filter [CUF] run data, parallel stirred-vessel leaching) along with the results from the specified Integrated tests.

During tests of the PEP, which is a $1 / 4.5$-scale mock-up of key Pretreatment Facility (PTF) process equipment, the efficiency of incremental washing of solids to remove dissolved species (such as aluminum hydroxide) and sparingly soluble salts (such as sodium oxalate) is assessed. The purpose of this data report is to summarize the test results that are related to washing efficiency to support modeling. Washing efficiency is defined as the amount of material removed relative to the amount expected to be removed assuming ideal volumetric mixing. Less material removed results in a lower efficiency.

The wash efficiency, denoted by the symbol $w_{\text {eff, }}$ is explicitly defined in Section 4.0 , but is a measure of the washing and removal of the fully soluble components as the ratio of the material removed to the amount of material expected to be removed in an ideal washing system. A washing efficiency less than 1 implies incomplete mixing. Alternatively, any increases in the dissolved species concentration caused by dissolution would give an apparent efficiency of less than 1 . The precipitation of a solute would result in an apparent washing efficiency greater than 1 .

Two different solids washing steps are carried out during slurry processing. The initial solids wash takes place after caustic leaching; its primary purpose is to remove the excess free hydroxide remaining after the caustic-leach. This is denoted in Test Plan TP-RPP-WTP-506, Rev. 0.4, ${ }^{\text {(a) }}$ as steps B.1.15 and B.2.11. The final solids wash comes after oxidative leaching and is intended to remove the sodium introduced during leaching and the dissolved Cr resulting from leaching. This is denoted in the Test Plan as steps B.1.20 and B.2.16.

Whether caustic leaching was carried out in UFP-VSL-T01A/B or UFP-VSL-T02A (henceforth referred to as Vessel T02A), both of the solids wash steps occurred in Vessel T02A. Both types of wash used the same procedure. Periodically, a small volume of inhibited water (IW) $(0.01 \mathrm{M} \mathrm{NaOH})$ was added upstream of the first recirculation pump and mixed in-line. At the same time, permeate was removed from the ultrafilters in the loop and collected in either UFP-VSL-T62A and/or UFP-VSL-T62B. The flowmeter for the line where wash liquid is added was used to monitor and control the wash volume.

The information of concern in the data analysis for the post-caustic-leach solids wash is the change in the concentration of free hydroxide, the washing efficiency, the removal of dissolved $\mathrm{Al}$ and other dissolved species, and the precipitation (i.e., $\mathrm{Al}$ ) or dissolution (i.e., $\mathrm{Na}$ ) of other species during washing. For the post-oxidative-leach solids wash, the washing efficiency for $\mathrm{Cr}(\mathrm{VI}), \mathrm{Na}$, and other dissolved species is of interest.

(a) GB Josephson, OP Bredt, JK Young, and DE Kurath. 2009. Pretreatment Engineering Platform (PEP) Testing (Phase I). TP-RPP-WTP-506, Rev. 0.4, Pacific Northwest National Laboratory, Richland Washington. 



\subsection{Quality Assurance}

The Pacific Northwest National Laboratory (PNNL) Quality Assurance Program is based upon the requirements as defined in the U.S. Department of Energy (DOE) Order 414.1C, Quality Assurance and 10 CFR 830, Energy/Nuclear Safety Management, Subpart A-Quality Assurance Requirements (a.k.a. the Quality Rule). PNNL has chosen to implement the following consensus standards in a graded approach:

- ASME NQA-1-2000, Quality Assurance Requirements for Nuclear Facility Applications, Part 1, Requirements for Quality Assurance Programs for Nuclear Facilities.

- ASME NQA-1-2000, Part II, Subpart 2.7, Quality Assurance Requirements for Computer Software for Nuclear Facility Applications.

- ASME NQA-1-2000, Part IV, Subpart 4.2, Graded Approach Application of Quality Assurance Requirements for Research and Development.

The procedures necessary to implement the requirements are documented in PNNL's "How Do I ...?" (HDI) system. ${ }^{(a)}$

PNNL implements the RPP-WTP quality requirements by performing work in accordance with the River Protection Project - Waste Treatment Plant Support Program (RPP-WTP) Quality Assurance Plan (RPP-WTP-QA-001, QAP). Work was performed to the quality requirements of NQA-1-1989, Part I, Basic and Supplementary Requirements, NQA-2a-1990, Part 2.7, and DOE/RW-0333P, Rev 13, Quality Assurance Requirements and Descriptions $(Q A R D)$ as applicable. These quality requirements are implemented through the River Protection Project- Waste Treatment Plant Support Program (RPP-WTP) Quality Assurance Manual (RPP-WTP-QA-003, QAM). The requirements of DOE/RW-0333P Rev 13, Quality Assurance Requirements and Descriptions (QARD) and 10 CFR 830, Subpart A, were not required for this work.

RPP-WTP addresses internal verification and validation activities by conducting an independent technical review of the final data report in accordance with RPP-WTP's procedure QA-RPP-WTP-604. This review procedure is part of PNNL's RPP-WTP Quality Assurance Manual (RPP-WTP-QA-003). Following this procedure, a technical review would verify that the reported results are traceable, that inferences and conclusions are soundly based, and the reported work satisfies the objectives.

Key analytes in the laboratory control sample (LCS) and PEP control sample were plotted over time to look for anomalies. The PEP control sample is a project-provided material generated from material very similar to the initial simulant feed. In general, the plots constructed to date associated with the inductively coupled plasma (ICP) and ion chromatography (IC) analyses of solutions show recoveries within limits of $80 \%$ to $120 \%$.

There is a nonconformance report, NCR 42317.1, that impacts this solids washing work and the first $\mathrm{CsBr}$ tracer mixing test tracer (test 1), involving a failure of flowmeter FE-0635. ${ }^{\text {(b) }}$ This flowmeter was located in the filter-loop downstream from the two filter-loop pumps, and it was one of two flowmeters

(a) HDI is PNNL's system for managing the delivery of laboratory-level policies, requirements, and procedures.

(b) This instrument is also designated as FT-0635 since the flow element (FE) and the flow transmitter are integrated into a single instrument. 
providing the flow rate in the filter-loop. The NCR states that "FE-0635 was reporting suspect flow values. A post failure evaluation by the manufacturer indicated the flow element liner was damaged and the instrument was providing low readings. Data from FE-0635 is unusable from 2/14/2009 through $2 / 27 / 2009$." This flowmeter was replaced after testing concluded on $2 / 27 / 09$. This information is taken into account throughout this report and in data interpretation. 


\subsection{Experimental Approach}

The data given in this report are derived solely from the simulant Integrated Test A: Vessel T01A/B caustic-leach test and Integrated Test B: Vessel T02A caustic-leach test conducted during PEP testing, as described in Test Plan TP-RPP-WTP-506, Rev. 0.4. ${ }^{(a)}$ There are no applicable data from smaller scale process tests.

\subsection{Process Description}

The pretreatment processes of interest include caustic leaching, oxidative leaching, solids washing, and all ultrafiltration processes. The purpose of these processes is to concentrate radioactive waste solids from various blended feeds, leach (dissolve) specific nonradioactive solids (i.e., $\mathrm{Na}, \mathrm{Al}, \mathrm{Cr}, \mathrm{C}_{2} \mathrm{O}_{4}$ ) that limit high-level waste (HLW) glass loading, and separate soluble species from the solids by washing. Feed can include HLW, low-activity waste (LAW), and Feed Evaporation Process (FEP) concentrates. The integrated processes produce concentrated high-level radioactive solids, low-sodium wash solutions that are returned to the FEP, and high-sodium solutions that are sent forward to the cesium ion exchange process.

The PEP was designed to perform an engineering-scale demonstration of the WTP solids wash, caustic leaching, oxidative leaching, and ultrafiltration processes. The unit operations tested included solids washing, chemical reagent addition and blending, heating, cooling, leaching, cross-flow filtration, and filter cleaning. The simplified flow diagram of PEP is shown in Figure 3.1.

The solids washing is conducted in process tank UFP-VSL-T02, as detailed in the PEP Phase I Testing Process Description (24590-WTP-RPT-PET-07-002, Rev 1), Appendix A. ${ }^{(b)}$ The appendix describes the detailed tank description, including the pulse jet mixer (PJM) and sparger operations.

Two operating scenarios were evaluated for the ultrafiltration process (UFP) system. One scenario had the caustic leaching performed in the UFP feed preparation vessels, UFP-VSL-T01A/B (Integrated Test A). The other scenario had caustic leaching conducted in the ultrafiltration feed vessel UFP-VSL-T02A (Integrated Test B). Leaching in Vessel T01A/B instead of Vessel T02A allows greater use of Vessel T02A B for filtration and oxidative leaching. The different flowsheets for these two scenarios are shown in Figure 3.2. In each scenario, the caustic leaching step was performed at a higher temperature $\left(\sim 98^{\circ} \mathrm{C}\right)$, which enhances leaching kinetics. The second scenario was also performed at a lower temperature $\left(\sim 85^{\circ} \mathrm{C}\right)$, which minimizes vessel corrosion.

(a) GB Josephson, OP Bredt, JK Young, and DE Kurath. 2009. Pretreatment Engineering Platform (PEP) Testing (Phase I). TP-RPP-WTP-506, Rev. 0.4, Pacific Northwest National Laboratory, Richland Washington.

(b) SD Lehrman. 2008. Pretreatment Engineering Platform (PEP) Phase 1 Testing Process Description. 24590-WTP-RPT-PET-07-002, Rev. 1, Bechtel National, Inc., Richland, Washington. 


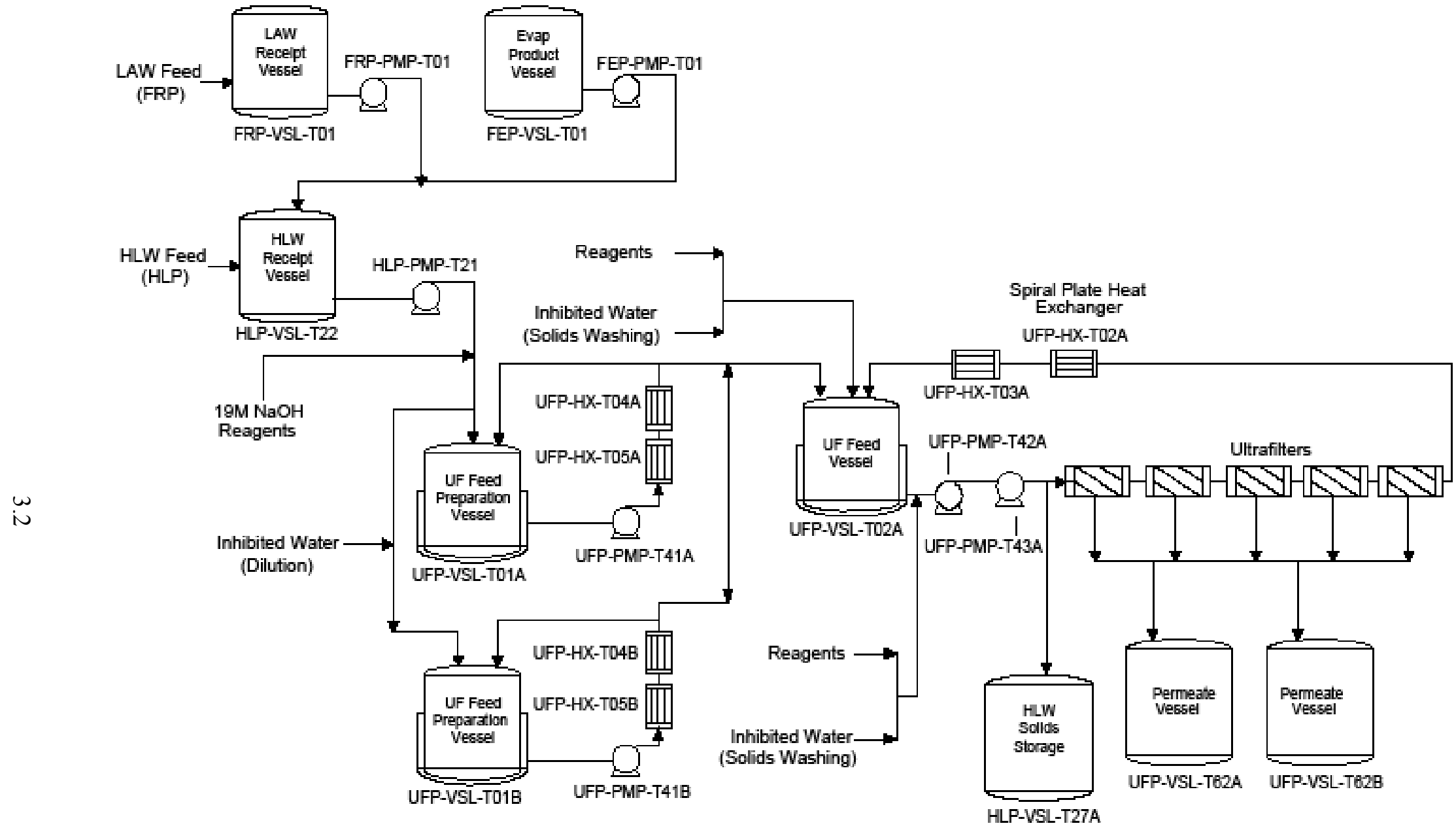

Figure 3.1. PEP Simplified Flow Diagram 


\author{
UFP-VSL-T01 Caustic-Leach \& \\ UFP-VSL-T02 Oxidative-Leach \\ Integrated Test A \\ Caustic Addition \\ Heat-Up \\ Caustic-Leach in UFP-VSL-T01 \\ Cool-Down \\ Transfer to UFP-VSL-T02 \\ Post-Caustic-Leach Solid Concentration \\ Post-Caustic-Leach Wash \\ Permanganate Addition \\ Oxidative-Leach \\ Post-Oxidative-Leach Wash \\ Post-Oxidative-Leach Solid Concentration
}

UFP-VSL-T02 Caustic-Leach \& Oxidative Leaching Integrated Test B

\author{
Initial Solid Concentration of Feed \\ Caustic Addition \\ Heat-Up \\ Caustic-Leach in UFP-VSL-T02 \\ Cool-Down \\ Post-Caustic-Leach Solid Concentration \\ Post-Caustic-Leach Wash \\ Permanganate Addition \\ Oxidative-Leach \\ Post-Oxidative-Leach Wash \\ Post-Oxidative-Leach Solid Concentration
}

Figure 3.2. Caustic- and Oxidative-Leach and Ultrafilter Operations

At the completion of the above two post-caustic-leach solids concentration steps, a tracer was injected into the filter-loop. Mid-tank samples were obtained containing the tracer during a 1-hour period from the injection to characterize tank mixing. Further, the tracer test for Integrated Test A was redone at the conclusion of Integrated Test B.

\subsubsection{Integrated Test A: Vessel T01A/B Caustic-Leach Test Process Description}

Figure 3.3 provides a process schematic of the equipment and instruments used to carry out the solids washing steps in the Integrated Test A: Vessel T01A/B caustic-leach test and Integrated Test B:

Vessel T02A caustic-leach test. It should be pointed out that though HX-T03A is shown in the figure, it is not in service during the washing steps.

In the Integrated Test A: Vessel T01A/B caustic-leach test, feed stored in HLP-VSL-T22 with simulant at 5.5-wt $\%$ undissolved solids (UDS) was transferred to either fill vessel UFP-VSL-T01A or vessel UFP-VSL-T01B in six separate batches. To each simulant batch, $19 \mathrm{M} \mathrm{NaOH}$ (nominal concentration) was added, and caustic leaching was carried out by using steam sparging to raise the temperature to $98^{\circ} \mathrm{C}$ for $16 \mathrm{hr}$, following which the partially cooled leached slurry from all six batches 
was transferred to UFP-VSL-T02A for solids concentration. During caustic leaching, antifoam agent (AFA) was added to maintain a target concentration of $350 \mathrm{ppm}$ before starting caustic washing. Caustic leaching, cooling, and transferring to Vessel T02A alternated between Vessel T01A and Vessel T01B. Solids concentration continued until Vessel T02A was filled with leached slurry concentrated to 18.3-wt\% UDS for the washing test.

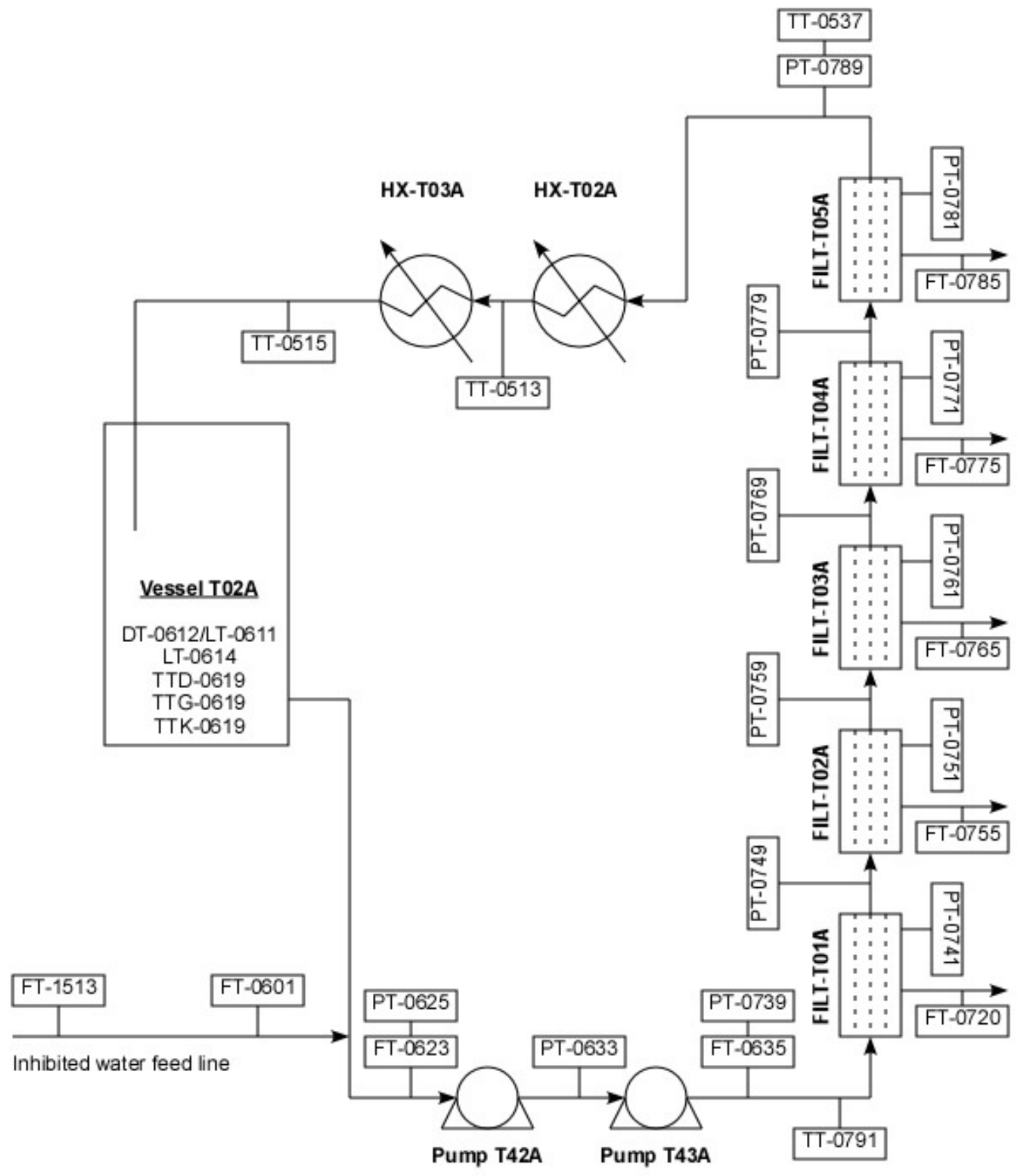

Figure 3.3. Schematic of Vessel T02A Loop and Filtration. Note that HX-T03A was bypassed during the washing operations of Integrated Tests A and B. 
The concentrated caustic-leached solids in Vessel T02A were washed incrementally with $0.01 \mathrm{M}$ $\mathrm{NaOH}$. The wash liquid was added in steps, 11 gallons target volume for each step, 100 steps total. The wash liquid was added to the filter-loop containing the leached and concentrated slurry upstream of the first pump UFP-PMP-T42A (see Figure 3.1). During every third wash step, AFA was added to maintain a target concentration of $350 \mathrm{ppm}$. Wash liquid additions were initiated when the level in Vessel T02A dropped below a set value of 44 inches. The slurry and wash liquid were recirculated and therefore mixed continuously while permeate was continuously removed at a rate between 4 and $17 \mathrm{~kg} / \mathrm{min}$ by ultrafiltration through all five filter bundles. Wash liquid additions occurred approximately every $2 \frac{1}{2}$ to 8 minutes, depending upon the permeate rate. An exception to the wash liquid addition frequency occurred between batches 7 and 8 in which there was a 14-hr hold time to address recirculation pump problems.

Mixing in Vessel T02A during the post-caustic-leach washing employed variable sparger and steamring purge air flow rates (see Table A.1) as well as a PJM. The PJM conditions recorded before the tracer test indicated a cycle time of 20.8 seconds, a PJM stroke length of 31.3 inches (83\%), and a PJM nozzle velocity of $12.1 \mathrm{~m} / \mathrm{s}$. The filter-loop recirculation flow ranged from 80 to $145 \mathrm{gpm}$.

When the post-caustic-leach wash was complete, a chromium oxyhydroxide slurry was added in-line. Rinsing and reconcentration followed to remove excess water and hydroxide, after which $37 \mathrm{gal}$ of $1 \mathrm{M}$ $\mathrm{NaMnO}_{4}$ was introduced, and the slurry was mixed for $6 \mathrm{hr}$ at a temperature of $25^{\circ} \mathrm{C}$ to oxidize (and dissolve) the chromium oxyhydroxide.

The oxidative-leached solids in Vessel T02A were washed incrementally with 86 steps (or batches) of $0.01 \mathrm{M} \mathrm{NaOH}$ with an 11-gallon target volume each. AFA was added to the tank during every third wash step to maintain a target concentration of $350 \mathrm{ppm}$. The method of washing was similar to that used after caustic leaching with additions of the 11 gallons of target volume wash liquid being offset by equal-volume continuous removal of permeate through all five filter bundles.

Data for volumes, liquid-phase concentrations, liquid density, slurry density, and weight fraction UDS were measured during the post-caustic-leach and post-oxidative-leach wash processes. Samples were taken from the lowest elevation Coriolis densitometer port furthest from the tank center, as stipulated in the Test Instruction (TI-WTP-PEP-065 Rev 0). The volumes and sample results form the basis for the wash-efficiency calculations.

Mixing during the post-oxidative-leach wash in Vessel T02A employed a PJM drive time of between 0.25 and 1.8 seconds and a cycle time of 20.8 seconds. The PJM conditions recorded before the post-oxidative-leach wash indicated that the PJM stroke length was $83 \%$, and the PJM nozzle velocity was $12.1 \mathrm{~m} / \mathrm{s}$. The filter-loop recirculation flow was between 80 and $155 \mathrm{gpm}$. During the wash, the lower sparger flow rate was $0.04 \mathrm{~kg} / \mathrm{min}$, and the upper sparger and steam-ring purge air were off.

Test deviations described in Appendix A during washing included an out-of-tolerance filter-loop recirculation flow rate. At the start of post-caustic washing, the target recirculation (109 gpm) could not be maintained, and the flowmeters in the loop read anywhere from 80 to $155 \mathrm{gpm}$ during the Integrated Test A washes. Attempts to increase the recirculation rate by turning off the PJMs and the lower air sparger had no effect. 


\subsubsection{Integrated Test B: Vessel T02A Caustic-Leach Test Process Description}

In the Integrated Test B: Vessel T02A caustic-leach test, feed stored in HLP-VSL-T22 with simulant at 5.2-wt $\%$ UDS was transferred to vessel UFP-VSL-T02A in two batches, using UFP-VSL-T01A/B as feed or storage vessels. The feed was concentrated to $22-\mathrm{wt} \% \mathrm{UDS}$, and then $19 \mathrm{M} \mathrm{NaOH}$ (nominal concentration) was added in-line to the slurry. AFA was added to maintain a target concentration of $350 \mathrm{ppm}$. Caustic leaching was carried out by using steam injection to raise the temperature to $98^{\circ} \mathrm{C}$ for $16 \mathrm{hr}$, following which the slurry was cooled to $25^{\circ} \mathrm{C}$ and was ultrafiltered to concentrate the slurry to $17.3-\mathrm{wt} \%$ UDS. A tracer test followed after the slurry was concentrated.

The concentrated caustic-leached solids in Vessel T02A were washed incrementally with $0.01 \mathrm{M}$ $\mathrm{NaOH}$. The wash liquid was added in steps, 11 gallons target volume each step, 52 steps total. During every third or fourth wash step, AFA was added to maintain a target concentration of $350 \mathrm{ppm}$. Wash liquid additions were initiated when the level in the Vessel T02A dropped below a set value, occurring approximately every 4 minutes. Permeate was continuously removed at a rate between 1 and $8 \mathrm{~kg} / \mathrm{min}$ by ultrafiltration through all five filter bundles.

When the post-caustic-leach wash was complete, a chromium oxyhydroxide slurry was added to the washed slurry. Rinsing and reconcentration followed to remove excess water and achieve the correct hydroxide concentration. The oxidative-leach step was conducted by adding 21 gal of $1 \mathrm{M} \mathrm{NaMnO}_{4}$, and the slurry was mixed for $6 \mathrm{hr}$ at a temperature of $25^{\circ} \mathrm{C}$.

The oxidative-leached solids in Vessel T02A were washed incrementally with 47 batches of $0.01 \mathrm{M}$ $\mathrm{NaOH}$. AFA was added during every third batch to maintain a target concentration of $350 \mathrm{ppm}$. The method of washing was similar to that used after caustic leaching, with additions of 11 gal of wash liquid being offset by equal-volume continuous removal of permeate through all five filter bundles.

Data for volumes, liquid-phase concentrations, liquid density, slurry density, and weight-fraction UDS were measured during the post-caustic-leach and post-oxidative-leach wash processes. Samples were taken from the lowest elevation Coriolis densitometer port furthest from the tank center. This information forms the basis for the wash efficiency calculations. Sample data on UDS and PJM conditions are provided in the appendix.

In the Integrated Test B post-caustic-leach wash, the PJMs were operated in star mode, ${ }^{(a)}$ in which only the center PJM and one radial PJM were operated at any given time (switching to a different radial PJM after five cycles), and was used because of the very low level of solids in Vessel T02A. The PJM drive measured before the start of the post-caustic-leach wash was 20.2 seconds, the PJM stroke length was $70 \%$ (27 in.), and the peak average nozzle velocity was $11.7 \mathrm{~m} / \mathrm{s}$. The flow rates at Pumps $42 \mathrm{~A}$ and 43A (Vessel T02A mixing) measured between 60 and $100 \mathrm{gpm}$. Mixing during the post-caustic-leach wash did not employ a steam-ring air purge or air sparging to avoid entrainment of air by the filter-loop pumps.

In the Integrated Test B post-oxidative-wash leach, the PJMs operated in star mode with similar conditions to the post-caustic-leach wash. Mixing in Vessel T02A during the post-oxidative-leach

(a) Star mode refers to a mode of operating the PJMs such that the center PJM is always operational, and the five radial PJMs operate one at a time during sequential PJM drives. 
washing also did not employ steam-ring air purge or sparging air flow. The flow rates of Pumps $42 \mathrm{~A}$ and 42B measured between 70 and $105 \mathrm{gpm}$.

\subsection{Slurry Properties}

Table 3.1 shows the composition of the slurry components in UFP-VSL-T02A after caustic-leach and solids concentration - the initial condition for the post-caustic-leach wash. Table 3.2 shows the composition of the slurry components in Vessel T02A after oxidative-leach — the initial condition for the final post-oxidative-leach wash. Note that the initial composition of the solids in the slurry was measured by ICP only; neither IC nor titration can be measured on slurry material, only on the decanted supernate. The decanted supernate from centrifuged slurry samples provides the results for the liquid-phase columns.

Table 3.1. Initial Slurry Composition for Post-Caustic-Leach Wash

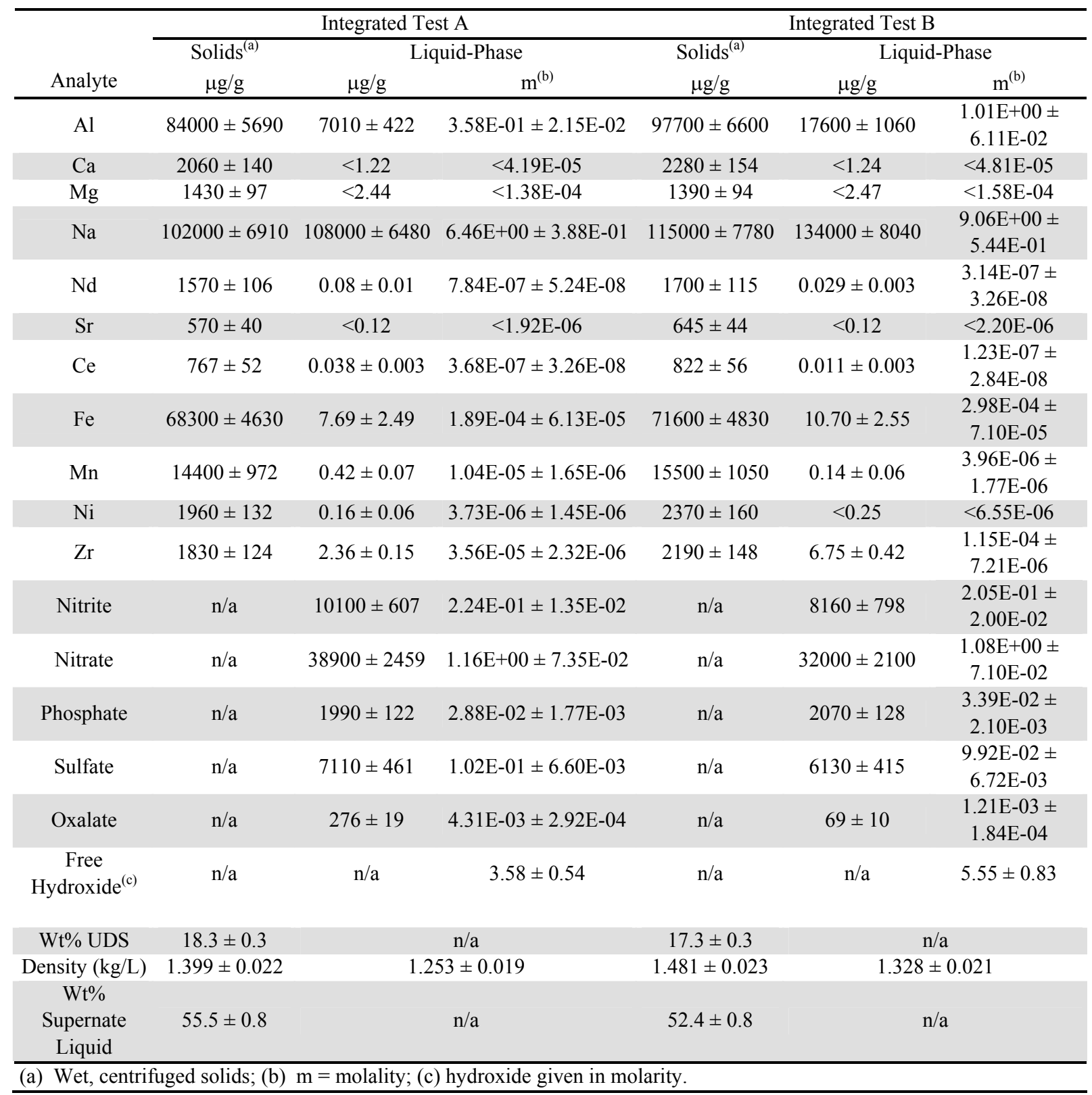


Table 3.2. Initial Slurry Composition for Post-Oxidative-Leach Wash

\begin{tabular}{|c|c|c|c|c|c|c|}
\hline \multirow[b]{3}{*}{ Analyte } & \multicolumn{3}{|c|}{ Integrated Test A } & \multicolumn{3}{|c|}{ Integrated Test B } \\
\hline & \multirow{2}{*}{$\begin{array}{c}\text { Solids }^{(a)} \\
\mu g / g\end{array}$} & \multicolumn{2}{|c|}{ Liquid-Phase } & \multirow{2}{*}{$\begin{array}{c}\text { Solids }^{(a)} \\
\mu g / g\end{array}$} & \multicolumn{2}{|c|}{ Liquid-Phase } \\
\hline & & $\mu \mathrm{g} / \mathrm{g}$ & $\mathrm{m}^{(\mathrm{b})}$ & & $\mu \mathrm{g} / \mathrm{g}$ & $\mathrm{m}^{(\mathrm{b})}$ \\
\hline $\mathrm{Al}$ & $122667 \pm 4787$ & $52.4 \pm 2.3$ & $2.00 \mathrm{E}-03 \pm 8.86 \mathrm{E}-05$ & $\begin{array}{c}120000 \pm \\
5728\end{array}$ & $165.3 \pm 5.8$ & $\begin{array}{c}6.34 \mathrm{E}-03 \pm \\
2.21 \mathrm{E}-04\end{array}$ \\
\hline $\mathrm{Ca}$ & $2943 \pm 115$ & $<1.66$ & $<4.28 \mathrm{E}-05$ & $3460 \pm 165$ & $<1.24$ & $<3.20 \mathrm{E}-05$ \\
\hline $\mathrm{Cr}$ & $1170 \pm 47$ & $6300 \pm 218$ & $1.25 \mathrm{E}-01 \pm 4.33 \mathrm{E}-03$ & $1700 \pm 81$ & $5550 \pm 192$ & $\begin{array}{c}1.10 \mathrm{E}-01 \pm \\
3.83 \mathrm{E}-03\end{array}$ \\
\hline $\mathrm{Mg}$ & $2050 \pm 80$ & $<3.32$ & $<1.41 \mathrm{E}-04$ & $1945 \pm 93$ & $<2.49$ & $<1.06 \mathrm{E}-04$ \\
\hline $\mathrm{Na}$ & $11767 \pm 535$ & $9657 \pm 355$ & 4.34E-01 $\pm 1.59 \mathrm{E}-02$ & $12850 \pm 647$ & $10300 \pm 368$ & $\begin{array}{c}4.63 \mathrm{E}-01 \pm \\
1.65 \mathrm{E}-02\end{array}$ \\
\hline $\mathrm{Nd}$ & $2407 \pm 94$ & $0.022 \pm 0.002$ & $1.61 \mathrm{E}-07 \pm 1.48 \mathrm{E}-08$ & $2415 \pm 115$ & $0.032 \pm 0.002$ & $\begin{array}{c}2.30 \mathrm{E}-07 \pm \\
1.32 \mathrm{E}-08\end{array}$ \\
\hline $\mathrm{Sr}$ & $1167 \pm 46$ & $<0.17$ & $<1.96 \mathrm{E}-06$ & $855 \pm 41$ & $<0.12$ & $<1.46 \mathrm{E}-06$ \\
\hline $\mathrm{Ce}$ & $1177 \pm 46$ & $0.009 \pm 0.002$ & $6.34 \mathrm{E}-08 \pm 1.43 \mathrm{E}-08$ & $1155 \pm 55$ & $0.012 \pm 0.001$ & $\begin{array}{c}8.51 \mathrm{E}-08 \pm \\
1.10 \mathrm{E}-08\end{array}$ \\
\hline $\mathrm{Fe}$ & $97167 \pm 3795$ & $<6.63$ & $<1.23 \mathrm{E}-04$ & $\begin{array}{c}100500 \pm \\
4798\end{array}$ & $4.24 \pm 0.74$ & $\begin{array}{c}7.86 \mathrm{E}-05 \pm \\
1.36 \mathrm{E}-05\end{array}$ \\
\hline $\mathrm{Mn}$ & $42100 \pm 1641$ & $0.29 \pm 0.05$ & $5.52 \mathrm{E}-06 \pm 9.21 \mathrm{E}-07$ & $41450 \pm 1976$ & $0.43 \pm 0.04$ & $\begin{array}{c}8.16 \mathrm{E}-06 \pm \\
7.35 \mathrm{E}-07\end{array}$ \\
\hline $\mathrm{Ni}$ & $2790 \pm 109$ & $<0.33$ & $<5.83 \mathrm{E}-06$ & $3585 \pm 171$ & $0.56 \pm 0.04$ & $\begin{array}{c}9.86 \mathrm{E}-06 \pm \\
7.24 \mathrm{E}-07\end{array}$ \\
\hline $\mathrm{Zr}$ & $2637 \pm 103$ & $<0.33$ & $<3.75 \mathrm{E}-06$ & $2950 \pm 141$ & $<0.12$ & $<1.41 \mathrm{E}-06$ \\
\hline Nitrite & $\mathrm{n} / \mathrm{a}$ & $81 \pm 19$ & $1.35 \mathrm{E}-03 \pm 3.12 \mathrm{E}-04$ & $\mathrm{n} / \mathrm{a}$ & $112 \pm 19$ & $\begin{array}{c}1.87 \mathrm{E}-03 \pm \\
3.11 \mathrm{E}-04\end{array}$ \\
\hline Nitrate & $\mathrm{n} / \mathrm{a}$ & $3490 \pm 123$ & $7.83 \mathrm{E}-02 \pm 2.77 \mathrm{E}-03$ & $\mathrm{n} / \mathrm{a}$ & $3863 \pm 136$ & $\begin{array}{c}8.69 \mathrm{E}-02 \pm \\
3.06 \mathrm{E}-03\end{array}$ \\
\hline Phosphate & $\mathrm{n} / \mathrm{a}$ & $208 \pm 19$ & $2.26 \mathrm{E}-03 \pm 2.03 \mathrm{E}-04$ & $\mathrm{n} / \mathrm{a}$ & $96 \pm 17$ & $\begin{array}{c}1.04 \mathrm{E}-03 \pm \\
1.88 \mathrm{E}-04\end{array}$ \\
\hline Sulfate & $\mathrm{n} / \mathrm{a}$ & $137 \pm 7$ & $1.47 \mathrm{E}-03 \pm 7.92 \mathrm{E}-05$ & $\mathrm{n} / \mathrm{a}$ & $153 \pm 8$ & $\begin{array}{c}1.65 \mathrm{E}-03 \pm \\
8.29 \mathrm{E}-05\end{array}$ \\
\hline $\begin{array}{c}\text { Free } \\
\text { Hydroxide }^{(c)}\end{array}$ & $\mathrm{n} / \mathrm{a}$ & $\mathrm{n} / \mathrm{a}$ & $0.080 \pm 0.012$ & $\mathrm{n} / \mathrm{a}$ & $\mathrm{n} / \mathrm{a}$ & $\begin{array}{c}0.157 \pm \\
0.024\end{array}$ \\
\hline $\mathrm{Wt} \%$ UDS & $16.7 \pm 0.1$ & & $\mathrm{n} / \mathrm{a}$ & $18.3 \pm 0.2$ & & \\
\hline $\begin{array}{l}\text { Density } \\
(\mathrm{kg} / \mathrm{L})\end{array}$ & $1.147 \pm 0.010$ & 1.02 & $28 \pm 0.009$ & $1.144 \pm 0.010$ & 1.027 & 0.016 \\
\hline $\begin{array}{c}\mathrm{Wt} \% \\
\text { Supernate } \\
\text { Liquid }\end{array}$ & $67.0 \pm 0.6$ & & $\mathrm{n} / \mathrm{a}$ & $62.5 \pm 0.5$ & & \\
\hline a) Wet, centr & iged solids; (b & $\mathrm{m}=$ molality & hydroxide given & olarity & & \\
\hline
\end{tabular}




\subsection{Wash Process Conditions}

The behavior of a wash depends on several process conditions, including the slurry temperature, permeate flux, slurry volume, filter-loop flow rate, and filter pressures. In addition, there are changes in physical properties of the slurry as the wash proceeds. Three of these properties were determined at several intervals: bulk density, supernate density, and UDS. To facilitate comparison between analytical results and process conditions, the data are presented as a function of the batch number. Each value is the state of the system at the beginning of each batch, that is, the moment when IW begins to flow into the filtration loop at the suction of Pump T42A. In this section, the wash process conditions for both Integrated Test A: Vessel T01A/B caustic leaching and Integrated Test B: Vessel T02A caustic leaching are presented together. The post-caustic-leach wash conditions are discussed in Section 3.3.1, and the post-oxidative-leach wash conditions are discussed in Section 3.3.2.

The ratio between the total volume of wash liquid added and the average volume of slurry and liquid present in the slurry were calculated for each wash. Table 3.3 shows the average values of the slurry volume and the slurry liquid volume as well as their ratio to the total amount of IW added during the wash processes. The uncertainty in each value is based on two standard deviations of the value.

Table 3.3. Wash Volume Parameters. In this table, uncertainty estimates are provided based on the accuracy and repeatability of the value during testing.

\begin{tabular}{|c|c|c|c|c|c|}
\hline & $\begin{array}{c}\text { Total Wash } \\
\text { Volume (gal) }\end{array}$ & $\begin{array}{l}\text { Average } \\
\text { Slurry } \\
\text { Volume } \\
\text { (gal) }\end{array}$ & $\begin{array}{l}\text { Average } \\
\text { Liquid Volume } \\
\text { in Slurry (gal) }\end{array}$ & $\begin{array}{l}\text { Ratio of Wash } \\
\text { Volume to } \\
\text { Slurry Volume }\end{array}$ & $\begin{array}{l}\text { Ratio of Wash } \\
\text { Volume to Slurry } \\
\text { Liquid Volume }\end{array}$ \\
\hline \multicolumn{6}{|c|}{ Post-Caustic-Leach Wash } \\
\hline $\begin{array}{c}\text { Integrated } \\
\text { Test A }\end{array}$ & $1,120 \pm 20$ & $269 \pm 1$ & $246 \pm 6$ & $4.2 \pm 0.1$ & $4.6 \pm 0.2$ \\
\hline $\begin{array}{c}\text { Integrated } \\
\text { Test B }\end{array}$ & $580 \pm 10$ & $154 \pm 3$ & $138 \pm 3$ & $3.8 \pm 0.1$ & $4.2 \pm 0.2$ \\
\hline \multicolumn{6}{|c|}{ Post-Oxidative-Leach Wash } \\
\hline $\begin{array}{c}\text { Integrated } \\
\text { Test A }\end{array}$ & $960 \pm 20$ & $297 \pm 1$ & $273 \pm 2$ & $3.3 \pm 0.1$ & $3.5 \pm 0.1$ \\
\hline $\begin{array}{c}\text { Integrated } \\
\text { Test B }\end{array}$ & $530 \pm 10$ & $173 \pm 1$ & $158 \pm 3$ & $3.1 \pm 0.1$ & $3.4 \pm 0.1$ \\
\hline
\end{tabular}

\subsubsection{Post-Caustic-Leach Wash Process Conditions}

The Vessel T01A/B caustic-leach test (Integrated Test A) post-caustic-leach wash occurred in two parts:

- 7 wash batches between 01:10 and 01:55 on 02/15/09, Pacific Standard Time

- 93 wash batches between 16:00 and 23:00 on 02/15/09, Pacific Standard Time. There was a short interruption of approximately 20 minutes during a shift change at 18:00-18:20. 
The 14-hour time period between the first 7 batches and the rest of the wash was spent troubleshooting problems encountered while operating the recirculation loop pumps. Air entrainment in the slurry and a flowmeter providing low readings resulted in difficulty in maintaining a steady flow rate and maintaining the temperature in the presence of excess heat from the pumps. A detailed comparison of the target run parameters and the actual run parameters for the Integrated Test A post-caustic-leach wash is available in Appendix A, Table A.1.

The Vessel T02A caustic-leach test (Integrated Test B) post-caustic-leach wash was conducted continuously over 52 batches between approximately 16:20 03/19/09 and 01:15 03/20/09, Pacific Standard Time. A detailed comparison of the target run parameters and the actual run parameters for the Integrated Test B post-caustic-leach wash is available in Appendix A, Table A.3.

The physical properties of the slurry as the post-caustic-leach wash evolved are presented in Figure 3.4 and Figure 3.5. The density of the slurry and the density of the supernate are shown in Figure 3.4, with the densities measured at discrete wash steps. Some of the wash-efficiency calculations require knowledge of the density at batches other than the ones at which it was sampled; thus, the densities needed to be modeled as a function of batch. Cubic polynomials were used for this purpose, not to reflect any physical reality, but only to faithfully model the sample data, and they are also provided in the figure. Figure 3.5 presents the UDS measured from separate samples taken at the same batches as the density samples. They were modeled as cubic functions of batch number in the same way as the densities were. The error bars on both figures are the analytical uncertainties in the measurement provided by Southwest Research Institute (SwRI). Some comment may be made regarding the UDS rise in the final measurements of both tests in Figure 3.5. In Integrated Test A, the liquid volume was decreasing, and this may help explain the rise in UDS at the end. In Integrated Test B, it was not. Integrated Test B was a much more abrupt change in UDS at the end, and this does not have an obvious physical explanation.

Figure 3.6 shows the time variation of the slurry temperature through the filters for the post-caustic washes of Integrated Tests A and B. The temperature in the plot is the temperature as measured by the prototypic sensor in Vessel T02A. The elevated temperature during Integrated Test A for the first 7 IW batches was due to excess pump heat. After the wash was interrupted to troubleshoot this problem, the temperature was stable at $24^{\circ} \mathrm{C}$ for the last 93 batches. In Integrated Test B, the temperature had two instances where the vessel temperature increased approximately 1 degree between two batches. In both instances, this was due to an operational change in the setpoint of the chiller on the filtration loop. Except for the early part of the washing (batches 1 to 16), the temperature was within the specified range of $25 \pm 2{ }^{\circ} \mathrm{C}$.

The total permeate flow rate during the post-caustic-leach washes is presented in Figure 3.7. In Integrated Test $\mathrm{A}$, the permeate rate varied along with changes in the physical properties of the slurry: density, rheology, and UDS. The permeate rate of filter T01A was lower than the others; this is because the filter had been used to dewater the contents of Vessel T02A for 13 days preceding this wash. In Integrated Test B, the permeate rates were similar for all five filters and rose from $\sim 0.5 \mathrm{~kg} / \mathrm{min}$ to $\sim 1.5$ $\mathrm{kg} / \mathrm{min}$ as the wash proceeded. The permeate flow rates for filters 4 and 5 were very noisy, but this does not appear to be related to any process conditions. 
The average normalized flux of the five filters is shown in Figure 3.8. The flux is normalized using corrections for both temperature and transmembrane pressure (TMP). ${ }^{(a)}$ Integrated Test A had a maximum in flux after approximately 30 washes and then fell to a minimum after 60 washes before increasing to its final value. No clear physical reason has been identified for this behavior. The average of the average normalized flux for the five filters over the entire wash was $0.037 \pm 0.011 \mathrm{gpm} / \mathrm{ft}^{2}$ (uncertainty is one standard deviation). Multiple extrema were not observed during Integrated Test B, which was essentially monotonically increasing with batch number. The filters were backpulsed just before washing started; this leads to the dip observed in the flux during the first few batches. The average of the average normalized flux for the five filters during the entire wash in Integrated Test B was $0.017 \pm 0.008 \mathrm{gpm} / \mathrm{ft}^{2}$.

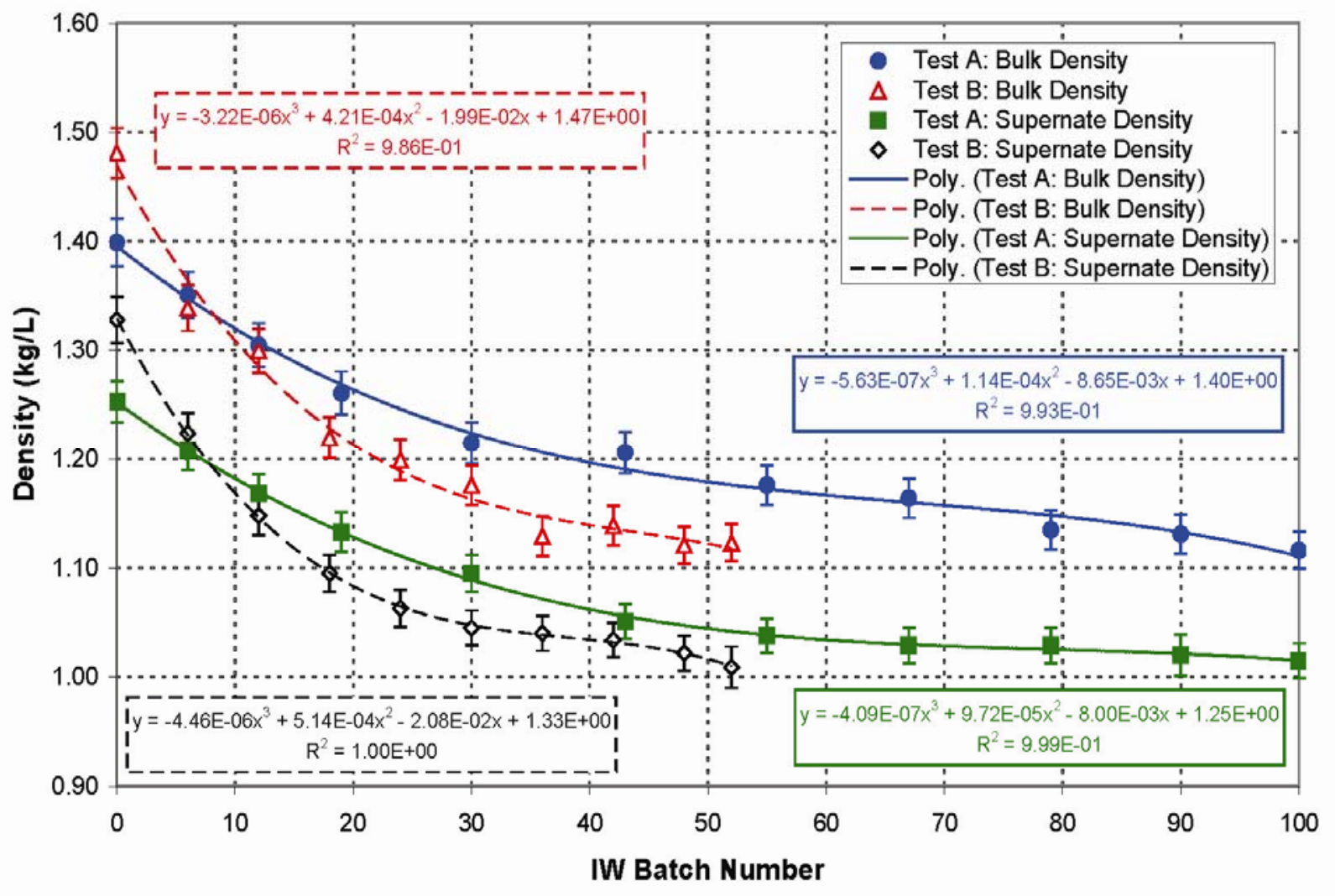

Figure 3.4. Measured Density for Post-Caustic-Leach Wash for Integrated Tests A and B. The trend curves shown are the cubic polynomial fit to the sample points. Shown with SwRI-reported uncertainty error bars.

(a) For more information on filtration and normalized flux methodology, see WTP-RPT-185. 


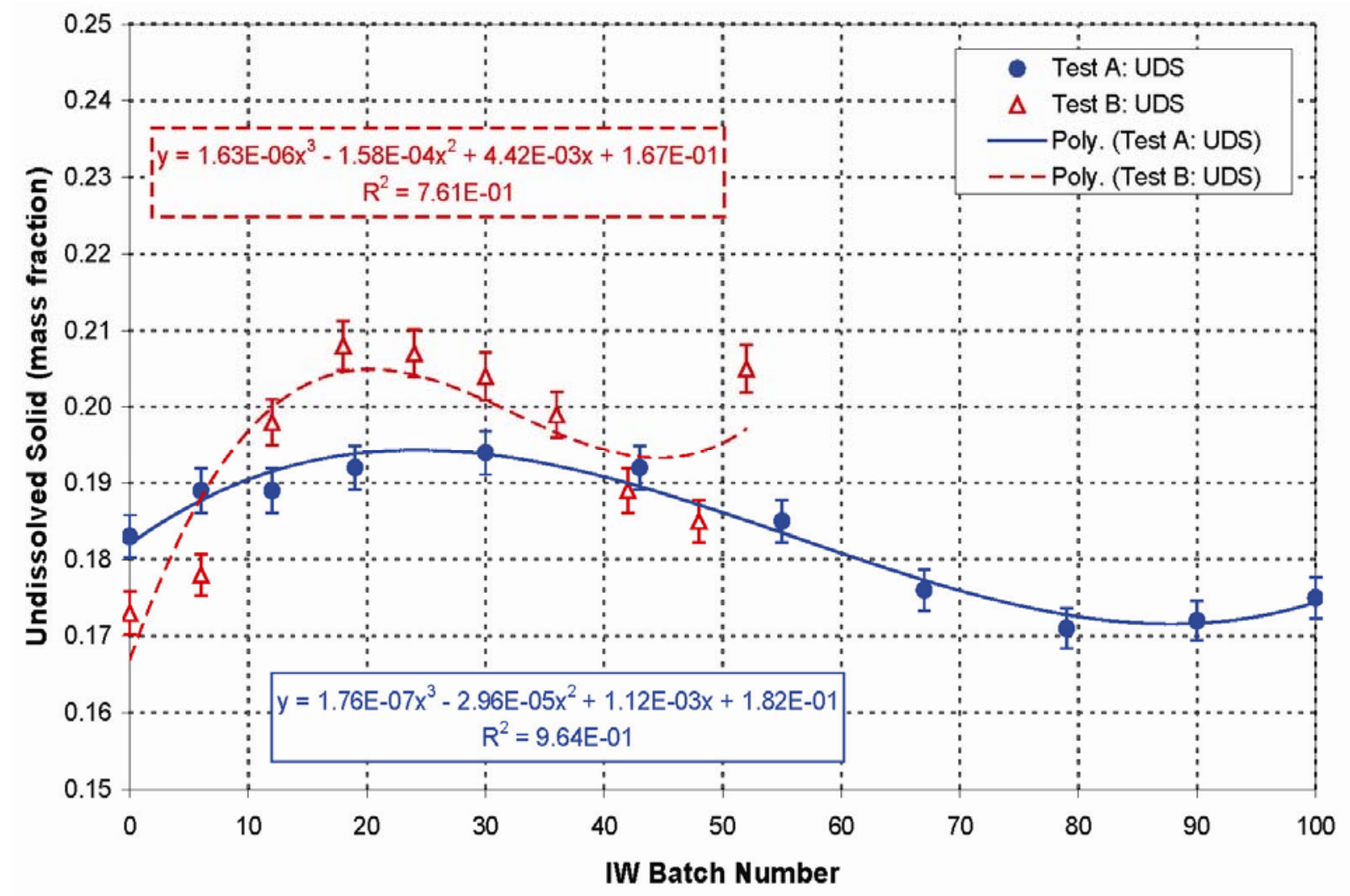

Figure 3.5. UDS for Post-Caustic-Leach Wash for Integrated Tests A and B. The trend curves shown are the cubic polynomial fit to the sample points. Note that the similar trend shape is seen in both Integrated Tests A and B, with the slight rise in UDS toward the end. This is shown with SwRI-reported uncertainty error bars. 


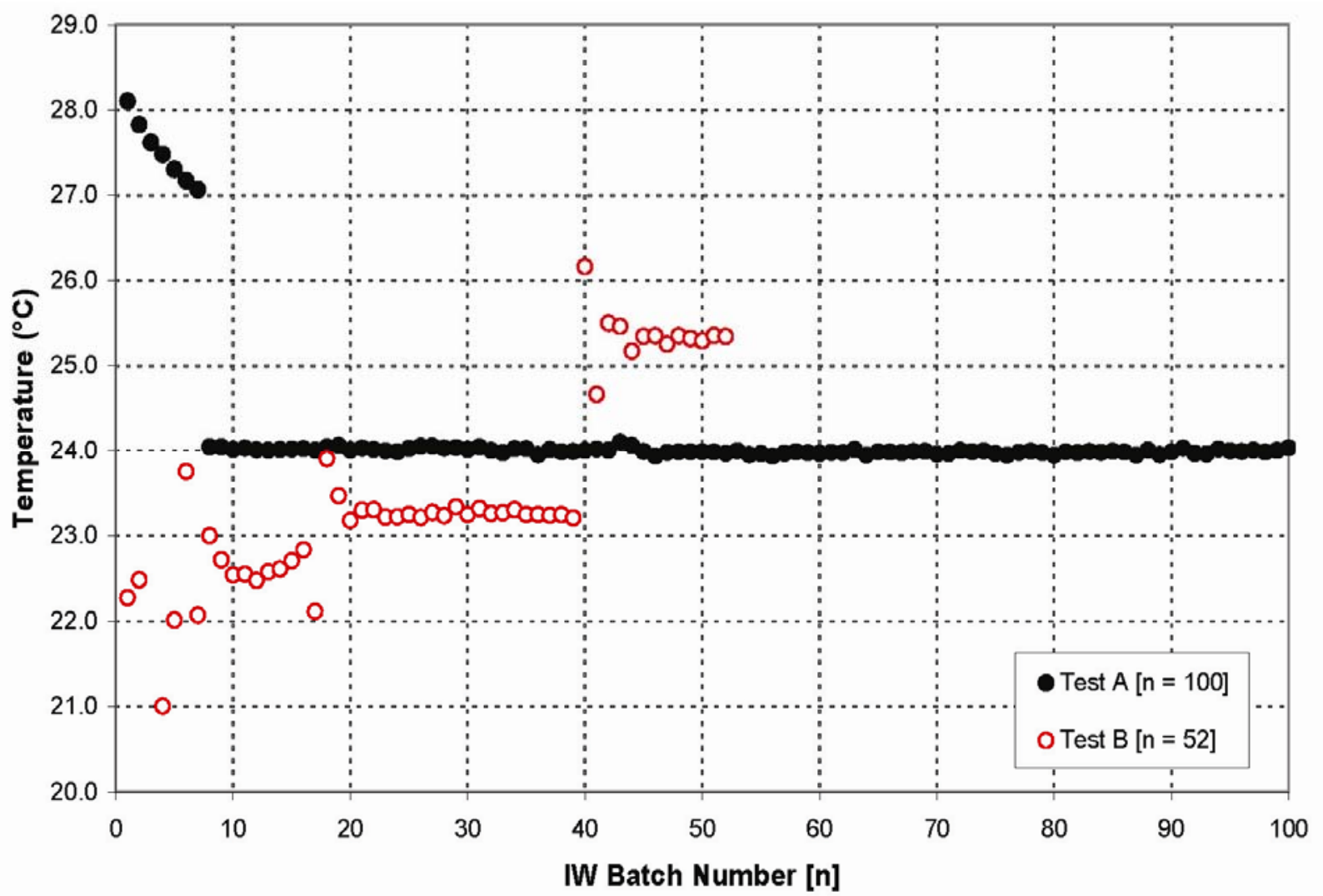

Figure 3.6. Temperature in Vessel T02A During Post-Caustic-Leach Washing as a Function of IW Batch Number. The temperatures were determined from the prototypic thermocouple; Integrated Test A is represented by black, closed symbols, and Integrated Test B by red, open symbols. 


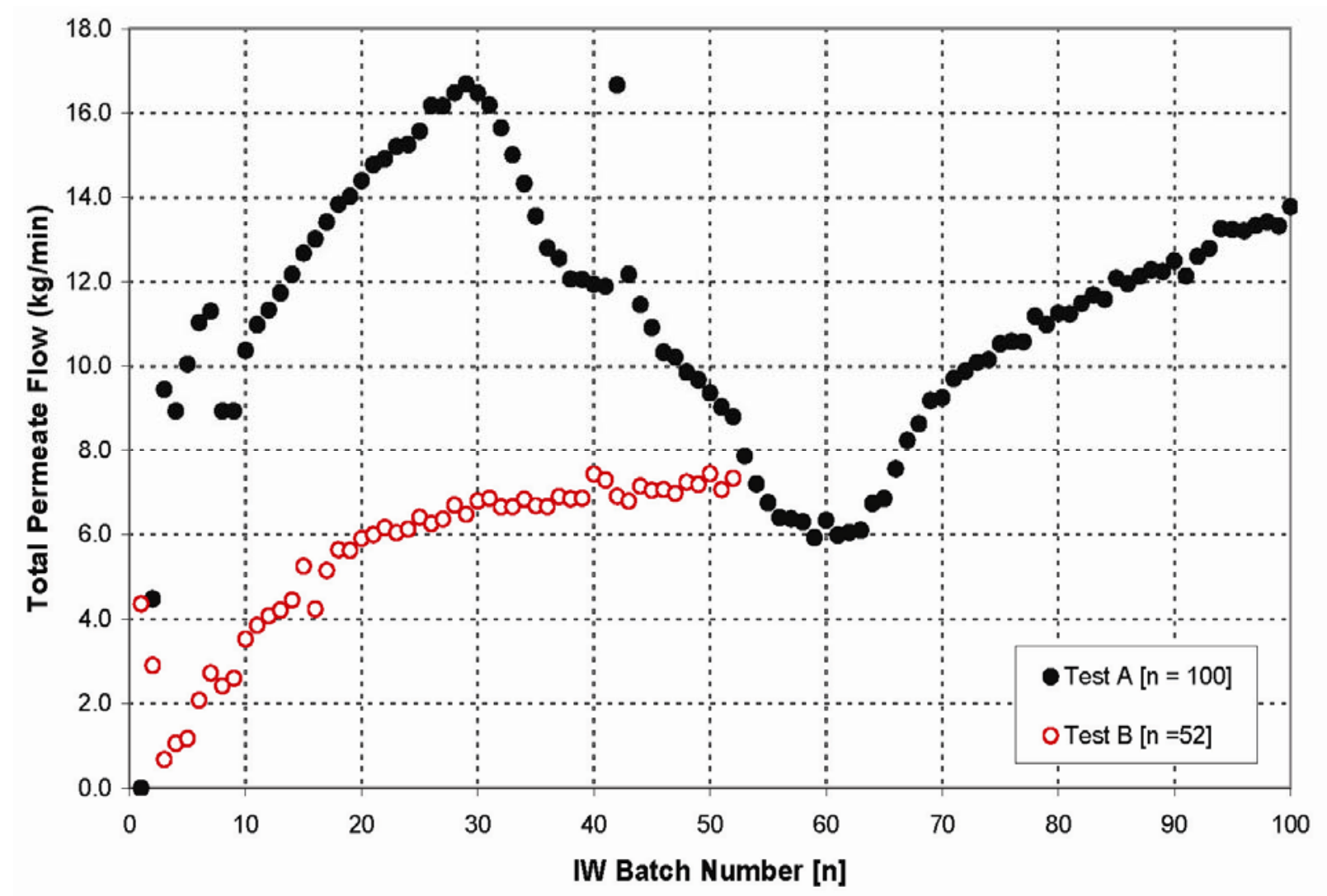

Figure 3.7. Total Permeate Flow Rate (sum of five filters) During Post-Caustic-Leach Washing as a Function of the IW Batch Number for Integrated Test A (black, closed symbols) and Integrated Test B (red, open symbols) 


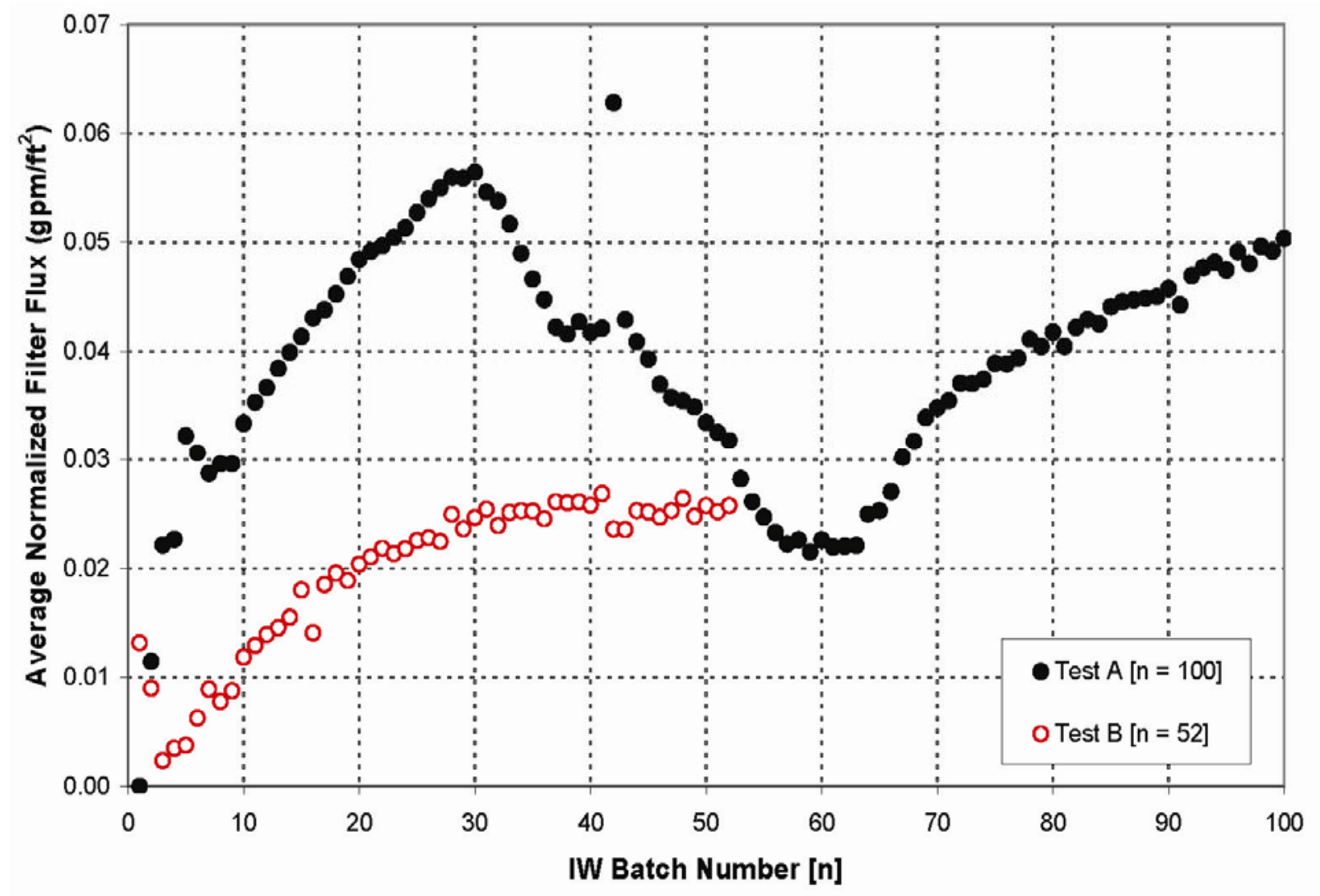

Figure 3.8. Average Normalized Flux (of the five filters) During Post-Caustic-Leach Washing as a Function of the IW Batch Number for Integrated Test A (black, closed symbols) and Integrated Test B (red, open symbols). The flux was normalized by the temperature shown in Figure 3.6 and the TMP.

Figure 3.9 shows the level at the beginning of each batch in Vessel T02A during the post-causticleach wash. In both tests, the level measurement shown is based on the laser instrument. It is clear from the figure that the control strategy using level setpoints to trigger each batch of IW performed as intended. The amount of IW and the rate at which it was added was very consistent for both post-caustic-leach washes (see Tables A.1 and A.3). Figure 3.9 also illustrates one of the major differences between the Integrated Test A and Integrated Test B washes. The operating level during Integrated Test A was approximately 2.6 times the level during Integrated Test B; this corresponds to a slurry volume (including the slurry in the loop) in Integrated Test A that is about double the Integrated Test B slurry volume.

Figure 3.10 illustrates the off-normal recirculation flow rate that was present during the washes. In Integrated Test A, a large difference in flow rates as indicated by the flowmeters - one which precedes the pumps and one which follows the pumps - was observed. The wide spread between the two flowmeters is thought to be largely due to entrained air in the slurry. One flowmeter (FT-0635, magnetic flowmeter) also is suspected of reading low due to a damaged liner. ${ }^{(a)}$ Regardless, the axial velocity in the filter tubes was almost certainly not the desired $15 \mathrm{ft} / \mathrm{s}$. It is also worth noting that the air spargers and steam-ring purge air were not operating for most of the final 93 IW batches in an effort to manage the entrained air in the system.

(a) NCR 42317.1. 


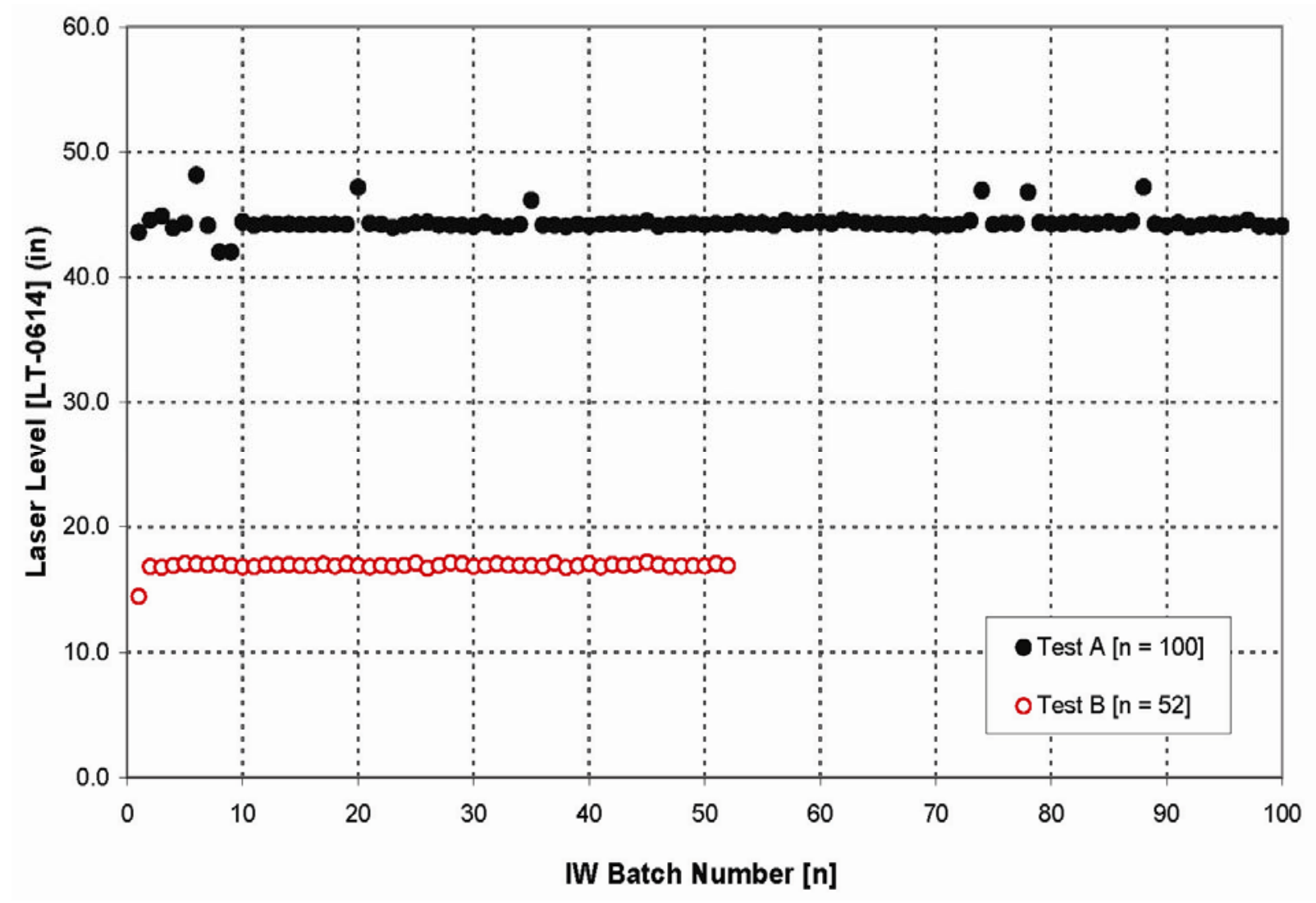

Figure 3.9. The Laser Level in Vessel T02A During Post-Caustic-Leach Washing as a Function of the IW Batch Number for Integrated Test A (black, closed symbols) and Integrated Test B (red, open symbols). This level represents the amount of slurry in the vessel as the batch is initiated. 


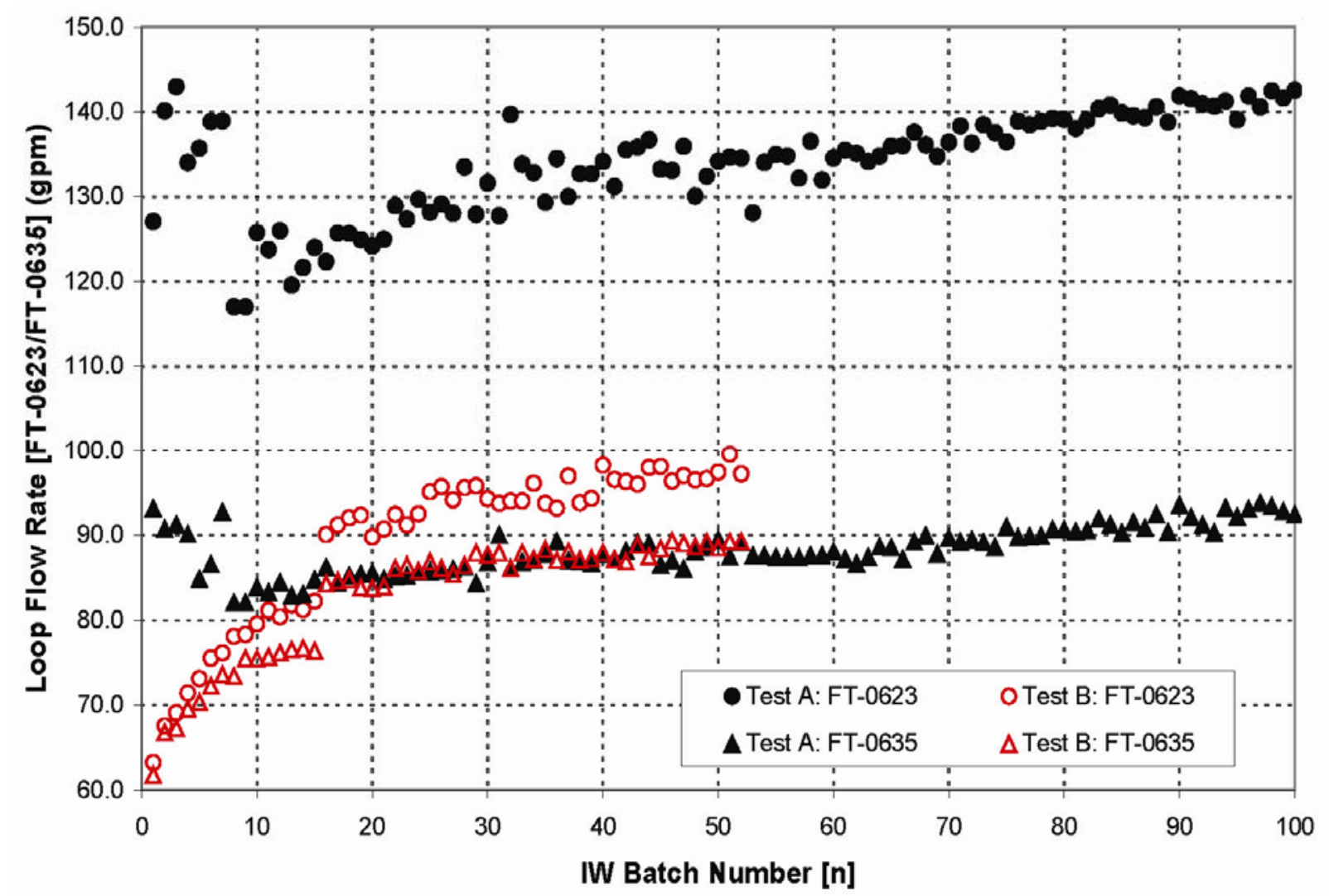

Figure 3.10. Flow Rate in the Filtration Loop During Post-Caustic-Leach Washing as a Function of the IW Batch Number for Integrated Test A (black, closed symbols) and Integrated Test B (red, open symbols). There are two flowmeters in the loop, one preceding the pumps (FT-0623, indicated by circles) and one after the pumps (FT-0635 ${ }^{(\mathrm{a})}$ indicated by triangles). Note that the flow rate was off-normal for the duration of both washes, as the target flow rate was $109 \mathrm{gpm}$.

In Integrated Test B, after FT-0635 was replaced, the flowmeters were more consistent but never reached the target recirculation rate of $109 \mathrm{gpm}$. The slurry volumetric flow rate averaged $85 \pm 10 \mathrm{gpm}$ during the wash. This was the maximum stable flow rate that could be achieved at this point in the test. Entrained gas was the suspected cause. This is why the mixing operations in Vessel T02A were not as indicated in Table A.3: the PJMs were run in star mode, and the air to the spargers and steam-ring was off. The steam-ring was above the slurry level in Integrated Test B when water additions were triggered and may not have even been submerged after the 11-gal water addition was complete (no effect on mixing). The axial velocity in the filter tubes was not the desired $15 \mathrm{ft} / \mathrm{s}$, but closer to 11 to $12 \mathrm{ft} / \mathrm{s}$.

A series of tracer tests performed in Vessel T02A and filtration loop were performed to evaluate the system for channeling, which would inhibit homogenous mixing in the vessel. As described later in Section 5.3, tracer tests that were performed at similar off-normal flow rates to Integrated Tests A and B indicated that the time required to achieve nearly complete blending between an injected liquid and the

(a) Flowmeter reading low per NCR 42317.1. 
slurry was 2 to 4 minutes. This was found to be consistent with the mixing time measured in a later tracer test that was performed at the target flow rate (Section 5.3.4).

Because of the off-normal recirculation flow rate, the initial portion of the Integrated Test A wash was outside of the run sheet tolerances for axial pressure drop and TMP. Even though the target recirculation rate was never obtained, the 14 hours that separated the first portion (of 7 IW batches) and the second portion (of 93 IW batches) was sufficient enough time to locate a more stable operating regime for the recirculation loop pumps. The axial pressures and TMPs were well behaved and were in the target ranges during the last 93 washes. In Integrated Test B, the axial pressure drops and TMPs met the target conditions for the duration of the wash.

\subsubsection{Post-Oxidative-Leach Wash Process Conditions}

The Vessel T01A/B caustic-leach test (Integrated Test A) post-oxidative-leach wash was conducted continuously for 86 wash batches between 17:05 and 23:15 on 2/16/09, Pacific Standard Time. A detailed comparison of the target run parameters and the actual run parameters for the Integrated Test $\mathrm{A}$ post-oxidative-leach wash is available in Appendix A, Table A.2.

The Vessel T02A caustic-leach test (Integrated Test B) post-oxidative-leach wash was conducted continuously for 47 wash batches between 15:45 and 18:30 on 3/20/09, Pacific Daylight Time. A detailed comparison of the target run parameters and the actual run parameters for the Integrated Test $\mathrm{A}$ post-oxidative-leach wash is available in Appendix A, Table A.4.

The physical properties of the slurry as the post-oxidative-leach wash evolved are presented in Figure 3.11 and Figure 3.12. In Figure 3.11, the density of the slurry and the density of the supernate are shown. The densities were measured at discrete wash steps as described in Section 3.5. The density, which does not change as significantly during post-oxidative washing as it does during post-caustic washing, was not sampled as often; generally, a sample was taken at the beginning, middle, and end of the wash. Some of the wash-efficiency calculations require knowledge of the density at batches other than the ones at which it was sampled; thus, the densities needed to be modeled as a function of batch. Quadratic or cubic polynomials were used for this purpose and are also provided in the figure. Figure 3.12 presents the UDS measured from separate samples taken at the same batches as the density samples. They were modeled as cubic functions of batch number in the same way as the densities were. The error bars on both figures are the analytical uncertainties in the measurement provided by SwRI.

Figure 3.13 shows the time variation of the slurry temperature through the filters for the post-oxidative washes of Integrated Tests A and B. The temperature in the plot is the temperature as measured by the prototypic sensor in Vessel T02A. The temperature was observed to be stable and within tolerance of the target of $25^{\circ} \mathrm{C}$.

The total permeate flow rate during the post-oxidative-leach washes is presented in Figure 3.14. In Integrated Test $A$, the permeate rate showed a steady decrease of approximately $6 \mathrm{~kg} / \mathrm{min}$ over the wash. In Integrated Test B, the permeate rate decreased about $5 \mathrm{~kg} / \mathrm{min}$ over the entire wash. 


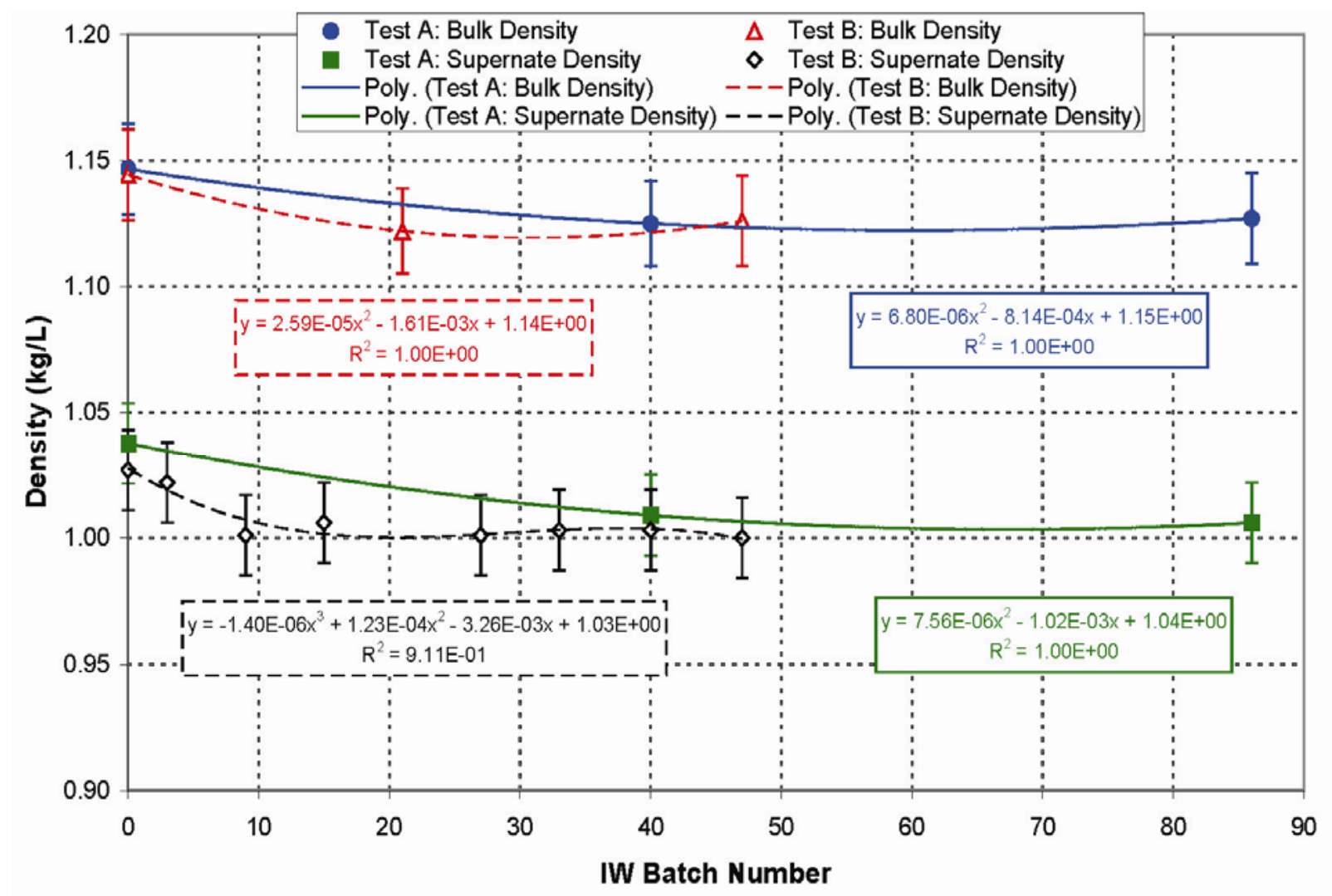

Figure 3.11. Bulk Slurry Density and Supernate Density for Both Integrated Tests A and B Post-Oxidative-Leach Wash as a Function of IW Batch Number. The error bars show the uncertainty in the measurement as provided by SwRI. The curves provided show either a quadratic or cubic polynomial fit to the data points. 


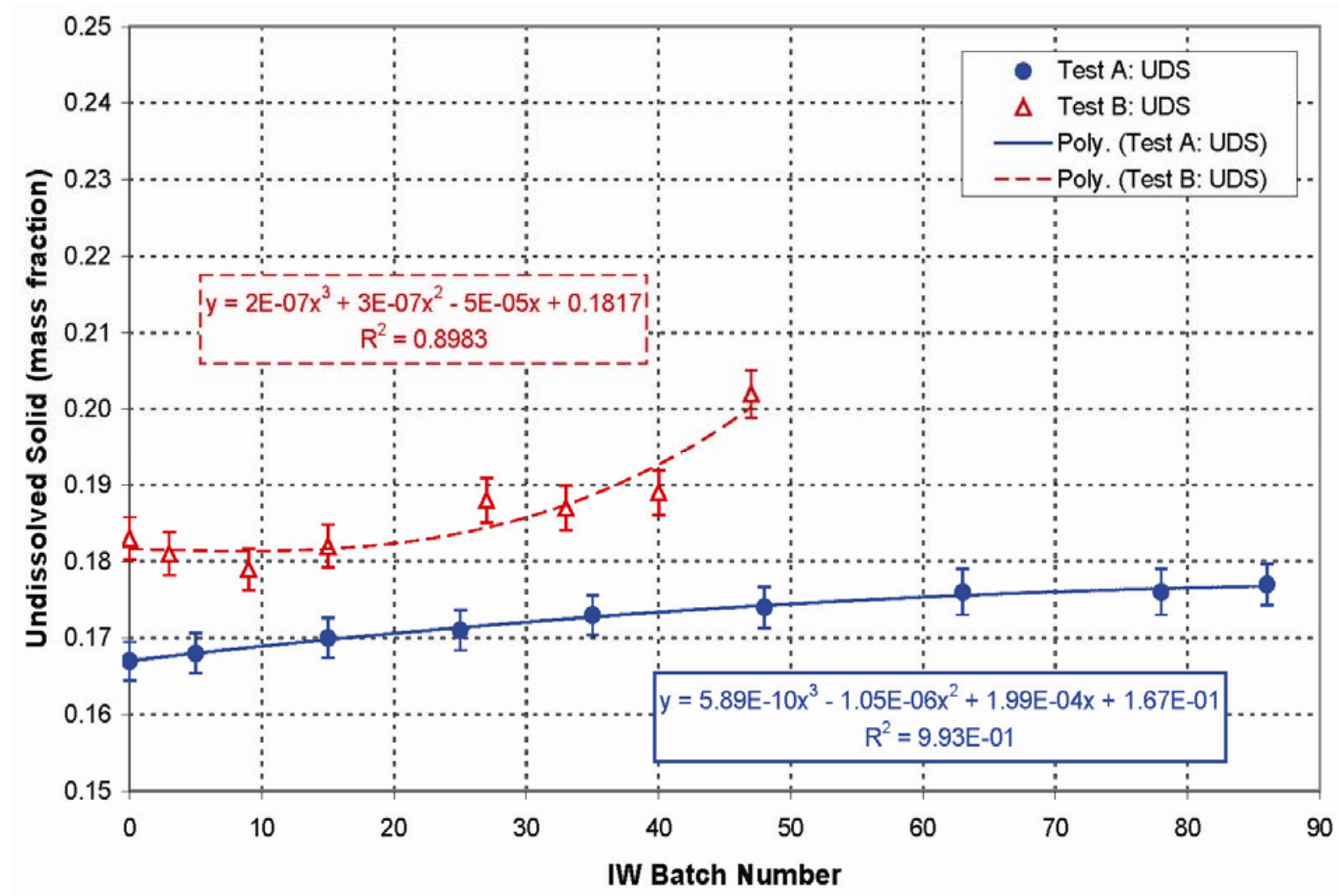

Figure 3.12. The UDS in the Slurry for Both Integrated Tests A and B for Post-Oxidative-Leach Wash as a Function of the IW Batch Number. The error bars show the uncertainty in the measurement as provided by SwRI. 


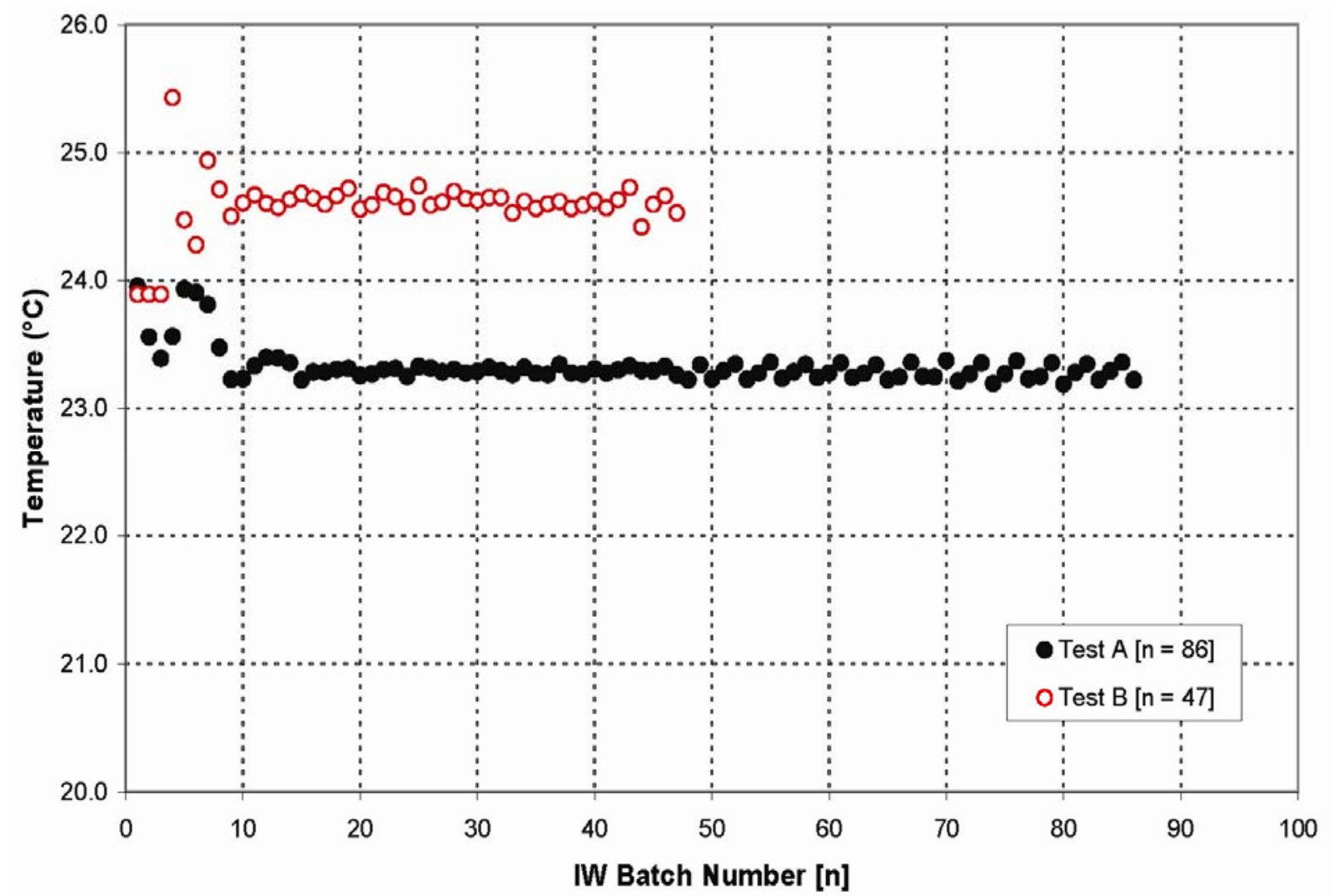

Figure 3.13. Temperature in Vessel T02A During Post-Oxidative-Leach Washing as a Function of IW Batch Number. The temperatures were determined from the prototypic thermocouple; Integrated Test A is represented by black and closed symbols and Integrated Test B by red, open symbols. 


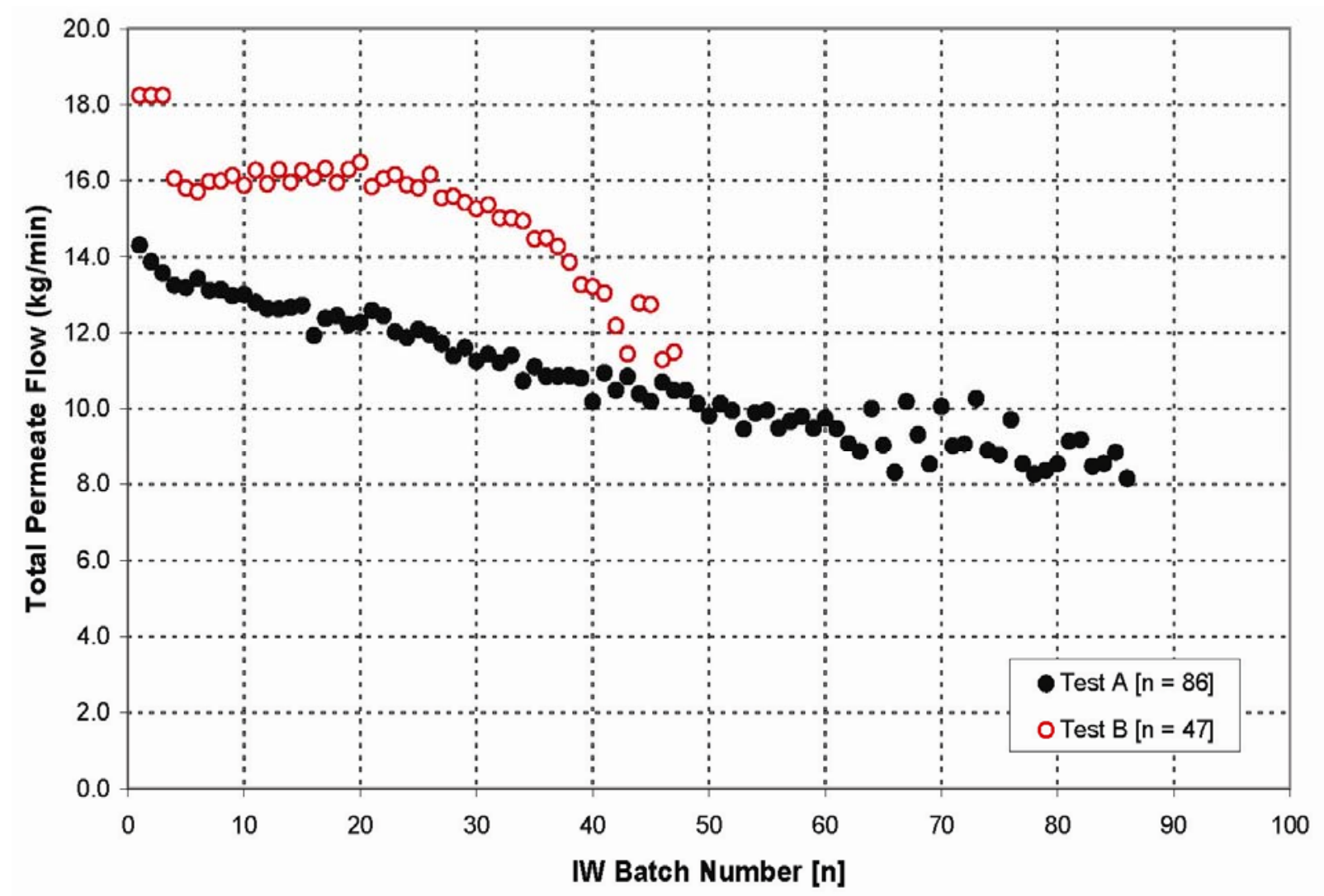

Figure 3.14. Total Permeate Flow Rate (sum of five filters) During Post-Oxidative-Leach Washing as a Function of the IW Batch Number for Integrated Test A (black, closed symbols) and Integrated Test B (red, open symbols).

The average normalized flux of the five filters is shown in Figure 3.15. The flux is normalized using corrections for both temperature and TMP. ${ }^{\text {(a) }}$ Integrated Test A has a gradually decreasing flux over the wash. The average of the average normalized flux for the five filters over the entire wash was $0.039 \pm 0.006 \mathrm{gpm} / \mathrm{ft}^{2}$ (uncertainty is one standard deviation). Integrated Test B behaved in much the same way as Integrated Test A. The average of the average normalized flux for the five filters during the entire wash in Integrated Test B was $0.052 \pm 0.014 \mathrm{gpm} / \mathrm{ft}^{2}$.

Figure 3.16 shows the level at the start of each batch in Vessel T02A during the post-oxidative-leach wash. In both tests, the level measurement shown is based on the laser instrument. It is clear from the figure that the control strategy using level setpoints to trigger each batch of IW performed as intended. The amount of IW and the rate at which it was added was very consistent for both post-caustic-leach washes (see Tables A.2 and A.4). A difference in volumes between the two tests similar to the post-caustic-leach washes is also reflected in the level data of Figure 3.16.

Figure 3.17 illustrates the off-normal recirculation flow rate that was present during the washes. In Integrated Test A, the large separation between flowmeters was observed in the post-oxidative-leach wash as in the post-caustic-leach wash for the same reasons. The values were more stable than in the

(a) For more information on filtration and normalized flux methodology, see WTP-RPT-185. 
post-caustic-leach wash. The air spargers were not on during the Integrated Test A post-oxidative-leach wash.

In Integrated Test B, after FT-0635 was replaced, the flowmeters were more consistent but never reached the target recirculation rate of $109 \mathrm{gpm}$. The slurry volumetric flow rate averaged $90 \pm 5 \mathrm{gpm}$ during the wash until the final few batches. This was the maximum stable flow rate that could be achieved at this point in the test. Entrained gas was the suspected cause. This is why the mixing operations in Vessel T02A were not within target ranges as indicated in Table A.4: the PJMs were run in star mode, and the air to the spargers and steam-ring was off. The axial velocity in the filter tubes was not the desired $15 \mathrm{ft} / \mathrm{s}$, but closer to $12 \mathrm{or} 13 \mathrm{ft} / \mathrm{s}$.

As before, a tracer test (as described in Section 5.3) was performed at conditions similar to each of the post-oxidative-leach washes, although the tracer tests were conducted at significantly higher liquid viscosities. From them, it can be concluded that the system reached $\sim 90 \%$ mixed in approximately 2 to 4 minutes. In both the Integrated Test A and Integrated Test B post-oxidative-leach washes, the axial pressures and TMPs were well-behaved and in the target ranges.

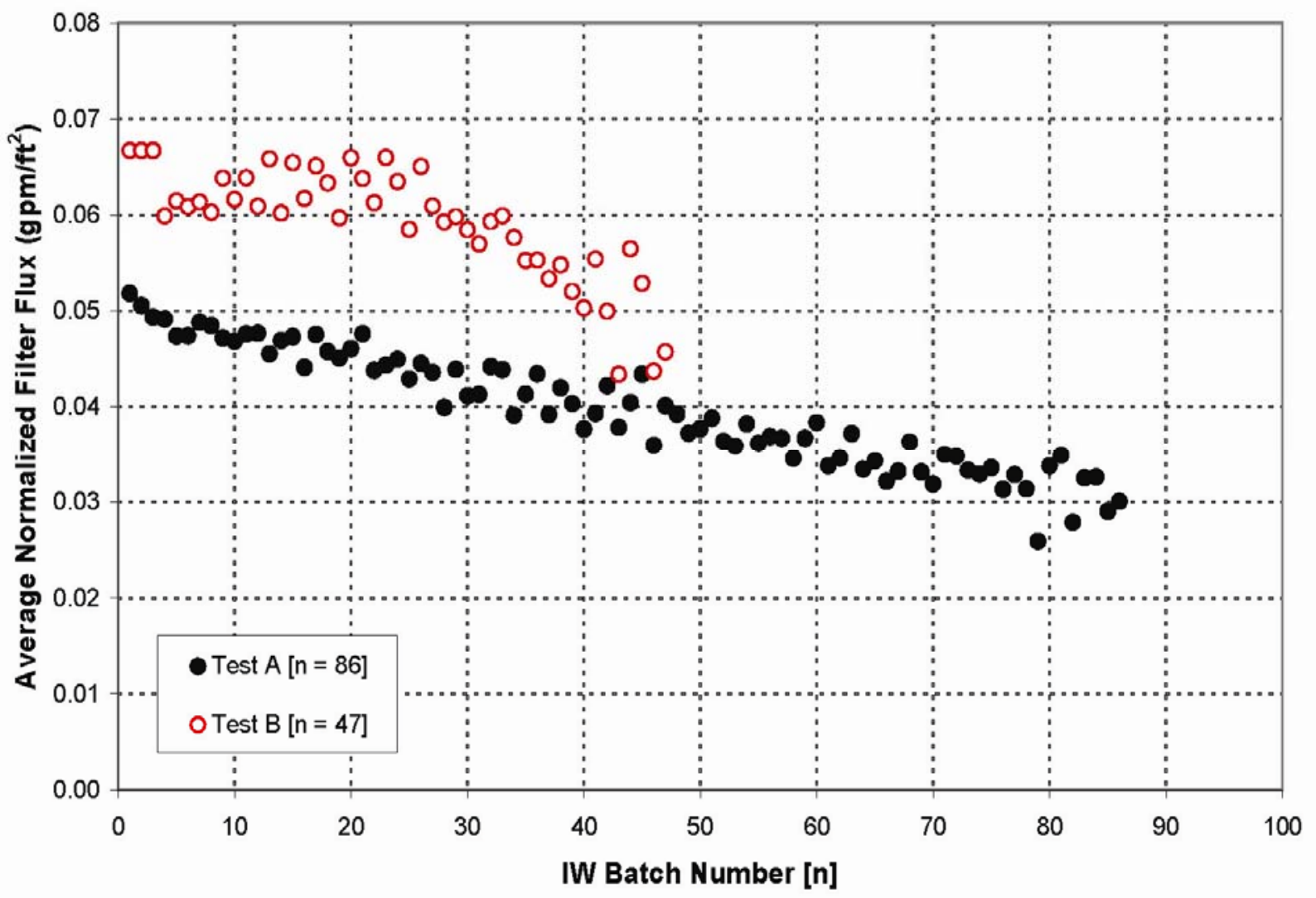

Figure 3.15. Average Normalized Flux (of the five filters) During Post-Oxidative-Leach Washing as a Function of the IW Batch Number for Integrated Test A (black, closed symbols) and Integrated Test B (red, open symbols). The flux was normalized by the temperature shown in Figure 3.13 and the TMP. 


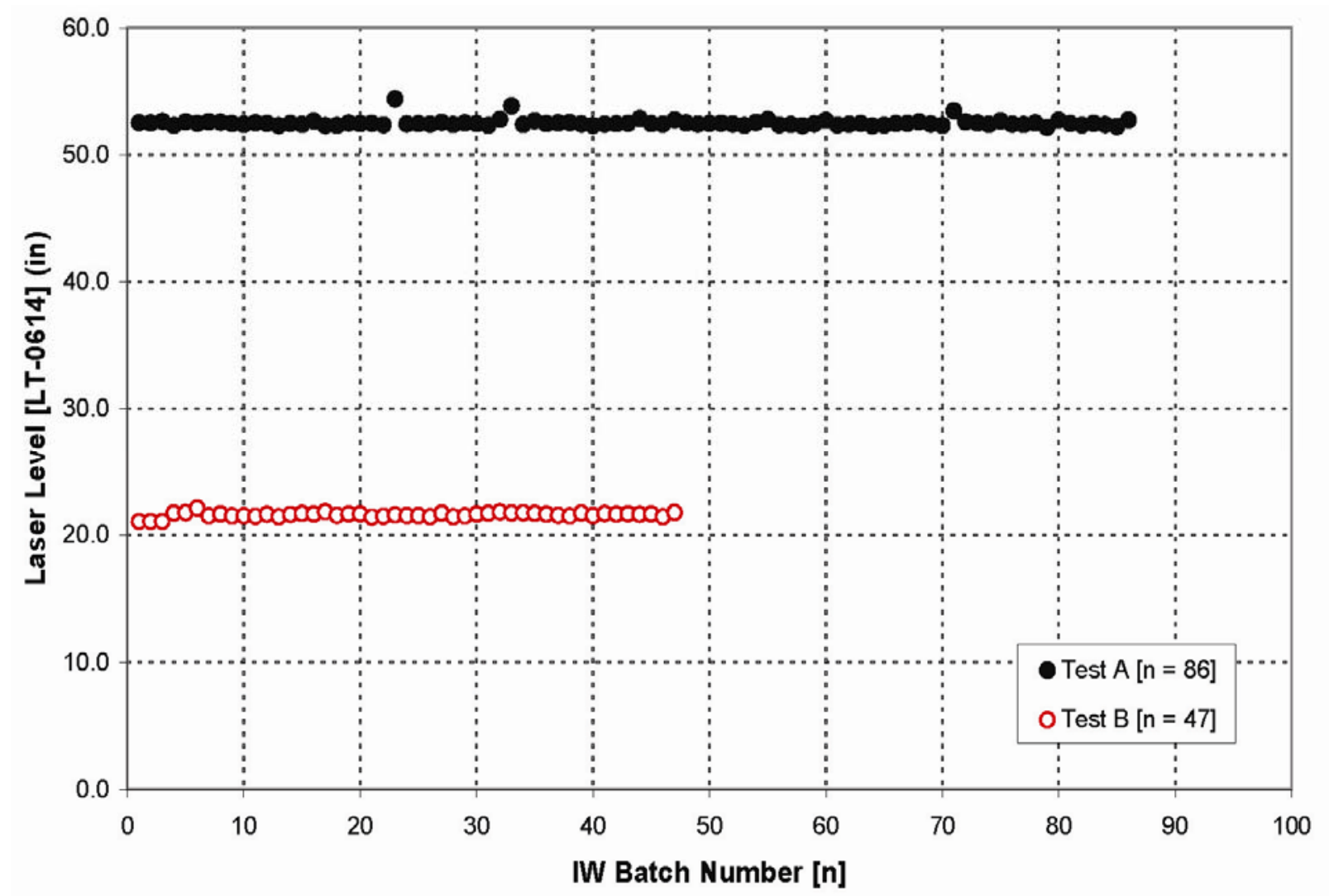

Figure 3.16. The Laser Level in Vessel T02A During Post-Oxidative-Leach Washing as a Function of the IW Batch Number for Integrated Test A (black, closed symbols) and Integrated Test B (red, open symbols). This level represents the amount of slurry in the vessel as the batch is initiated. 


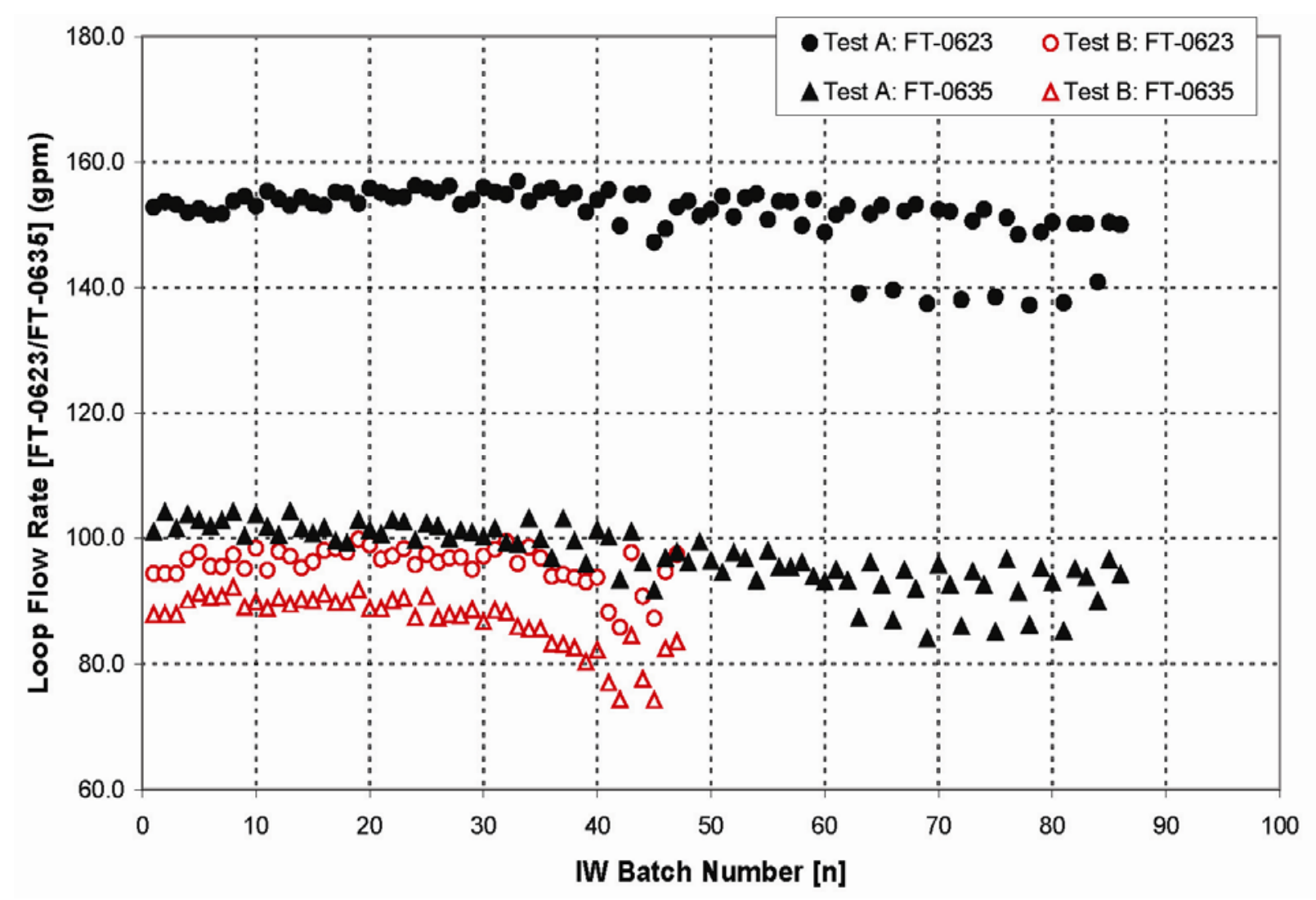

Figure 3.17. Flow Rate in the Filtration Loop During Post-Oxidative-Leach Washing as a Function of the IW Batch Number for Integrated Test A (black, closed symbols) and Integrated Test B (red, open symbols). Two flowmeters are in the loop, one preceding the pumps (FT-0623, indicated by circles) and one after the pumps (FT-0635, indicated by triangles). Note that the flow rate was off-normal for the duration of both washes, as the target flow rate was 109 gpm.

\subsection{Process Parameters}

Target process parameters for the Integrated tests were derived principally from Pretreatment Engineering Platform (PEP) Phase 1 Testing Process Description, 24590-WTP-RPT-PET-07-002 Rev. $1^{\text {(a) }}$ and are provided in the Appendix in Tables A.1, A.2, A.3, and A.4. The specific target run parameters for each test were developed as part of the Test Instruction for each Integrated process test and were provided as approved run sheets by the Joint Test Group (JTG). The run parameter list, for the applicable wash process for each test, is shown in Appendix A. Each list contains a comparison of the target value run parameters and actual data acquisition system (DAS) value run parameters for each test, plus comments on any deviation.

(a) SD Lehrman. 2008. Pretreatment Engineering Platform (PEP) Phase 1 Testing Process Description. 24590-WTP-RPT-PET-07-002, Rev. 1, Bechtel National, Inc., Richland, Washington. 


\subsection{Sampling Scheme}

Sampling and analysis are described in the Test Plan, TP-RPP-WTP-506, Rev. 0.4. ${ }^{\text {(a) }}$ PNNL implements the RPP-WTP quality requirements by performing work in accordance with the River Protection Project-Hanford Tank Waste Treatment and Immobilization Plant Support Program (RPP-WTP) Quality Assurance Plan (RPP-WTP-QA-001, QAP). A simplified discussion of the PEP sampling scheme is described in the following sections.

All samples were taken at a nominal 1 to 2 minutes after end of the IW injection. However, this timeframe was broad, and mixing was not necessarily complete at the time of sampling. Analyses were performed at SwRI unless otherwise indicated. Solids samples were submitted for metals analysis by ICP-optical emission spectrometry (OES). Slurry samples were submitted for analysis of density, metals content, and wt $\%$ UDS. The decanted supernate from centrifuged slurry samples were submitted for metals content, anions content, and free hydroxide concentration (the last performed by PNNL's Analytical Support Operations [ASO]) as described in Section 3.5.1.

\subsubsection{Wash Sampling and Analysis}

Wash slurry samples were collected from Vessel T02A and measured for cations, anions, free hydroxide, density, UDS, and total dissolved solids (TDS). ${ }^{\text {(b) }}$ All samples were obtained with the sampling system for Vessel T02A shown in Figure 3.18. Samples were obtained with the sample loop in recirculation mode with slurry returned to the vessel. To obtain a sample, a valve was used to divert the entire flow to the sample bottle. The sampling valve and line were purged before each sample to minimize any cross contamination with previous sampling events. The wash samples for this test were taken at the lowest height and most outer position, 16.4 inches from the center ( $88 \%$ of total radius) and 11 inches from the bottom (compare with slurry levels given in Figure 3.9 and Figure 3.16).

All Vessel T02A slurry samples retrieved for chemical analysis were approximately $40 \mathrm{~mL}$. Supernatant samples for measurements of cations, anions, and free hydroxide were obtained by centrifuging slurry samples at $4500 \mathrm{G}$ for 10 minutes and decanting the supernate. The cations (sodium, aluminum, and chromium) were measured using ICP spectroscopy. The anions (nitrate, nitrite, oxalate, phosphate, and sulfate) were measured using IC. Free hydroxide concentrations were determined by a standardized titration method.

The solutions for ICP were prepared by acidification with $\mathrm{HCl}$. Details of the sampling and analysis conditions are provided in Appendix F of TP-RPP-WTP-506, Rev. 0.4. ${ }^{\text {(a) }}$

The slurry samples for the post-caustic-leach and post-oxidative-leach washes were taken approximately every third wash step. Density, UDS, and dissolved solids samples were also taken approximately every five to seven washes. However, certain density samples for the post-oxidative-leach wash tests were taken only at the beginning, middle, and end of the tests. These include the bulk slurry

(a) GB Josephson, OP Bredt, JK Young, and DE Kurath. 2009. Pretreatment Engineering Platform (PEP) Testing (Phase I). TP-RPP-WTP-506, Rev. 0.4, Pacific Northwest National Laboratory, Richland Washington.

(b) A complete reporting of the analytical results will be provided in the PEP run reports: WTP-RPT-191 (Integrated Test A run report) and WTP-RPT-192 (Integrated Test B run report). 
densities for Integrated Tests A and B and supernate density for Integrated Test A. The supernate density for Integrated Test B was taken at several wash steps throughout the test.

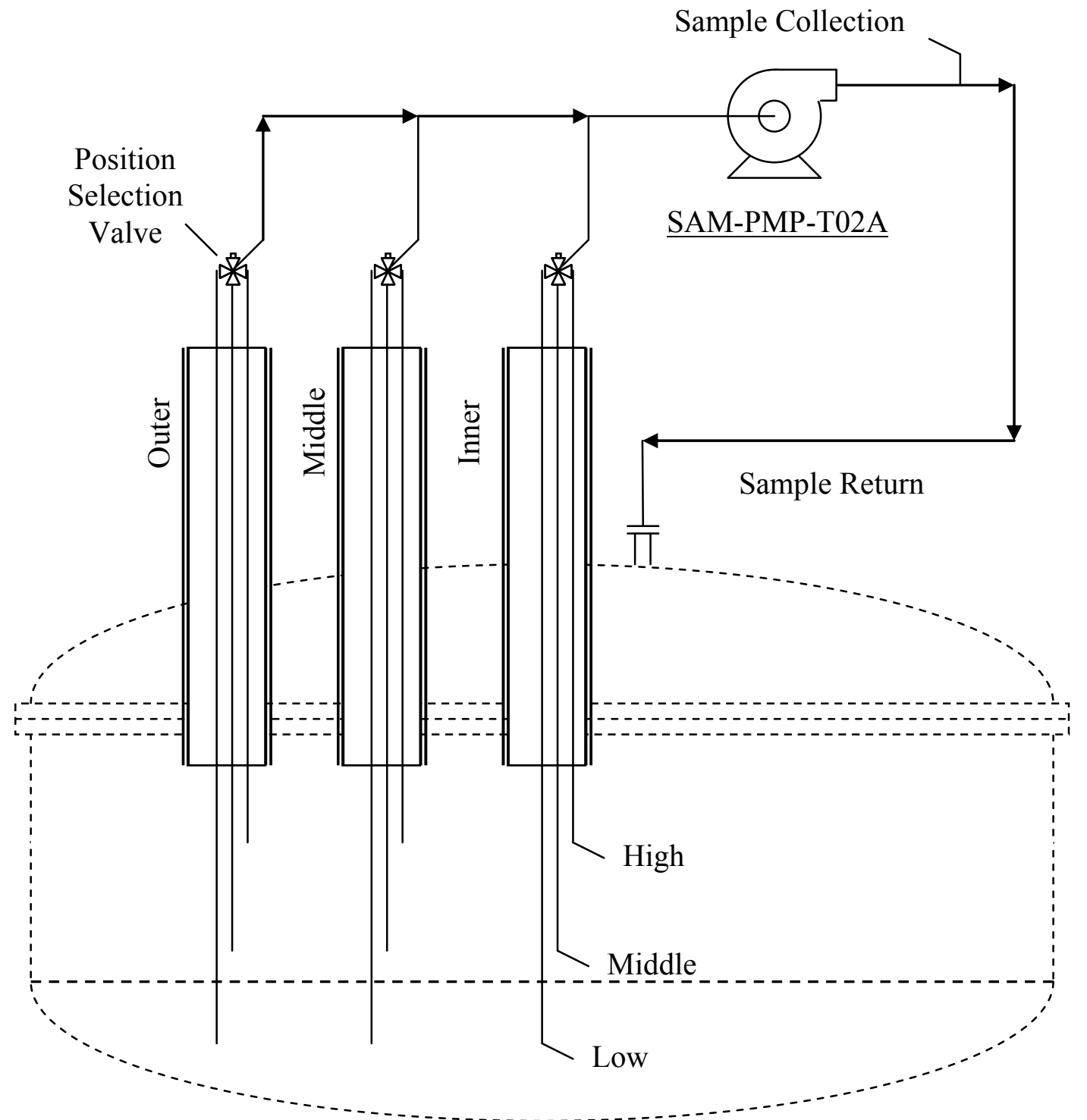

Figure 3.18. In-Tank Sampling, Showing the Three Radial Positions at Three Heights and Sampling Flow Loop. All Vessel T02A slurry samples for the washing tests were retrieved from the outer radius, lowest sampling position.

\subsubsection{Tracer Tests}

The primary objective of the tracer tests was to evaluate Vessel T02A for evidence of channeling between the recirculation loop return nozzle and the suction of Pump T42A. The presence of channeling could result in a "short circuit," thereby reducing the effectiveness of the mixing system. These data also provide an estimate of the time required for mixing and provide insight into the rate at which the wash solutions are blended with the slurry over a 1-hour time period. 
The chemical tracer used in these tests was $\mathrm{CsBr}$, with cesium measured by ICP-mass spectrometry (MS). The tracer was injected into the suction of recirculation Pump T42A when UFP-VSL-T02A had a prototypic volume of the slurry at target concentration. Although not recorded, the nominal time for the tracer injection was approximately $30 \mathrm{~s}$. The tracer concentrations in UFP-VSL-T02A and the filter-loop were monitored via sample collections for 1 hour.

Originally, the Test Plan called for two tracer tests to evaluate short-circuiting in Vessel T02A at the very beginning of the post-caustic-leach wash (i.e., when the slurry is $\sim 17$-wt $\%$ UDS, and liquid viscosity is high), the first when the slurry level in Vessel T02A is low (i.e., when caustic leaching is conducted in Vessel T02A) and the second when the level in Vessel T02A is high (i.e., when caustic leaching is conducted in Vessel T01A). Difficulty in obtaining target mixing conditions necessitated that the tracer test be repeated for the high vessel level in Vessel T02A. 


\subsection{Equations and Definitions}

The definition of wash efficiency is the quantity of a fully soluble solute actually removed divided by the quantity of solute expected to be removed, assuming an ideal permeate concentration. In the G-2 washing model, the ideal permeate (liquid-phase) concentration is defined as

$$
C_{n}^{*}=C_{n-1}\left(\frac{V_{L}}{V_{L}+V_{w}}\right)
$$

where $\quad n=$ wash step number, where each step adds an increment of $V_{w}$ volume (targeted at 11 gallons) of wash liquid and removes $V_{w}$ volume of permeate

$C_{n}{ }^{*}=$ ideal permeate concentration of a species as defined by the G-2 model

$C_{n-1}=$ molar concentration of a species at the end of the preceding wash step

$C_{n}=$ molar concentration of a species at the current wash step

$V_{w}=$ volume of IW added at each wash step (targeted at 11 gallons)

$V_{L}=$ volume of liquid in the slurry before wash liquid is added.

This equation assumes that the wash-water, after being injected into the loop, mixes instantaneously with the slurry to achieve a new equilibrium solute concentration $C_{n}{ }^{*}$. A wash efficiency of one is achieved if the permeate removed has a concentration of $C_{n}{ }^{*}$. A wash efficiency of less than one occurs when the concentration of solute in the permeate is less than ideal, i.e., when $C_{n}<C_{n-1} V_{L} /\left(V_{L}+V_{w}\right)$.

The model is developed starting with a component mass balance of the form

$$
C_{n} V_{L}=C_{n-1} V_{L}-C_{n} V_{w} w_{e f f}
$$

where $w_{\text {eff }}$ is the wash efficiency, which is assumed to be constant.

Note that if the wash efficiency is equal to one, the ideal permeate concentration from the G-2 model is recovered from Equation 4.2. The wash efficiency defined by Equation 4.2 is a measure of the removal of dissolved species and should not be confused with the "wash factor" used elsewhere as a measure of the dissolution of soluble species.

The liquid volume in the slurry is calculated using the following relationship

$$
V_{L}=\frac{\rho V\left(1-\omega_{s}\right)}{\rho_{L}}
$$

where $\rho=$ slurry density, as determined by analytical samples

$V=$ slurry volume, as determined by level in Vessel T02A

$\omega_{\mathrm{s}}=$ mass fraction of UDS, as determined by analytical samples

$\rho_{\mathrm{L}}=$ liquid-phase density, as determined by analytical samples. 
The liquid volume is not constant and needed to be calculated for each wash step. The slurry volume was determined at every $n$ using the level in Vessel T02A, a correction for the volume in the PJM tubes, and the known volume in the filtration loop. However, the physical properties were not measured at every $n$, so they were modeled as functions of $n$ to calculate $V_{L}$ at all the steps where analytical concentrations were measured. The slurry density, supernate density, and mass fraction of UDS were calculated at every batch. Finally, $V_{L}$ was modeled by a cubic polynomial as a function of $n$. This approach was used for all four of the washes discussed in this report.

As described by Equation 4.2, the wash efficiency is a measure of how closely the PEP process matches the G-2 washing model predictions. If the washing liquid were instantaneously added and mixed with the slurry, $w_{\text {eff }}$ would be equal to one, and the amount of solute currently in the system $\left(C_{n} V_{L}\right)$ would be the previous amount $\left(C_{n-1} V_{L}\right)$ less the amount removed via filtration $\left(C_{n} V_{w}\right)$. The assumed mixing behavior requires that the permeate be removed at the current concentration (which is instantaneously achieved) and in amounts equivalent to the amount of IW that was added. A wash efficiency that is not equal to one indicates that the permeate was removed at a concentration other than $C_{n}{ }^{*}$. It can be thought of as water that does not participate in the process, i.e., a fraction of the water was not ideally mixed with the slurry, and the dilution of analytes would be less than expected.

Equation 4.2 can be applied to the washing data by a simple rearrangement:

$$
\frac{C_{n-1}}{C_{n}}=1+\frac{V_{w}}{V_{L}} w_{e f f} .
$$

Equation 4.4 could be solved algebraically for $w_{\text {eff; }}$, however, analytical concentrations were not measured at every $n$. It was expected that the wash efficiency should be constant or nearly so, and therefore a useful approach is to model the entire wash with $w_{\text {eff }}$ as an adjustable parameter. A model can be constructed by referencing each IW batch where samples were taken back to $C_{o}$, yielding the expression

$$
\left(\frac{C_{n-1}}{C_{n}}\right)\left(\frac{C_{n-2}}{C_{n-1}}\right) \ldots\left(\frac{C_{o}}{C_{n-(n-1)}}\right)=\left(\frac{C_{o}}{C_{n}}\right)=\left(1+\frac{V_{w}}{V_{L}} w_{e f f}\right)^{n} .
$$

In this case, the subscript $\mathrm{n}$ refers to the IW batches at which concentrations were measured. For instance, if a sample was taken at $\mathrm{n}=6$, then

$$
\left(\frac{C_{5}}{C_{6}}\right)\left(\frac{C_{4}}{C_{5}}\right) \ldots\left(\frac{C_{o}}{C_{1}}\right)=\left(\frac{C_{o}}{C_{6}}\right)=\left(1+\frac{V_{w}}{V_{L}} w_{\text {eff }}\right)^{6} .
$$

A straightforward way to determine the parameter $w_{\text {eff }}$ is to compare the right-hand side of Equation 4.5 (expected concentration ratio) with the left-hand side (actual concentration ratio). This can be done by calculating the residuals at each $n$, defined as 


$$
\Delta_{n}=\left[\left(\frac{C_{o}}{C_{n}}\right)-\left(1+\frac{V_{w}}{V_{L}} w_{e f f}\right)^{n}\right]^{2},
$$

where $\Delta_{n}$ is the residual at $n$.

At this point, the model is developed in two different directions, providing two types of wash efficiency, each with a different purpose. A single wash efficiency for each analyte may be determined using a weighted least squares best fit of the entire data set. This is shown in Equation 4.8. This provides an overall wash efficiency of the entire wash process. Alternatively, an incremental step-by-step wash efficiency may be determined to provide a quantitative measure of wash performance throughout the wash process and to test the assumption that $w_{\text {eff }}$ is approximately constant. This is described in Equations 4.9 to 4.11 .

Weighted Least Squares method: In the classical sum of the least squares method, the residuals as given in Equation 4.7 were summed over the range of interest, and $w_{\text {eff }}$ was selected to minimize that sum. A modification to that approach is to weight the sum using the magnitude of the analytical measurements. The weighing normalizes the contributions of each residual to the least squares calculation:

$$
\bar{\Delta}_{w}=\sum \Delta_{w, n}=\sum\left[\frac{\left(\frac{C_{o}}{C_{n}}\right)-\left(1+\frac{V_{w}}{V_{L}} w_{\text {eff }}\right)^{n}}{\left(\frac{C_{o}}{C_{n}}\right)}\right]^{2},
$$

where $\bar{\Delta}_{w}$ is the quantity to be minimized by varying $w_{\text {eff }}$, and the subscript $w$ denotes that the residuals were weighted. The weighted least squares approach of Equation 4.8 was used to determine $w_{\text {eff }}$ by an iterative solution method, subject to the constraint $0 \leq w_{\text {eff }} \leq 2$.

Incremental method: To obtain an idea of the performance during the wash, Equation 4.4 can also be rearranged to determine the wash efficiency algebraically:

$$
w_{\text {eff }}=\left[\left(\frac{C_{n-1}}{C_{n}}\right)-1\right]\left(\frac{V_{L}}{V_{w}}\right) .
$$

Equation 4.9 can be applied incrementally to compute the wash efficiency over a small number of wash steps. If analytical information is available at two steps, $n_{1}$ and $n_{2}$, then

$$
w_{e f f, i}=\left[\left(\frac{C_{n_{1}}}{C_{n_{2}}}\right)^{\frac{1}{n_{2}-n_{1}}}-1\right]\left(\frac{\left\langle V_{L}\right\rangle}{V_{w}}\right),
$$


where $\left\langle V_{L}\right\rangle$ is the average liquid volume over the increment, and the subscript $i$ indicates that the wash efficiency is incremental. Equation 4.10 as written requires that $n_{2}$ occurs after $n_{1}$. For example, in the post-caustic-leach wash of Integrated Test A, samples were taken for $n=3$ and $n=6$. This can be written

$$
w_{e f f, i}=\left[\left(\frac{C_{3}}{C_{6}}\right)^{\frac{1}{6-3}}-1\right]\left(\frac{\left\langle V_{L}\right\rangle}{V_{w}}\right)
$$

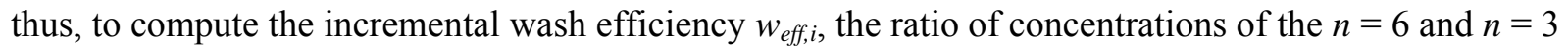
samples will be raised to the $1 / 3$ power. The result of the calculation using Equation 4.11 would be the wash efficiency for batches 4,5 , and 6 . The incremental calculation has the added benefit of providing feedback on the assumption that $w_{\text {eff }}$ is a constant over an entire wash since it is calculated for only a few steps at a time. 


\subsection{Results}

The presentation of results includes the plotted and tabulated washing efficiencies and concentration behavior for all selected analytes for Integrated Tests A and B. Wash efficiencies were calculated using the model and equations described in Section 4. The post-caustic-leach and post-oxidative-leach wash efficiencies are discussed separately below.

Also, the tracer test results are presented and discussed in Section 5.3. The tracer tests were conducted to evaluate Vessel T02A for evidence of channeling and provide an estimate of the time required for mixing. These results provide insight into the rate at which the wash solutions are blended with the slurry. Plots of the data and discussion are provided.

Finally, the IW batch time interval data are provided and discussed. As a response to the tracer test data and resulting mixing time, the question is raised regarding how the IW batch time interval compared to the measured mixing time and how that may impact washing efficiency. The IW batch time interval for each batch, in units of minutes, was defined as the duration between the start of the IW wash injection for a batch to the start for the IW wash injection for the subsequent batch. These data are presented in plots and discussed.

\subsection{Post-Caustic-Leach Wash Tests}

The best-choice analytes for determining wash efficiency were those analytes that were fully dissolved throughout the entire washing procedure. For the post-caustic-leach wash, these are dissolved aluminum, free hydroxide, nitrate, nitrite, and sulfate. Other originally considered analytes, including sodium, oxalate, phosphate, and TDS, clearly show evidence of partial solubility or slow dissolution of solids throughout the wash steps with resulting concentration behavior so are therefore unsuitable for use in monitoring wash efficiency and will not be discussed here. The concentrations of these partially soluble analytes are included in tables described below.

Table 5.1 summarizes the overall washing efficiencies for the analytes of interest, using the weighted least squares method, in each test for the post-caustic-leach wash. An average of all overall wash efficiencies is calculated and presented to provide a single value best-estimate of wash efficiency for the entire process for each test. See discussion of this table and data in Section 6.0.

Figure 5.1 through Figure 5.5 are plots of the incremental method washing efficiencies for post-caustic-leach wash for these fully dissolved analytes. These plots of incremental wash efficiency provide a measure of wash performance throughout the wash process. The incremental washing efficiency is plotted versus the IW batch number. Each plot also shows the semi-log of the ratio of the measured concentration at each step to the initial measured concentration. The semi-log view provides two benefits:

1. True log-linearity should result if the analyte is subject to ideal mixing. The expected ideal concentration ratio is provided for reference; by definition, ideal behavior is when the wash efficiency is equal to 1 in Equation 4.3. So any deviation from log-linearity may indicate slow dissolution or precipitation of analytes, an approach to the measurement detection limit, or other concentration behavior problems. 
2. The semi-log view provides greater detail of concentration behavior as the end of washing is approached.

All wash-step analyte concentrations, $\mathbf{C}_{\mathbf{n}} / \mathbf{C}_{\mathbf{0}}$ ratios, and washing efficiency data for all analytes are shown in Table 5.2 through Table 5.5 for post-caustic-leach wash.

Table 5.1. Wash Efficiency for Completely Soluble Analytes During Post-Caustic-Leach Washing as Calculated Using the Weighted Least Squares Method of Equation 4.7

\begin{tabular}{ccc}
\hline Analyte & $\begin{array}{c}\text { Integrated } \\
\text { Test A }\end{array}$ & $\begin{array}{c}\text { Integrated } \\
\text { Test B }\end{array}$ \\
\hline Aluminum & $1.00 \pm 0.03$ & $1.01 \pm 0.03$ \\
Sulfate & $1.00 \pm 0.03$ & $1.02 \pm 0.03$ \\
Nitrate & $1.00 \pm 0.02$ & $1.01 \pm 0.03$ \\
Nitrite & $1.01 \pm 0.03$ & $1.02 \pm 0.04$ \\
Free OH & $0.93 \pm 0.05$ & $0.99 \pm 0.06$ \\
Average & $0.99 \pm 0.01$ & $1.01 \pm 0.02$ \\
\hline
\end{tabular}

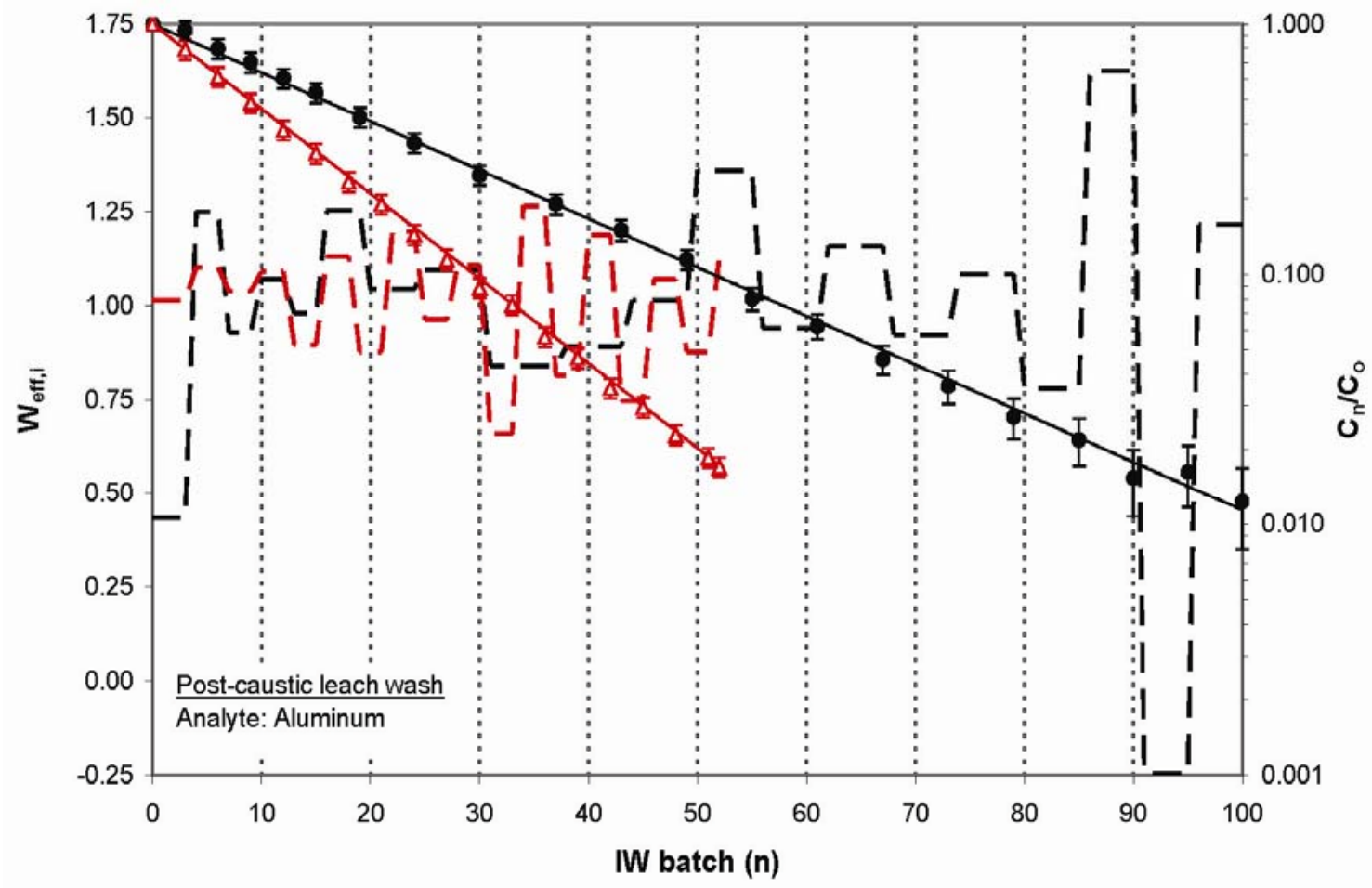

$$
\begin{array}{cc}
\text { - Test A: Incremental wash efficiency } & - \\
\text { Test A: Concentration at n/Initial Concentration } & \Delta \quad \text { Test B: Incremental wash efficiency } \\
\text { Test A: Ideal model (wash efficiency = 1) } & \text { Test B: Ideal model (wash efficiency = 1) }
\end{array}
$$

Figure 5.1. Incremental Wash Efficiency (left y-axis) and Concentration Ratio (right y-axis) for Aluminum During Post-Caustic-Leach Washing, Comparing Integrated Test A and Integrated Test B. The sample data, by ICP, reflects 100 washes in Integrated Test A and 52 washes in Integrated Test B. $\log C_{n} / C_{o}$ is plotted to show concentration behavior. 


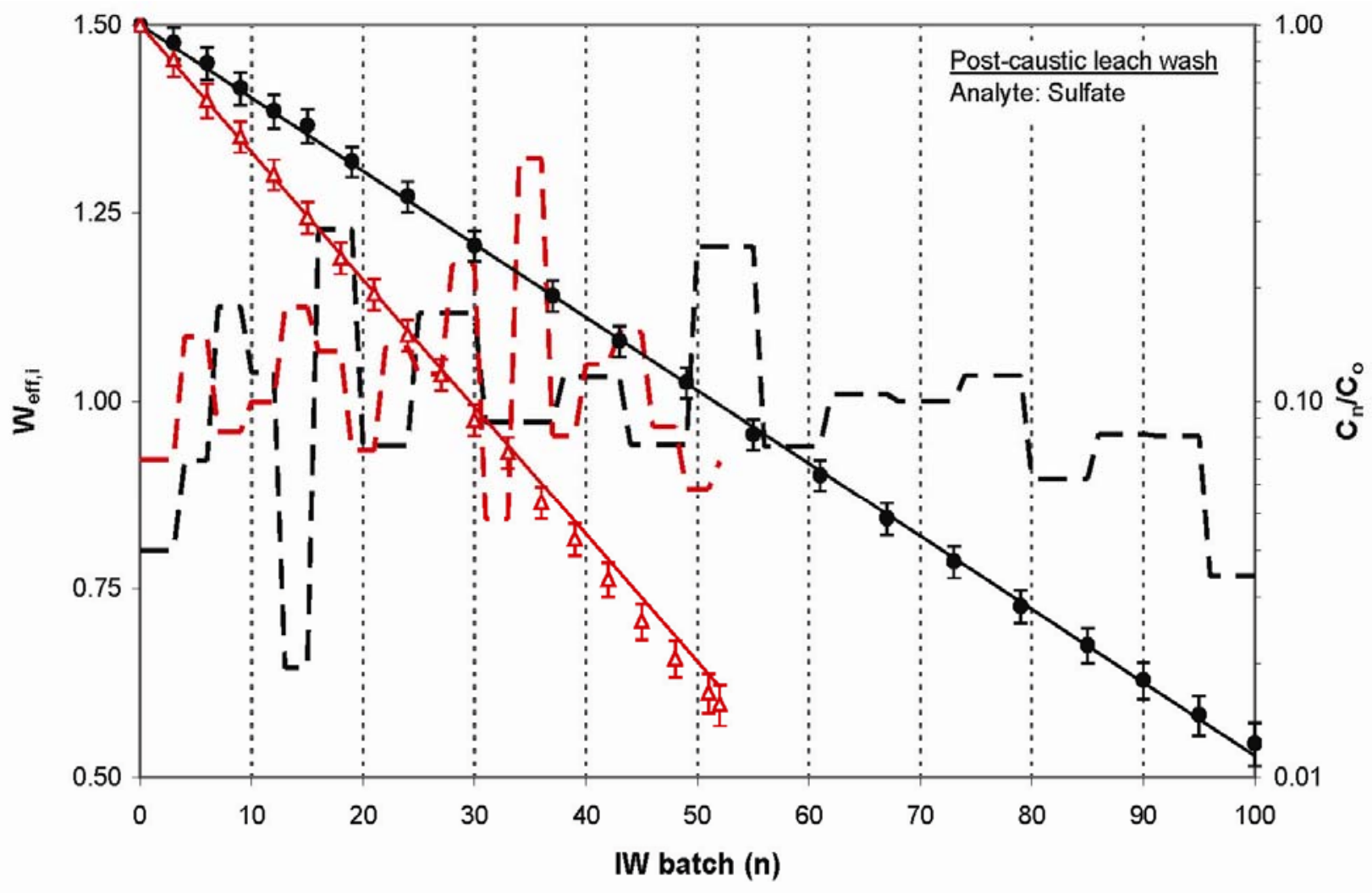

$\begin{array}{cc}\text { - Test A: Incremental wash efficiency } & - \text { Test B: Incremental wash efficiency } \\ \text { Test A: Concentration at n/Initial concentration } & \Delta \quad \text { Test B: Concentration at n/Initial concentration } \\ \text { - Test A: Ideal model (wash efficiency = 1) } & \text { Test B: Ideal model (wash efficiency = 1) }\end{array}$

Figure 5.2. Incremental Wash Efficiency (left y-axis) and Concentration Ratio (right y-axis) for Sulfate During Post-Caustic-Leach Washing, Comparing Integrated Test A and Integrated Test B. The sample data, by IC, reflects 100 washes in Integrated Test A and 52 washes in Integrated Test B. $\log \mathrm{C}_{\mathrm{n}} / \mathrm{C}_{\mathrm{o}}$ is plotted to show concentration behavior. 


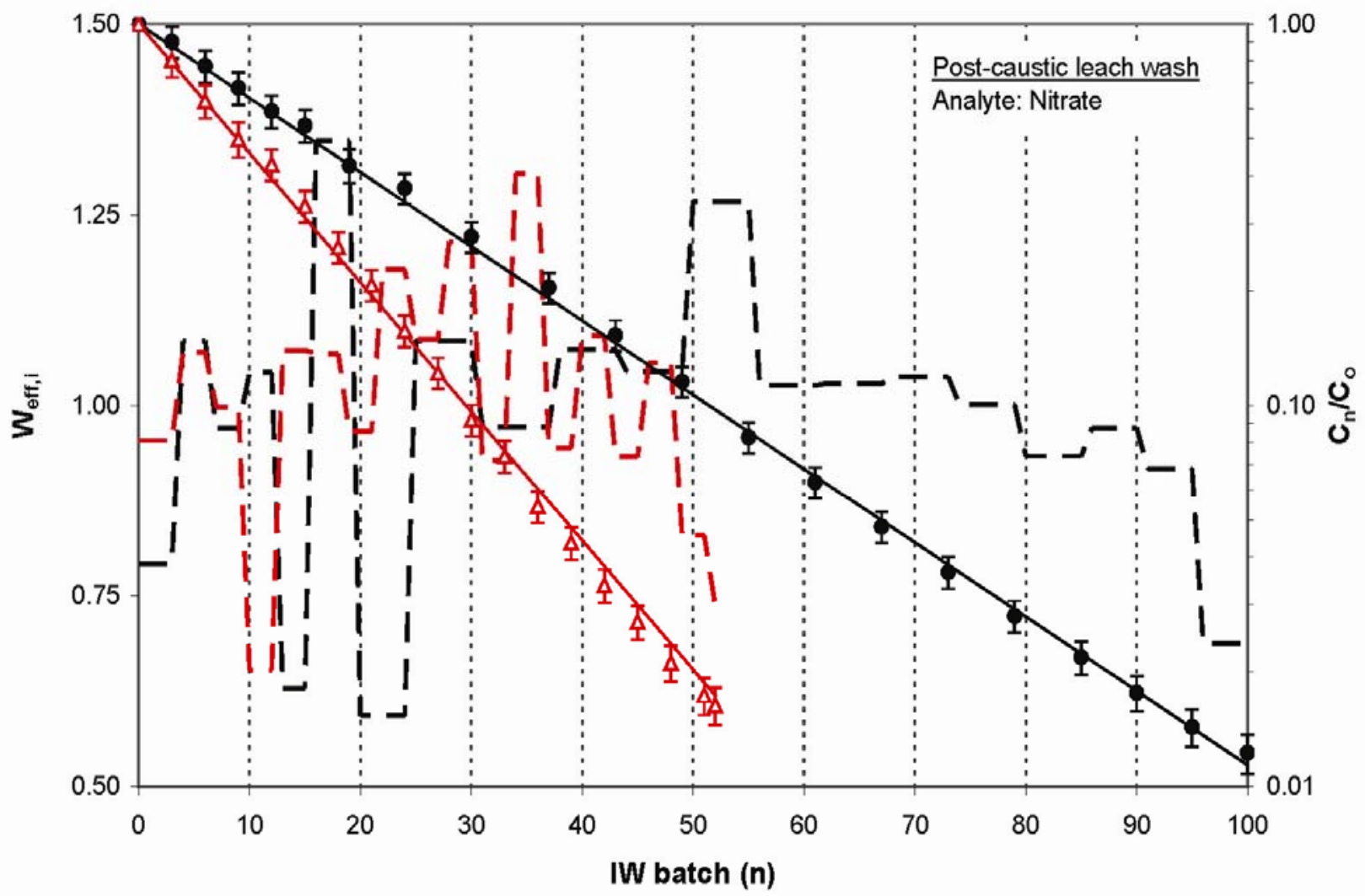

$\begin{array}{cc}\text { - Test A: Incremental wash efficiency } & - \text { - Test B: Incremental wash efficiency } \\ \text { Test A: Concentration at n/Initial concentration } & \Delta \quad \text { Test B: Concentration at n/Initial concentration } \\ \text {-Test A: Ideal model (wash efficiency = 1) } & \text { Test B: Ideal model (wash efficiency = 1) }\end{array}$

Figure 5.3. Incremental Wash Efficiency (left y-axis) and Concentration Ratio (right y-axis) for Nitrate During Post-Caustic-Leach Washing, Comparing Integrated Test A and Integrated Test B. The sample data, by IC, reflects 100 washes in Integrated Test A and 52 washes in Integrated Test $B$. $\log C_{n} / C_{o}$ is plotted to show concentration behavior. 


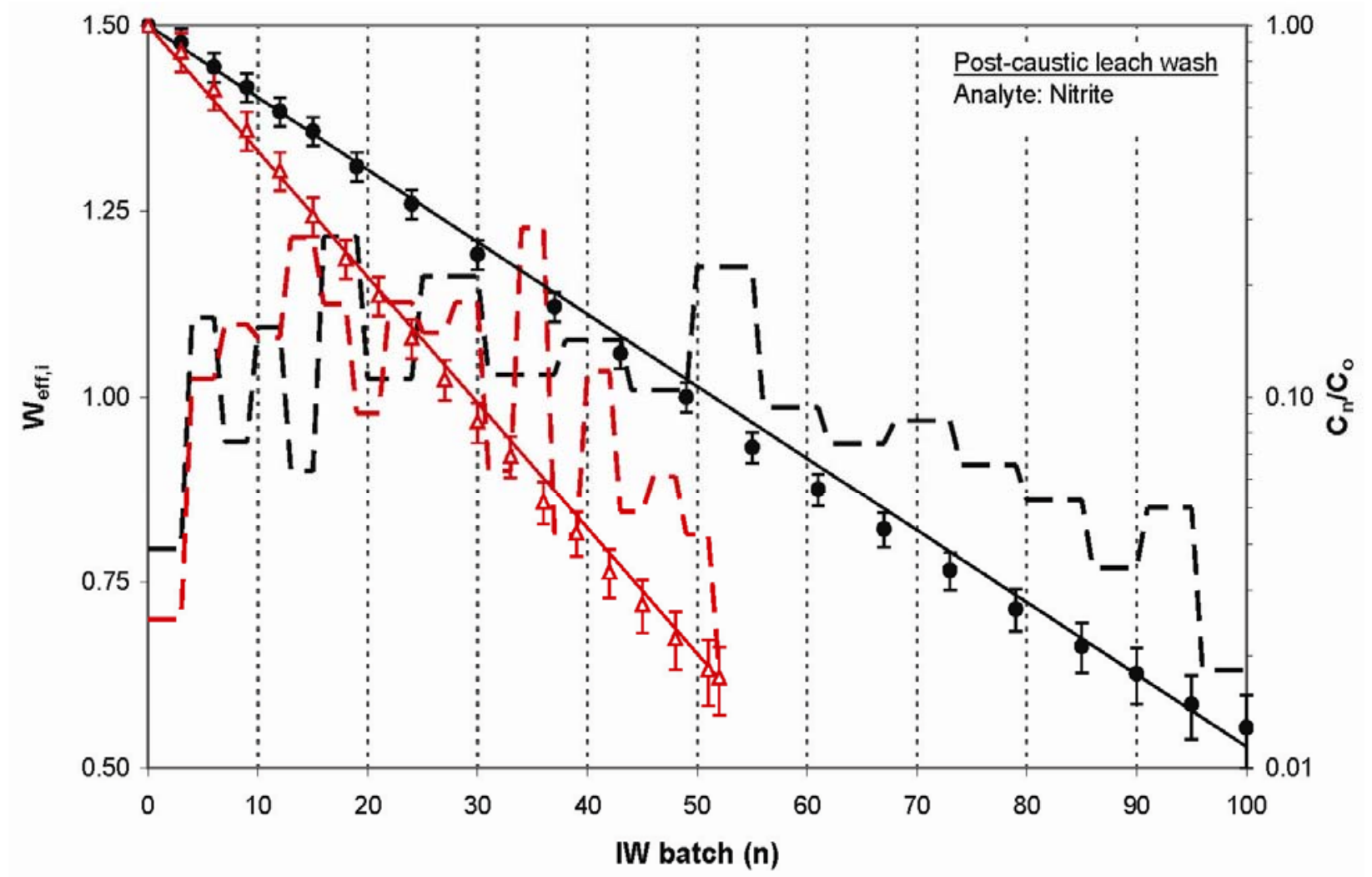

\begin{tabular}{|cc|}
\hline- - Test A: Incremental wash efficiency & - - Test B: Incremental wash efficiency \\
Test A: Concentration at n/Initial Concentration & $\Delta \quad$ Test B: Concentration at n/Initial Concentration \\
Test A: Ideal model (wash efficiency = 1) & Test B: Ideal model (wash efficiency = 1) \\
\hline
\end{tabular}

Figure 5.4. Incremental Wash Efficiency (left y-axis) and Concentration Ratio (right y-axis) for Nitrite During Post-Caustic-Leach Washing, Comparing Integrated Test A and Integrated Test B. The sample data, by IC, reflects 100 washes in Integrated Test A and 52 washes in Integrated Test $B$. $\log C_{n} / C_{o}$ is plotted to show concentration behavior. 

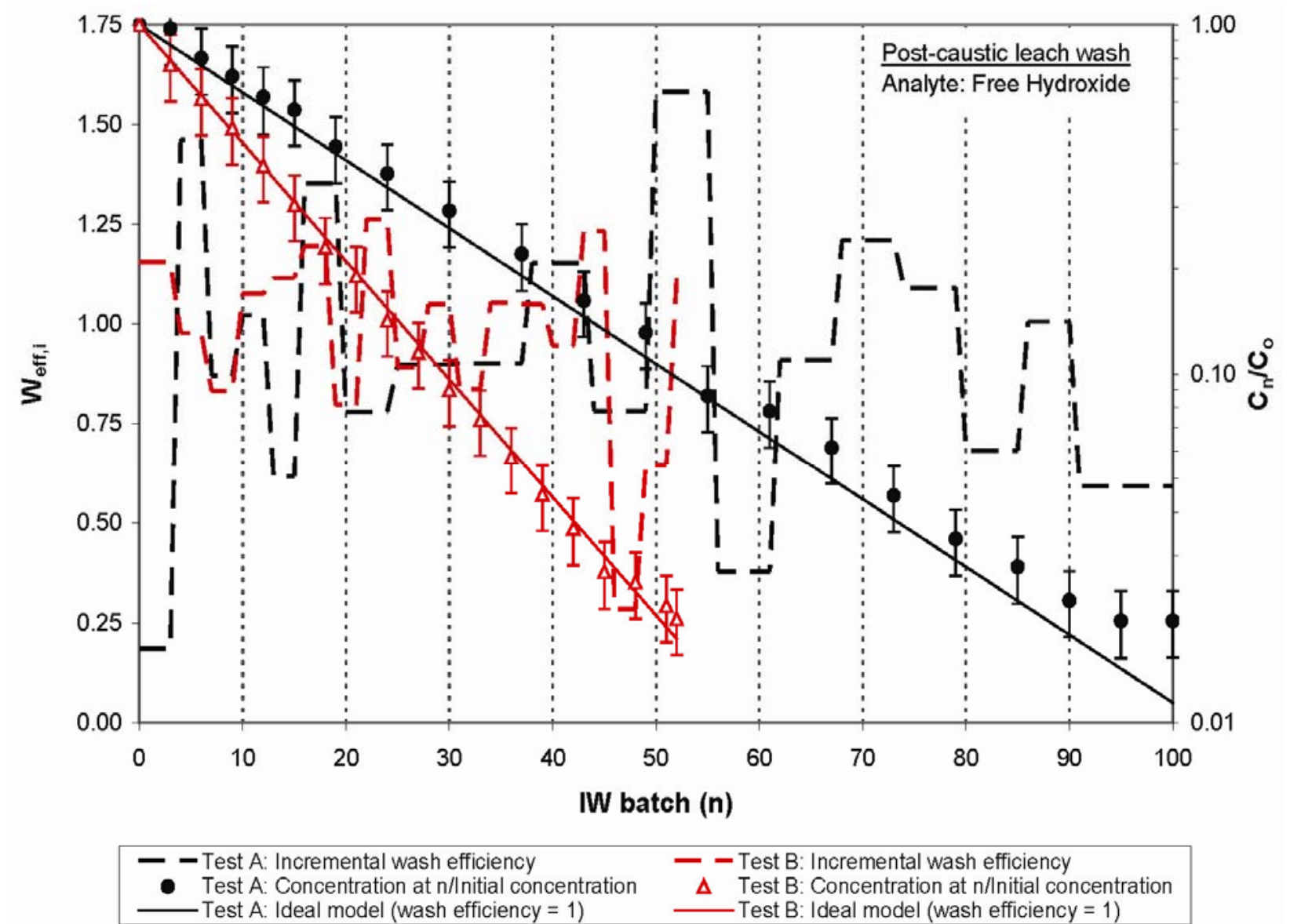

Figure 5.5. Incremental Wash Efficiency (left y-axis) and Concentration Ratio (right y-axis) for Free Hydroxide During Post-Caustic-Leach Washing, Comparing Integrated Test A and Integrated Test B. The sample data, by titration, reflects 100 washes in Integrated Test A and 52 washes in Integrated Test B. $\log C_{n} / C_{o}$ is plotted to show concentration behavior. 
Table 5.2. Concentration and Incremental Wash Efficiency for Soluble Analytes Measured During the Integrated Test A Post-Caustic-Leach Wash. The last row labeled "RL" is the reporting limit ${ }^{(a)}$ for each analyte.

\begin{tabular}{|c|c|c|c|c|c|c|c|c|c|c|c|c|c|c|c|}
\hline \multirow{2}{*}{$\begin{array}{l}\text { Wash } \\
\text { Step }\end{array}$} & \multicolumn{3}{|c|}{ Nitrate } & \multicolumn{3}{|c|}{ Nitrite } & \multicolumn{3}{|c|}{ Sulfate } & \multicolumn{3}{|c|}{ Aluminum } & \multicolumn{3}{|c|}{ Free $\mathrm{OH}$} \\
\hline & $\mathrm{C}_{\mathrm{n}}(\mathrm{M})$ & $\mathrm{C}_{\mathrm{n}} / \mathrm{C}_{\mathrm{o}}$ & $\mathrm{W}_{\mathrm{eff}, \mathrm{i}}$ & $\mathrm{C}_{\mathrm{n}}(\mathrm{M})$ & $\mathrm{C}_{\mathrm{n}} / \mathrm{C}_{\mathrm{o}}$ & $\mathrm{W}_{\mathrm{eff}, \mathrm{i}}$ & $\mathrm{C}_{\mathrm{n}}(\mathrm{M})$ & $\mathrm{C}_{\mathrm{n}} / \mathrm{C}_{\mathrm{o}}$ & $\mathrm{w}_{\mathrm{eff}, \mathrm{i}}$ & $\mathrm{C}_{\mathrm{n}}(\mathrm{M})$ & $\mathrm{C}_{\mathrm{n}} / \mathrm{C}_{\mathrm{o}}$ & $\mathrm{w}_{\mathrm{eff}, \mathrm{i}}$ & $\mathrm{C}_{\mathrm{n}}(\mathrm{M})$ & $\mathrm{C}_{\mathrm{n}} / \mathrm{C}_{\mathrm{o}}$ & $\mathrm{w}_{\mathrm{eff}, \mathrm{i}}$ \\
\hline 0 & 0.786 & 1.000 & -- & 0.275 & 1.000 & -- & 0.093 & 1.000 & -- & 0.326 & 1.000 & -- & 3.580 & 1.000 & -- \\
\hline 3 & 0.706 & 0.898 & 0.79 & 0.247 & 0.898 & 0.79 & 0.083 & 0.897 & 0.80 & 0.307 & 0.942 & 0.44 & 3.490 & 0.975 & 0.19 \\
\hline 6 & 0.610 & 0.776 & 1.08 & 0.213 & 0.773 & 1.11 & 0.073 & 0.792 & 0.92 & 0.259 & 0.797 & 1.25 & 2.870 & 0.802 & 1.46 \\
\hline 9 & 0.535 & 0.680 & 0.97 & 0.187 & 0.681 & 0.94 & 0.063 & 0.680 & 1.13 & 0.229 & 0.702 & 0.93 & 2.550 & 0.712 & 0.87 \\
\hline 12 & 0.464 & 0.591 & 1.04 & 0.162 & 0.587 & 1.09 & 0.055 & 0.591 & 1.04 & 0.198 & 0.608 & 1.07 & 2.220 & 0.620 & 1.02 \\
\hline 15 & 0.426 & 0.542 & 0.63 & 0.143 & 0.520 & 0.90 & 0.050 & 0.541 & 0.64 & 0.173 & 0.532 & 0.98 & 2.040 & 0.570 & 0.62 \\
\hline 19 & 0.334 & 0.425 & 1.35 & 0.115 & 0.417 & 1.22 & 0.040 & 0.434 & 1.23 & 0.138 & 0.424 & 1.25 & 1.600 & 0.447 & 1.35 \\
\hline 24 & 0.292 & 0.372 & 0.59 & 0.091 & 0.331 & 1.02 & 0.033 & 0.351 & 0.94 & 0.109 & 0.335 & 1.04 & 1.340 & 0.374 & 0.78 \\
\hline 30 & 0.218 & 0.277 & 1.09 & 0.067 & 0.242 & 1.16 & 0.024 & 0.259 & 1.12 & 0.081 & 0.249 & 1.10 & 1.050 & 0.293 & 0.90 \\
\hline 37 & 0.160 & 0.204 & 0.97 & 0.048 & 0.175 & 1.03 & 0.018 & 0.191 & 0.97 & 0.062 & 0.191 & 0.84 & 0.790 & 0.221 & 0.90 \\
\hline 43 & 0.120 & 0.153 & 1.07 & 0.036 & 0.131 & 1.08 & 0.013 & 0.145 & 1.03 & 0.049 & 0.150 & 0.89 & 0.580 & 0.162 & 1.15 \\
\hline 49 & 0.091 & 0.116 & 1.05 & 0.028 & 0.100 & 1.01 & 0.010 & 0.112 & 0.94 & 0.037 & 0.115 & 1.01 & 0.470 & 0.131 & 0.78 \\
\hline 55 & 0.065 & 0.083 & 1.27 & 0.020 & 0.073 & 1.18 & 0.008 & 0.082 & 1.21 & 0.026 & 0.080 & 1.36 & 0.310 & 0.087 & 1.58 \\
\hline 61 & 0.050 & 0.063 & 1.03 & 0.016 & 0.056 & 0.99 & 0.006 & 0.064 & 0.94 & 0.020 & 0.062 & 0.94 & 0.280 & 0.078 & 0.38 \\
\hline 67 & 0.038 & 0.048 & 1.03 & 0.012 & 0.044 & 0.94 & 0.005 & 0.049 & 1.01 & 0.015 & 0.046 & 1.16 & 0.220 & 0.061 & 0.91 \\
\hline 73 & 0.029 & 0.036 & 1.04 & 0.009 & 0.034 & 0.97 & 0.003 & 0.037 & 1.00 & 0.012 & 0.036 & 0.92 & 0.160 & 0.045 & 1.21 \\
\hline 79 & 0.022 & 0.028 & 1.00 & 0.007 & 0.027 & 0.91 & 0.003 & 0.028 & 1.03 & 0.009 & 0.027 & 1.08 & 0.120 & 0.034 & 1.09 \\
\hline 85 & 0.017 & 0.022 & 0.93 & 0.006 & 0.021 & 0.86 & 0.002 & 0.022 & 0.90 & 0.007 & 0.022 & 0.78 & 0.100 & 0.028 & 0.68 \\
\hline 90 & 0.014 & 0.018 & 0.97 & 0.005 & 0.018 & 0.77 & 0.002 & 0.018 & 0.96 & 0.005 & 0.015 & 1.62 & 0.080 & 0.022 & 1.01 \\
\hline 95 & 0.011 & 0.014 & 0.92 & 0.004 & 0.015 & 0.85 & 0.001 & 0.015 & 0.95 & 0.005 & 0.016 & -0.24 & 0.070 & 0.020 & 0.59 \\
\hline 100 & 0.010 & 0.012 & 0.69 & 0.004 & 0.013 & 0.63 & 0.001 & 0.012 & 0.77 & 0.004 & 0.012 & 1.22 & 0.070 & 0.020 & 0.00 \\
\hline RL & 0.001 & & & 0.001 & & & 0.0002 & & & 0.003 & & & 0.100 & & \\
\hline
\end{tabular}

(a) The reporting limit (RL) as defined by SwRI is an achievable concentration they determine on a daily basis. The criterion they use is that the RL must be greater than or equal to the calculated minimum detection limit (MDL)/instrument detection limit (IDL). They do not apply a specific factor to MDL/IDLs for determining the RL since these can change every time a new MDL/IDL study is performed. For techniques that use a calibration curve (total organic carbon $[\mathrm{TOC}]$ and $\mathrm{IC})$, the RL is equal to the lowest calibration standard. 
Table 5.3. Concentration and Incremental Wash Efficiency for Partially Soluble Analytes Measured During the Integrated Test A Post-Caustic-Leach Wash. TDS was not measured for the steps where there are blank entries. ${ }^{\text {(a) }}$ The value given in the last row labeled "RL" is the reporting limit for each analyte.

\begin{tabular}{|c|c|c|c|c|c|c|c|c|c|c|c|c|}
\hline \multirow{2}{*}{$\begin{array}{l}\text { Wash } \\
\text { Step }\end{array}$} & \multicolumn{3}{|c|}{ Sodium } & \multicolumn{3}{|c|}{ Phosphate } & \multicolumn{3}{|c|}{ Oxalate } & \multicolumn{3}{|c|}{ TDS } \\
\hline & $\mathrm{C}_{\mathrm{n}}(\mathrm{M})$ & $\mathrm{C}_{\mathrm{n}} / \mathrm{C}_{\mathrm{o}}$ & $\mathrm{w}_{\mathrm{eff}, \mathrm{i}}$ & $\mathrm{C}_{\mathrm{n}}(\mathrm{M})$ & $\mathrm{C}_{\mathrm{n}} / \mathrm{C}_{\mathrm{o}}$ & $\mathrm{W}_{\mathrm{eff}, \mathrm{i}}$ & $\mathrm{C}_{\mathrm{n}}(\mathrm{M})$ & $\mathrm{C}_{\mathrm{n}} / \mathrm{C}_{\mathrm{o}}$ & $\mathrm{w}_{\mathrm{eff}, \mathrm{i}}$ & $\mathrm{C}_{\mathrm{n}}(\mathrm{kg} / \mathrm{L})$ & $\mathrm{C}_{\mathrm{n}} / \mathrm{C}_{\mathrm{o}}$ & $\mathrm{W}_{\mathrm{eff}, \mathrm{i}}$ \\
\hline 0 & 5.884 & 1.000 & -- & 0.026 & 1.000 & -- & 0.004 & 1.000 & -- & 0.342 & 1.000 & -- \\
\hline 3 & 5.401 & 0.918 & 0.63 & 0.033 & 1.273 & -- & 0.005 & 1.376 & -- & -- & -- & -- \\
\hline 6 & 4.614 & 0.784 & 1.17 & 0.038 & 1.439 & -- & 0.008 & 2.016 & -- & 0.274 & 0.802 & 0.81 \\
\hline 9 & 4.016 & 0.682 & 1.03 & 0.044 & 1.678 & -- & 0.010 & 2.622 & -- & -- & -- & -- \\
\hline 12 & 3.679 & 0.625 & 0.64 & 0.050 & 1.891 & -- & 0.014 & 3.486 & -- & 0.218 & 0.636 & 0.85 \\
\hline 24 & 2.339 & 0.397 & 0.78 & 0.096 & 3.659 & -- & 0.031 & 8.002 & -- & -- & -- & -- \\
\hline 30 & 1.814 & 0.308 & 0.94 & 0.086 & 3.268 & 0.41 & 0.044 & 11.215 & -- & 0.110 & 0.322 & 0.78 \\
\hline 37 & 1.437 & 0.244 & 0.74 & 0.063 & 2.419 & 0.96 & 0.062 & 15.738 & -- & -- & -- & -- \\
\hline 43 & 1.166 & 0.198 & 0.77 & 0.048 & 1.847 & 1.00 & 0.082 & 20.767 & -- & 0.070 & 0.204 & 0.78 \\
\hline 49 & 0.964 & 0.164 & 0.71 & 0.037 & 1.418 & 0.99 & 0.106 & 27.075 & -- & -- & -- & -- \\
\hline 79 & 0.468 & 0.080 & 1.01 & 0.009 & 0.361 & 0.99 & 0.141 & 35.886 & 1.09 & 0.031 & 0.090 & 0.58 \\
\hline 85 & 0.373 & 0.063 & 0.86 & 0.007 & 0.278 & 0.99 & 0.110 & 28.032 & 0.93 & -- & -- & -- \\
\hline 90 & 0.303 & 0.051 & 0.94 & 0.006 & 0.231 & 0.83 & 0.088 & 22.512 & 0.99 & 0.019 & 0.056 & 0.97 \\
\hline 95 & 0.246 & 0.042 & 0.93 & 0.005 & 0.189 & 0.90 & 0.070 & 17.886 & 1.03 & -- & -- & -- \\
\hline 100 & 0.203 & 0.034 & 0.86 & 0.004 & 0.156 & 0.86 & 0.057 & 14.505 & 0.93 & 0.012 & 0.036 & 1.00 \\
\hline $\mathrm{RL}$ & 0.0136 & & & 0.0007 & & & 0.0046 & & & N/A & & \\
\hline
\end{tabular}

(a) The wash efficiencies for phosphate and oxalate are not recorded during the earlier parts of the wash because their sodium salts are still dissolving, and the wash efficiency is not, by definition, meaningful for phase-changing species. 
Table 5.4. Concentration Data and Incremental Wash Efficiency for Fully Soluble Analytes Measured During the Integrated Test B Post-Caustic-Leach Wash. The value given in the last row labeled "RL" is the reporting limit for each analyte.

\begin{tabular}{|c|c|c|c|c|c|c|c|c|c|c|c|c|c|c|c|}
\hline \multirow{2}{*}{$\begin{array}{l}\text { Wash } \\
\text { Step }\end{array}$} & \multicolumn{3}{|c|}{ Nitrate } & \multicolumn{3}{|c|}{ Nitrite } & \multicolumn{3}{|c|}{ Sulfate } & \multicolumn{3}{|c|}{ Aluminum } & \multicolumn{3}{|c|}{ Free $\mathrm{OH}$} \\
\hline & $\mathrm{C}_{\mathrm{n}}(\mathrm{M})$ & $\mathrm{C}_{\mathrm{n}} / \mathrm{C}_{\mathrm{o}}$ & $\mathrm{w}_{\mathrm{eff}, \mathrm{i}}$ & $\mathrm{C}_{\mathrm{n}}(\mathrm{M})$ & $\mathrm{C}_{\mathrm{n}} / \mathrm{C}_{\mathrm{o}}$ & $\mathrm{w}_{\mathrm{eff}, \mathrm{i}}$ & $\mathrm{C}_{\mathrm{n}}(\mathrm{M})$ & $\mathrm{C}_{\mathrm{n}} / \mathrm{C}_{\mathrm{o}}$ & $\mathrm{w}_{\mathrm{eff}, \mathrm{i}}$ & $\mathrm{C}_{\mathrm{n}}(\mathrm{M})$ & $\mathrm{C}_{\mathrm{n}} / \mathrm{C}_{\mathrm{o}}$ & $\mathrm{w}_{\mathrm{eff}, \mathrm{i}}$ & $\mathrm{C}_{\mathrm{n}}(\mathrm{M})$ & $\mathrm{C}_{\mathrm{n}} / \mathrm{C}_{\mathrm{o}}$ & $\mathrm{w}_{\text {eff,i }}$ \\
\hline 0 & 0.686 & 1.000 & -- & 0.236 & 1.000 & -- & 0.085 & 1.000 & -- & 0.867 & 1.000 & -- & 5.550 & 1.000 & -- \\
\hline 3 & 0.551 & 0.804 & 0.95 & 0.201 & 0.851 & 0.70 & 0.069 & 0.810 & 0.92 & 0.688 & 0.793 & 1.01 & 4.270 & 0.769 & 1.16 \\
\hline 6 & 0.431 & 0.629 & 1.07 & 0.159 & 0.673 & 1.02 & 0.054 & 0.631 & 1.09 & 0.535 & 0.616 & 1.10 & 3.410 & 0.614 & 0.98 \\
\hline 9 & 0.343 & 0.500 & 1.00 & 0.123 & 0.522 & 1.10 & 0.043 & 0.506 & 0.96 & 0.421 & 0.485 & 1.04 & 2.810 & 0.506 & 0.83 \\
\hline 12 & 0.294 & 0.428 & 0.65 & 0.096 & 0.407 & 1.08 & 0.034 & 0.401 & 1.00 & 0.327 & 0.377 & 1.09 & 2.190 & 0.395 & 1.08 \\
\hline 15 & 0.229 & 0.334 & 1.07 & 0.072 & 0.307 & 1.21 & 0.026 & 0.309 & 1.12 & 0.265 & 0.305 & 0.90 & 1.690 & 0.305 & 1.12 \\
\hline 18 & 0.178 & 0.260 & 1.07 & 0.056 & 0.236 & 1.13 & 0.020 & 0.241 & 1.07 & 0.203 & 0.235 & 1.13 & 1.280 & 0.231 & 1.20 \\
\hline 21 & 0.142 & 0.207 & 0.97 & 0.044 & 0.188 & 0.98 & 0.016 & 0.193 & 0.94 & 0.165 & 0.191 & 0.88 & 1.060 & 0.191 & 0.80 \\
\hline 24 & 0.108 & 0.157 & 1.18 & 0.034 & 0.144 & 1.13 & 0.013 & 0.150 & 1.07 & 0.125 & 0.144 & 1.20 & 0.790 & 0.142 & 1.26 \\
\hline 27 & 0.084 & 0.122 & 1.09 & 0.026 & 0.112 & 1.09 & 0.010 & 0.118 & 1.04 & 0.100 & 0.115 & 0.96 & 0.640 & 0.115 & 0.89 \\
\hline 30 & 0.063 & 0.092 & 1.21 & 0.020 & 0.086 & 1.13 & 0.008 & 0.089 & 1.18 & 0.077 & 0.089 & 1.11 & 0.500 & 0.090 & 1.05 \\
\hline 33 & 0.051 & 0.074 & 0.93 & 0.016 & 0.069 & 0.90 & 0.006 & 0.073 & 0.84 & 0.066 & 0.076 & 0.66 & 0.410 & 0.074 & 0.84 \\
\hline 36 & 0.037 & 0.054 & 1.30 & 0.012 & 0.052 & 1.23 & 0.005 & 0.054 & 1.32 & 0.049 & 0.056 & 1.27 & 0.320 & 0.058 & 1.05 \\
\hline 39 & 0.030 & 0.044 & 0.94 & 0.010 & 0.043 & 0.81 & 0.004 & 0.043 & 0.95 & 0.040 & 0.046 & 0.82 & 0.250 & 0.045 & 1.05 \\
\hline 42 & 0.023 & 0.034 & 1.09 & 0.008 & 0.034 & 1.03 & 0.003 & 0.034 & 1.05 & 0.031 & 0.035 & 1.19 & 0.200 & 0.036 & 0.95 \\
\hline 45 & 0.019 & 0.027 & 0.93 & 0.006 & 0.028 & 0.85 & 0.002 & 0.026 & 1.09 & 0.026 & 0.029 & 0.75 & 0.150 & 0.027 & 1.23 \\
\hline 48 & 0.014 & 0.021 & 1.06 & 0.005 & 0.022 & 0.89 & 0.002 & 0.021 & 0.97 & 0.020 & 0.023 & 1.07 & 0.140 & 0.025 & 0.29 \\
\hline 51 & 0.012 & 0.017 & 0.83 & 0.004 & 0.018 & 0.81 & 0.001 & 0.017 & 0.88 & 0.016 & 0.019 & 0.88 & 0.120 & 0.022 & 0.65 \\
\hline 52 & 0.011 & 0.016 & 0.74 & 0.004 & 0.018 & 0.63 & 0.001 & 0.016 & 0.92 & 0.015 & 0.017 & 1.13 & 0.110 & 0.020 & 1.11 \\
\hline $\mathrm{RL}$ & 0.001 & & & 0.001 & & & 0.0002 & & & 0.0001 & & & 0.100 & & \\
\hline
\end{tabular}


Table 5.5. Concentration Data and Incremental Wash Efficiency for Partially Soluble Analytes Measured During the Integrated Test B Post-Caustic-Leach Wash. TDS was not measured for the steps where there are blank entries in the table. ${ }^{\text {(a) }}$ The value given in the last row labeled "RL" is the reporting limit for each analyte.

\begin{tabular}{|c|c|c|c|c|c|c|c|c|c|c|c|c|}
\hline \multirow{2}{*}{$\begin{array}{l}\text { Wash } \\
\text { Step }\end{array}$} & \multicolumn{3}{|c|}{ Sodium } & \multicolumn{3}{|c|}{ Phosphate } & \multicolumn{3}{|c|}{ Oxalate } & \multicolumn{3}{|c|}{ TDS } \\
\hline & $\mathrm{C}_{\mathrm{n}}(\mathrm{M})$ & $\mathrm{C}_{\mathrm{n}} / \mathrm{C}_{\mathrm{o}}$ & $\mathrm{w}_{\mathrm{eff}, \mathrm{i}}$ & $\mathrm{C}_{\mathrm{n}}(\mathrm{M})$ & $\mathrm{C}_{\mathrm{n}} / \mathrm{C}_{\mathrm{o}}$ & $\mathrm{w}_{\mathrm{eff}, \mathrm{i}}$ & $\mathrm{C}_{\mathrm{n}}(\mathrm{M})$ & $\mathrm{C}_{\mathrm{n}} / \mathrm{C}_{\mathrm{o}}$ & $\mathrm{w}_{\mathrm{eff}, \mathrm{i}}$ & $\mathrm{C}_{\mathrm{n}}(\mathrm{kg} / \mathrm{L})$ & $\mathrm{C}_{\mathrm{n}} / \mathrm{C}_{\mathrm{o}}$ & $\mathrm{w}_{\mathrm{eff}, \mathrm{i}}$ \\
\hline 0 & 7.744 & 1.000 & -- & 0.029 & 1.000 & -- & 0.001 & 1.000 & -- & 0.474 & 1.000 & -- \\
\hline 3 & 6.467 & 0.835 & 0.78 & 0.013 & 0.462 & 3.72 & 0.002 & 2.077 & -- & -- & -- & -- \\
\hline 6 & 4.935 & 0.637 & 1.18 & 0.020 & 0.697 & -- & 0.005 & 4.489 & -- & 0.305 & 0.644 & 0.96 \\
\hline 9 & 3.998 & 0.516 & 0.91 & 0.029 & 1.000 & -- & 0.008 & 8.129 & -- & -- & -- & -- \\
\hline 12 & 3.044 & 0.393 & 1.18 & 0.023 & 0.791 & 1.01 & 0.014 & 13.321 & -- & 0.191 & 0.403 & 1.01 \\
\hline 15 & 2.508 & 0.324 & 0.83 & 0.018 & 0.617 & 1.07 & 0.021 & 20.349 & -- & -- & -- & -- \\
\hline 18 & 1.938 & 0.250 & 1.11 & 0.015 & 0.502 & 0.88 & 0.031 & 30.150 & -- & 0.122 & 0.256 & 0.97 \\
\hline 21 & 1.612 & 0.208 & 0.78 & 0.012 & 0.403 & 0.93 & 0.042 & 40.540 & -- & -- & -- & -- \\
\hline 24 & 1.259 & 0.163 & 1.05 & 0.009 & 0.312 & 1.10 & 0.056 & 54.044 & -- & 0.081 & 0.170 & 0.87 \\
\hline 27 & 1.059 & 0.137 & 0.73 & 0.007 & 0.248 & 0.97 & 0.079 & 76.438 & -- & -- & -- & -- \\
\hline 30 & 0.865 & 0.112 & 0.85 & 0.005 & 0.189 & 1.17 & 0.091 & 88.209 & -- & 0.059 & 0.124 & 0.66 \\
\hline 33 & 0.811 & 0.105 & 0.27 & 0.004 & 0.149 & 1.00 & 0.106 & 102.177 & -- & -- & -- & -- \\
\hline 36 & 0.682 & 0.088 & 0.73 & 0.003 & 0.119 & 0.96 & 0.129 & 124.121 & -- & 0.047 & 0.100 & 0.45 \\
\hline 39 & 0.653 & 0.084 & 0.18 & 0.003 & 0.096 & 0.92 & 0.145 & 139.624 & -- & -- & -- & -- \\
\hline 42 & 0.583 & 0.075 & 0.47 & 0.002 & 0.076 & 0.96 & 0.182 & 175.371 & -- & 0.041 & 0.087 & 0.28 \\
\hline 45 & 0.594 & 0.077 & -0.08 & 0.002 & 0.065 & 0.69 & 0.188 & 181.407 & -- & -- & -- & -- \\
\hline 48 & 0.471 & 0.061 & 0.99 & 0.001 & 0.048 & 1.25 & 0.153 & 147.883 & 0.86 & 0.032 & 0.067 & 0.54 \\
\hline 51 & 0.378 & 0.049 & 0.94 & 0.001 & 0.039 & 0.86 & 0.123 & 118.916 & 0.92 & -- & -- & -- \\
\hline 52 & 0.347 & 0.045 & 1.07 & 0.001 & 0.037 & 0.90 & 0.113 & 109.549 & 1.05 & 0.024 & 0.050 & 0.93 \\
\hline $\mathrm{RL}$ & 0.0137 & & & 0.0006 & & & 0.0045 & & & N/A & & \\
\hline
\end{tabular}

(a) The wash efficiencies for phosphate and oxalate are not recorded during the earlier parts of the wash because their sodium salts are still dissolving, and the wash efficiency is not, by definition, meaningful for phase-changing species. 


\subsection{Post-Oxidative-Leach Wash Tests}

As described for the post-caustic-leach wash case, the best-choice analytes for determining wash efficiency were those analytes that begin and remain fully dissolved throughout the entire washing procedure and are well above measurement detection limits.

For the post-oxidative-leach wash, the fully dissolved analytes of interest are dissolved chromium and oxalate. All other originally considered analytes, including sodium, manganese, nitrate, and TDS, show clear deviations from the expected linear behavior on a semi-log plot and are therefore unsuitable for use in monitoring wash efficiency. See more discussion in Section 6.0. For example, sodium $\mathrm{C}_{\mathrm{n}} / \mathrm{C}_{\mathrm{o}}$ behavior shows significant curvature, likely explained by the expected asymptotic approach to $0.01 \mathrm{M}$, the IW concentration. Manganese shows large sections below the detection limit. Nitrate shows a large curvature in the $\mathrm{C}_{\mathrm{n}} / \mathrm{C}_{\mathrm{o}}$ curve towards the end of the washing steps with the reason not clear, though likely related to approaching the reporting limit near the end of the wash, or $\sim 4 \times \mathrm{RL}$ after step 63 . In addition, other analytes, such as aluminum, phosphate, sulfate, and nitrite, are at low concentrations, all within 10× of the reporting limit for most or all of the wash steps, and for carbonate, there was little Raman data obtained during the post-oxidative wash.

Table 5.6 summarizes the overall washing efficiencies for the species of interest, chromium and oxalate, using the weighted least squares method, in each test for the post-oxidative-leach washes. An average of the two overall wash efficiencies is calculated and presented to provide a single-value best-estimate of wash efficiency for the entire process. See the discussion of this table and data in Section 6.0.

Figure 5.6 through Figure 5.10 are plots of the incremental method washing efficiencies for the post-oxidative-leach wash for all analytes. These figures include the two fully dissolved analytes, chromium and oxalate, as well as those requested, but not included, in the overall washing efficiency: sodium, nitrate, and TDS. These plots of incremental wash efficiency provide a measure of wash performance throughout the wash process. The incremental washing efficiency is plotted versus the IW batch number. Each plot also shows the semi-log of the ratio of the measured concentration at each step to the initial measured concentration. The semi-log view provides two benefits:

1) True log-linearity should result if the analyte is subject to ideal mixing. The expected ideal concentration ratio is provided for reference; by definition, the ideal behavior is when the wash efficiency is equal to 1 in Equation 4.3. So any deviation from log-linearity may indicate slow dissolution or precipitation of analytes, an approach to the measurement detection limit, or other concentration behavior problems.

2) The semi-log view provides greater detail of concentration behavior as the end of washing is approached.

All wash-step analyte concentrations, $\mathbf{C}_{\mathbf{n}} / \mathbf{C}_{\mathbf{0}}$ ratios, and washing efficiency data for $\mathrm{Cr}$, nitrate, sodium, oxalate, and TDS are shown in Table 5.7 and Table 5.8 for the post-oxidative-leach wash. 
Table 5.6. Wash Efficiency for Completely Soluble Analytes During Post-Oxidative-Leach Washing as Calculated Using the Weighted Least Squares Method of Equation 4.7

\begin{tabular}{ccc}
\hline Analyte & $\begin{array}{c}\text { Integrated } \\
\text { Test A }\end{array}$ & $\begin{array}{c}\text { Integrated } \\
\text { Test B }\end{array}$ \\
\hline $\mathrm{Cr}$ & $0.98 \pm 0.02$ & $1.01 \pm 0.02$ \\
Oxalate $^{(\mathrm{a})}$ & $1.00 \pm 0.04$ & $0.99 \pm 0.03$ \\
Average & $0.99 \pm 0.02$ & $1.00 \pm 0.02$ \\
\hline
\end{tabular}

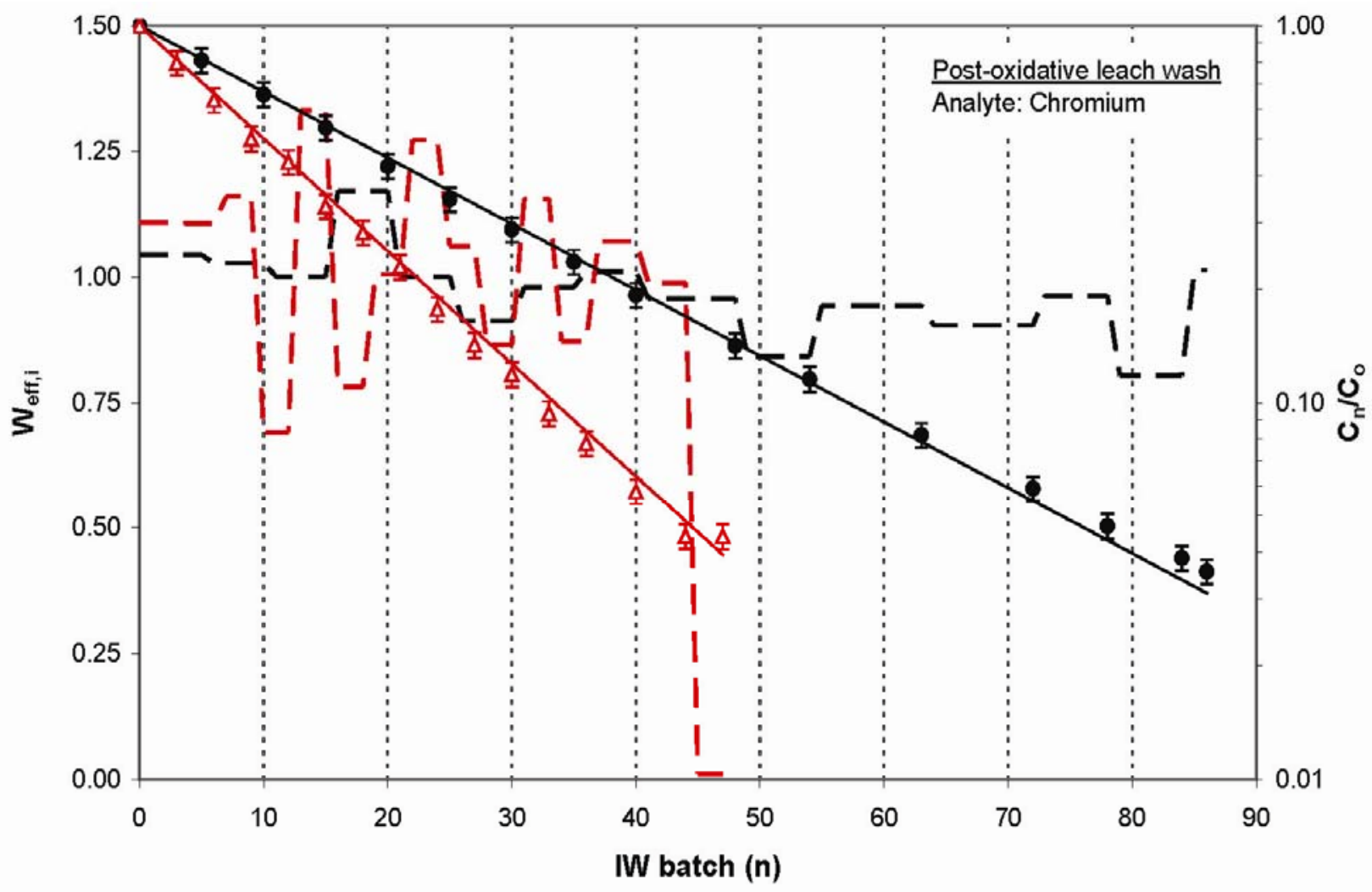

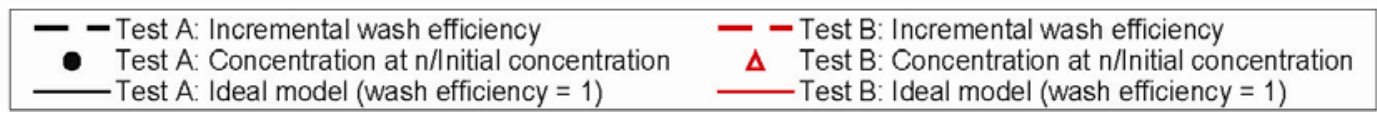

Figure 5.6. Incremental Wash Efficiency (left y-axis) and Concentration Ratio (right y-axis) for Chromium During Post-Oxidative-Leach Washing, Comparing Integrated Test A and Integrated Test B. The sample data, by ICP, reflects 86 washes in Integrated Test A and 47 washes in Integrated Test $B . \log C_{n} / C_{o}$ is plotted to show concentration behavior.

(a) The oxalate washing efficiency values are based on a modified data set. As can be seen in Figure 5.8 as well as Tables 5.7 and 5.8, the concentration behavior and incremental washing efficiency values show that the final one or two wash data points are anomalous and clearly off-trend due to the concentration approaching the measurement detection limit, or reporting limit. The balance of the oxalate concentration behavior curves show excellent log-linearity, resulting in the conclusion that the oxalate data are very well behaved except for the final two low-concentration data points. Therefore, the final two data points for both oxalate data sets were removed and the washing efficiency recalculated based on the revised data set. 


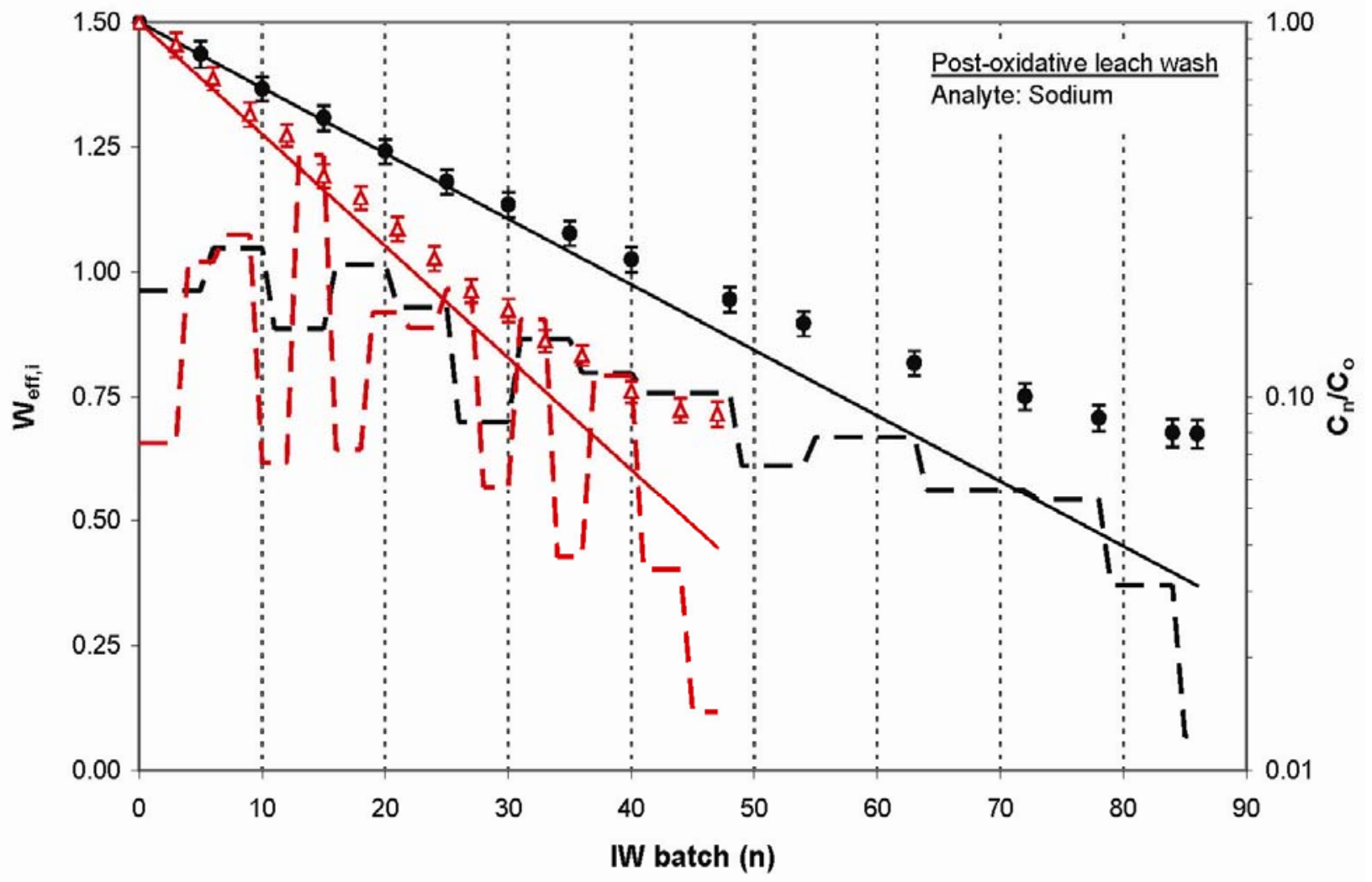

$\begin{array}{cc}\text { - Test A: Incremental wash efficiency } & - \text { Test B: Incremental wash efficiency } \\ \text { Test A: Concentration at n/Initial concentration } & \Delta \quad \text { Test B: Concentration at nVnitial concentration } \\ \text { - Test A: Ideal model (wash efficiency = 1) } & \text {-Test B: Ideal model (wash efficiency = 1) }\end{array}$

Figure 5.7. Incremental Wash Efficiency (left y-axis) and Concentration Ratio (right y-axis) for Sodium During Post-Oxidative-Leach Washing, Comparing Integrated Test A and Integrated Test B. The sample data, by ICP, reflects 86 washes in Integrated Test A and 47 washes in Integrated Test $B . \log C_{n} / C_{o}$ is plotted to show concentration behavior. 


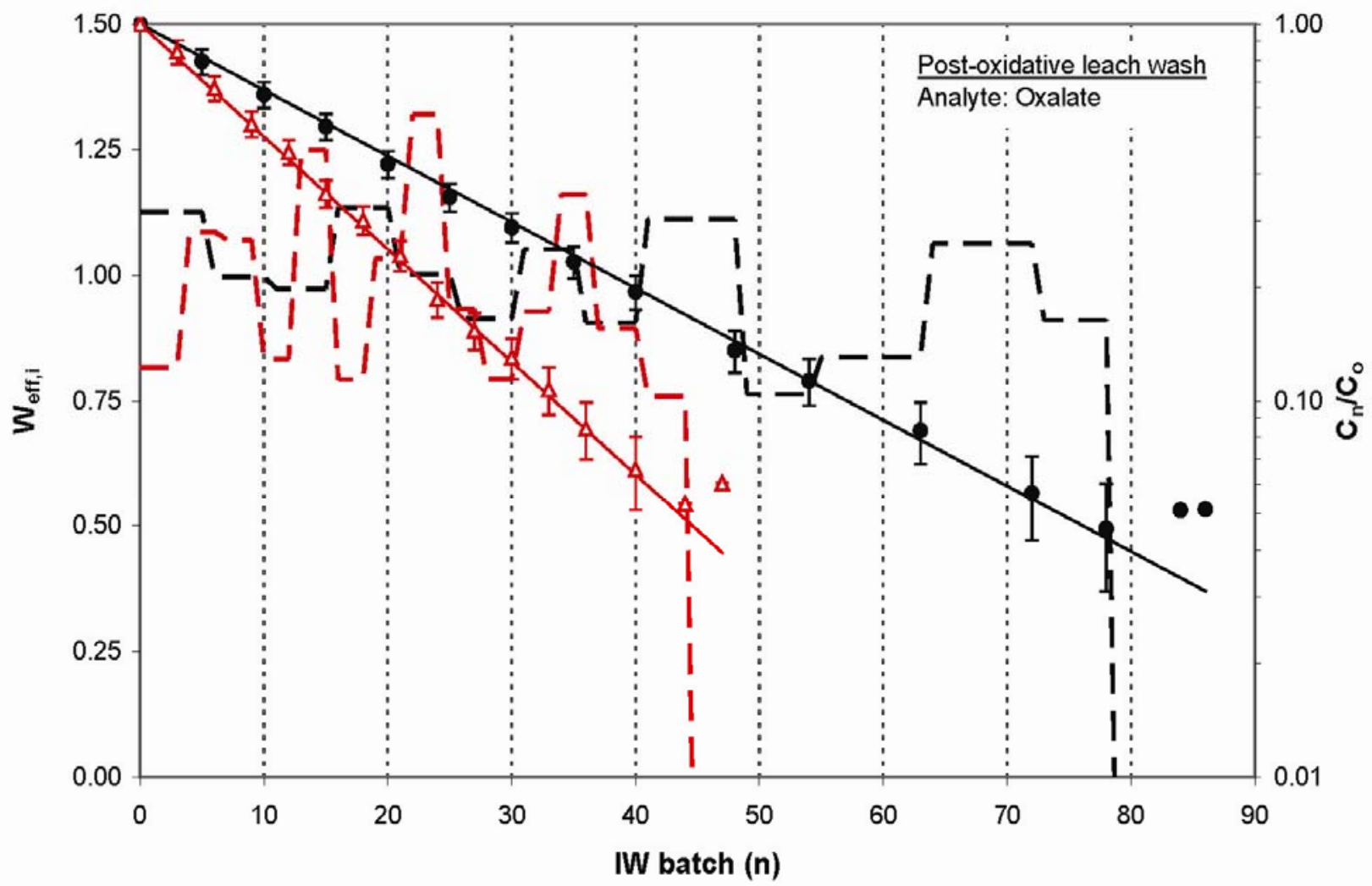

$\begin{array}{cc}\text { - Test A: Incremental wash efficiency } & - \text { Test B: Incremental wash efficiency } \\ \text { Test A: Concentration at n/Initial concentration } & \Delta \quad \text { Test B: Concentration at } n / \text { Initial concentration } \\ \text {-Test A: Ideal model (wash efficiency = 1) } & \end{array}$

Figure 5.8. Incremental Wash Efficiency (left y-axis) and Concentration Ratio (right y-axis) for Oxalate During Post-Oxidative-Leach Washing, Comparing Integrated Test A and Integrated Test B. The sample data, by IC, reflects 86 washes in Integrated Test A and 47 washes in Integrated Test B. $\log C_{n} / C_{o}$ is plotted to show concentration behavior. 


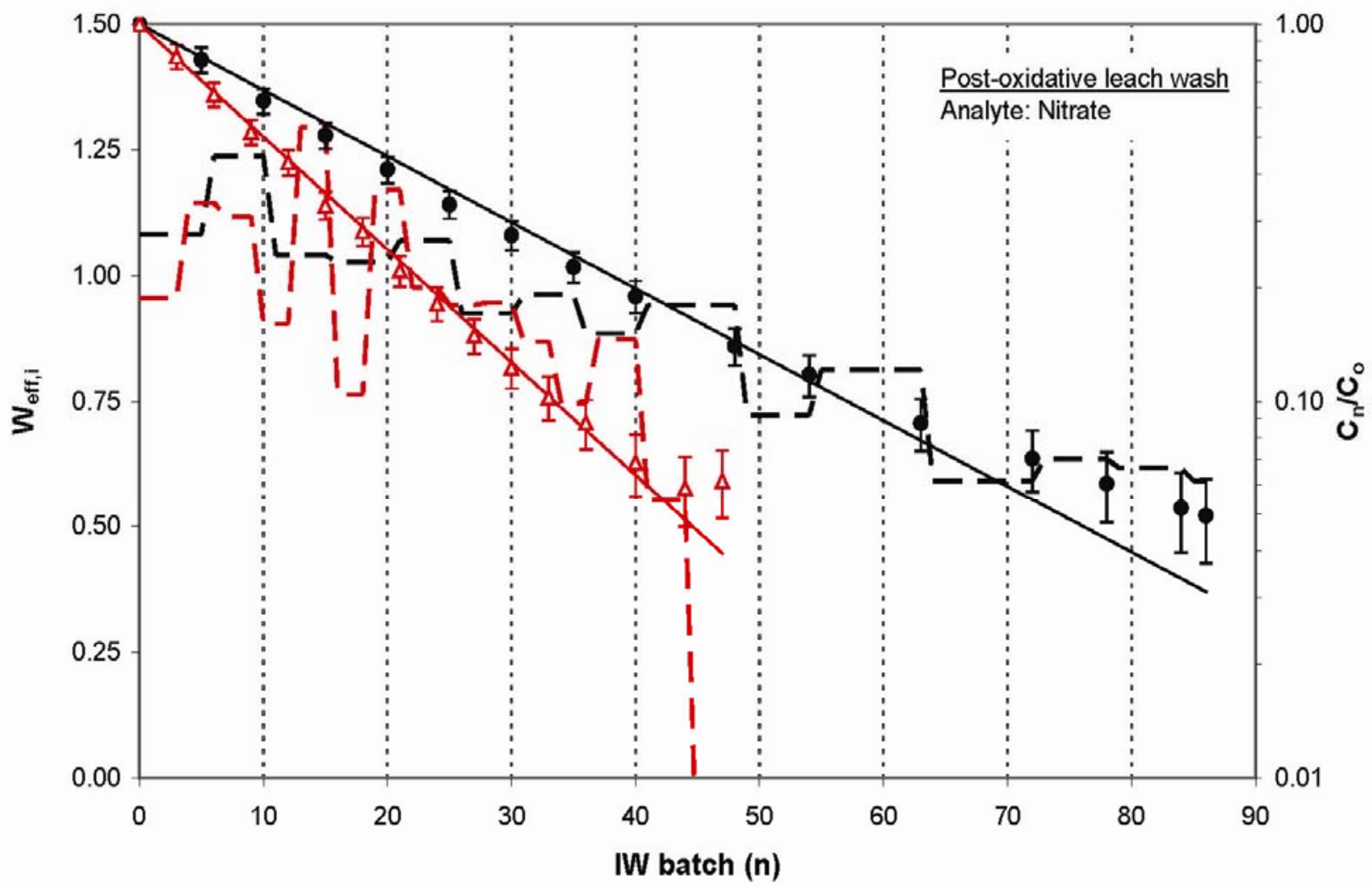

$\begin{array}{cc}\text { - Test A: Incremental wash efficiency } & - \text { Test B: Incremental wash efficiency } \\ \text { Test A: Concentration at n/Initial concentration } & \Delta \quad \text { Test B: Concentration at } n / \text { Initial concentration } \\ \text { - Test A: Ideal model (wash efficiency = 1) } & \text { Test B: Ideal model (wash efficiency = 1) }\end{array}$

Figure 5.9. Incremental Wash Efficiency (left y-axis) and Concentration Ratio (right y-axis) for Nitrate During Post-Oxidative-Leach Washing, Comparing Integrated Test A and Integrated Test B. The sample data, by IC, reflects 86 washes in Integrated Test A and 47 washes in Integrated Test $B . \log C_{n} / C_{o}$ is plotted to show concentration behavior. 


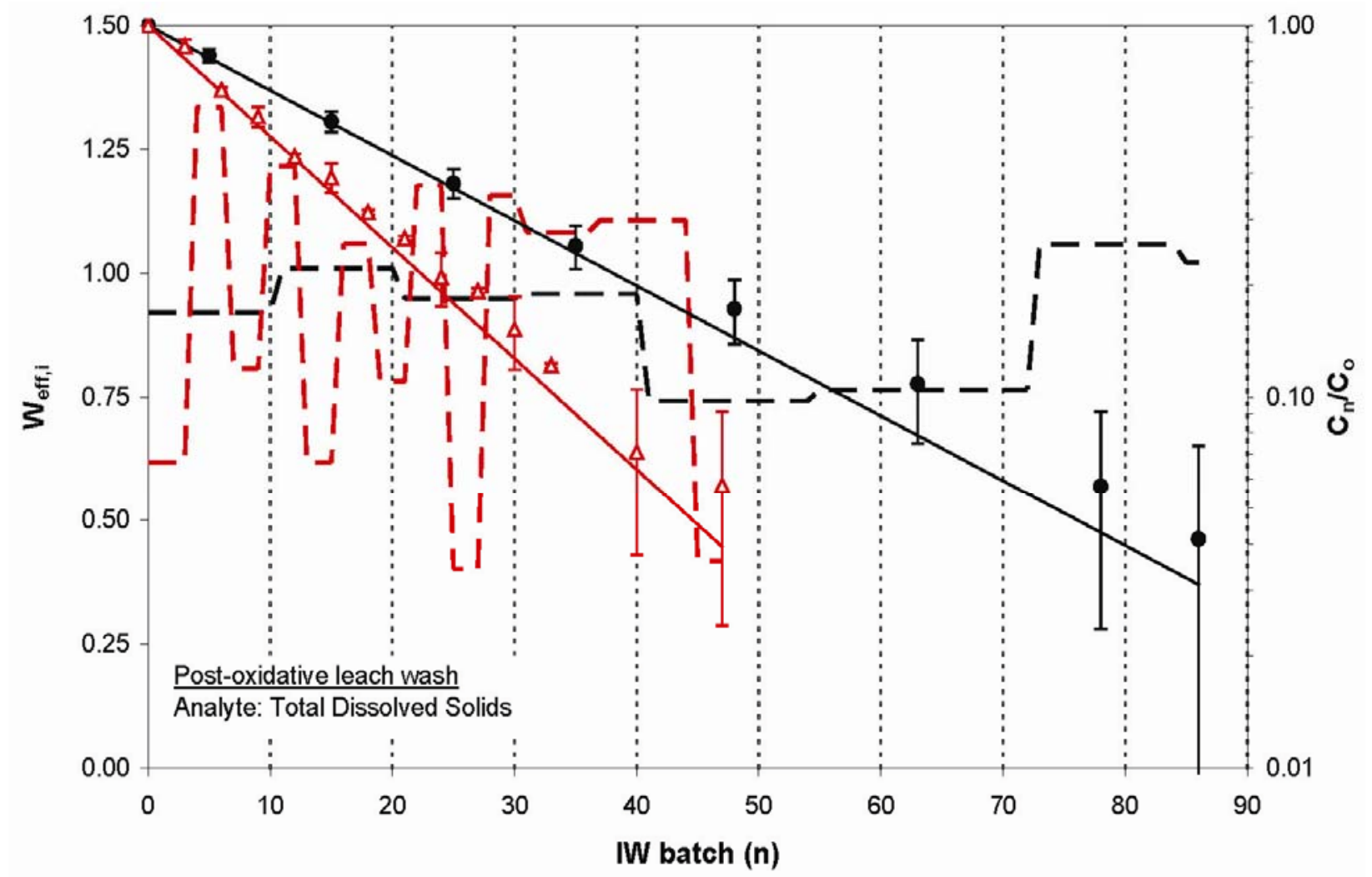

\begin{tabular}{|c|c|}
\hline - - Test A: incremental wash efficiency & - - Test B: incremental wash efficiency \\
\hline - Test A: Ideal model (wash efficiency = 1) & $\begin{array}{c}\Delta \quad \text { Test B: Concentration at } \mathrm{n} / \text { /nitial Concentration } \\
\end{array}$ \\
\hline
\end{tabular}

Figure 5.10. Incremental Wash Efficiency (left y-axis) and Concentration Ratio (right y-axis) for TDS During Post-Oxidative-Leach Washing. The sample data, by IC, reflects 86 washes in Integrated Test $A$ and 47 washes in Integrated Test $B$. $\log C_{n} / C_{o}$ is plotted to show concentration behavior. 
Table 5.7. Concentration Data and Incremental Wash Efficiency for Selected Analytes Measured During the Integrated Test A Post-Oxidative-Leach Wash. TDS was not measured for the steps where there are blank entries in the table. The value given in the last row labeled "RL" is the reporting limit for each analyte.

\begin{tabular}{|c|c|c|c|c|c|c|c|c|c|c|c|c|c|c|c|}
\hline \multirow{2}{*}{$\begin{array}{l}\text { Wash } \\
\text { Step }\end{array}$} & \multicolumn{3}{|c|}{ Nitrate } & \multicolumn{3}{|c|}{ Chromium } & \multicolumn{3}{|c|}{ Sodium } & \multicolumn{3}{|c|}{ Oxalate } & \multicolumn{3}{|c|}{ TDS } \\
\hline & $\mathrm{C}_{\mathrm{n}}(\mathrm{M})$ & $\mathrm{C}_{\mathrm{n}} / \mathrm{C}_{\mathrm{o}}$ & $\mathrm{w}_{\text {eff,i }}$ & $\mathrm{C}_{\mathrm{n}}(\mathrm{M})$ & $\mathrm{C}_{\mathrm{n}} / \mathrm{C}_{\mathrm{o}}$ & $\mathrm{w}_{\mathrm{eff}, \mathrm{i}}$ & $\mathrm{C}_{\mathrm{n}}(\mathrm{M})$ & $\mathrm{C}_{\mathrm{n}} / \mathrm{C}_{\mathrm{o}}$ & $\mathrm{w}_{\mathrm{eff}, \mathrm{i}}$ & $\mathrm{C}_{\mathrm{n}}(\mathrm{M})$ & $\mathrm{C}_{\mathrm{n}} / \mathrm{C}_{\mathrm{o}}$ & $\mathrm{w}_{\mathrm{eff}, \mathrm{i}}$ & $\mathrm{C}_{\mathrm{n}}(\mathrm{kg} / \mathrm{L})$ & $\mathrm{C}_{\mathrm{n}} / \mathrm{C}_{\mathrm{o}}$ & $\mathrm{w}_{\mathrm{eff}, \mathrm{i}}$ \\
\hline 0 & 0.059 & 1.000 & -- & 0.127 & 1.000 & -- & 0.440 & 1.000 & -- & 0.008 & 1.000 & -- & 0.033 & 1.000 & -- \\
\hline 5 & 0.047 & 0.803 & 1.08 & 0.103 & 0.809 & 1.04 & 0.362 & 0.822 & 0.96 & 0.006 & 0.796 & 1.13 & 0.027 & 0.829 & 0.92 \\
\hline 10 & 0.037 & 0.626 & 1.24 & 0.083 & 0.657 & 1.03 & 0.293 & 0.665 & 1.05 & 0.005 & 0.651 & 1.00 & -- & -- & -- \\
\hline 15 & 0.030 & 0.507 & 1.04 & 0.068 & 0.537 & 1.00 & 0.245 & 0.556 & 0.89 & 0.004 & 0.534 & 0.97 & 0.018 & 0.551 & 1.01 \\
\hline 20 & 0.024 & 0.412 & 1.03 & 0.054 & 0.424 & 1.17 & 0.199 & 0.453 & 1.01 & 0.003 & 0.425 & 1.13 & -- & -- & -- \\
\hline 25 & 0.020 & 0.332 & 1.07 & 0.044 & 0.346 & 1.00 & 0.165 & 0.375 & 0.93 & 0.003 & 0.347 & 1.00 & 0.012 & 0.376 & 0.95 \\
\hline 30 & 0.016 & 0.276 & 0.93 & 0.037 & 0.288 & 0.91 & 0.143 & 0.326 & 0.70 & 0.002 & 0.289 & 0.91 & -- & -- & -- \\
\hline 35 & 0.013 & 0.227 & 0.96 & 0.030 & 0.237 & 0.98 & 0.120 & 0.274 & 0.86 & 0.002 & 0.234 & 1.05 & 0.008 & 0.255 & 0.96 \\
\hline 40 & 0.011 & 0.190 & 0.89 & 0.024 & 0.193 & 1.01 & 0.102 & 0.233 & 0.80 & 0.002 & 0.195 & 0.91 & -- & -- & -- \\
\hline 48 & 0.008 & 0.140 & 0.94 & 0.018 & 0.142 & 0.96 & 0.080 & 0.182 & 0.76 & 0.001 & 0.136 & 1.11 & 0.006 & 0.173 & 0.74 \\
\hline 54 & 0.007 & 0.118 & 0.72 & 0.015 & 0.116 & 0.84 & 0.069 & 0.157 & 0.61 & 0.001 & 0.113 & 0.76 & -- & -- & -- \\
\hline 63 & 0.005 & 0.088 & 0.81 & 0.010 & 0.082 & 0.94 & 0.054 & 0.123 & 0.67 & 0.001 & 0.084 & 0.84 & 0.004 & 0.109 & 0.76 \\
\hline 72 & 0.004 & 0.071 & 0.59 & 0.008 & 0.059 & 0.90 & 0.044 & 0.100 & 0.56 & 0.0005 & 0.057 & 1.06 & -- & -- & -- \\
\hline 78 & 0.004 & 0.060 & 0.64 & 0.006 & 0.047 & 0.96 & 0.039 & 0.088 & 0.54 & 0.0004 & 0.046 & 0.91 & 0.002 & 0.057 & 1.06 \\
\hline 84 & 0.003 & 0.052 & 0.62 & 0.005 & 0.039 & 0.80 & 0.035 & 0.080 & 0.37 & 0.0004 & 0.051 & -0.45 & -- & -- & -- \\
\hline 86 & 0.003 & 0.050 & 0.59 & 0.005 & 0.036 & 1.01 & 0.035 & 0.080 & 0.07 & 0.0004 & 0.051 & -0.08 & 0.001 & 0.041 & 1.02 \\
\hline $\mathrm{RL}$ & 0.001 & & & 0.00002 & & & 0.003 & & & 0.0002 & & & N/A & & \\
\hline
\end{tabular}


Table 5.8. Concentration Data and Incremental Wash Efficiency for Selected Analytes Measured During the Integrated Test B Post-Oxidative-Leach Wash. TDS was not measured for the steps where there are blank entries in the table. The value given in the last row labeled "RL" is the reporting limit for each analyte.

\begin{tabular}{|c|c|c|c|c|c|c|c|c|c|c|c|c|c|c|c|}
\hline \multirow{2}{*}{$\begin{array}{l}\text { Wash } \\
\text { Step }\end{array}$} & \multicolumn{3}{|c|}{ Nitrate } & \multicolumn{3}{|c|}{ Chromium } & \multicolumn{3}{|c|}{ Sodium } & \multicolumn{3}{|c|}{ Oxalate } & \multicolumn{3}{|c|}{ TDS } \\
\hline & $C_{n}(M)$ & $\mathrm{C}_{\mathrm{n}} / \mathrm{C}_{\mathrm{o}}$ & $\mathrm{w}_{\mathrm{eff}, \mathrm{i}}$ & $\mathrm{C}_{\mathrm{n}}(\mathrm{M})$ & $\mathrm{C}_{\mathrm{n}} / \mathrm{C}_{\mathrm{o}}$ & $\mathrm{W}_{\mathrm{eff}, \mathrm{i}}$ & $C_{n}(M)$ & $\mathrm{C}_{\mathrm{n}} / \mathrm{C}_{\mathrm{o}}$ & $\mathrm{W}_{\mathrm{eff}, \mathrm{i}}$ & $\mathrm{C}_{\mathrm{n}}(\mathrm{M})$ & $\mathrm{C}_{\mathrm{n}} / \mathrm{C}_{\mathrm{o}}$ & $\mathrm{W}_{\mathrm{eff}, \mathrm{i}}$ & $\mathrm{C}_{\mathrm{n}}(\mathrm{kg} / \mathrm{L})$ & $\mathrm{C}_{\mathrm{n}} / \mathrm{C}_{\mathrm{o}}$ & $\mathrm{w}_{\mathrm{eff},}$ \\
\hline 0 & 0.064 & 1.000 & -- & 0.110 & 1.000 & -- & 0.460 & 1.000 & -- & 0.018 & 1.000 & -- & 0.034 & 1.000 & -- \\
\hline 3 & 0.053 & 0.821 & 0.96 & 0.087 & 0.797 & 1.11 & 0.402 & 0.872 & 0.66 & 0.016 & 0.844 & 0.82 & 0.030 & 0.879 & 0.62 \\
\hline 6 & 0.042 & 0.650 & 1.14 & 0.070 & 0.635 & 1.11 & 0.326 & 0.708 & 1.02 & 0.012 & 0.676 & 1.09 & 0.023 & 0.670 & 1.34 \\
\hline 9 & 0.033 & 0.518 & 1.12 & 0.055 & 0.502 & 1.16 & 0.262 & 0.568 & 1.07 & 0.010 & 0.543 & 1.07 & 0.020 & 0.568 & 0.81 \\
\hline 12 & 0.028 & 0.430 & 0.90 & 0.048 & 0.435 & 0.69 & 0.230 & 0.500 & 0.62 & 0.008 & 0.458 & 0.83 & 0.015 & 0.443 & 1.22 \\
\hline 15 & 0.021 & 0.330 & 1.29 & 0.036 & 0.332 & 1.33 & 0.179 & 0.389 & 1.23 & 0.007 & 0.355 & 1.25 & 0.013 & 0.390 & 0.62 \\
\hline 18 & 0.018 & 0.282 & 0.76 & 0.031 & 0.282 & 0.78 & 0.157 & 0.340 & 0.64 & 0.006 & 0.301 & 0.79 & 0.011 & 0.314 & 1.06 \\
\hline 21 & 0.014 & 0.222 & 1.17 & 0.025 & 0.230 & 1.01 & 0.130 & 0.282 & 0.92 & 0.004 & 0.244 & 1.03 & 0.009 & 0.267 & 0.78 \\
\hline 24 & 0.012 & 0.182 & 0.98 & 0.019 & 0.177 & 1.27 & 0.108 & 0.234 & 0.89 & 0.003 & 0.186 & 1.32 & 0.007 & 0.210 & 1.18 \\
\hline 27 & 0.010 & 0.150 & 0.94 & 0.016 & 0.142 & 1.06 & 0.088 & 0.192 & 0.97 & 0.003 & 0.154 & 0.93 & 0.007 & 0.193 & 0.40 \\
\hline 30 & 0.008 & 0.123 & 0.95 & 0.013 & 0.119 & 0.86 & 0.078 & 0.170 & 0.57 & 0.002 & 0.130 & 0.79 & 0.005 & 0.152 & 1.16 \\
\hline 33 & 0.007 & 0.103 & 0.87 & 0.010 & 0.094 & 1.16 & 0.065 & 0.141 & 0.90 & 0.002 & 0.107 & 0.93 & 0.004 & 0.122 & 1.08 \\
\hline 36 & 0.006 & 0.088 & 0.75 & 0.009 & 0.078 & 0.87 & 0.059 & 0.129 & 0.43 & 0.002 & 0.084 & 1.16 & -- & -- & -- \\
\hline 40 & 0.004 & 0.069 & 0.87 & 0.006 & 0.058 & 1.07 & 0.048 & 0.103 & 0.79 & 0.001 & 0.066 & 0.89 & 0.002 & 0.071 & 1.11 \\
\hline 44 & 0.004 & 0.059 & 0.55 & 0.005 & 0.044 & 0.99 & 0.042 & 0.092 & 0.40 & 0.001 & 0.053 & 0.76 & -- & -- & -- \\
\hline 47 & 0.004 & 0.061 & -0.20 & 0.005 & 0.044 & 0.01 & 0.041 & 0.090 & 0.12 & 0.001 & 0.060 & -0.58 & 0.002 & 0.058 & 0.42 \\
\hline RL & 0.001 & & & 0.0001 & & & 0.001 & & & 0.0002 & & & N/A & & \\
\hline
\end{tabular}




\subsection{Tracer Test Results}

\subsubsection{Introduction}

The primary objective of the tracer tests was to evaluate Vessel T02A for evidence of channeling between the recirculation loop return nozzle and the suction of Pump T42A. The presence of channeling could result in a "short circuit," thereby reducing the effectiveness of the mixing system. These data also provide an estimate of the time required for mixing and provides insight into the rate at which the wash solutions are blended with the slurry over a 1-hour time period. Results are presented here as supporting evidence of the washing results; more extensive analyses of the tracer tests will be reported later.

The chemical tracer used in these tests was $\mathrm{CsBr}$, with cesium measured by ICP-MS. The tracer was injected into the suction of recirculation Pump T42A when UFP-VSL-T02A had a prototypic volume of the slurry at target concentration. Although not recorded, the nominal time for the tracer injection was approximately $30 \mathrm{~s}$. The tracer concentrations in UFP-VSL-T02A and the filter-loop were monitored via sample collections for 1 hour.

Originally, the Test Plan called for two tracer tests to evaluate short-circuiting in Vessel T02A at the very beginning of the post-caustic-leach wash (i.e., when the slurry is $\sim 17-\mathrm{wt} \%$ UDS, and liquid viscosity is high): the first when the slurry level in Vessel T02A is low (i.e., when caustic leaching is conducted in Vessel T02A) and the second when the level in Vessel T02A is high (i.e., when caustic leaching is conducted in Vessel T01A). Difficulty in obtaining target mixing conditions necessitated that the tracer test be repeated for the high vessel level in Vessel T02A. The results of all three tests are presented in chronological order.

\subsubsection{Tracer Test 1}

Tracer Test 1 occurred during Integrated Test A: Vessel T01A/B caustic-leach test on 02/14/2009 21:26 to 22:26, Pacific Standard Time. The initial tracer solution contained $200 \mathrm{~g}$ of CsBr; based on the slurry volume during the test, the concentration of Cs after complete mixing in the system was estimated to be $109 \mathrm{ppm}$. The tank level in Vessel T02A during the test was 43.1 inches. The total slurry volume, including the filtration loop and PJM tubes, was $1004 \mathrm{~L}$ (265 gal). ${ }^{\text {(a) }}$

The slurry used in this test was the dewatered material from the caustic leaching process in Vessel T01A/B. The Bingham plastic rheological parameters were determined based on a sample taken 1 minute after the tracer was injected. The yield stress was found to be $2.7 \mathrm{~Pa}$, and the consistency was $1.5 \mathrm{cP}$. Both values are based on data obtained during the "down ramp" where the applied shear stress was decreasing.

With the exception of the filter-loop flow rate, the target mixing conditions were met. Spargers and steam-ring purge air were on at target values during this test. The PJM peak average nozzle velocity was $12.1 \mathrm{~m} / \mathrm{s}$ (target was $12 \pm 0.6 \mathrm{~m} / \mathrm{s}$ ), and the average stroke length was $83 \%$ (target was $80 \pm 5 \%$ ). All six PJMs were operational. During this test, the filter-loop flow rate was abnormal because of the presence

(a) Using a conversion factor of $0.26418 \mathrm{~L}$ per gal: $1004 \mathrm{~L} \times 0.26418 \mathrm{~L} / \mathrm{gal}=265.24$ gal. 
of entrained air and suspect data from FT-0635. (a) This is manifested as a deviation between the flowmeters FT-0623 and FT-0635, which on average was approximately $36 \mathrm{gpm}$. The actual filter-loop flow rate is difficult to determine (see Figure 5.11). Though the filter-loop is not precisely known, this test and the resultant tracer data were not adversely affected. Precise determination of the filter-loop rate would be important for more complex mixing models that were not used during analysis of the tracer tests.

The concentrations of the Cs tracer measured at the filtration loop before entry into Vessel T02A and from the outer-low sampling location in Vessel T02A are shown in Figure 5.12. The initial tracer concentration spiked to $\sim 300 \mathrm{ppm}$ in the filtration loop and decayed quickly towards the target tracer concentration of $100 \mathrm{ppm}$. The filtration loop and Vessel T02A samples were in agreement within the analytical uncertainty of the measurements at 4 minutes. They remained in agreement for the duration of the test, ending at $101 \mathrm{ppm}$. The concentration dropped slowly from approximately $110 \mathrm{ppm}$ to $101 \mathrm{ppm}$ over the final 56 minutes of the test, for an $8 \%$ decrease. These results suggest that the slurry was nearly completely mixed between 2 and 4 minutes, but there was a relatively small unmixed region that mixed over the course of the 1-hour test.

Since it was unknown if the target recirculation rate had been achieved for this test, it was performed again in between Integrated Tests B and D (see Tracer Test 3). The results of Tracer Test 1 are still relevant to the washing data because it was performed immediately before the start of the post-caustic-leach wash step in the Integrated Test A: Vessel T01A/B caustic-leach test; the mixing conditions present during the wash and Tracer Test 1 were very similar.

\subsubsection{Tracer Test 2}

Tracer Test 2 occurred during Integrated Test B on 03/19/2009 13:16 to 14:16 Pacific Daylight Time. The initial tracer solution contained $108 \mathrm{~g}$ of $\mathrm{CsBr}$; based on the slurry volume during the test, the concentration of Cs after complete mixing in the system was estimated to be $99.5 \mathrm{ppm}$. The tank level in Vessel T02A during the test was 14.9 inches. The total slurry volume, including the filtration loop and PJM tubes, was 553 L (146 gal). ${ }^{(b)}$

The slurry used in this test was the dewatered material from the caustic leaching process in Vessel T02A. The Bingham plastic rheological parameters were determined based on a sample taken 1 minute after the tracer was injected. The yield stress was found to be 7.6 Pa, and the consistency was $3.0 \mathrm{cP}$. Both values are based on data obtained during the "down ramp" where the applied shear stress was decreasing.

During this test, the mixing parameters were modified to minimize air entrainment in the slurry. The filter-loop flow rate was reduced to approximately $30 \mathrm{gpm}$ less than the target value of $109 \mathrm{gpm}$; see Figure 5.13. The spargers and the steam-ring purge air were not on during this test for the same reason. The PJM peak average nozzle velocity was $11.7 \mathrm{~m} / \mathrm{s}$ (target was $12 \pm 0.4 \mathrm{~m} / \mathrm{s}$ ), and the average stroke length was $70 \%$ (target was $80 \pm 5 \%$ ). The PJMs were operated in star mode.

(a) The flowmeter was damaged and provided low readings per NCR 42317.1.

(b) Using a conversion factor of $0.26418 \mathrm{~L}$ per gal: $553 \mathrm{~L} \times 0.26418 \mathrm{~L} / \mathrm{gal}=146.1 \mathrm{gal}$. 
The concentrations of the Cs tracer measured at the filtration loop before entry into Vessel T02A and from the outer-low sampling location in Vessel T02A are shown in Figure 5.14. There is not as drastic a spike in Cs concentration as was observed in Tracer Test 1. The Cs tracer reached a maximum of approximately $150 \mathrm{ppm}$, which occurred at the 2-minute sample time rather than the sample at 1 minute. Similar to Tracer Test 1, the filtration loop and Vessel T02A samples are in agreement within the analytical uncertainty at 4 minutes. The concentrations continued to follow each other for the duration of the test, ending at approximately $96 \mathrm{ppm}$. The concentration dropped slowly from $\sim 108 \mathrm{ppm}$ to $96 \mathrm{ppm}$ over the final 56 minutes of the test for a $10 \%$ decrease. These results suggest that the slurry was nearly completely mixed between 2 and 4 minutes, but there was a relatively small unmixed region that mixed over the course of the 1-hour test.

Tracer Test 1

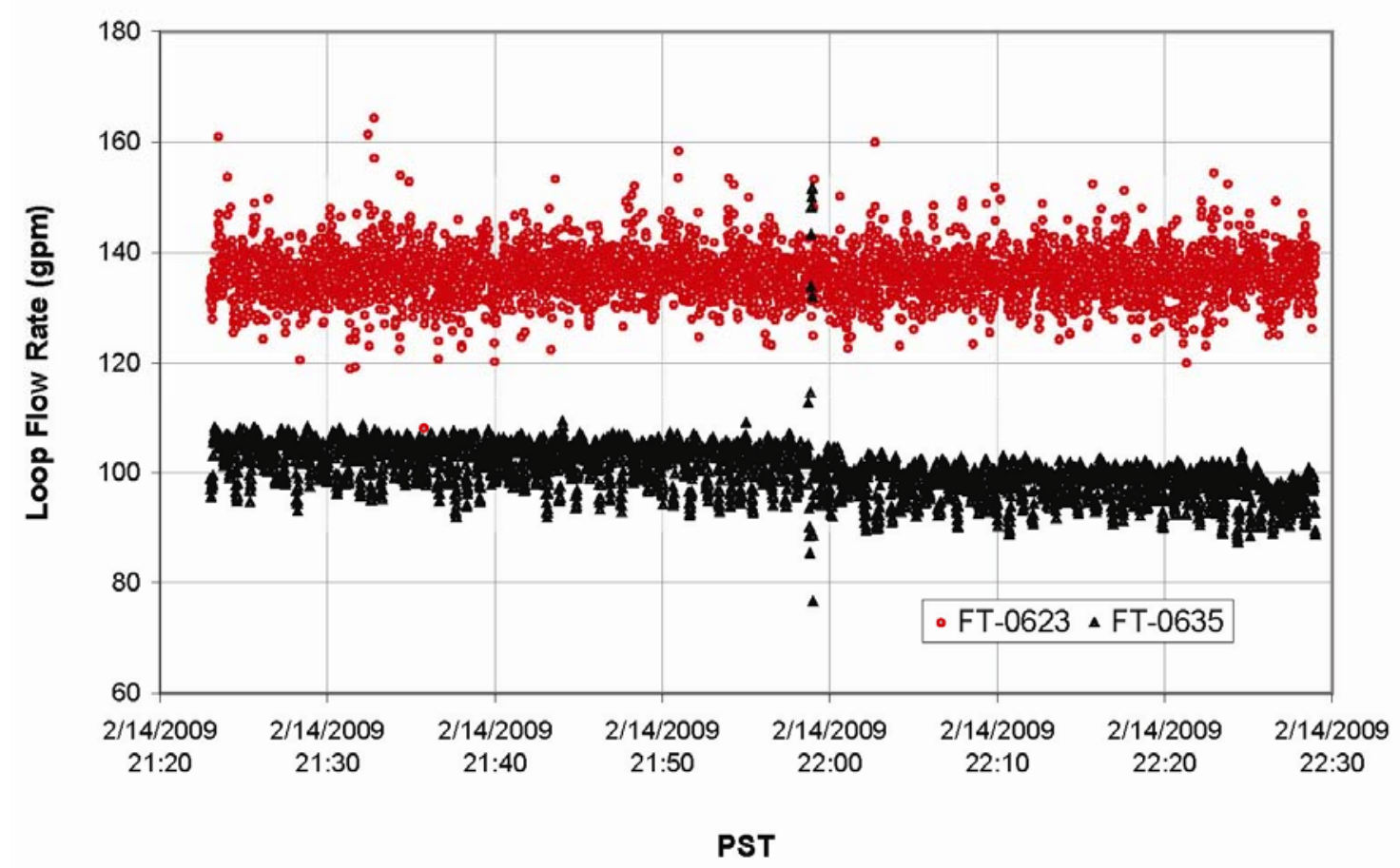

Figure 5.11. Loop Flow Rate During Tracer Test 1. FT-0623 precedes the pumps (red points), and FT-0635 is after the pumps (black points). Note that the flowmeter (FT-0635) was damaged and provided low readings per NCR 42402.1. 
Tracer Test 1: 02/14/09 21:26-22:26

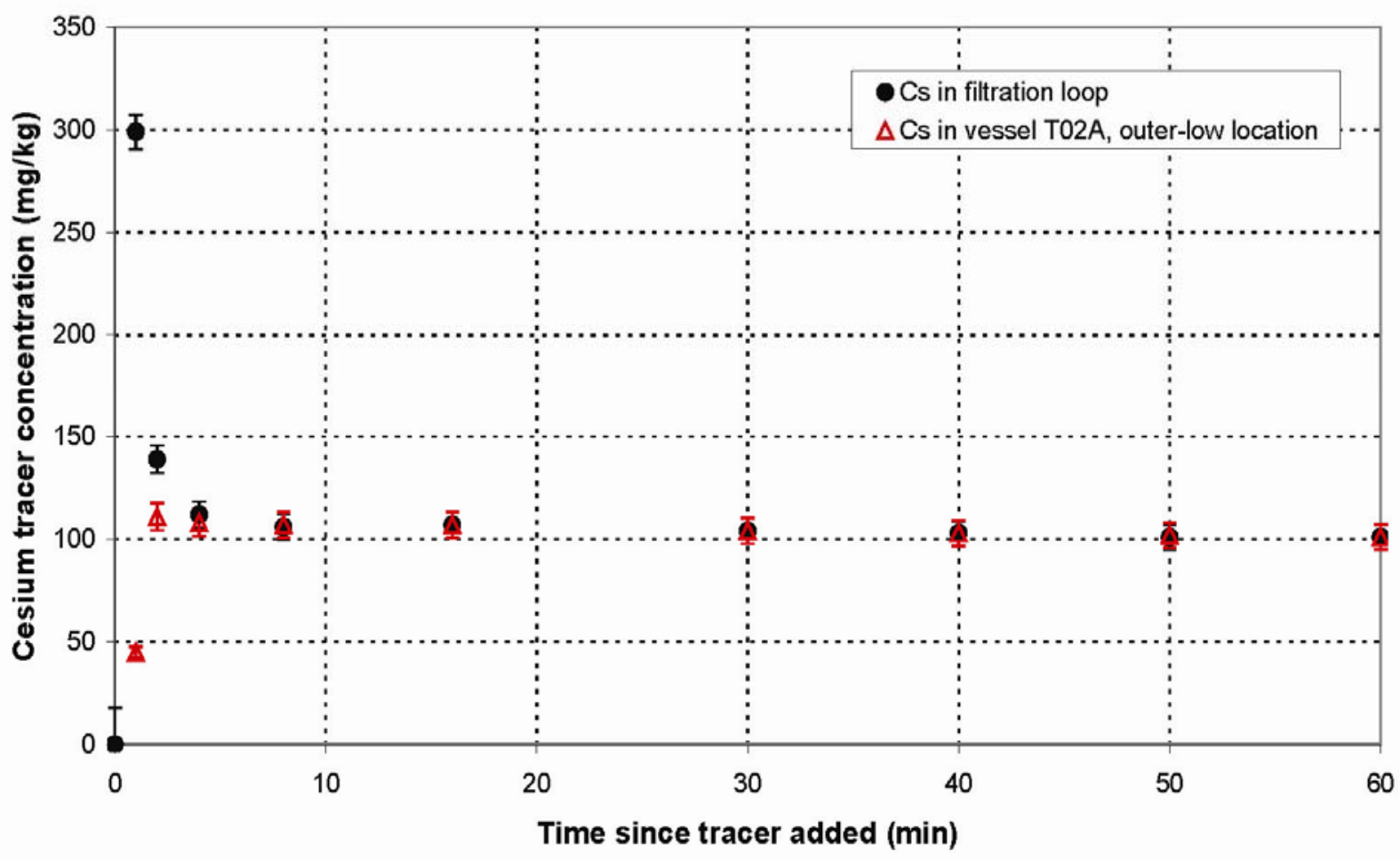

Figure 5.12. Cesium Tracer Concentration During Tracer Test 1 Sampled from Two Locations: The Filtration Loop (black) and Vessel T02A at the Outer-Low Location (red). The error bars are the analytical uncertainties provided by SwRI. 
Tracer Test 2

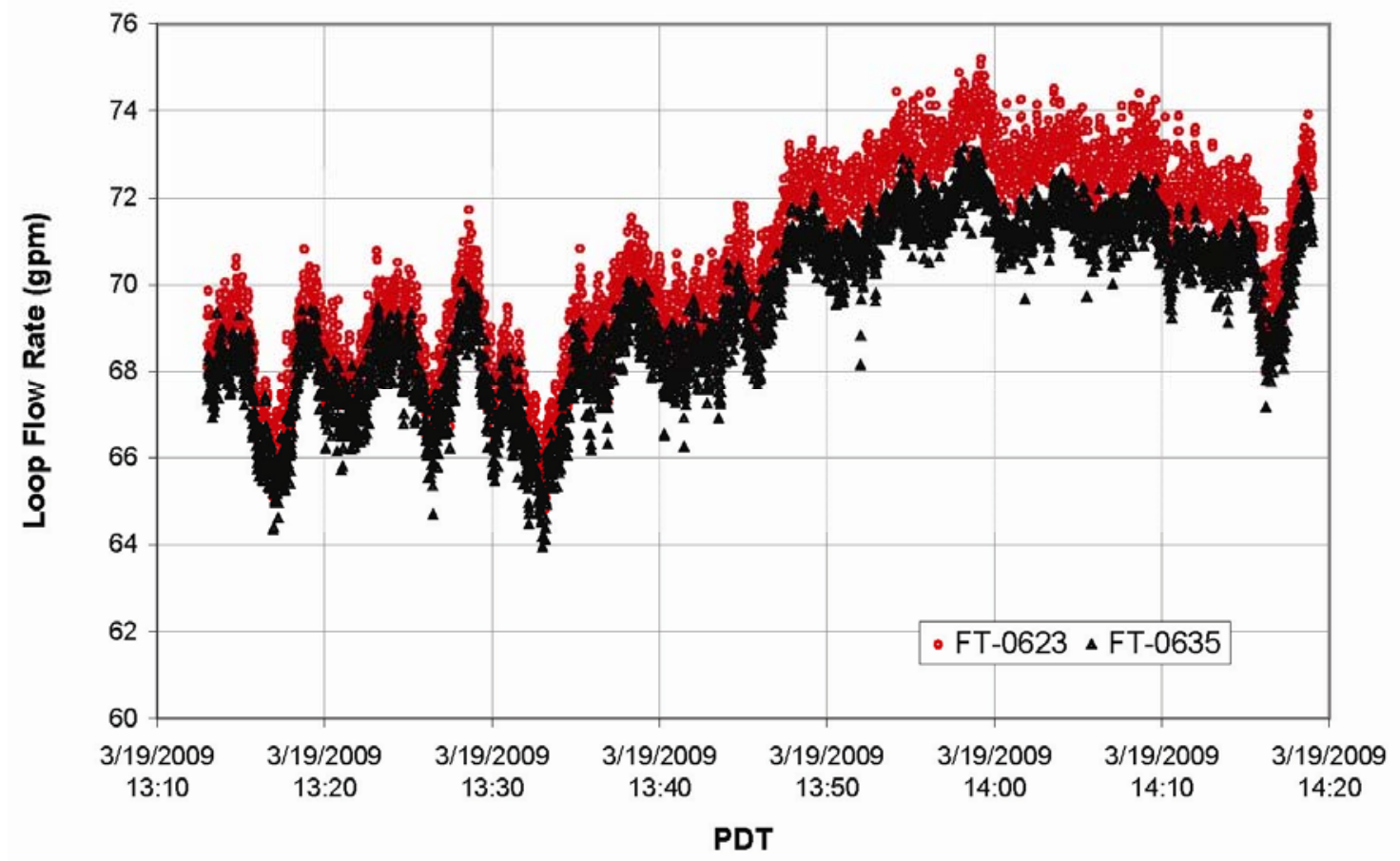

Figure 5.13. Loop Flow Rate During Tracer Test 2. FT-0623 precedes the pumps (red points), and FT-0635 is after the pumps (black points). 
Tracer Test 2: 03/19/09 13:16-14:16

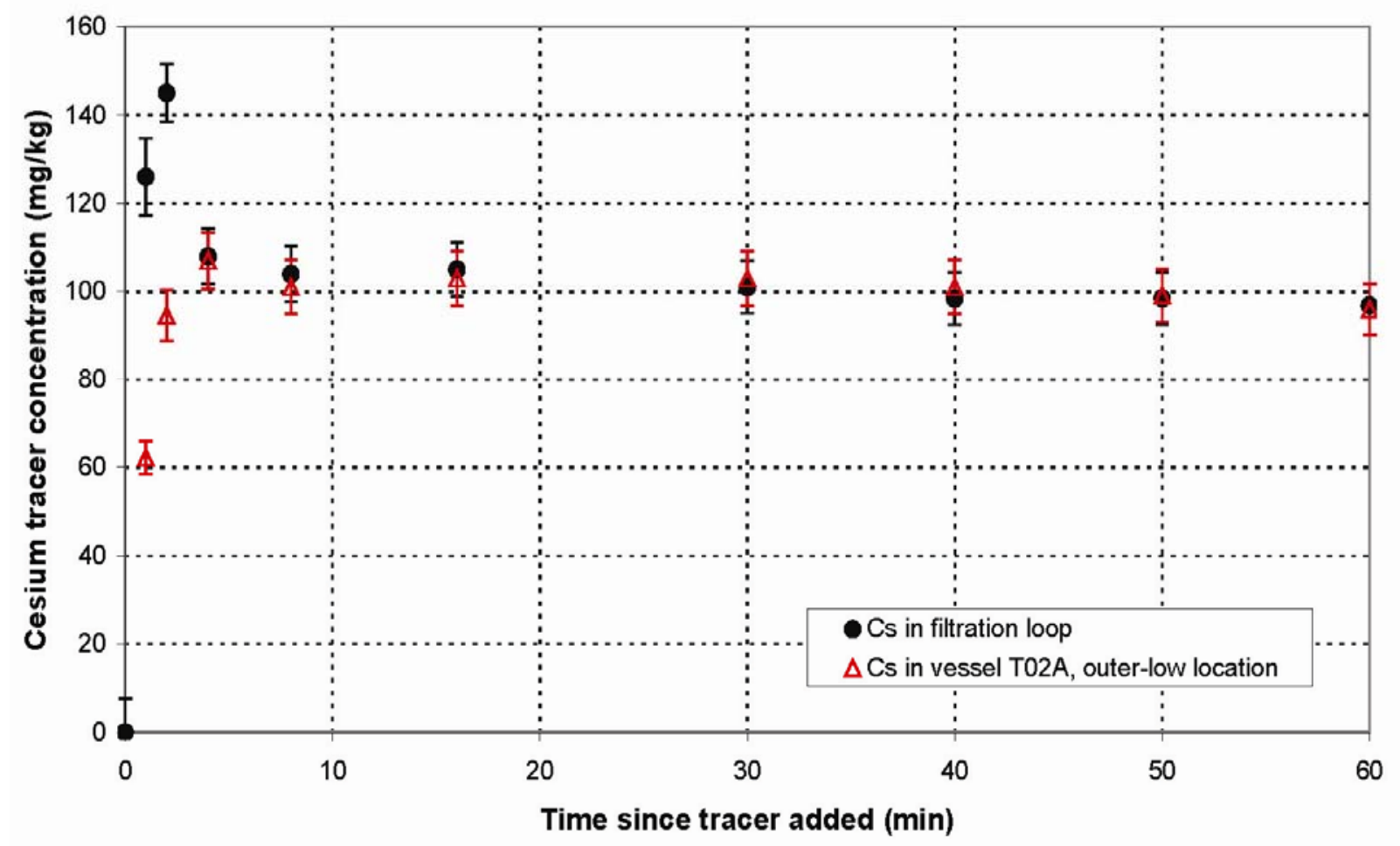

Figure 5.14. Cesium Tracer Concentration During Tracer Test 2 Sampled from Two Locations: The Filtration Loop (black) and Vessel T02A at the Outer-Low Location (red). The error bars are the analytical uncertainties provided by SwRI.

The target filter-loop recirculation rate was not achieved for this test, but lower recirculation rates provide less mixing in Vessel T02A, so better mixing would be expected if the recirculation rate had been prototypic (109 gpm). The results of Tracer Test 2 are still relevant to the washing data because it was performed immediately before the start of the post-caustic-leach wash step in Integrated Test B; the mixing conditions present during the wash and Tracer Test 2 were very similar.

\subsubsection{Tracer Test 3}

Tracer Test 3 occurred between Integrated Tests B and D on 03/21/2009 16:15 to 17:25 Pacific Daylight Time and was a repeat of the high vessel level test. The initial tracer solution contained $200 \mathrm{~g}$ of $\mathrm{CsBr}$; based on the slurry volume during the test, the concentration of Cs after complete mixing in the system was estimated to be $104 \mathrm{ppm}$. The tank level in Vessel T02A during the test was 41.3 inches. The total slurry volume, including the filtration loop and PJM tubes, was $981 \mathrm{~L}$ (259 gal). ${ }^{\text {(a) }}$

The slurry used in this test was a combination of the solids from Integrated Tests A and B. Both batches of solids had been processed through all of the steps in both Integrated tests. To adjust the supernatant composition to approximate a leaching solution and increase the viscosity, the solids were

(a) Using a conversion factor of $0.26418 \mathrm{~L}$ per gal: $981 \mathrm{~L} \times 0.26418 \mathrm{~L} / \mathrm{gal}=259.16$ gal. 
washed twice with $19 \mathrm{M} \mathrm{NaOH}$. The Bingham plastic rheological parameters were determined based on a sample taken 1 minute after the tracer was injected. The yield stress was found to be $9.5 \mathrm{~Pa}$, and the consistency was $3.6 \mathrm{cP}$. Both values are based on data obtained during the "down ramp" where the applied shear stress was decreasing.

During this test, the loop flow rate was on target and very precisely so (see Figure 5.15). Spargers and the steam-ring purge air were not on during this test (except for the time noted below). The PJM peak average nozzle velocity was $11.6 \mathrm{~m} / \mathrm{s}$ (target was $12 \pm 0.4 \mathrm{~m} / \mathrm{s}$ ), and the average stroke length was $78 \%$ (target was $80 \pm 5 \%$ ). All six PJMs were operational.

The concentrations of the Cs tracer measured at the filtration loop before entry into Vessel T02A and from the outer-low sampling location in Vessel T02A are shown in Figure 5.16. The BT (before tracer) sample taken from the filtration loop indicates a non-zero concentration of Cs (71.5 ppm). This did not occur in the other two tests. There was almost no concentration spike in the filtration loop at the beginning of the test. The Cs tracer reached a maximum of $112 \mathrm{ppm}$. More than likely, this is due to a lag between tracer injection and sample collection.

The filtration loop and Vessel T02A samples were in agreement within the analytical uncertainty at 2 minutes, which is even faster than what was observed in Tracer Tests 1 and 2 . The concentrations in the filtration loop and Vessel T02A did not follow each other as closely as in the previous two tests, but they were in agreement. At 60 minutes, a sample was also taken from the outer-middle sampling location in Vessel T02A to check for spatial variability in the tracer concentrations. This is the only sample that was not taken from the outer-low location during the test. The concentration at this sample location was 98 ppm, which is comparable to the 50- and 70-minute sample concentrations taken from the outer-low locations. The concentration for the outer-low location at 60 minutes is nonsensical (208 ppm) and is presented only in the interest of completeness. An additional sample was taken at 70 minutes from the outer-low location after 10 minutes of vessel mixing with the lower spargers on at $0.4 \mathrm{~kg} / \mathrm{min}$. That final value is $101 \mathrm{ppm}$. The agreement of the 70-minute sample (after 10 minutes of sparger-induced mixing) with the values from the previous 60 minutes suggests that the slurry in the vessel was sufficiently mixed even without the assistance of the spargers.

\subsubsection{Tracer Test Conclusions}

The major conclusion of all three tracer tests is that nearly complete mixing was achieved within 2 to 4 minutes of tracer injection. The filter-loop flow rates and other mixing parameters were not consistent across the tests, so the process conditions should be taken into account during further interpretation of these data.

Additionally, a slight decrease in tracer concentration, ranging from 8 to $10 \%$, was observed in all three tracer tests between 4 and 60 minutes. The decrease is generally within the limits of analytical uncertainty, but the consistency of these results suggests that there was a portion of the slurry that slowly mixed. The fraction of slurry that mixes slowly could be due to a combination of factors. There is a dead volume of 9 gallons in the filter-loop, which probably does not participate significantly in the mixing. Slurry in the PJM tubes may remain isolated from the larger scale mixing behavior occurring in Vessel T02A. 
More specifically, for washing operations, the first two tracer tests are more relevant to the current report because they were performed at mixing conditions that were very similar to the mixing conditions of the washes in Integrated Tests A and B. Since the wash solutions and the tracer were both injected into the recirculation pump suction, it is appropriate to use 2 to 4 minutes as an indication of the time required for wash solutions to blend into the slurry.

Tracer Test 3

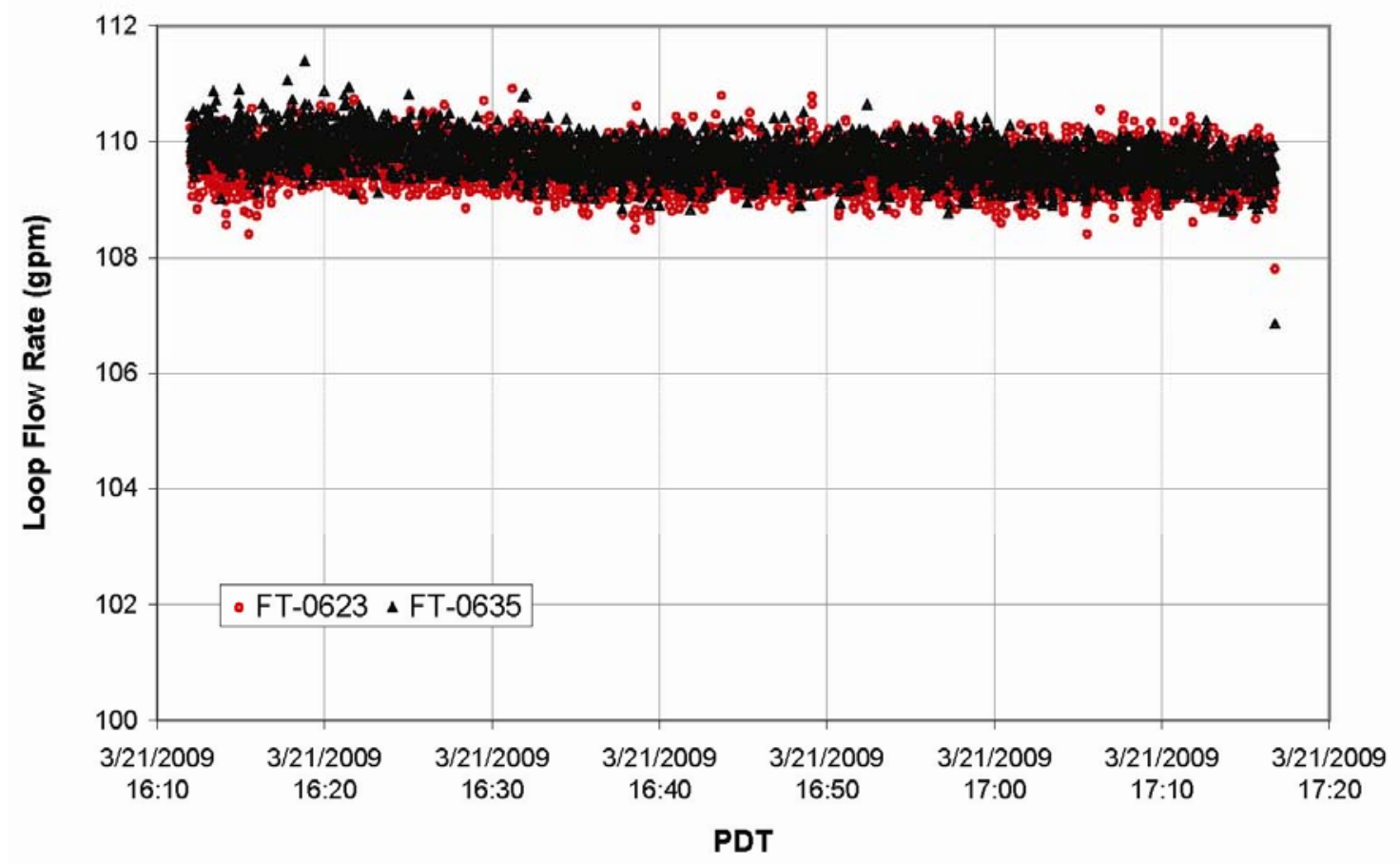

Figure 5.15. Loop Flow Rate During Tracer Test 3. FT-0623 precedes the pumps (red points), and FT-0635 is after the pumps (black points). 
Tracer Test 3: 03/21/09 16:15-17:25

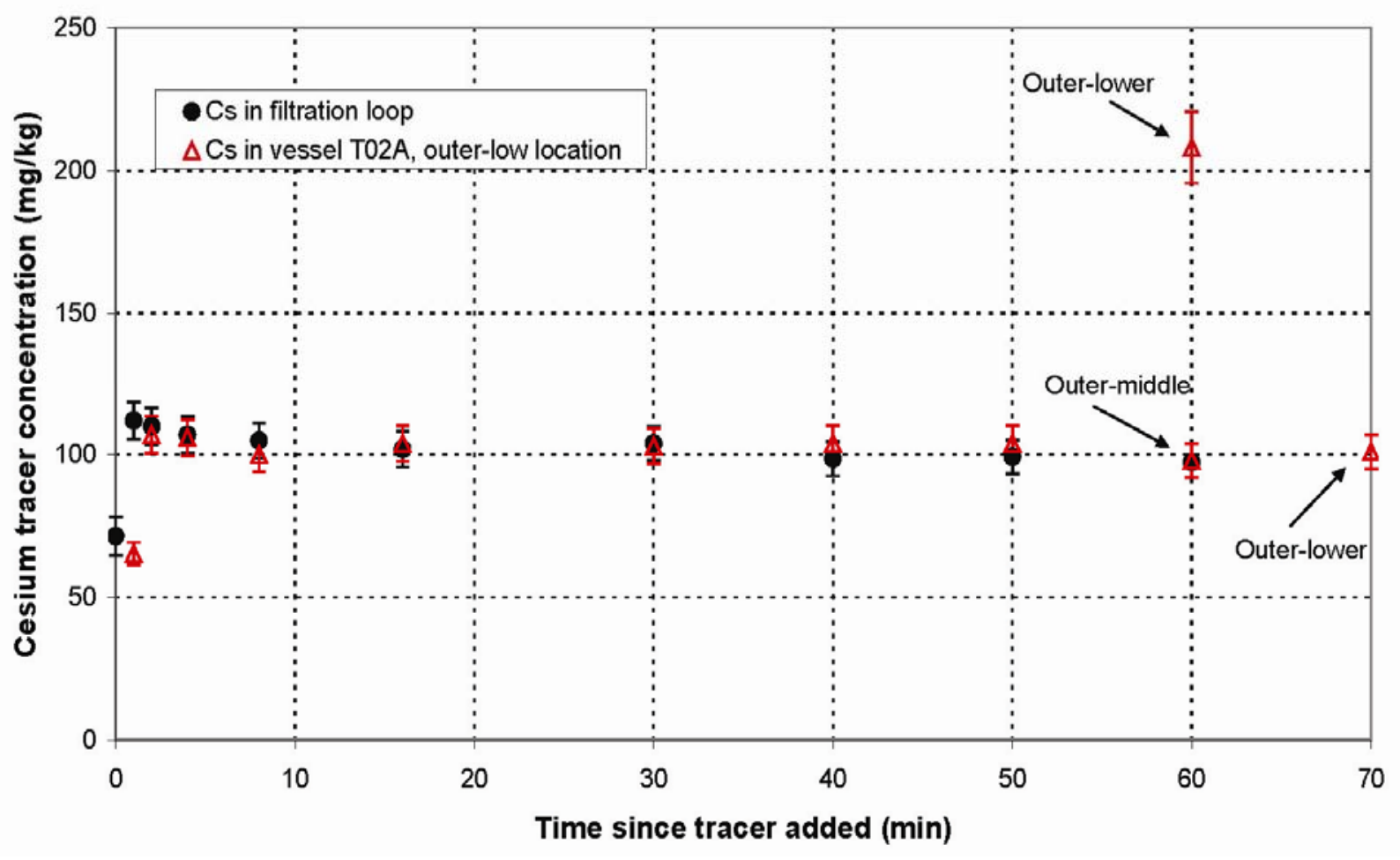

Figure 5.16. Cesium Tracer Concentration During Tracer Test 3 Sampled from Two Locations: The Filtration Loop (black) and Vessel T02A at the Outer-Low Location (red). The error bars are the analytical uncertainties provided by SwRI.

\subsection{IW Batch Time Interval}

As noted in the above Section 5.3, the major conclusion from the tracer tests is that except for a relatively small volume of slurry that mixed slowly, nearly complete mixing within Vessel T02A was achieved between 2 and 4 minutes under prototypic test conditions during the wash process. This suggests that IW batch time intervals significantly less than the mixing time could lead to incomplete mixing, while any time longer than 4 minutes between IW wash batches should presumably lead to complete mixing. This leads to the question of how the IW batch-to-batch time interval compared to the 2- to 4-minute mixing time may impact washing efficiency.

Shown in the following four figures, Figure 5.17 through Figure 5.20, is the IW batch time interval plotted versus IW batch number for each of the wash processes. The time between IW batches is generally correlated with the permeate rate since an IW batch addition was triggered by a decrease in level. Hence, a lower permeate rate leads to a greater duration between batches. The IW batch time interval for each batch, in units of minutes, was defined as the duration between the start of the IW wash injection for a batch to the start for the IW wash injection for the subsequent batch. IW batch time intervals were only determined when Vessel T02A mixing was operational (i.e., PJMs and the recirculation loop were operating). 


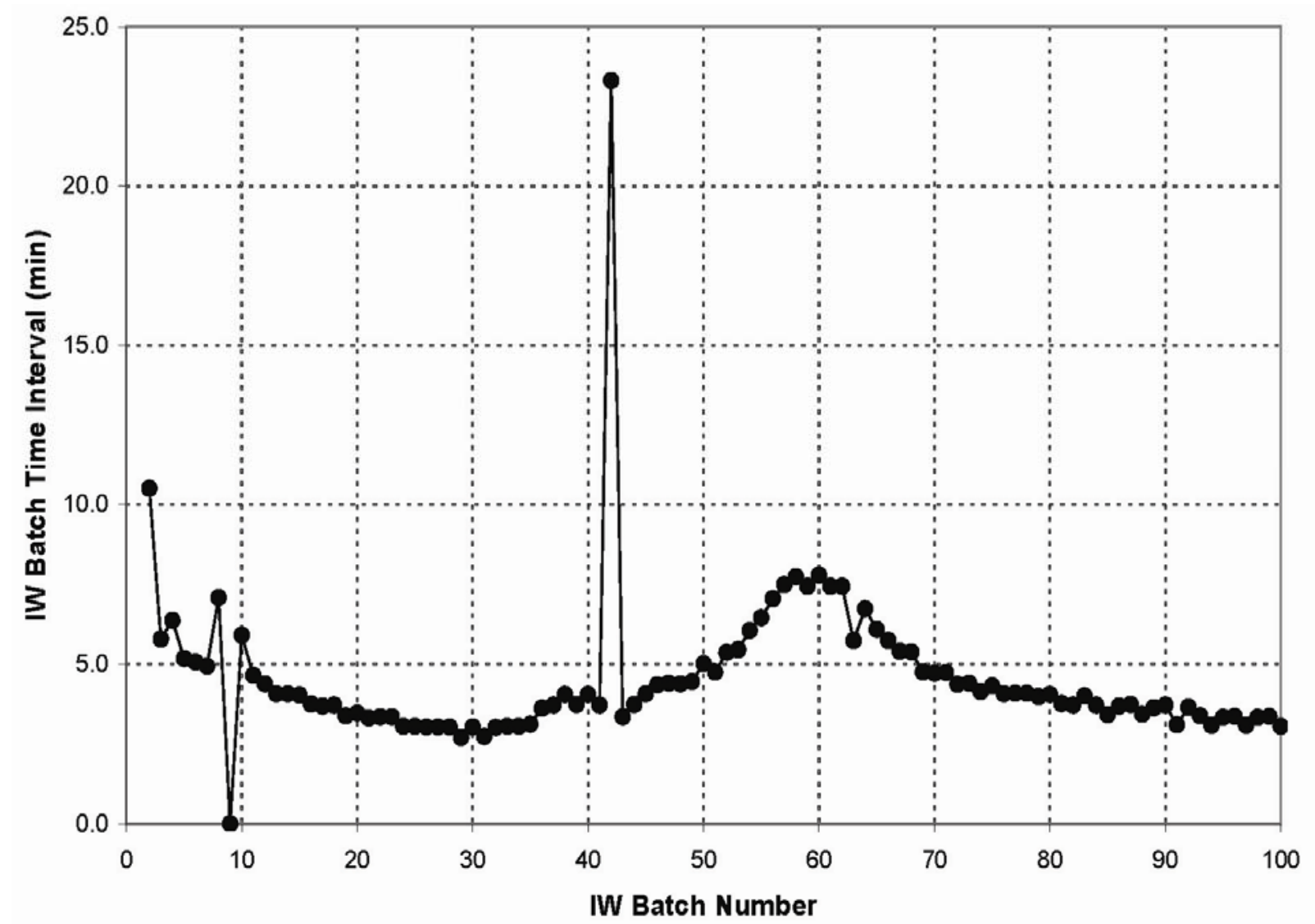

Figure 5.17. IW Batch Time Interval, in Minutes, for Integrated Test A Post-Caustic-Leach Wash. Note there are two regions where the batch time interval is less than 4 minutes. A shift change occurred during batch 42 . 


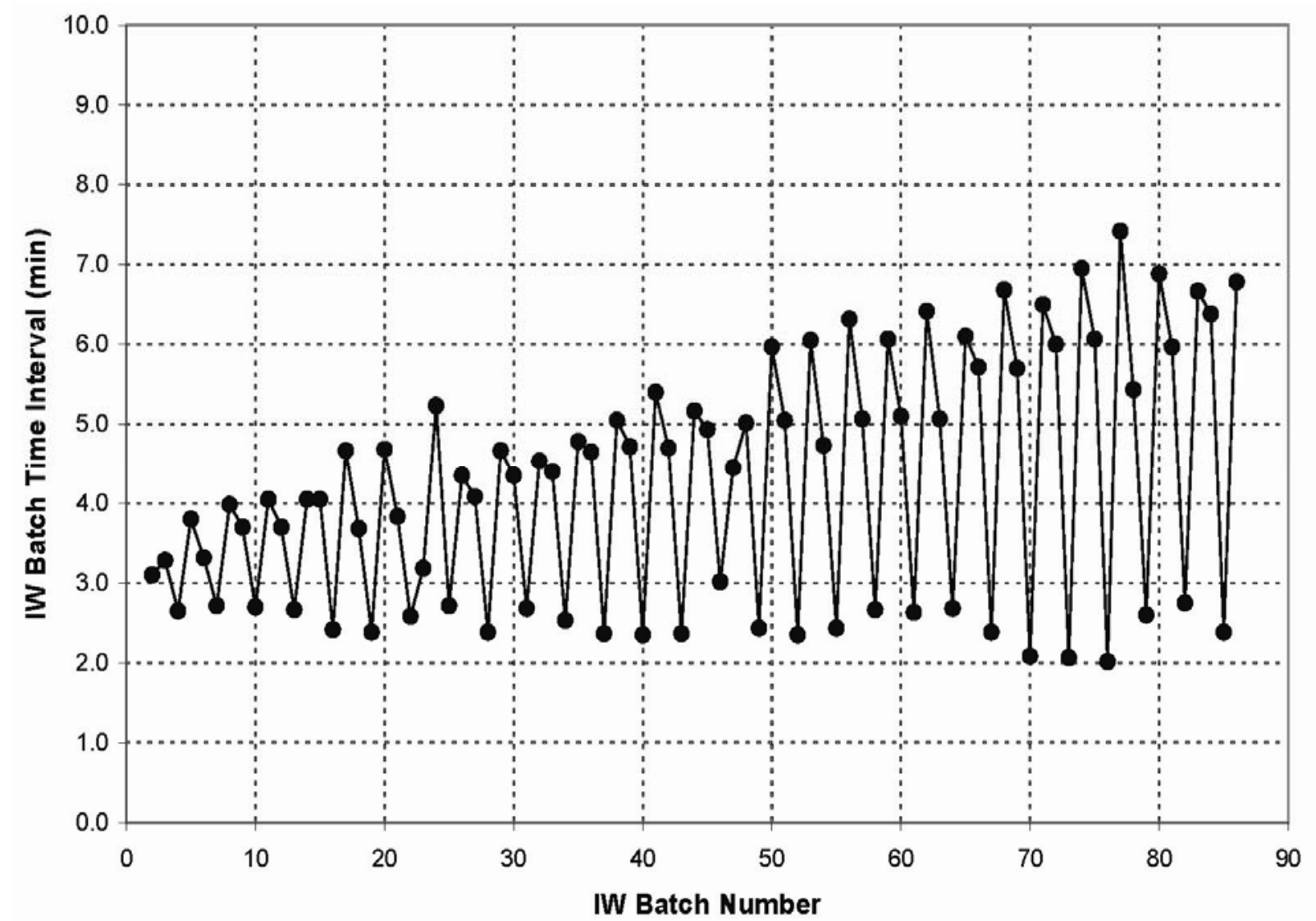

Figure 5.18. IW Batch Time Interval, in Minutes, for Integrated Test A Post-Oxidative-Leach Wash. Note that the IW batch-time interval times oscillated above and below 4 minutes. 


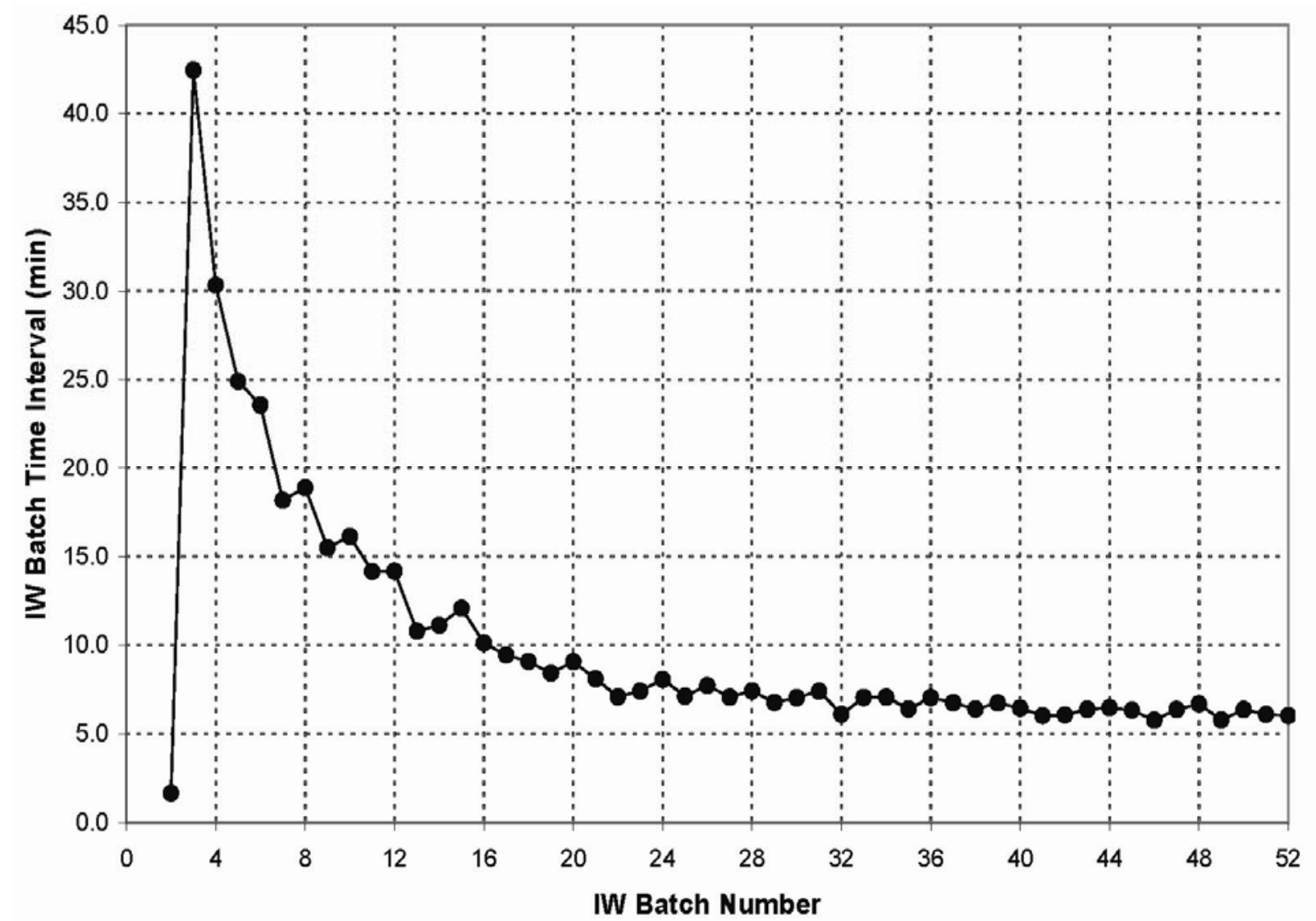

Figure 5.19. IW Batch Time Interval, in Minutes, for Integrated Test B Post-Caustic-Leach Wash. Note that all IW batch-time interval times were greater than 4 minutes. 


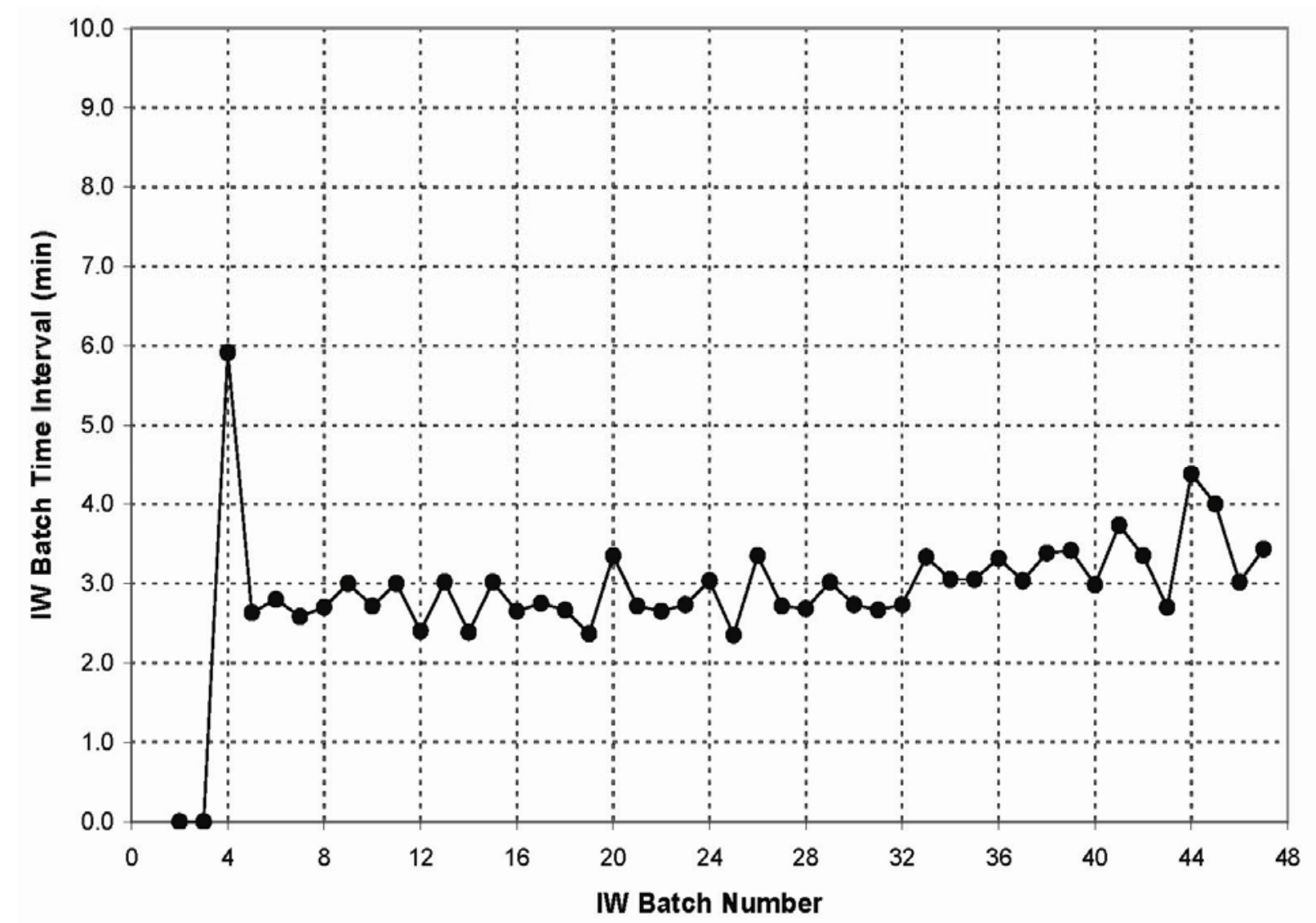

Figure 5.20. IW Batch Time Interval, in Minutes, for Integrated Test B Post-Oxidative-Leach Wash. Note that nearly all IW batch time interval times were less than 4 minutes.

The behavior of the IW batch time intervals for Integrated Test A post-caustic-leach wash is seen in Figure 5.17. There are two regions above 4 minutes and two regions below 4 minutes. At $n=11-41$, the duration drops to below 4 minutes to even below 3 minutes at $n=30$. At $n=45-80$, the duration climbs to above 4 minutes, implying complete mixing. At $n=80$ to termination, the duration drops again to below 4 minutes. For Integrated Test A post-caustic-leach wash, the batch time interval between batch 7 and batch 8 is recorded as zero during a 14-hour hold time where attempts were made to increase the flow-loop recirculation rate, which varied from zero to approximately $80 \mathrm{gpm}$.

In the Integrated Test A post-oxidative-leach wash in Figure 5.18, the IW batch time-interval times exhibited an unexpected sinusoidal pattern, oscillating above and below the 4 minutes of interest. Batches before batch 8 all washed with times below 4 minutes. Thereafter, the batch time intervals oscillated above and below 4 minutes, from $2 \frac{1}{2}$ minutes to 6 to 7 minutes. The shortest batch interval was batch 76, exhibiting an interval time of 2.0 minutes, and the largest interval was during batch 77 , exhibiting an interval of 7.4 minutes.

The batch time-interval oscillations are attributed to the air introduced while AFA was added, not the AFA itself, during every third batch. The tank headspace is kept at slight negative pressure, and when the nozzle was opened to introduce AFA (it was poured in via a nozzle in the tank lid), the jet of incoming air blew the bubbles away from the spot on the surface that the laser hit. This was also observed by camera 
when AFA was not injected; therefore, the AFA itself is likely not the cause. The recorded time of the AFA additions on the Test Instruction and the Laboratory Record Book (BNW-60230) coincide with the occurrence of the reduced batch time intervals. Admitting AFA to the tank removes foam on the liquid surface, and causes an apparent drop in tank liquid levels, as measured by the laser instrument LT-0614. The apparent drop of the liquid level triggers the start of the IW injection. The early start of the IW injection results in cutting short the wash duration to less than 3 minutes for every third wash.

Referring back to the case in point for batches 76 and 77 in the Integrated Test A post-oxidative-leach wash, Figure 5.21 shows a plot of the tank level and IW addition rate upon which the reported times for the AFA additions are superimposed. The plot shows the measured liquid level and the IW injection rates for 28 minutes, from 22:14 to 22:42 during wash batches 76 through batches 80 . During the 28-minute period, the AFA was added once, at 22:30, during the progression of wash batch 78. Immediately following the AFA addition, the tank level measurement dropped and triggered the start of the IW addition, representing the start for the wash batch 79 .

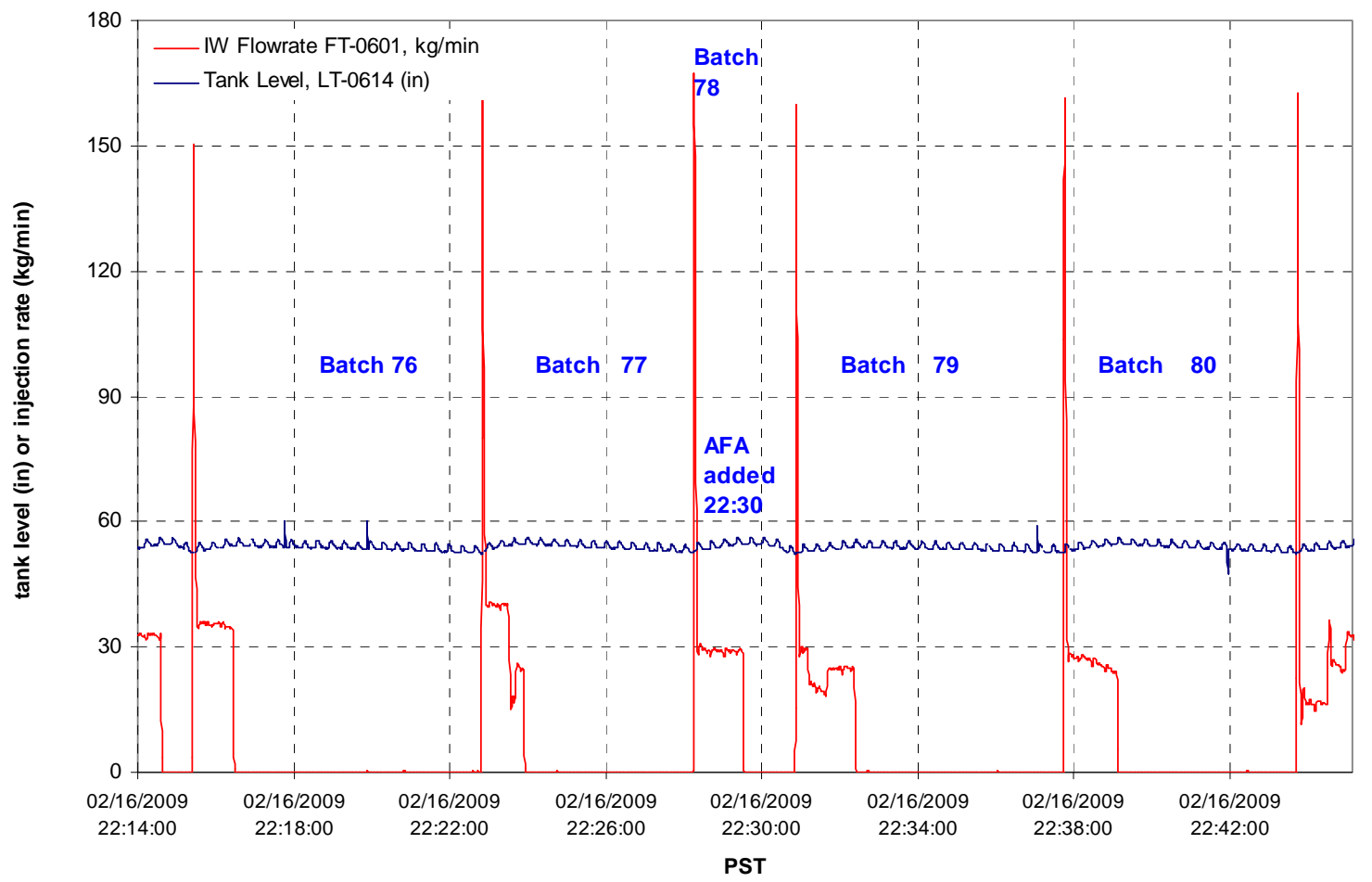

Figure 5.21. Tank Liquid Level and IW Additions to Vessel T02A During Post-Oxidative-Leach Wash for Batches 76 to 80 . The AFA addition at 22:30 is shown to truncate the wash batch time for batch 78 .

In the Integrated Test B post-caustic-leach wash in Figure 5.19, all IW batch time intervals were greater than 4 minutes, implying that full mixing should be expected throughout the wash process, based at least upon the IW batch time interval. 
The behavior of IW batch time intervals for the Integrated Test B post-oxidative-leach wash is shown in Figure 5.20. In this test, nearly all batch durations were less than 4 minutes, with the exception of batch 3 and batch 43. Many of the batch durations were less than 3 minutes.

In summary, IW batch time-interval times significantly less than the 4 minutes that were estimated for nearly complete mixing might reasonably be expected to have led to a decrease in washing efficiency for the Integrated Test A post-caustic-leach wash and the Integrated Test B post-oxidative-leach wash. Since the wash efficiencies in these tests are essentially equal to 1 , this effect does not appear to be significant for the PEP wash and mixing conditions tested. 



\subsection{PEP Results as Measures of PTF Performance}

This section provides a brief overview of the bases for treating PEP results as prototypic of the PTF. Design features and operational parameters of the PEP chosen to make PEP slurry washing performance as similar to PTF performance as possible are discussed below in the first two subsections.

Two non-prototypic conditions that could impact the applicability of PEP wash efficiencies to PTF modeling were identified. First, the PEP filter-loop volume was significantly larger than would be prototypic of the PTF, so the total volume of slurry in the filter-loop and Vessel T02A was larger than would be prototypic of the PTF. Second, not all PEP operational parameters (specified to achieve prototypic washing performance) could be maintained at their target values during PEP testing. These two issues are considered in the third and fourth subsections.

\subsection{PEP Design}

The PEP was designed to achieve prototypic slurry washing performance by employing the following design features (PEP Functional Requirements ${ }^{(\mathrm{a})}$ ):

1. PEP ultrafiltration feed Vessel T02A is dimensionally prototypic of the PTF vessel, with its filterloop outlet and inlet nozzles located prototypically, and its primary internal structure (the PJM cluster) also sized and located prototypically.

2. Mixing equipment within Vessel T02A is prototypic: PJMs, PJM nozzles, and the filter-loop return nozzle are dimensionally scaled and located to achieve prototypic mixing of non-Newtonian slurries; air sparge mixers are prototypically located and can be operated to mix the region above the PJM mixing cavity to simulate their operation in the PTF; and mixing from the air purge of the steam injection ring can be controlled to simulate its effects in the PTF.

3. The filter-loop is designed with pumps, filters, pulse-pots, wash-water inlet, a spiral-plate chiller, and all appropriate instruments and controls to operate prototypically.

4. Five cross-flow ultrafilter bundles are installed in the filter-loop (three 10-ft bundles, two 8-ft bundles), each with 12 PTF-size filter tubes to prototypically mimic the filtration rates and behavior of the PTF.

The filter-loop is volumetrically larger than would be prototypic, and some of the Vessel T02A internals (e.g., PJM support structure) are not prototypic and could affect mixing dynamics. These are deviations from prototypic configurations. Only the filter-loop volume is considered here to be of significant concern; it is discussed later in this section.

\subsection{PEP Operational Parameters}

Operation of the PEP to achieve slurry washing prototypic of the PTF is based on guidelines described in Technical Basis for Scaling Relationships for the Pretreatment Engineering Platform

(a) B Stiver. 2007. Functional Requirements for Pretreatment Engineering Platform (PEP),

24590-PTF-3YD-UFP-00002 Rev. 1, Bechtel National Incorporated, Richland, Washington. 
(Kuhn et al. 2008) and specific directions given in the Test Plan Pretreatment Engineering Platform (PEP) Testing (Phase I). ${ }^{(a)}$ Key elements of the approach are:

1. Prototypic mixing in Vessel T02A is best achieved for non-Newtonian slurries by maintaining the same mixing jet velocities in the PEP as in the PTF. Specifically, PJMs should be operated to achieve $12-\mathrm{ft} / \mathrm{s}$ jet velocities and cycle times that are $1 / 4.5$ that of the PTF, and the filter-loop flow rate should be $109 \mathrm{gpm}$ to achieve a prototypic jet velocity at its return nozzle in Vessel T02A. These choices result in mixing the contents of the PEP Vessel T02A approximately 4.5 times faster than in the PTF.

2. The PEP filter-loop should be configured to employ all five filter bundles, resulting in an overall slurry wash duration that is approximately $1 / 4.5$ that of the PTF. This is necessary, given the mixing parameters chosen above, to maintain

$$
\frac{\text { PEP slurry wash duration }}{\text { PEP mixing time }} \approx \frac{\text { PTF slurry wash duration }}{\text { PTF mixing time }}
$$

Josephson et al discuss the impacts of this choice on the solids/(filter area) ratio and on filter flux. ${ }^{\text {(a) }}$

3. The PEP filter-loop operation should be controlled to match the PTF axial velocity (in individual filter tubes), filter TMP, and temperature.

4. Wash-water should be added at a prototypic location (i.e., upstream of PMP-T42A). The wash-water batch volume should maintain

$$
\frac{\text { PEP wash water batch volume }}{\text { PEP UFP }-2 \text { slurry volume }} \approx \frac{\text { PTF wash water batch volume }}{\text { PTF UFP }-2 \text { slurry volume }}
$$

and the wash-water addition rate should maintain

$$
\frac{\text { PEP wash water addition rate }}{\text { PEP filter - loop flow rate }} \approx \frac{\text { PTF wash water addition rate }}{\text { PTF filter - loop flow rate }}
$$

5. The slurry level in Vessel T02A should be prototypic of the level in PTF so the volume of slurry being mixing in this vessel is prototypic.

The air sparge and steam-injection-ring air purge flow rates were scaled in the PEP to approximately match the (mixing power)/volume ratio in the PTF in the region above the PJM mixing cavity (Kuhn et al. 2008). However, in all four slurry washing processes considered in this report, the lower air spargers were set to their "idle" flow rate (as they would be in the PTF), and slurry levels in Vessel T02A were always below the upper air sparger (as they would be in the PTF). As such, the air sparge mixers were expected to contribute little to the mixing in Vessel T02A. Matching (mixing power)/volume with the air spargers and steam-injection-ring air purge will result in mixing times similar to those of the PTF and less mixing than in the PTF for a slurry wash duration that is $1 / 4.5$ times that of the PTF (as is the objective of elements 1 and 2 above). Though the impact is expected to be very minor, the less-than-prototypic air

(a) GB Josephson, OP Bredt, JK Young, and DE Kurath. 2009. Pretreatment Engineering Platform (PEP) Testing (Phase I). TP-RPP-WTP-506, Rev. 0.4, Pacific Northwest National Laboratory, Richland Washington. 
bubble mixing in the PEP should lead to less mixing in the PEP than in the PTF and slightly lower wash efficiencies in the PEP.

\subsection{Non-Prototypic Filter-Loop Volume}

The PEP filter-loop volume, about 82 gal, was significantly larger than would be prototypic of the PTF - the prototypic would be ${ }^{1780} / 4.5^{3}=19.5$ gal $^{\text {(a) }}$ In Integrated Test A, the post-caustic-leach wash prototypic volume of slurry in Vessel T02A was about $185 \mathrm{gal}$, and the total prototypic slurry volume should have been $19.5+185=204.5$ gal. The actual Integrated Test A volume was about $82+185=267$ gal. In Integrated Test B, the prototypic total slurry volume should have been about 77, gal but actually was about 139 gal. Post-oxidative-leach wash slurry volumes are similar. Because the wash-water batch volume was a fixed quantity (11 gal) in the PEP (see operational parameter key elements 4 and 5 above), an increase in the total volume of slurry being washed will increase the number of wash batches needed to achieve a targeted dilution. The non-prototypically large filter-loop volume also results in a greater fraction of the slurry residing in the filter-loop (where it does not participate in mixing within Vessel T02A) and a longer time for the wash-water (which is introduced near the start of filter-loop) to reach Vessel T02A.

To help assess the effects of the larger-than-prototypic PEP filter-loop volume on wash efficiency, a simple mathematical model of the system was developed and solved numerically for conditions of interest. The model itself is presented in Appendix B. The model includes the time lag between the time that a water addition is started and the time the water-diluted slurry reaches Vessel T02A as (filter-loop volume)/(filter-loop flow rate). Mixing within the filter-loop is assumed to be locally instantaneous but the axial mixing is negligible. This is based on the view of the filter-loop as a pipe with turbulent plug flow, so the slurry that was diluted with wash-water moves as a slug from the point of water injection to the end of the loop at the return nozzle in Vessel T02A. Slurry entering Vessel T02A is divided into a fraction that mixes instantaneously with the contents of Vessel T02A, and a fraction that bypasses the contents of the vessel and is fed directly into the filter-loop inlet. The model allows the slurry volume in Vessel T02A to increase during wash-water addition (because water rate $>$ permeate production rate), and decrease when wash-water addition is stopped (because permeate production reduces total slurry volume). Wash-water additions are initiated when the slurry volume in Vessel T02A drops to a specified value (equivalent to the level-based control used in PEP), and stopped when the specified volume (11 gal) has been added. The point of the model is not to predict actual wash efficiencies, but rather to examine changes in wash efficiencies associated with different filter-loop volumes and flow rates.

Figure 6.1 illustrates the model results for a simplified Integrated Test A scenario using the parameters given in Table 6.1 and two different filter-loop volumes: Case 1 uses the prototypic 19.5-gal filter-loop volume, and Case 2 uses the actual 82-gal filter-loop volume. Clearly, the normalized solute concentrations are quite different for Cases 1 and 2 because their total initial volumes differ by 62.5 gal, and the 11-gal wash-water batches have different impacts on the average solute concentrations. However, the calculated wash efficiencies for Cases 1 and 2 differ only a little, both being always greater than 0.988 and trending gradually upward the entire wash. In this case, the larger-than-prototypic filter-loop volume of the PEP (Case 2) leads to slightly lower wash efficiencies.

(a) SD Lehrman. 2008. Pretreatment Engineering Platform (PEP) Phase 1 Testing Process Description. 24590-WTP-RPT-PET-07-002, Rev. 1, Bechtel National Inc., Richland, Washington. 


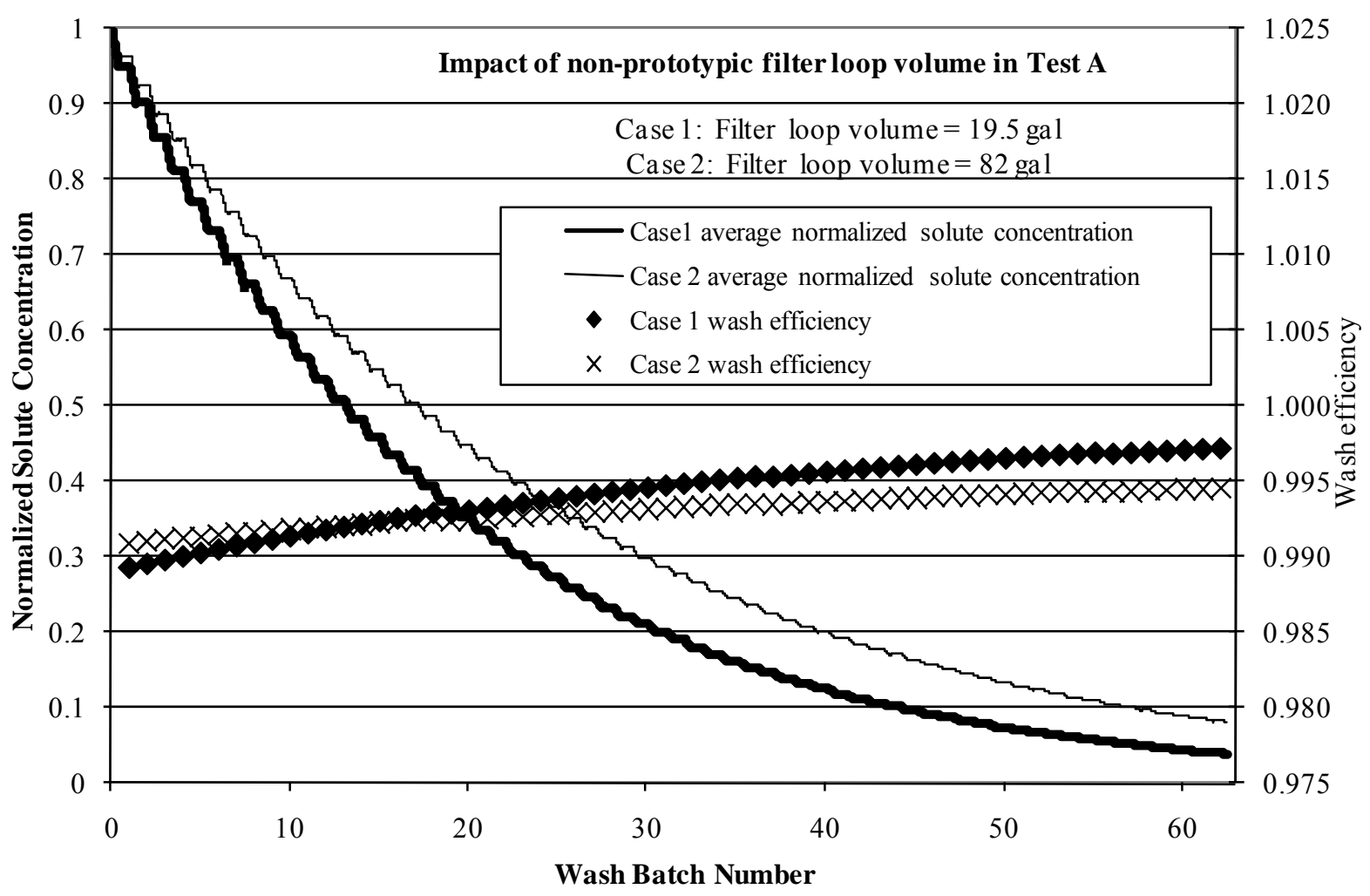

Figure 6.1. Plot of Normalized Solute Concentrations and Wash Efficiencies as Functions of Wash Batch Number for Two Filter-Loop Volumes Under Integrated Test A Conditions as Predicted by Appendix B Model

Table 6.1. Appendix B Model Input Parameters for Figure 6.1

\begin{tabular}{lcl}
\hline \multicolumn{1}{c}{ Model Parameter } & Value & \multicolumn{1}{c}{ Basis } \\
\hline $\begin{array}{l}\text { Initial slurry volume in } \\
\text { Vessel T02A }\end{array}$ & $185 \mathrm{gal}$ & $\begin{array}{l}\text { PEP Integrated Test A post-caustic-leach wash } \\
\text { target volume }\end{array}$ \\
Filter-loop flow rate & $109 \mathrm{gpm}$ & $\begin{array}{l}\text { PEP target value } \\
\text { Wash-water batch volume }\end{array}$ \\
$\begin{array}{ll}\text { Wash-water addition rate } \\
\text { Permeate production rate }\end{array}$ & $7.4 \mathrm{gpm}$ & PEP target value \\
\hline
\end{tabular}

Similarly, Figure 6.2 illustrates the model results for a simplified Integrated Test B scenario using the parameters given in Table 6.2 and the same two different filter-loop volumes: Case 1 uses the prototypic 19.5-gal filter-loop volume, and Case 2 uses the actual 82-gal filter-loop volume. As in the model results for Integrated Test A, the normalized concentrations are quite different for the two different filter-loop volumes, but the corresponding wash efficiencies are nearly the same, and the larger-than-prototypic volume of the PEP (Case 2) leads to slightly lower wash efficiencies.

The model indicates that the primary effects associated with the larger-than-prototypic PEP filter-loop volume of 1) delaying the time that wash-water-diluted slurry reaches Vessel T02A, and 2) changing the fraction of slurry that resides in the loop (and does not participate in mixing in Vessel T02A) affect the wash efficiency by less than $1 \%$ in both Integrated Test A and Integrated Test B washing scenarios. 
When compared to observed differences between wash efficiencies of solute species (see Table 5.1 and Table 5.6), these effects appear to be negligible.

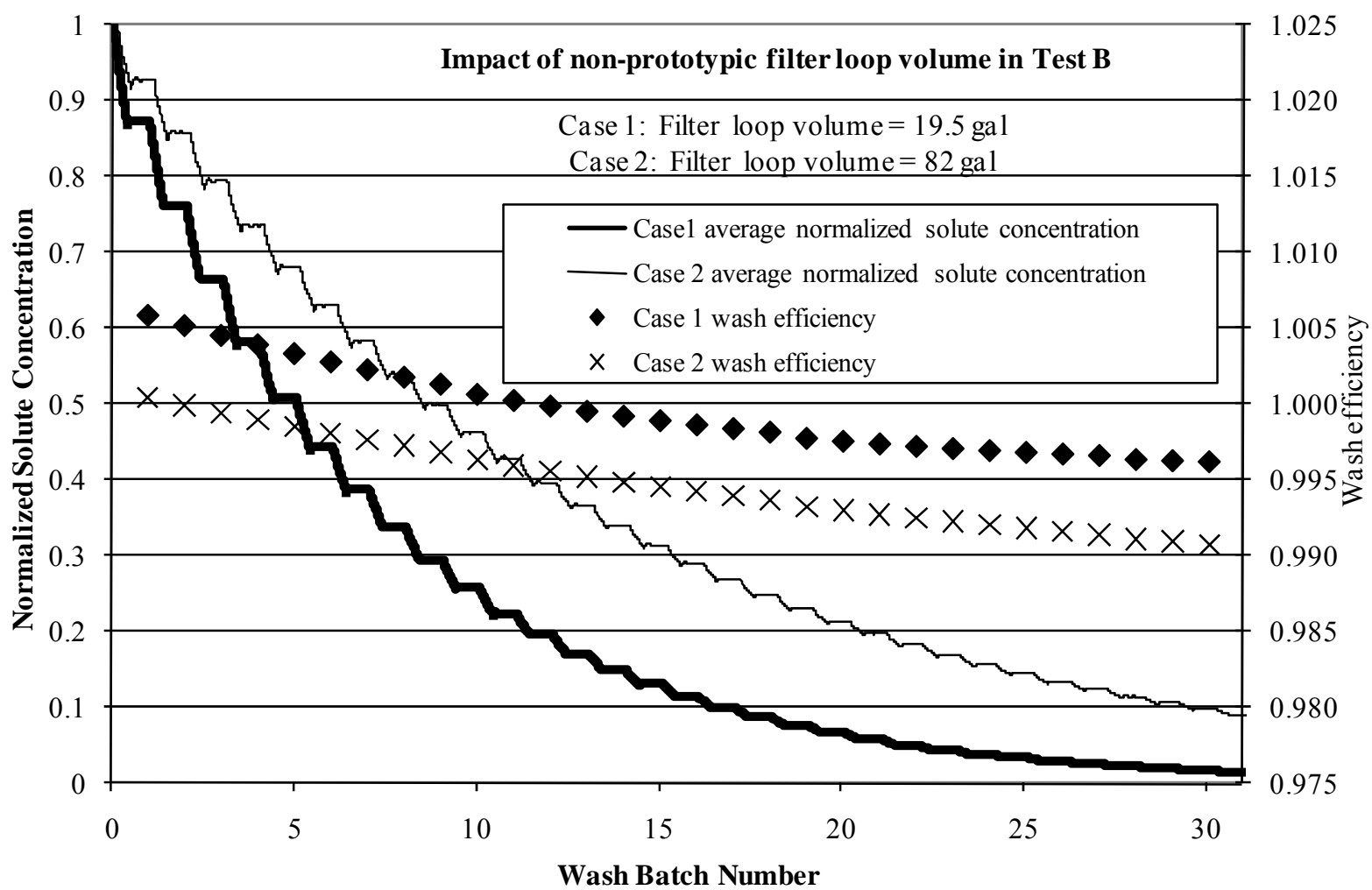

Figure 6.2. Plot of Normalized Solute Concentrations and Wash Efficiencies as Functions of Wash Batch Number for Two Filter-Loop Volumes Under Integrated Test B Conditions as Predicted by Appendix B Model

Table 6.2. Appendix B Model Input Parameters for Figure 6.2

\begin{tabular}{lcl}
\hline \multicolumn{1}{c}{ Model Parameter } & Value & \multicolumn{1}{c}{ Basis } \\
\hline $\begin{array}{l}\text { Initial slurry volume in } \\
\text { Vessel T02A }\end{array}$ & $57 \mathrm{gal}$ & $\begin{array}{l}\text { PEP Integrated Test B post-caustic-leach wash } \\
\text { target volume }\end{array}$ \\
Filter-loop flow rate & $109 \mathrm{gpm}$ & PEP target value \\
Wash-water batch volume & $11 \mathrm{gal}$ & PEP target value \\
Wash-water addition rate & $7.4 \mathrm{gpm}$ & PEP target value \\
Permeate production rate & $2.75 \mathrm{gpm}$ & Achieves 4-min wash cycles \\
\hline
\end{tabular}

\subsection{Deviations of Operational Parameters from Targeted Values}

Drift in a filter-loop flowmeter reading and air entrainment at the filter-loop inlet resulted in poor control of the filter-loop flow rate during Integrated Test A slurry washing. The actual slurry flow rate may have been much higher than the prototypic $109 \mathrm{gpm}$, with correspondingly higher filter-loop return nozzle velocities in Vessel T02A and potentially better mixing in that vessel. An increase in the filterloop flow rate also decreases the amount of dilution in the filter-loop while wash-water is being added, improving the wash efficiency during the period that wash-water is added. The opposite was experienced 
during Integrated Test B; filter-loop flow rates were generally less than 109 gpm, resulting in slightly less jet mixing in Vessel T02A and higher local dilution while wash-water was added.

Recall that the wash-water is introduced upstream of the filter-loop pumps and filters. Therefore, from the time that a wash-water addition is initiated and begins to dilute the slurry until the time the diluted slurry has flowed through the loop and is reentering the loop from Vessel T02A, the solute concentration in the permeate, $C_{P}$, can be expressed by

$$
C_{P}=C_{n-1}\left(\frac{Q_{\text {loop }}-Q_{w w}}{Q_{\text {loop }}}\right)
$$

where $C_{n-1}$ is the solute concentration entering the filter-loop, $Q_{\text {loop }}$ is the total loop flow rate, and $Q_{w w}$ is the wash-water addition flow rate. If $C_{P}$ in Equation (6.4) is greater than $C_{n}$ as defined in Equation (4.1), then the wash efficiency during the addition of water will be greater than 1 (i.e., more solute will be removed than if the entire system were well mixed before any permeate is removed); if $C_{p}$ is less than $C_{n}$, then the wash efficiency during the addition of water will be less than 1.

This aspect of the non-prototypic filter-loop flow rates on Integrated Test A and Integrated Test B washes can be evaluated using the model described in Appendix B. Figure 6.3 graphs the normalized solute concentrations and wash efficiencies predicted by the model for the Integrated Test A conditions given in Table 6.3. Normalized solute concentrations for the two different flow rates are very similar, so their curves are not resolved in this figure. Calculated wash efficiencies are also very similar, being generally less than $0.5 \%$ different. As expected from considerations in the previous paragraph, the higher filter-loop flow rate is predicted to result in a higher wash efficiency, but the difference is small and assumed to be negligible in this study.

The low filter-loop flow rate experienced in Integrated Test B was also modeled. Results were similar to those presented in Figure 6.3, except that, as expected, the lower flow rate in Integrated Test B resulted in a slightly lower wash efficiency than would have been observed if the flow rate had been prototypic. Given that the direction of the error is conservative (wash efficiencies would be slightly higher if the flow rate had been at its target value) and the impact on the wash efficiency is very small, this aspect of the non-prototypic flow rate is assumed to be negligible. 


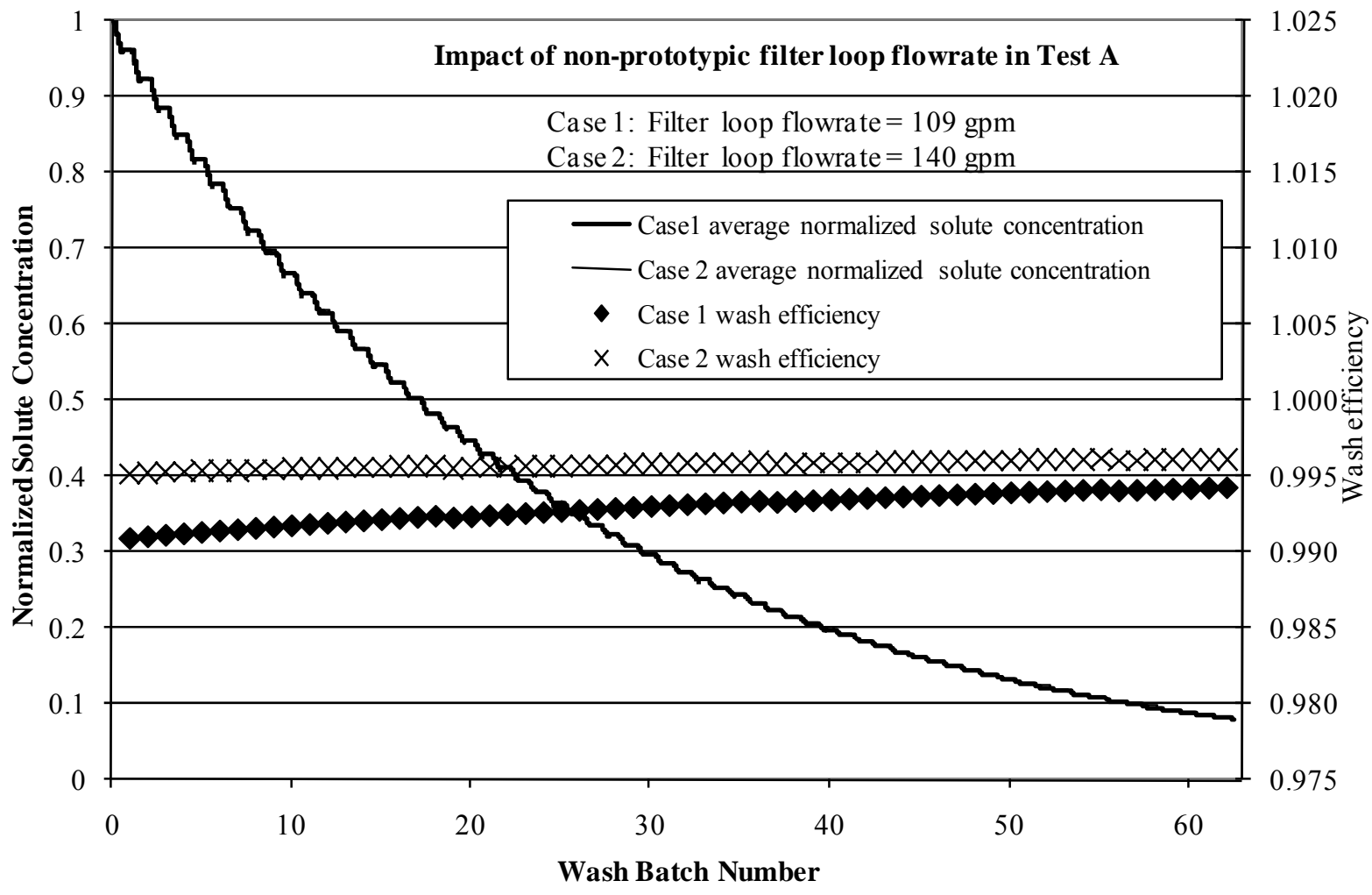

Figure 6.3. Plot of Normalized Solute Concentrations and Wash Efficiencies as Functions of Wash Batch Number for Two Filter-Loop Flow Rates Under Integrated Test A Conditions as Predicted by the Appendix B Model. The normalized solute concentrations of the two cases are very similar and not resolved in this figure.

Table 6.3. Appendix B Model Input Parameters for Figure 6.3

\begin{tabular}{|c|c|c|}
\hline Model Parameter & Value & Basis \\
\hline $\begin{array}{l}\text { Initial slurry volume in } \\
\text { Vessel T02A }\end{array}$ & $185 \mathrm{gal}$ & $\begin{array}{l}\text { PEP Integrated Test A post-caustic-leach wash } \\
\text { target volume }\end{array}$ \\
\hline Filter-loop volume & $82 \mathrm{gal}$ & Estimated PEP value \\
\hline Wash-water batch volume & $11 \mathrm{gal}$ & PEP target value \\
\hline Wash-water addition rate & $7.4 \mathrm{gpm}$ & PEP target value \\
\hline Permeate production rate & $2.75 \mathrm{gpm}$ & Achieves 4-min wash cycles \\
\hline
\end{tabular}





\subsection{Discussion}

Reviewing the figures, tables, and data shown in the Results Section (5.0) on washing efficiency and concentration behavior, for both post-caustic-leach wash and post-oxidative-leach wash, a number of observations and trends is presented and discussed.

To assist in interpreting the concentration behavior for all analytes, a brief discussion is provided about interpreting the shape of the concentration behavior curve, $\log \mathbf{C}_{\mathbf{n}} / \mathbf{C}_{\mathbf{0}}$, as follows:

1. Perfectly straight: This implies a constant $w_{\text {eff }}$.

2. Smoothly changing curve: Several phenomena could explain this, such as washing with $0.01 \mathrm{M}$ caustic on the measurement of sodium, slow dissolution or precipitation occurring, or a slow diffusion rate from a concentration inhomogeneity such as a dead-leg or PJM tube.

3. Straight line then flat/jagged/curved at end: Implies constant $w_{\text {eff }}$ during the straight-line portion and then becoming flat, jagged, or curved as the measurement detection limit is approached or reached (such as oxalate in post-oxidative-leach wash or Al, nitrate, nitrite, or $\mathrm{OH}$ in post-caustic-leach wash).

4. Straight line except for bump or jagged section: Implies sampling/analysis artifact, or a real process condition effect (i.e., such as the post-wash sample, taken after the washing has ended, such as nitrate in the post-caustic-leach wash).

5. For cases where $\mathbf{C}_{\mathbf{n}} / \mathbf{C}_{\mathbf{0}}$ is jagged or bumpy: It could also be the result of potentially improper mixing time, process control issues, or analytical or sampling issues. If a series of batches is too short (i.e., less than $4 \mathrm{~min}$ in these PEP tests), the IW may not mix as well. Thus, the slurry may not be properly diluted, and the concentration could go up or down, depending on the local concentration that is being removed in the filters. Then, if the next set of batches is more spaced out ( $>4 \mathrm{~min})$, the concentration could swing the other way as the slurry is properly mixed.

\subsection{Post-Caustic-Leach Wash}

In Table 5.1 of the weighted least squares method values for $w_{\text {eff, }}$ we see there is good consistency in $w_{\text {eff }}$ between analytes. For Integrated Test A, 4 of 5 analytes range from 1.00 to 1.01, with one outlier at 0.93, discussed below. For Integrated Test B, all 5 analytes are consistent, ranging from 0.99 to 1.02 . The overall average (using the data from both tests) for the post-caustic-leach wash is $1.00 \pm 0.01$. The consistency among multiple analytes provides good confidence in the reported average $w_{\text {eff }}$ for both tests. The reason for the Integrated Test A free-hydroxide low $w_{\text {eff }}$ value is likely related to very low concentrations by the end of the wash. Looking at Table 5.2, we see that the last four $\mathrm{OH}$ values are actually below the reporting limit; consequently, confidence in the accuracy of those values is low.

For aluminum in Figure 5.1, note that both Integrated Tests A and B are in agreement with the overall weighted least squares $w_{\text {eff }}$ values shown in Table 5.1. The tabular $w_{\text {eff }}$ values are 1.00 for Integrated Test A and 1.01 for Integrated Test B. Even recognizing the large variability observed in the incremental wash-efficiency curves over the wash process, the incremental wash efficiency trends near 1.0 throughout the washing process. The Integrated Test A curve in Figure 5.1 shows a particularly large variability at the later wash steps, $n=85-95$, and this is clearly reflected in the $\log \mathbf{C}_{\mathbf{n}} / \mathbf{C}_{\mathbf{0}}$ curve. Both $\log \mathbf{C}_{\mathbf{n}} / \mathbf{C}_{\mathbf{0}}$ curves show good log-linear behavior throughout the wash range, with only Integrated Test A showing the off-normal behavior at the late wash steps. A positive peak at $n=50-55$ (where the incremental wash 
efficiency is approximately 1.35) shows up very consistently across all post-caustic-leach wash analytes. This is not a measurement problem but may be caused by a sampling artifact. It should be noted that the $\mathrm{Al}$ concentration is approaching the measurement detection limit by $\mathrm{n}=79$, and this is likely the reason for the deviation from log-linear behavior for $\mathrm{Al}$ at later wash steps.

For sulfate, the incremental wash efficiency curves in Figure 5.2 for Integrated Tests A and B are in agreement with the overall weighted least squares $w_{\text {eff }}$ of 1.00 and 1.02, respectively, shown in Table 5.1, throughout the range until the final wash steps when the incremental wash efficiencies trend towards values less than 1 . The likely reason for this behavior is that sulfate is approaching the detection limit at the later wash steps for both tests. In addition, for several of the analytes, the fact that the last points in several of the $\mathrm{C}_{\mathrm{n}} / \mathrm{C}_{\mathrm{o}}$ plots are different than the trend up to that point may be due to the fact that these final samples were taken 5+ min after the permeate valves had been closed, and they are arguably more representative of the average tank/loop concentration than a sample collected at the end of water addition. The $\mathbf{C}_{\mathbf{n}} / \mathbf{C}_{\mathbf{0}}$ curves for both tests show relatively log-linear behavior, which supports well-behaved wash efficiencies. A positive-trending hump at $\mathrm{n}=50-55$ (where the incremental wash efficiency is approximately 1.20) shows up very consistently across all post-caustic-leach wash test analytes. This is not a measurement problem but may be caused by a sampling artifact.

For nitrate, in Figure 5.3, for the post-caustic-leach wash for both Integrated Test A and Integrated Test B, the incremental wash efficiency curves match the weighted least squares $w_{\text {eff }}$ values of 1.00 and 1.01 , respectively, very well until the final washes. Both incremental curves oscillate about 1.0 until $\mathrm{n}=80$ for Integrated Test $\mathrm{A}$ and $\mathrm{n}=48$ for Integrated Test B. Large variability is seen at early wash steps for Integrated Test $A$ and then stabilizes. The $\mathbf{C}_{\mathbf{n}} / \mathbf{C}_{\mathbf{0}}$ curves are similar for both tests, with a relatively log-linear curve throughout except for a slight upward curvature starting at approximately $n=75$ for Integrated Test $\mathrm{A}$ and $\mathrm{n}=35$ for Integrated Test B; this corresponds in both cases to a downward-trending $w_{\text {eff }, \text { i }}$ A positive-trending hump at $\mathrm{n}=50-55$ (where the incremental wash efficiency is approximately 1.25) again shows up very consistently across all post-caustic-leach wash test analytes. This is not a measurement problem but may be caused by a sampling artifact.

For nitrite, in Figure 5.4, for the post-caustic-leach wash for both Integrated Test A and Integrated Test B, the incremental wash efficiency curves match the weighted least squares $w_{\text {eff }}$ values of 1.01 and 1.02 , respectively, very well until the final washes. Both incremental curves oscillate about 1.0 until $\mathrm{n}=70$ for Integrated Test $A$ and $n=40$ for Integrated Test $B$. The $\mathbf{C}_{\mathbf{n}} / \mathbf{C}_{\mathbf{0}}$ curves are very similar for both tests, with a relatively log-linear curve throughout except for a distinct upward curvature starting at approximately $n=65-70$ for Integrated Test A and $n=35$ for Integrated Test B, corresponding, in both cases, to a downward-trending $w_{\text {eff,i }}$. A positive-trending hump at $\mathrm{n}=50-55$ (where the incremental wash efficiency is approximately 1.20) again shows up very consistently across all post-caustic-leach wash test analytes. This is not a measurement problem but may be caused by a sampling artifact.

For free hydroxide, in Figure 5.5, for the post-caustic-leach wash for both Integrated Test A and Integrated Test $\mathrm{B}$, the incremental wash efficiency curves are in agreement with the weighted least squares $w_{\text {eff }}$ values in Table 5.1 of 0.93 and 0.99 , respectively, until the final washes. Both incremental curves oscillate about 1.0 until $n=70$ for Integrated Test A and $n=40$ for Integrated Test $B$. The $\mathbf{C}_{\mathbf{n}} / \mathbf{C}_{\mathbf{0}}$ curves are somewhat similar for both tests, with a relatively log-linear curve throughout except for jaggedness starting at $n=60$ for Integrated Test $A$ and around $n=40$ for Integrated Test $B$; this corresponds, in both cases, to a downward-trending $w_{\text {eff, } i}$. The initial $\mathrm{C}_{\mathrm{o}}$ starting concentration for Integrated Test A shows a definite non-log-linear value, indicating a likely contributor for the very low 
$w_{\text {eff }}$ value of 0.92. In addition, a jagged curvature in the $\mathbf{C}_{\mathbf{n}} / \mathbf{C}_{\mathbf{0}}$ curve towards the end suggests analytical variability, likely due to analytical variability throughout the concentration range. An upward-trending hump at $\mathrm{n}=50-55$ (where the incremental wash efficiency is approximately 1.20 ) again shows up very consistently across all post-caustic-leach wash test analytes. This is not a measurement problem but may be caused by a sampling artifact. Both the initial $\mathrm{C}_{\mathrm{o}}$ value and the jaggedness for later washes give likely reasons for poorly behaving incremental wash efficiencies. By extrapolating using the data in Table 5.1, it was estimated that the free hydroxide concentration reaches the PEP target value of $0.25 \mathrm{M}$ by $n=64$ washes.

\subsection{Post-Oxidative-Leach Wash}

Reviewing Table 5.6 for the post-oxidative-leach wash $w_{\text {eff }}$ results using the weighted least squares method, there are two analytes suitable for use as indicators for monitoring washing efficiency, chromium and oxalate. Other possible analytes, such as nitrate and sodium, were at or near the analytical quantification threshold of 10 times the reporting limit. There is good consistency for Integrated Test A washing-efficiency results, ranging from 0.98 to 1.00, and for Integrated Test B, ranging from 0.99 to 1.01. The overall average (based on the data from both tests) for the post-oxidative-leach wash is $0.99 \pm 0.01$.

Reviewing the behavior of analytes in the post-oxidative-leach wash tests, chromium is shown in Figure 5.6. The Integrated Test A and Integrated Test B incremental wash-efficiency curves are seen to match the weighted least squares values of 0.98 and 1.01, respectively, fairly well. The Integrated Test A: Vessel T01A/B caustic-leach test curve appears to decrease very slightly over the wash process until the final point, while the Integrated Test B curve appears to average about 1.0 until dropping off at the last point, though both curves show quite large variability throughout the wash. Looking at the $\mathbf{C}_{\mathbf{n}} / \mathbf{C}_{\mathbf{0}}$ curves, both curves show relatively good behavior throughout the wash process, though the final point for Integrated Test $\mathrm{B}$ shows deviation. Of all the analytes monitored during post-oxidative leaching, only $\mathrm{Cr}$ is expected to be unaffected by the dead-legs (i.e., there's very little dissolved $\mathrm{Cr}$ in the dead-legs). This may help explain the good log-linearity of $\mathrm{Cr}$ and the fact that the $\mathrm{Cn} / \mathrm{Co}$ curve does not curve up as concentrations get very low.

For sodium in the post-oxidative-leach wash tests, shown in Figure 5.7, both incremental wash efficiency curves are seen to move downward, matching the weighted least squares values of 0.78 and 0.80 , respectively (this is provided only for information as sodium is unsuitable for inclusion in Table 5.6). Matching these, both $\mathbf{C}_{\mathbf{n}} / \mathbf{C}_{\mathbf{0}}$ curves are seen to curve smoothly upward significantly throughout the wash process or for the final half of the wash process. The reason for this upward-curving concentration curve for sodium is likely because $0.01 \mathrm{M} \mathrm{NaOH}$ was used for washing, and the concentration for sodium was slowly approaching this value. This effect should only be significant during the post-oxidative-leach wash with all analytes at lower concentrations; the effect is probably insignificant during the post-caustic-leach wash. This behavior makes this analyte unsuitable for monitoring washing efficiency.

For oxalate in the post-oxidative-leach wash tests, shown in Figure 5.8, the washing efficiency values are based on a modified data set. As can be seen in Figure 5.8 as well as Table 5.7 and Table 5.8, the concentration behavior and incremental washing efficiency values show that the final two wash data points are anomalous and clearly off-trend due to the concentration approaching the measurement 
detection limit or reporting limit. The balance of the oxalate concentration behavior curves shows excellent log-linearity, resulting in the conclusion that the oxalate data are very well behaved except for the final two low-concentration data points. Therefore, the final two data points for both oxalate data sets were removed and the washing efficiency recalculated based on the revised data set. Both incremental wash-efficiency curves reflect similar slight downward-trending behavior to the weighted least squares values of 1.00 and 0.99 , respectively, in Table 5.6. After the final two problematic data points were removed, this analyte is in agreement with the wash efficiency calculated from chromium.

For nitrate in the post-oxidative-leach wash tests, shown in Figure 5.9, both incremental wash-efficiency curves reflect similar strongly downward-trending behavior matching the weighted least squares values of 0.91 and 0.94 , respectively (this is provided only for information as nitrate is unsuitable for inclusion in Table 5.6). Matching these, both $\mathbf{C}_{\mathbf{n}} / \mathbf{C}_{\mathbf{0}}$ curves are seen to either curve smoothly upward significantly throughout the wash process or at least toward the final half of the process. Solubility issues are not expected, so the cause of this curvature is not clear, though the final points are approaching the reporting limit. The final point for Integrated Test B shows deviation from the trend. This curvature behavior makes this analyte unsuitable for monitoring washing efficiency.

For TDS in the post-oxidative-leach wash tests, shown in Figure 5.10, both incremental wash efficiency curves show large variabilities but appear to match the weighted least squares values of 0.90 and 0.90 , respectively (this is provided only for information as TDS is unsuitable for inclusion in Table 5.6). In particular, the Integrated Test $B$ data show large variability. Both $\mathbf{C}_{\mathbf{n}} / \mathbf{C}_{\mathbf{0}}$ curves appear fairly log-linear though with severe jaggedness throughout much of the process, implying some type of odd behavior, likely related to the effect of changing sodium and hydroxide on TDS. This behavior makes this analyte unsuitable for monitoring washing efficiency. 


\subsection{Conclusions}

Several major conclusions may be reached regarding the washing operations in the PEP. These are as follows:

1. Washing operations in PEP Integrated Tests A and B were conducted successfully as per the approved Test Instructions. However, minor instrumentation problems occurred, and some of the process conditions specified in the run sheet were not met during the wash operations, such as filter-loop flow rate targets. The filter-loop flow rate was off-normal due to slurry air entrainment and pumping difficulties.

2. Five analytes were selected based on full solubility and monitored in the post-caustic-leach wash as successful indicators of washing efficiency: aluminum, sulfate, nitrate, nitrite, and free hydroxide. Other analytes, including sodium, oxalate, phosphate, and TDS, showed indications of slow dissolution or precipitation and therefore were unsuitable for monitoring washing efficiency.

3. In the post-oxidative-leach wash, two analytes with full solubility and good concentration behavior were selected as suitable indicators of washing efficiency: chromium and oxalate. All other originally considered analytes, including sodium, manganese, nitrate, and TDS, show clear deviations from the expected linear behavior on a semi-log plot. For example, sodium $\mathrm{C}_{\mathrm{n}} / \mathrm{C}_{\mathrm{o}}$ behavior shows significant curvature, likely explained by the expected asymptotic approach to $0.01 \mathrm{M}$, the IW concentration. Manganese shows large washing portions below the detection limit. Nitrate shows large curvature in the $\mathrm{C}_{\mathrm{n}} / \mathrm{C}_{\mathrm{o}}$ curve towards the end of the washing steps; the reason for this is not clear, though it is likely related to approaching the reporting limit near the end of the wash, or $\sim 4 \times$ RL after step 63 . TDS is at or below the detection limit for much of the washing steps. In addition, other analytes, such as aluminum, phosphate, sulfate, and nitrite, are at low concentrations, all within $10 \times$ of the reporting limit for most or all of the wash steps, and for carbonate, there was little Raman data obtained during the post-oxidative wash. These other analytes are therefore unsuitable for use in monitoring wash efficiency.

4. An overall wash efficiency of $1.00 \pm 0.01$ was determined for the post-caustic-leach wash. Similarly, the overall wash efficiency for the post-oxidative-leach wash was determined to be $0.99 \pm 0.01$. These wash efficiencies were based on the weighted least squares fit of the full data set for each applicable analyte and are an average of several analytes traced during the washing steps in Integrated Tests A and B. Incremental wash efficiencies as a function of wash step were also given to provide indication of the variability during the washing process.

5. Chemical tracer tests resulted in the major conclusion that about $90 \%$ complete mixing was achieved within 2 to 4 minutes after tracer injection. With inconsistent filter-loop flow rates and other mixing parameters, future process conditions should be taken into account during further interpretation of these data. A slight decrease of 8 to $10 \%$ in the tracer concentration in between 4 and 60 minutes suggests that there was a relatively small unmixed region that mixed over the course of the 1-hour test. Some of this may be attributed to the dead-leg volume of approximately 9 gallons in the filter-loop.

6. The IW batch time interval, defined as the duration between the start of the IW wash injection for a batch to the start for the IW wash injection for the subsequent batch, was often comparable to the required 2- to 4-minute mixing time indicated by the tracer tests. Such short batch durations did not 
appear to have significantly impacted the washing efficiencies. In addition, the presence of a 9-gallon dead-leg in the filter-loop does not appear to have significantly impacted the washing efficiencies.

7. The number of IW batches required to reach the target of $0.25 \mathrm{M}$ free hydroxide following the aluminum leaching stage was 64 batches for Integrated Test A and 39 batches for Integrated Test B. The IW volume required to reach the $0.25 \mathrm{M}$ hydroxide target was 718 gal for Integrated Test $\mathrm{A}$ and 436 gal for Integrated Test B. As part of an assessment of the WTP process control strategy, these are compared to the WTP projections to reach the target of $0.25 \mathrm{M}$ free hydroxide of 64 for Integrated Test A and 38 for Integrated Test B. The WTP process control strategy for specifying the number of wash batches for post-caustic-leach washing was successful. 


\subsection{References}

Kuhn WL, ST Arm, JL Huckaby, DE Kurath and SD Rassat. July 2008. Scaling Relationships for the Pretreatment Engineering Platform. WTP-RPT-160, PNNL-16948, Pacific Northwest National Laboratory, Richland, Washington.

Rapko BM, GJ Lumetta, JR Deschane, and RA Peterson. 2007. Process Development for Permanganate Addition During Oxidative Leaching of Hanford Tank Sludge Simulants. WTP-RPT-164, PNNL-16794, Pacific Northwest National Laboratory, Richland, Washington.

Russell RL, RA Peterson, HD Smith, DE Rinehart, PM Aker, and EC Buck. 2009a. Development and Characterization of Boehmite Component Simulant. WTP-RPT-184, PNNL-18176, Pacific Northwest National Laboratory, Richland Washington.

Russell RL, Peterson RA, DE Rinehart, and HD Smith. 2009b. Development and Characterization of Gibbsite Component Simulant. WTP-RPT-176, PNNL-18013, Pacific Northwest National Laboratory, Richland Washington.

Russell RL, JM Billing, RA Peterson, DE Rinehart, and HD Smith. 2009c. Development and Demonstration of Ultrafiltration Simulants. WTP-RPT-183, PNNL-18090, Pacific Northwest National Laboratory, Richland Washington. 

Appendix A

\section{Target Parameters for Each Wash Step} Compared to Actual Parameters 



\section{Appendix A: Target Parameters for Each Wash Step Compared to Actual Parameters}

In this appendix, the target parameters for each wash step are compared to the actual parameters as recorded by the data acquisition system (DAS). Each table is composed of target values (and if applicable, tolerances ranges) from the Test Instruction governing the wash step. In general, the measured values are averages or cumulative sums of the parameter of interest over the entire washing operation. If applicable, the value is calculated using more than one method, and an uncertainty range is supplied (one standard deviation from the average). In the comments column, the impact of out-of-tolerance values and other off-normal behavior is briefly discussed. Footnotes were added if additional clarification was required.

In Tables A.1 and A.2, regarding the filter-loop flow rate, the impact on solids washing is difficult to quantify without knowing the true filter-loop flow rate. It is certain that the off-normal flow rate will affect mixing conditions in the vessel and achievable filtration (permeate) rates. However, a tracer test performed just before this wash at similar conditions indicated the system was well-mixed within 4 minutes. Provided that the deviation in axial velocity affects only the magnitude of the permeate removal and not the composition, the effect on the wash is small. The off-normal flow rates were attributed to entrained air in the system and the failure of flowmeter FT-0635. The presence of entrained air in the system would primarily affect level control, pump performance, and mixing behavior.

In Tables A.3 and A.4, regarding the filter-loop flow rate, the operational strategy for the recirculation loop pumps was revised after experience with pumping problems in Integrated Test A: Vessel T01A/B caustic-leach test. Pumps were operated to manage problems with entrained air and maintain stable, sustainable flow rates. A tracer test was performed at similar conditions (in fact, the loop flow rate was even lower, around $70 \mathrm{gpm}$ ), and mixing was still found to occur in 4 minutes or less. Thus, it can be concluded that the impact of the lower flow rate on the mixing behavior for this washing step is minimal. 
Table A.1. Integrated Test A, Post-Caustic-Leach Wash: Comparison of Target to Actual Run Parameters from TI-065, pgs. 49-51, with DAS Recorded Data. When uncertainties are provided for the DAS values (the numbers following the \pm ), they are one standard deviation from the average value.

\begin{tabular}{|c|c|c|c|c|}
\hline Quantity & Target Value & Units & DAS value $( \pm \sigma)$ & Comments \\
\hline Total IW & $4,164 \pm 20$ & $\mathrm{~kg}$ & $\begin{array}{l}\text { FT-0601: } 4,251.4 \\
\text { FT-1513: } 4,254.8\end{array}$ & $\begin{array}{l}\text { Outside of target } \\
\text { tolerance; occurs due to } \\
\text { adding approximately } \\
1 \text { extra kg of IW each } \\
\text { batch-it does not } \\
\text { significantly affect } \\
\text { washing operations. }\end{array}$ \\
\hline IW flow rate & $28 \pm 3$ & $\mathrm{~kg} / \mathrm{min}$ & $\begin{array}{l}\text { FT-0601: } 31.0 \\
\text { FT-1513: } 25.3\end{array}$ & $\begin{array}{l}\text { On boundaries of } \\
\text { tolerance; no significant } \\
\text { effect on washing } \\
\text { operations. }\end{array}$ \\
\hline IW batch mass & $41.6 \pm 1$ & $\mathrm{~kg}$ & $\begin{array}{c}\text { FT-0601: } 42.5 \pm 0.3 \\
\text { FT-1513: } 42.5 \pm 0.4 \\
{[11.2 \pm 0.1 \text { gallons }]}\end{array}$ & $\begin{array}{l}\text { On boundaries of } \\
\text { tolerance; no significant } \\
\text { effect on washing } \\
\text { operations. }\end{array}$ \\
\hline IW batches & 100 & -- & 100 & $\begin{array}{l}\text { Meets target if an } \\
\text { apparent double batch } \\
(\# 8 / 9) \text { at 16:05 is } \\
\text { counted as two batches. }\end{array}$ \\
\hline $\begin{array}{c}\text { Vessel T02A } \\
\text { level for IW } \\
\text { batch addition }\end{array}$ & $44.3 \pm 1$ & inches & Consistently met & $\begin{array}{l}\text { Based on laser } \\
\text { instrument; bubbler was } \\
\text { not useable due to } \\
\text { physically impossible } \\
\text { readings. }\end{array}$ \\
\hline $\begin{array}{c}\text { Total permeate } \\
\text { mass }\end{array}$ & $\begin{array}{l}4,400-100 / \\
+200\end{array}$ & $\mathrm{~kg}$ & $4,571^{(a)}[1,103$ gallons $]$ & Within tolerance. \\
\hline $\begin{array}{l}\text { Filter-loop flow } \\
\text { rate }\end{array}$ & 109 & gpm & $\begin{array}{c}\text { FT-0623: } 133.9 \pm 5.6 \\
\text { FT-0635: } 88.5 \pm 2.9\end{array}$ & $\begin{array}{l}\text { The target loop flow rate } \\
\text { was not achieved. Due } \\
\text { to a failure of FT-0635 } \\
\text { (NCR 42317.1) and air } \\
\text { entrainment in the slurry, } \\
\text { it was unknown what the } \\
\text { actual axial velocity in } \\
\text { filters was; it could have } \\
\text { ranged from } 12.1 \text { to } \\
\text { 18.2 ft/s based on the } \\
\text { average flow rates } \\
\text { measured over the } \\
\text { washing period. }\end{array}$ \\
\hline
\end{tabular}

(a) This permeate mass value does not include an estimate of the permeate on the shellside but did not pass through the flowmeters. If that estimate is included, the total permeate mass is $4,789 \mathrm{~kg}$. 
Table A.1. Integrated Test A, Post-Caustic-Leach Wash: Comparison of Target to Actual Run Parameters from TI-065, pgs. 49-51, with DAS Recorded Data. When uncertainties are provided for the DAS values (the numbers following the \pm ), they are one standard deviation from the average value.

\begin{tabular}{|c|c|c|c|}
\hline Quantity & Target Value & Units & DAS value $( \pm \sigma)$ \\
\hline TMP & $40 \pm 4$ & psi & $\begin{array}{c}\text { Several TMPs out of tolerance } \\
\text { during first } 7 \text { washes* (during } \\
\text { which }<\text { TMP }>\text { was } \\
37.1 \pm 6.0 \text { ) }<<\mathrm{TMP}>\text { over } \\
\text { entire wash period was } \\
39.4 \pm 2.2 \text {. }\end{array}$ \\
\hline Temperature & $25 \pm 2$ & ${ }^{\circ} \mathrm{C}$ & $\begin{array}{l}\text { Target range violated for first } \\
7 \text { batches (during which }<\mathrm{T}> \\
\text { was } 27.5 \pm 0.3 \text { ) } ;<\mathrm{T}>\text { over } \\
\text { entire wash period was } \\
24.3 \pm 1.0 \text { (and } 24.0 \pm 0.04 \text { for } \\
\text { the last } 93 \text { batches) }\end{array}$ \\
\hline Axial $\Delta \mathrm{P}$ & $<25$ & psi & $\begin{array}{c}\text { Criterion violated for first } \\
7 \text { washes* (during which } \\
<\Delta \mathrm{P}>\text { was } 24.2 \pm 1.0 \text { ); }<\Delta \mathrm{P}> \\
\text { over entire wash period was } \\
17.5 \pm 1.1 .\end{array}$ \\
\hline
\end{tabular}

PJM jet velocity $\quad 12 \pm 0.6 \quad \mathrm{~m} / \mathrm{s}$

PJM stroke

$80 \pm 5$

$\%$

31.3 inches, which is $83 \%$
*Related to extreme behavior of Pumps T42A/T43A; TMPs are highly oscillatory.

* Related to extreme behavior of Pumps T42A/T43A; temperature likely affected by additional pump heat.

*Related to extreme behavior of Pumps T42A/T43A; axial $\Delta \mathrm{Ps}$ are highly oscillatory.

Met. The jet velocity was calculated from the last time the PJMs were tuned. The tuning was performed before the beginning of this wash at 02/14/09 19:19.

Met. The stroke was calculated from the last time the PJMs were tuned. The tuning was performed before the beginning of this wash at 02/14/09 19:19.

Met. The cycle time was calculated from the last time the PJMs were tuned. The tuning was performed before the beginning of this wash at 02/14/09 19:19. 
Table A.1. Integrated Test A, Post-Caustic-Leach Wash: Comparison of Target to Actual Run Parameters from TI-065, pgs. 49-51, with DAS Recorded Data. When uncertainties are provided for the DAS values (the numbers following the \pm ), they are one standard deviation from the average value.

\begin{tabular}{|c|c|c|c|c|}
\hline Quantity & Target Value & Units & DAS value $( \pm \sigma)$ & Comments \\
\hline $\begin{array}{l}\text { Steam-ring } \\
\text { purge air flow } \\
\text { rate }\end{array}$ & $0.14 \pm 0.02$ & $\mathrm{~kg} / \mathrm{min}$ & $\begin{array}{c}\text { Variable: } \\
\text { Entire wash: } 0.023 \pm 0.046 \\
1^{\text {st }} 7 \text { batches: } 0.137 \pm 0.003 \\
\text { Last } 93 \text { batches: Off for a } \\
\text { majority of the time, when on } \\
\text { the flow rate was } \\
0.068 \pm 0.009\end{array}$ & $\begin{array}{l}\text { For the first } 7 \text { IW } \\
\text { batches, the run sheet } \\
\text { specification was met. It } \\
\text { was not turned on for } \\
\text { most of the last } 93 \mathrm{IW} \\
\text { batches in an effort to } \\
\text { manage air entrainment } \\
\text { in the system. The effect } \\
\text { on washing operations is } \\
\text { negligible. }\end{array}$ \\
\hline $\begin{array}{l}\text { Total lower air } \\
\text { sparger flow } \\
\text { rate }\end{array}$ & $0.04 \pm 0.005$ & $\mathrm{~kg} / \mathrm{min}$ & $\begin{array}{c}\text { Variable: } \\
\text { Entire wash: } 0.008 \pm 0.016 \\
\text { First } 7 \text { batches: } 0.040 \pm 0.002 \\
\text { Last } 93 \text { batches: Off for a } \\
\text { majority of the time, when on, } \\
\text { the flow rate was } \\
0.040 \pm 0.004 .\end{array}$ & $\begin{array}{l}\text { For the first } 7 \text { IW } \\
\text { batches, the run sheet } \\
\text { specification was met. It } \\
\text { was not turned on for } \\
\text { most of the last } 93 \text { IW } \\
\text { batches in an effort to } \\
\text { manage air entrainment } \\
\text { in the system. } \text {. }^{\text {a }}\end{array}$ \\
\hline $\begin{array}{l}\text { Upper air } \\
\text { sparger flow } \\
\text { rate }\end{array}$ & $0.01 \pm 0.005$ & $\mathrm{~kg} / \mathrm{min}$ & $\begin{array}{c}\text { Variable: } \\
\text { Entire wash: Average not } \\
\text { meaningful } \\
\text { First } 7 \text { batches: } 0.010 \pm 0.001 \\
\text { Last } 93 \text { batches: Off for the } \\
\text { entire time period. }\end{array}$ & $\begin{array}{l}\text { For the first } 7 \text { IW } \\
\text { batches, the run sheet } \\
\text { specification was met. It } \\
\text { was not turned on for the } \\
\text { last } 93 \text { IW batches in an } \\
\text { effort to manage air } \\
\text { entrainment in the } \\
\text { system. }^{\text {(b) }}\end{array}$ \\
\hline $\begin{array}{c}\text { Number of filter } \\
\text { bundles }\end{array}$ & 5 & -- & 5 filters used. & -- \\
\hline
\end{tabular}

(a) Since the spargers were turned off for most of the test, it is probable that the system was not as well-mixed as was demonstrated by the tracer test, which was conducted with the spargers at the target values shown in Table D.1.

(b) The lack of sparger-induced mixing for the majority of the wash will impact the mixing behavior of the system. It was likely not as well-mixed as was indicated in the tracer test. 
Table A.2. Integrated Test A, Post-Oxidative-Leach Wash: Comparison of Target to Actual Run Parameters from TI-065, pgs. 56-57 with DAS Recorded Data. When uncertainties are provided for the DAS values (the numbers following the \pm ), they are one standard deviation from the average value.

\begin{tabular}{|c|c|c|c|c|}
\hline Quantity & Target Value & Units & DAS value $( \pm \sigma)$ & Comments \\
\hline Total IW & $3,581 \pm 20$ & $\mathrm{~kg}$ & $\begin{array}{l}\text { FT-0601: } 3,656.5 \\
\text { FT-1513: } 3,657.9\end{array}$ & $\begin{array}{l}\text { Outside of target } \\
\text { tolerance; occurs due to } \\
\text { adding approximately } \\
1 \text { extra kg of IW each } \\
\text { batch-it does not } \\
\text { significantly affect } \\
\text { washing operations. }\end{array}$ \\
\hline IW flow rate & $28 \pm 3$ & $\mathrm{~kg} / \mathrm{min}$ & $\begin{array}{l}\text { FT-0601: } 31.6 \\
\text { FT-1513: } 25.8\end{array}$ & $\begin{array}{l}\text { On boundaries of } \\
\text { tolerance; no significant } \\
\text { effect on washing } \\
\text { operations. }\end{array}$ \\
\hline IW batch mass & $41.6 \pm 1$ & $\mathrm{~kg}$ & $\begin{array}{c}\text { FT-0601: } 42.5 \pm 0.4 \\
\text { FT-1513: } 42.5 \pm 0.3 \\
{[11.2 \pm 0.1 \text { gallons }]}\end{array}$ & $\begin{array}{l}\text { On boundaries of } \\
\text { tolerance; no significant } \\
\text { effect on washing } \\
\text { operations. }\end{array}$ \\
\hline IW batches & 86 & -- & 86 & Met. \\
\hline $\begin{array}{l}\text { Vessel T02A } \\
\text { level for IW } \\
\text { batch addition }\end{array}$ & $52.5 \pm 1$ & inches & Consistently met & $\begin{array}{l}\text { Based on laser } \\
\text { instrument; qualitatively } \\
\text { confirmed by the } \\
\text { bubbler. }\end{array}$ \\
\hline $\begin{array}{l}\text { Total permeate } \\
\text { mass }\end{array}$ & $\begin{array}{l}3,500-100 / \\
\quad+200\end{array}$ & $\mathrm{~kg}$ & 3,792 [988 gallons] & $\begin{array}{l}\text { Outside of target } \\
\text { tolerance; no significant } \\
\text { effect on washing } \\
\text { operations. }\end{array}$ \\
\hline $\begin{array}{l}\text { Filter-loop flow } \\
\text { rate }\end{array}$ & 109 & gpm & $\begin{array}{c}\text { FT-0623: } 151.9 \pm 3.8 \\
\text { FT-0635: } 97.4 \pm 4.6\end{array}$ & $\begin{array}{l}\text { The target loop flow rate } \\
\text { was not achieved. It is } \\
\text { unknown what the actual } \\
\text { axial velocity in filters } \\
\text { was; it could have rangec } \\
\text { from } 13.3 \text { to } 20.7 \mathrm{ft} / \mathrm{s} \\
\text { based on the average } \\
\text { flow rates measured over } \\
\text { the washing period. }\end{array}$ \\
\hline TMP & $40 \pm 4$ & psi & $\begin{array}{c}<\mathrm{TMP}>\text { over wash period was } \\
39.8 \pm 0.9\end{array}$ & Met. \\
\hline Temperature & $25 \pm 2$ & ${ }^{\circ} \mathrm{C}$ & $\begin{array}{c}<\mathrm{T}>\text { over wash period was } \\
23.3 \pm 0.1\end{array}$ & Met. \\
\hline Axial $\Delta \mathrm{P}$ & $<25$ & psi & $\begin{array}{c}<\Delta \mathrm{P}>\text { over wash period was } \\
16.3 \pm 0.5\end{array}$ & Met. \\
\hline
\end{tabular}


Table A.2. Integrated Test A, Post-Oxidative-Leach Wash: Comparison of Target to Actual Run Parameters from TI-065, pgs. 56-57 with DAS Recorded Data. When uncertainties are provided for the DAS values (the numbers following the \pm ), they are one standard deviation from the average value.

\begin{tabular}{|c|c|c|c|c|}
\hline Quantity & Target Value & Units & DAS value $( \pm \sigma)$ & Comments \\
\hline PJM jet velocity & $12 \pm 0.6$ & $\mathrm{~m} / \mathrm{s}$ & 12.1 & $\begin{array}{l}\text { Met. The jet velocity } \\
\text { was calculated from the } \\
\text { last time the PJMs were } \\
\text { tuned. The tuning was } \\
\text { performed before the } \\
\text { beginning of the } \\
\text { post-caustic wash at } \\
02 / 14 / 0919: 19 \text {. }\end{array}$ \\
\hline PJM stroke & $80 \pm 5$ & $\%$ & 31.3 inches, which is $83 \%$ & $\begin{array}{l}\text { Met. The stroke was } \\
\text { calculated from the last } \\
\text { time the PJMs were } \\
\text { tuned. The tuning was } \\
\text { performed before the } \\
\text { beginning of the } \\
\text { post-caustic wash at } \\
02 / 14 / 0919: 19 \text {. }\end{array}$ \\
\hline PJM cycle time & $20 \pm 1$ & $\mathrm{~S}$ & 20.8 & $\begin{array}{l}\text { Met. The cycle time was } \\
\text { calculated from the last } \\
\text { time the PJMs were } \\
\text { tuned. The tuning was } \\
\text { performed before the } \\
\text { beginning of the } \\
\text { post-caustic wash at } \\
02 / 14 / 0919: 19 \text {. }\end{array}$ \\
\hline
\end{tabular}


Table A.2. Integrated Test A, Post-Oxidative-Leach Wash: Comparison of Target to Actual Run Parameters from TI-065, pgs. 56-57 with DAS Recorded Data. When uncertainties are provided for the DAS values (the numbers following the \pm ), they are one standard deviation from the average value.

\begin{tabular}{|c|c|c|c|c|}
\hline Quantity & Target Value & Units & DAS value $( \pm \sigma)$ & Comments \\
\hline $\begin{array}{l}\text { Steam-ring } \\
\text { purge air flow } \\
\text { rate }\end{array}$ & $0.14 \pm 0.02$ & $\mathrm{~kg} / \mathrm{min}$ & Effectively zero & $\begin{array}{l}\text { The steam-ring purge air } \\
\text { was off for the duration } \\
\text { of this wash to manage } \\
\text { air entrainment in the } \\
\text { system. The effect on } \\
\text { washing operations is } \\
\text { negligible. }^{(\text {a) }}\end{array}$ \\
\hline $\begin{array}{l}\text { Total lower air } \\
\text { sparger flow } \\
\text { rate }\end{array}$ & $0.04 \pm 0.005$ & $\mathrm{~kg} / \mathrm{min}$ & $0.0402 \pm 0.0006$ & Met. \\
\hline $\begin{array}{l}\text { Upper air } \\
\text { sparger flow } \\
\text { rate }\end{array}$ & $0.01 \pm 0.005$ & $\mathrm{~kg} / \mathrm{min}$ & Effectively zero & $\begin{array}{l}\text { The upper spargers were } \\
\text { off for the duration of } \\
\text { this wash because the } \\
\text { slurry level was below } \\
\text { the outlet for the upper } \\
\text { spargers. }\end{array}$ \\
\hline $\begin{array}{c}\text { Number of filter } \\
\text { bundles }\end{array}$ & 5 & -- & 5 filters used & -- \\
\hline
\end{tabular}

(a) Since the steam-ring air purge was turned off during the test, it is probable that the system was not as well-mixed as was demonstrated by the tracer test, which was conducted with the spargers at the target values shown in Table D.1. 
Table A.3. Integrated Test B, Post-Caustic-Leach Wash: Comparison of Target to Actual Run Parameters from TI-066, pg. 28, with DAS Recorded Data. When uncertainties are provided for the DAS values (the numbers following the \pm ), they are one standard deviation from the average value.

\begin{tabular}{|c|c|c|c|c|}
\hline Quantity & Target Value & Units & DAS value $( \pm \sigma)$ & Comments \\
\hline Total IW & $2,165 \pm 20$ & $\mathrm{~kg}$ & $\begin{array}{l}\text { FT-0601: } 2,204.2 \\
\text { FT-1513: } 2,204.3\end{array}$ & $\begin{array}{l}\text { Outside of target } \\
\text { tolerance; occurs due to } \\
\text { adding approximately } \\
1 \text { extra kg of IW each } \\
\text { batch-it does not } \\
\text { significantly affect } \\
\text { washing operations. }\end{array}$ \\
\hline IW flow rate & $28 \pm 3$ & $\mathrm{~kg} / \mathrm{min}$ & $\begin{array}{l}\text { FT-0601: } 29.4 \\
\text { FT-1513: } 25.8\end{array}$ & Within tolerance. \\
\hline IW batch mass & $41.6 \pm 1$ & $\mathrm{~kg}$ & $\begin{array}{c}\text { FT-0601: } 42.4 \pm 0.4 \\
\text { FT-1513: } 42.4 \pm 0.3 \\
{[11.2 \pm 0.1 \text { gallons }]}\end{array}$ & $\begin{array}{l}\text { On boundaries of } \\
\text { tolerance; no significant } \\
\text { effect on washing } \\
\text { operations. }\end{array}$ \\
\hline IW batches & 52 & -- & 52 & Met. \\
\hline $\begin{array}{c}\text { Vessel T02A } \\
\text { level for IW } \\
\text { batch addition }\end{array}$ & $16.7 \pm 1$ & inches & Consistently met & $\begin{array}{l}\text { Based on laser } \\
\text { instrument; bubbler was } \\
\text { not useable due to } \\
\text { physically impossible } \\
\text { readings. }\end{array}$ \\
\hline $\begin{array}{l}\text { Total permeate } \\
\text { mass }\end{array}$ & $\begin{array}{l}2,400-100 / \\
+200\end{array}$ & $\mathrm{~kg}$ & 2,486 [597 gallons] & Within tolerance. \\
\hline $\begin{array}{l}\text { Filter-loop flow } \\
\text { rate }\end{array}$ & 109 & gpm & $\begin{array}{ll}\text { FT-0623: } & 85.5 \pm 9.8 \\
\text { FT-0635: } & 81.0 \pm 7.4\end{array}$ & $\begin{array}{l}\text { Below target values. } \\
\text { This was the largest } \\
\text { sustainable flow rate that } \\
\text { could be achieved during } \\
\text { this wash. It translates to } \\
\text { an axial velocity of } 11.0 \\
\text { to } 11.6 \mathrm{ft} / \mathrm{s} \text { based on the } \\
\text { average flow rates. }\end{array}$ \\
\hline TMP & $40 \pm 4$ & psi & $\begin{array}{c}<\mathrm{TMP}>\text { over wash period was } \\
\quad 39.4 \pm 2.1\end{array}$ & Met. \\
\hline Temperature & $25 \pm 2$ & ${ }^{\circ} \mathrm{C}$ & $\begin{array}{c}<\mathrm{T}>\text { over wash period was } \\
23.0 \pm 1.5 .\end{array}$ & Met. \\
\hline Axial $\Delta \mathrm{P}$ & $<25$ & psi & $\begin{array}{c}<\Delta \mathrm{P}>\text { over wash period was } \\
12.8 \pm 0.4\end{array}$ & Met. \\
\hline PJM jet velocity & $12 \pm 0.4$ & $\mathrm{~m} / \mathrm{s}$ & 11.7 & $\begin{array}{l}\text { Met. The jet velocity } \\
\text { was calculated from the } \\
\text { last time the PJMs were } \\
\text { tuned. The tuning was } \\
\text { performed before the } \\
\text { beginning of this wash at } \\
\text { 03/19/09 10:35. }\end{array}$ \\
\hline
\end{tabular}


Table A.3. Integrated Test B, Post-Caustic-Leach Wash: Comparison of Target to Actual Run Parameters from TI-066, pg. 28, with DAS Recorded Data. When uncertainties are provided for the DAS values (the numbers following the \pm ), they are one standard deviation from the average value.

\begin{tabular}{|c|c|c|c|c|}
\hline Quantity & Target Value & Units & DAS value $( \pm \sigma)$ & Comments \\
\hline PJM stroke & $80 \pm 5$ & $\%$ & 26.7 inches, which is $70 \%$ & $\begin{array}{l}\text { Below target value; the } \\
\text { stroke was calculated } \\
\text { from the last time the } \\
\text { PJMs were tuned. The } \\
\text { tuning was performed } \\
\text { before the beginning of } \\
\text { this wash at } 03 / 19 / 09 \\
\text { 10:35. The effect on } \\
\text { washing is minimal since } \\
\text { the PJMs were run in stal } \\
\text { mode, and the level in } \\
\text { Vessel T02A was low. }\end{array}$ \\
\hline PJM cycle time & $20 \pm 1$ & $\mathrm{~S}$ & 20.2 & $\begin{array}{l}\text { Met. The cycle time was } \\
\text { calculated from the last } \\
\text { time the PJMs were } \\
\text { tuned. The tuning was } \\
\text { performed before the } \\
\text { beginning of this wash at } \\
\text { 03/19/09 10:35. }\end{array}$ \\
\hline $\begin{array}{l}\text { Steam-ring } \\
\text { purge air flow } \\
\text { rate }\end{array}$ & $0.14 \pm 0.02$ & $\mathrm{~kg} / \mathrm{min}$ & Effectively zero & $\begin{array}{l}\text { The steam-ring air purge } \\
\text { was not on to minimize } \\
\text { air entrainment in the } \\
\text { slurry. The effect on } \\
\text { washing operations is } \\
\text { negligible. } \text { (a) }^{\text {nation }}\end{array}$ \\
\hline $\begin{array}{l}\text { Total lower air } \\
\text { sparger flow } \\
\text { rate }\end{array}$ & $0.01 \pm 0.005$ & $\mathrm{~kg} / \mathrm{min}$ & Effectively zero & $\begin{array}{l}\text { The lower spargers were } \\
\text { not in operation to } \\
\text { minimize air entrainment } \\
\text { in the slurry. Based on a } \\
\text { tracer test, this did not } \\
\text { appear to greatly impact } \\
\text { mixing behavior. }^{(\text {b) }}\end{array}$ \\
\hline $\begin{array}{l}\text { Upper air } \\
\text { sparger flow } \\
\text { rate }\end{array}$ & $0.01 \pm 0.005$ & $\mathrm{~kg} / \mathrm{min}$ & Effectively zero & $\begin{array}{l}\text { The upper spargers were } \\
\text { not in operation because } \\
\text { the tank level was below } \\
\text { the sparger elevation. }\end{array}$ \\
\hline $\begin{array}{c}\text { Number of filter } \\
\text { bundles }\end{array}$ & 5 & -- & 5 filters used & -- \\
\hline
\end{tabular}

(a) Since the steam-ring air purge was turned off during the test, it is probable that the system was not as well-mixed as was demonstrated by the tracer test, which was conducted with the spargers at the target values shown in Table D.1.

(b) The lack of sparger-induced mixing for the majority of the wash will impact the mixing behavior of the system. It was likely not as well-mixed as was indicated in the tracer test. 
Table A.4. Integrated Test B, Post-Oxidative-Leach Wash: Comparison of Target to Actual Run Parameters from TI-066, pg. 30, with DAS Recorded Data. When uncertainties are provided for the DAS values (the numbers following the \pm ), they are one standard deviation from the average value.

\begin{tabular}{|c|c|c|c|c|}
\hline Quantity & Target Value & Units & DAS value $( \pm \sigma)$ & Comments \\
\hline Total IW & $1,955 \pm 20$ & $\mathrm{~kg}$ & $\begin{array}{l}\text { FT-0601: } 1,997.6 \\
\text { FT-1513: } 2,000.5\end{array}$ & $\begin{array}{l}\text { Outside of target } \\
\text { tolerance; occurs due to } \\
\text { adding approximately } \\
1 \text { extra kg of IW each } \\
\text { batch-it does not } \\
\text { significantly affect } \\
\text { washing operations. }\end{array}$ \\
\hline IW flow rate & $28 \pm 3$ & $\mathrm{~kg} / \mathrm{min}$ & $\begin{array}{l}\text { FT-0601: } 31.3 \\
\text { FT-1513: } 27.8\end{array}$ & $\begin{array}{l}\text { On boundaries of } \\
\text { tolerance; no significant } \\
\text { effect on washing } \\
\text { operations. }\end{array}$ \\
\hline IW batch mass & $41.6 \pm 1$ & $\mathrm{~kg}$ & $\begin{array}{l}\text { FT-0601: } 42.7 \pm 0.4 \\
\text { FT-1513: } 42.8 \pm 0.4 \\
{[11.3 \pm 0.1 \text { gallons }]}\end{array}$ & $\begin{array}{l}\text { On boundaries of } \\
\text { tolerance; no significant } \\
\text { effect on washing } \\
\text { operations. }\end{array}$ \\
\hline IW batches & 47 & -- & 47 & Met. \\
\hline $\begin{array}{l}\text { Vessel T02A } \\
\text { level for IW } \\
\text { batch addition }\end{array}$ & $21.4 \pm 1$ & inches & Consistently met & $\begin{array}{l}\text { Based on laser instrument; } \\
\text { qualitatively confirmed by } \\
\text { the bubbler. }\end{array}$ \\
\hline $\begin{array}{l}\text { Total permeate } \\
\text { mass }\end{array}$ & $\begin{array}{l}2,000-100 / \\
+200\end{array}$ & $\mathrm{~kg}$ & 2,124 [558 gallons] & Within tolerance. \\
\hline $\begin{array}{l}\text { Filter-loop flow } \\
\text { rate }\end{array}$ & 109 & gpm & $\begin{array}{l}\text { FT-0623: } 94.8 \pm 15.1 \\
\text { FT-0635: } 87.0 \pm 12.2\end{array}$ & $\begin{array}{l}\text { Below the target flow rate; } \\
\text { this was the maximum } \\
\text { sustainable flow rate } \\
\text { achievable. It translates to } \\
\text { an axial velocity of } 11.8 \text { to } \\
12.9 \mathrm{ft} / \mathrm{s} \text { based on the } \\
\text { average flow rates. }\end{array}$ \\
\hline TMP & $40 \pm 4$ & psi & $\begin{array}{c}<\mathrm{TMP}>\text { over wash period was } \\
\quad 37.3 \pm 4.2\end{array}$ & Met. \\
\hline Temperature & $25 \pm 2$ & ${ }^{\circ} \mathrm{C}$ & $\begin{array}{c}<\mathrm{T}>\text { over wash period was } \\
24.6 \pm 0.2\end{array}$ & Met. \\
\hline Axial $\Delta \mathrm{P}$ & $<25$ & psi & $\begin{array}{c}<\Delta \mathrm{P}>\text { over wash period was } \\
10.4 \pm 1.2\end{array}$ & Met. \\
\hline $\begin{array}{l}\text { Mixing } \\
\text { parameters }\end{array}$ & $\begin{array}{l}\text { PJM, spargers, } \\
\text { steam-ring air }\end{array}$ & N/A & $\begin{array}{l}\text { No target parameters given in } \\
\text { the run sheet. }\end{array}$ & $\begin{array}{l}\text { Air sources (steam-ring } \\
\text { purge air, lower and upper } \\
\text { spargers) were not in } \\
\text { operation during this test. } \\
\text { PJMs were on and } \\
\text { operated in star mode. For } \\
\text { previous tuned values, see } \\
\text { Table D.3. }\end{array}$ \\
\hline $\begin{array}{c}\text { Number of filter } \\
\text { bundles }\end{array}$ & 5 & -- & 5 filters used & -- \\
\hline
\end{tabular}




\section{Appendix B}

Filter-Loop Volume vs. Filter-Loop Flow Rate Model 



\section{Appendix B: Filter-Loop Volume vs. Filter-Loop Flow Rate Model}

A simple model has been developed to examine the impacts of 1) a larger-than-prototypic filter-loop volume in the PEP, and 2) non-prototypic filter-loop flow rates experienced during the Integrated tests. The model assumes instantaneous mixing in Vessel T02A (with an allowance made for a portion of the filter-loop return jet to by-pass the slurry in Vessel T02A), so it does not address the impacts of different jet velocities on mixing in Vessel T02A. It provides continuous values for the average concentration of a solute in Vessel T02A by tracking the solute concentrations and flow rates of streams entering and leaving Vessel T02A, the wash-water flow rate, and the permeate solute concentration and flow rate.

$C_{L I}(t) \quad=$ Solute concentration entering the filter-loop

${ }_{-L O}(t)=$ Solute concentration leaving the filter-loop

$C_{P}(t) \quad=$ Solute concentration in permeate

$C_{T}(t)=$ Average solute concentration in Vessel T02A

$Q_{L I}(t) \quad=$ Slurry flow rate entering the filter-loop

$Q_{L O} \quad=$ Slurry flow rate leaving the filter-loop

$Q_{P} \quad=$ Permeate flow rate, assumed to be constant during the wash

$Q_{w w}(t)=$ Wash-water flow rate

$V_{T}(t) \quad=$ Slurry volume in Vessel T02A

$V_{L} \quad=$ Filter-loop volume

$V_{W W} \quad=$ Wash-water batch volume

$X \quad=$ Fraction of $Q_{L I}$ from filter-loop return nozzle (by-pass/short circuit)

In general, most of the quantities listed above are functions of time. The value of a quantity at a particular time $t$ will be denoted using subscripts. The by-pass/short circuit of T02A is expressed

$$
C_{L I, t}=X C_{L O, t}+(1-X) C_{T, t}
$$

A material balance around loop gives

$$
Q_{L I, t}+Q_{W W, t}=Q_{P}+Q_{L O}
$$

To simplify model timing, the volume of slurry between the pump suction nozzle in Vessel T02A and the filters is assumed to be zero, so that at any time

$$
C_{P, t}=C_{L I, t}\left(\frac{Q_{L I, t}}{Q_{L I, t}+Q_{W W, t}}\right)
$$


Assuming there is no axial mixing of solute within the filter-loop (i.e., plug flow), the solute concentration leaving the filter-loop will be the same as the solute permeate concentration at an earlier time. This introduces a time lag $\Delta t$ between the concentrations. Specifically,

$$
C_{L O, t}=C_{P, t-\Delta t} ; \text { where } \Delta t=\frac{V_{L}}{Q_{\text {Total }}}
$$

During testing, filter-loop flow rates were to be controlled so that

$$
Q_{P}+Q_{L O}=Q_{\text {Total }}
$$

where $Q_{\text {Total }}$ is the filter-loop flow rate and is a constant assigned by the user, with a prototypic value of $109 \mathrm{gpm}$.

The average solute concentration in Vessel T02A can be determined from a material balance on the tank, taking into account that the slurry volume in Vessel T02A is itself changing with time:

$$
\begin{gathered}
\frac{d}{d t}\left(C_{T, t} V_{T, t}\right)=C_{L O, t} Q_{L O}-C_{L I, t} Q_{L I, t} \\
\frac{d V_{T, t}}{d t}=Q_{L O}-Q_{L I, t}
\end{gathered}
$$

The initial conditions (at $t=0$, before any washing has begun) are

$$
\begin{aligned}
C_{L I, 0} & =C_{0} \\
C_{L O, 0} & =C_{0} \\
C_{P, 0} & =C_{0} \\
C_{T, 0} & =C_{0} \\
V_{T, 0} & =V_{T 0}
\end{aligned}
$$

For this model, $Q_{P}$ is assumed to be constant and is assigned by the user. The user also assigns the wash-water batch volume, $V_{W w}$, and the rate that wash-water is added, $Q_{W w}$. Generally, the permeate flow rate is smaller than the wash-water addition rate, with the wash-water addition being stopped $\left(Q_{W W}=0\right)$ when $V_{W W}$ has been added and restarted when $V_{T} \leq V_{T 0}$ (i.e., wash-water batch additions are triggered by level in Vessel T02A).

Equation (B.6) was solved using a finite difference forward time step routine in Excel. Specifically, the average solute concentration in Vessel T02A at the time step $n+1$ is calculated from the $n^{\text {th }}$ step using the discretization scheme 


$$
C_{T, n+1}=\frac{C_{T, n}+\left(C_{L O, n} Q_{L O}+C_{L I, n} Q_{L I, n}\right)\left(t_{n+1}-t_{n}\right)}{V_{T, n+1}}
$$

where

$$
V_{T, n+1}=V_{T, n}+\left(Q_{L O}-Q_{L I, n}\right)\left(t_{n+1}-t_{n}\right)
$$

The first wash-water addition is started at $t=0$ and stopped when $t>V_{W W} / Q_{W W}$ (i.e., when a full wash-water batch volume has been added). Subsequent wash-water additions are started whenever $V_{T} \leq V_{T 0}$ (i.e., when removal of permeate drops the volume of slurry in Vessel T02A to or below its initial volume) and stopped after $V_{W W} / Q_{W W}$ minutes have elapsed. In practice, this is tracked in the spreadsheet by a separate time variable that is reset to zero at the start of each wash-water addition. 

WTP-RPT-187, Rev 1

PNNL-18499, Rev 1

\section{Distribution}

No. of

Copies

OFFSITE
No. of

Copies

ONSITE

Pacific Northwest National Laboratory

(authors will be notified electronically)

DL Baldwin

P7-22

PW Eslinger

K6-52

BD Hanson

P7-27

PP Schonewill

P7-25

JJ Toth

P7-22

DE Kurath

K3-52

JL Huckaby

H4-02

MJ Minette

P7-25

Information Release (pdf)

2 Bechtel National, Inc.

WTP R\&T Docs

$\mathrm{H} 4-02$

SM Barnes

H4-02 


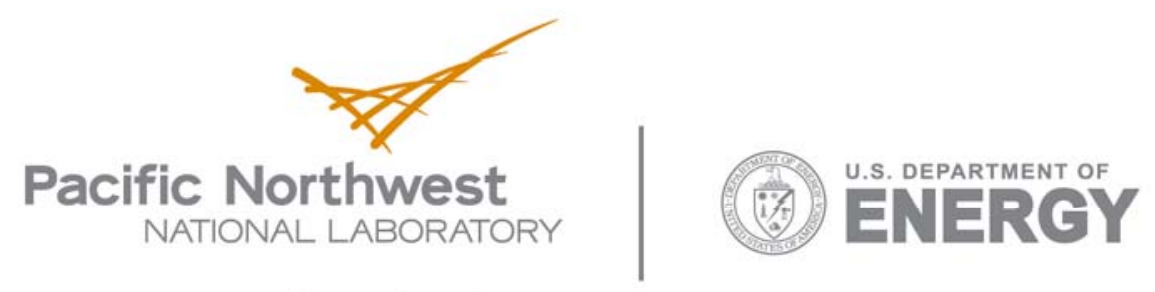

902 Battelle Boulevard

P.O. Box 999

Richland, WA 99352

1-888-375-PNNL (7665)

www.pnl.gov 